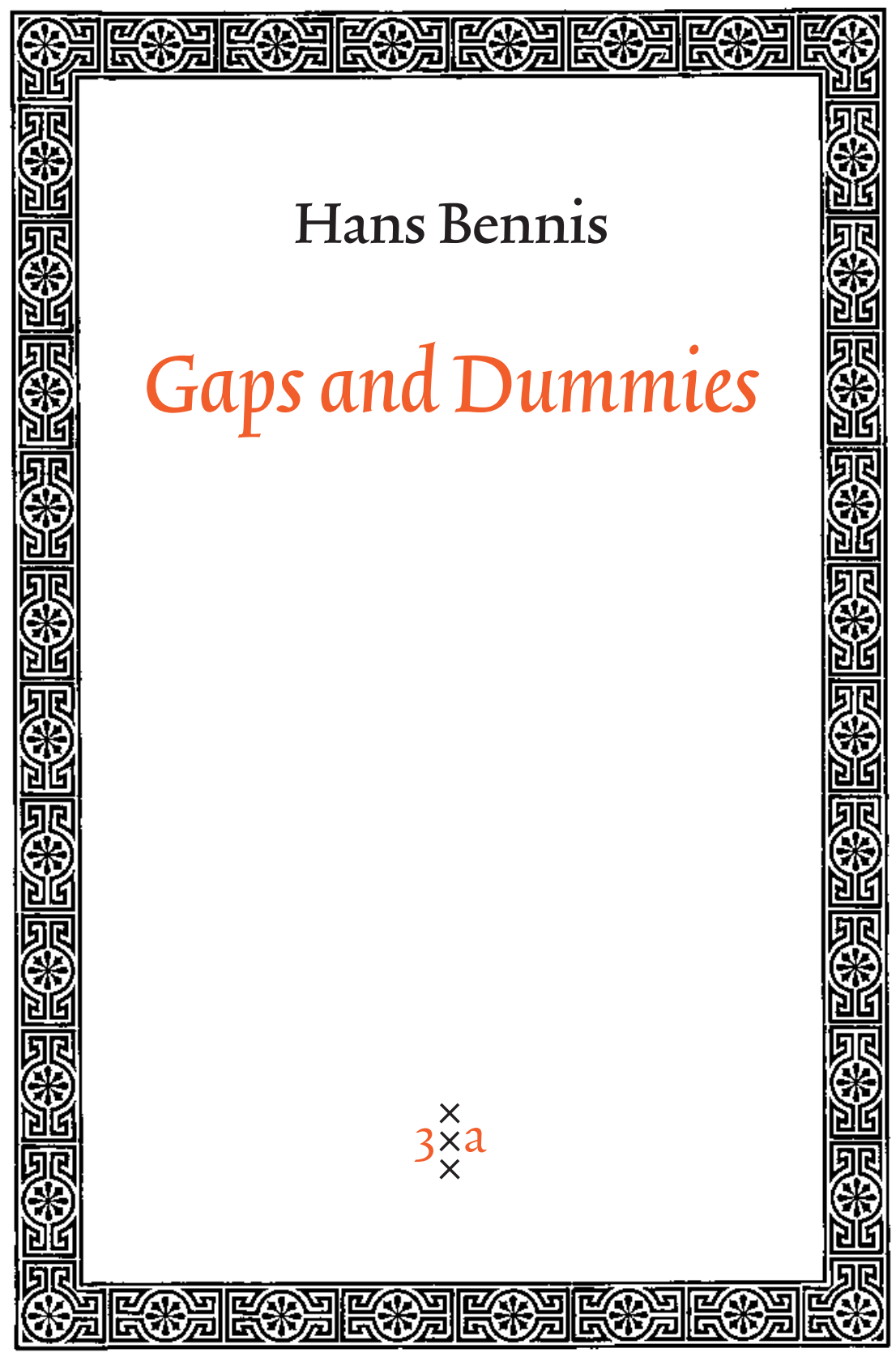

Amsterdam Academic Archive 
GAPS AND DUMMIES 
The Amsterdam Academic Archive is an initiative of Amsterdam University Press. The series consists of scholarly titles which were no longer available, but which are still in demand in the Netherlands and abroad. Relevant sections of these publications can also be found in the repository of Amsterdam University Press: www.aup.nl/repository. At the back of this book there is a list of all the AAA titles published in 2005. 


\section{Hans Bennis}

\section{Gaps and Dummies}

$3 \stackrel{\times}{\times} a$

Amsterdam Academic Archive 
Gaps and Dummies was originally published as a $\mathrm{PhD}$-dissertation in 1986 at the Katholieke Hogeschool Tilburg. It later appeared in the Linguistic Models-series from Foris Publications, Dordrecht (ISBN 906765245 8).

Cover design: René Staelenberg, Amsterdam ISBN $905356859 \mathrm{x}$ NUR 616

(C) Amsterdam University Press · Amsterdam Academic Archive, 2005

All rights reserved. Without limiting the rights under copyright reserved above, no part of this book may be reproduced, stored in or introduced into a retrieval system, or transmitted, in any form or by any means (electronic, mechanical, photocopying, recording or otherwise) without the written permission of both the copyright owner and the author of the book. 
Gaps and Dummies was originally published as a PhD-dissertation in 1986 (defense May 1986). In addition to the dissertation version, it has appeared as a book in the series Linguistic Models, volume 9, with Foris Publications (second printing in 1987). Later, the series Linguistic Models has been taken over by Mouton de Gruyter (Berlin, New York). Although the book has appeared in various versions, the text is in all cases identical to the original dissertation version, which was camera-ready produced on a Commodore64 computer and a daisy-wheel printer.

Gaps and Dummies has received a lot of attention nationally and internationally due to the fact that it addressed a very central theme in generative linguistics, the nature of the subject. The central questions in the book were directed towards the formal status of the subject: is the presence of a subject a consequence of structural or thematic properties?

If syntactic structure itself determines the presence of a subject position in a clause, it follows that all clauses have subject positions; given the fact that positions should be detectable, the consequence is that sentences without thematic subjects must have dummy subjects. Sentences without a thematic subject and without a lexical dummy subject must have empty dummy subjects consequently. It thus leads to the postulation of linguistic objects that have neither form nor interpretation. This view was formulated in the Extended Projection Principle, the dominant perspective in generative theory within the Government-Binding framework in the nineteen-eighties, and is nowadays still present in the minimalist framework of generative syntax, in more or less the same way.

The other perspective is that the presence of a subject is determined by independent linguistic principles. If the verb or construction requires an external argument lexically, the projection of arguments into syntactic structure makes sure that a subject is present. This subject might be lexically empty in the case of prodrop languages. Another arguable instance of subjects being present is the case in which thematic noun phrases that are not projected as subjects will be promoted to become subjects due to Case reasons. This situation occurs in the case of passive, ergative and raising constructions. This view leads to a position in which there are no lexical or empty dummy subjects as place holders for an absent or demoted thematic subject. More generally, it follows that there are no dummy pronouns. This was the view advocated in Gaps and Dummies. The discussion on these two different views has attracted a lot of attention.

Another reason for Gaps and Dummies to receive attention in the literature is the fact that it contains a detailed discussion of the two potential dummy pronouns in Dutch: the adverbial pronoun er and the neuter pronoun het. In order to show the correctness of the approach in which dummy pronouns do not exist, it had to be demonstrated that apparent dummy pronouns are referential pronouns instead. Chapter 2 ('Het as a referential expression') and Chapter 3 ('The adverbial pronoun $e^{\prime}$ ') show in detail that a view in which apparent dummy pronouns are taken to be referential has a number of interesting consequences and is preferable to the dummy perspective. 
These two chapters are still often referred to in the literature. Especially the arguments to show that there are no dummy object pronouns have been generally adopted in Dutch linguistics. The discussion about the extremely complex pronoun er in Chapter 3 is still relevant for contempory work on Dutch syntax.

Given the fact that Gaps and Dummies is both theoretically and empirically relevant for present-day linguistics, I welcome the possibility to include this book in the AAA-series of Amsterdam University Press.

Hans Bennis

Meertens Instituut (KNAW), Amsterdam

October 2005 


\section{Table of Contents}

Acknowledgements

\section{Introduction}

1. Gaps and Parasitic Gaps 7

$\begin{array}{lll}1.1 & \text { Introduction } & 7\end{array}$

1.2 Connectedness 8

1.2.1 Kayne's g-projection 8

1.2.2 Two modifications of Kayne's g-projection 11

$\begin{array}{ll}\text { 1.2.3 Extraction from complement clauses } & 15\end{array}$

$\begin{array}{lll}1.3 & \text { Complex cases of PPs } & 18\end{array}$

1.3.1 Van Riemsdijk's analysis of P-stranding 19

$\begin{array}{ll}\text { 1.3.2 Adjacency and P-stranding } & 21\end{array}$

1.3.3 Extraction from complex PPs 25

1.3.4 Reanalysis in complex PPs 29

$\begin{array}{lll}1.4 & \text { Parasitic gaps } & 39\end{array}$

1.5 Parasitic gaps in Dutch 44

1.5.1 The distribution of parasitic gaps 44

1.5.2 Parasitic gaps without real gaps 54

1.6 Chains and features 71

$\begin{array}{lll}1.7 & \text { An alternative approach to parasitic gaps in Dutch } 79\end{array}$

1.7.1 The analysis of Huybregts and Van Riemsdijk $8 \emptyset$

$\begin{array}{lll}1.7 .2 & \text { An argument against our analysis } & 82\end{array}$

1.7.3 Parallelism between across-the-board and 83 parasitic-gap constructions

$\begin{array}{ll}\text { Notes } & 88\end{array}$

2. Het as a referential expression 93

$\begin{array}{lll}2.1 & \text { Introduction } & 93\end{array}$

$\begin{array}{lll}2.2 & \text { Weather-het } & 95\end{array}$

2.3 Referential properties of the dummy pronoun het 98

$2.4 \quad$ Het and sentential complements 103

2.4.1 Het in object position 103 
2.4.2 Het in subject position 108

2.5 Het-Raising 110

$\begin{array}{lll}2.6 & \text { Bisentential verbs } & 116\end{array}$

2.7 Het in Small-Clause constructions 120

2.8 Het and ergative verbs 131

2.9 Psychological verbs 134

2. 10 Inversion phenomena 146

2.10.1 Previous proposals 147

2.10.2 Inversion and the Extended Projection Principle 151

2.10 .3 Het and Inversion 160

$\begin{array}{lll}2.11 & \text { Summary } & 163\end{array}$

Notes $\quad 165$

3. The adverbial pronoun er 171

$\begin{array}{lll}3.1 & \text { Introduction } & 171\end{array}$

$\begin{array}{lll}3.2 & \text { The distribution of er } & 174\end{array}$

3.2.1 EXistential/expletive er 174

$\begin{array}{lll}3.2 .2 & \text { Prepositional er } & 176\end{array}$

$\begin{array}{lll}3.2 .3 & \text { Quantitative er } & 177\end{array}$

$\begin{array}{lll}3.2 .4 & \text { Locative er } & 177\end{array}$

3.2.5 Co-occurrence of syntactic functions of er 178

$\begin{array}{lll}3.2 .6 & \text { An analysis of co-occurrence } & 181\end{array}$

$\begin{array}{lll}3.3 & \text { Categorial status and derivation } & 188\end{array}$

3.3.1 The categorial status of prepositional R-pronouns 188

3.3.2 Movement of prepositional R-pronouns 195

$\begin{array}{lll}3.3 \cdot 3 & \text { The syntax of locative er } & 197\end{array}$

3.3.4 Quantitative er as a non-thematic argument 198

3.4 R-movement and the double-R-constraint 205

3.4.1 Van Riemsdijk's double-R-constraint 206

$\begin{array}{lll}3.4 .2 & \text { R-movement and adjunction } & 207\end{array}$

3.5 Expletive er: a dummy pronoun? 211

3.5.1 The distribution of expletive er 212

3.5.2 Syntactic analyses of the construction with 217 expletive er

3.5.3 Pragmatic motivation of er-insertion 221

3.5.3.1 Pragmatic principles governing the application 222 of adjunction

3.5.3.2 Pragmatic principles and expletive er 224 
$\begin{array}{lll}3.6 & \text { Er and wh-movement } 228\end{array}$

3.6.1 Dat-t phenomena 229

3.6.1.1 Previous accounts 229

3.6.1.2 Subject extraction and the Gap Condition 239

3.6.1.3 Subject extraction and the EPC 243

$\begin{array}{lll}3.6 .2 & \text { Subject extraction in main clauses } & 247\end{array}$

$\begin{array}{lll}3.7 & \text { Conclusion } & 248\end{array}$

Notes 250

4. Some related topics 259

$\begin{array}{lll}4.1 & \text { Introduction } & 259\end{array}$

4.2 Adjunction and Connection 260

4.3 The external argument and the structure of 267 Modern English

$\begin{array}{lll}4.4 & \text { The structure of Old English and its development } 275\end{array}$ into Modern English

4.4.1 The structure of Old English 276

4.4.1.1 P-stranding 276

4.4.1.2 That-t configurations 281

4.4.1.3 Impersonal constructions 282

4.4.2 Development into Modern English: 291

the INFL parameter

4.5 Some remarks on the structure of the 295

Romance languages

4.5.1 The postverbal subject in Spanish 296

4.5.2 Stylistic Inversion in French 297

4.5 _3 The structure of Italian and the syntax of ne 301

4.6 The pronoun es in German 308

$\begin{array}{lll}4.7 & \text { It as a referential expression } & 312\end{array}$

$\begin{array}{lll}4.8 & \text { Concluding remarks } & 317\end{array}$

$\begin{array}{ll}\text { Notes } & 319\end{array}$ 



\section{Acknowledgements}

So many people have -directly or indirectly- contributed by their presence, friendship and thinking to this book and more generally to my pleasure and interest in linguistics that I cannot even begin to try to acknowledge their support by mentioning their names here, for $\mathrm{I}$ am bound to forget one or the other. Instead, I shall single out the three people who have contributed most to this book.

Heartfelt thanks go to Henk van Riemsdijk who has been a most influential person throughout my linguistic career, first as my teacher, then as the supervisor of my research project, as a short-time employer, and finally as the supervisor of this thesis. He has always been a good friend.

Teun Hoekstra has had a profound influence on the contents of this book. For three years now we have worked together quite closely on a variety of projects. One concrete result of our collaberation is the first chapter of this book, and his influence is pervasive in the other chapters. I have benefited a great deal from discussions with him which have led to substantial revisions of earlier versions.

Frits Beukema is the third person whose influence is very evident to the eye. I have profited much from his comments on earlier versions.

I would also like to thank my parents, who have always encouraged me in my search for knowledge and insight.

My final and deepest thanks go to Annabertha. Her love and friendship helped me through difficult periods and made it possible for me to finish this book. The dedication of this book to her is only a minor compensation for the lack of attention, the touchiness and the weariness she had to put up with during the past two years. That she has been able to cope with this, even in those times when our personal situation was under great stress and in distress, leaves me deeply in her debt. 



\section{Introduction}

In this study the syntactic properties are investigated of empty categories, i.e."gaps", and what are sometimes referred to as "semi-empty categories". i.e."dummies". Whereas the existence of lexical categories is relatively theory-neutral, it is clear that the existence of gaps and dummies is to a large extent determined by theoretical considerations. One can easily imagine a theory without empty categories and dummy pronouns. The theoretical framework adopted here is the Government-Binding Theory, as developed in Chomsky (1981,1982). Throughout this study I will assume familiarity with the central concepts of this theory, such as the notions of Universal Grammar, the Projection Principle, Government, the theories of Binding, Case and thematic roles, and so on. I shall not sketch these major theoretical assumptions here. For readers unfamiliar with GB-theory a rapid overview would be insufficient, while it would be superfluous for readers familiar with this theory.

GB-theory differs quite substantially from early transformational theories such as Chomsky $(1957,1965)$. The main difference is that the centre of attention has shifted from rules to principles. Specific transformational rules have been replaced by the general rule schema "move $\alpha{ }^{\prime}$. The application of this general rule is restricted by a variety of conditions, which are derived from the subtheories of Case, Government, Q-roles etc. Like transformational rules, phrase-structure rules have also been replaced by general concepts and principles. This development was initiated in Chomsky (1970) and has been developed further in Jackendoff (1977) and Stowell (1981). 


\section{Introduction}

As a consequence of these two changes the explanatory power of the theory has increased considerably. At the same time, however, these changes have led to an increase of the complexity of linguistic research. It is now no longer possible to study a particular aspect of a particular language in isolation. We have to take into account the whole theory with all its subtheories and all the intricate interconnections. A minor change in one of the principles of a subtheory might have various far-reaching consequences for other subtheories. Although this can be seen as a positive development that indicates the cohesion of the theory, it makes it rather difficult to evaluate a specific proposal and its consequences for the theory.

The main objective of this study is to demonstrate that it is not a defining property of clauses that they consist of a subject and a predicate. The assumption that clauses must have a subject is implicitly or explicitly present in most, if not all, linguistic theories. In generative grammar this assumption has been incorporated in various ways. Until recently it has generally been accepted that there is a PS-rule of the form $S \rightarrow N P-V P$. Although several theories have been developed to reduce the amount of stipulation in the base component of the grammar, the rule that introduces the subject of $\mathrm{S}$ has been very tenuous. In Chomsky (1982) the rule was replaced by an equally stipulative extension of the Projection Principle. As Chomsky argues "the requirement that a clause have a subject position is independent of the Projection Principle". But since this requirement is "conceptually quite closely related" to the Projection Principle, he introduced the Extended Projection Principle, which combines the Projection Principle and the subject-stipulation. Stowell (1981,1983) argues quite convincingly that the notions 'clause' and 'subject' should be generalized across categories. His solution to the supposedly general condition that $S$ contains a subject is to assume that only constituents which consist of a subject-predicate configuration may be interpreted as a clause at the level of Logical Form. This conclusion is to a large extent similar to that of Williams (1980,1981,1984). Williams argues against the relevance of grammatical relations in the theory. In his view the 'subject' of $S$ must be present as a consequence of predication. 
In this study a different approach to the presence of the subject of $\mathrm{S}$ is chosen. I agree with Williams that grammatical relations are redundant in the theory. In my view the presence of a 'subject' is entirely dependent on Q-theory or Case theory. What is generally referred to as the sUbject is either an external argument of the verb or an internal argument which has been moved in order to receive Case. I agree with Stowell that the external argument is a daughter of the maximal projection of its Q-assigning head. In my view the ensuing endocentric SUbject conception does not require an additional predication rule at LF. It is a consequence of this theory that there are subjectless clauses if the verb does not select an external argument and if there is no internal NP-argument that has to be moved in order to receive Case.

It will be shown that such subjectless sentences are abundantly present in Dutch in precisely the circumstances indicated above. Some relevant constructions are passive constructions in which verbs occur that do not subcategorize for an internal NP complement, but for a PP-complement, a sententia1 complement or no complement at a11. Other instances can be found with raising and ergative verbs. Crucial in this discussion is the status of the so-called dummy pronouns. If the theory outlined above is correct, we do not expect the occurrence of dummy subjects. The appearance of dummy subjects is the strongest argument in favour of a subject stipulation in whatever form. I argue that there are no dummy subjects in Dutch. One of the arguments supporting this claim is that an analysis which incorporates a base-generated subject position has to assume the existence of various types of empty dummy pronouns. While the concept of empty dummy pronouns is undesirable in general, it is particularly unattractive in a language without pronoun-drop, as is DutCh. There are two potential lexical dummy pronouns in Dutch, i.e. het and er. It will be argued that het is not a dummy pronoun but a regular pronoun that needs a $\theta-r o l e$ and Case. $\mathrm{Er}$ is not a dummy subject either, but rather a pp Which may have various functions. If this view is correct, it follows that the central but unattractive stipulation concerning the presence of the SUbject of $S$ may be removed from the theory. 
Chapter 1, which presents the results of work done jointly by Teun Hoekstra and myself (Sennis \& Hoekstra 1984a,b,1985), introduces a theory of empty categories. This theory is an elaboration of Kayne's connectedness approach (Kayne 1984). Two new conditions are proposed, the Gap Condition and the Theta-Referent Condition, which play a central role in this study. It is argued that these conditions enable us to explain the distribution of empty categories, in particular the gaps in P-stranding constructions. In collaboration with the independently motivated rule of $\mathrm{S}$-internal adjunction, these two conditions make precise and correct predictions with respect to the occurrence of parasitic gaps as well.

In Chapter 2 it is argued that the Dutch pronoun het is a referential expression in all its OCCurrences. This implies that het requires a thematic role as well as Case. As indicated above, the relevance of this claim lies in the non-dummy status of het. A variety of arguments supporting this proposal is provided. It is shown that 'dummy' het can be the antesenent of PRO, reflexives and parasitic gaps. The non-dummy status of het is further motivated by an asymmetry in wh-movement from sentential complements. The proposed analysis of het requires an extensive discussion of a variety of constructions in which het appears, such as constructions with raising verbs, ergative verbs and 'psychological' verbs, small-clause constructions and inversion constructions.

Having established that het is not a dummy pronoun, I argue in chapter 3 that the other potential candidate for a dummy-subject status, i.e. er, should not be analysed as a dummy subject either. The R-pronoun er displays a variety of syntactic functions. These are discussed in turn. It is argued that none of these different functions justi.fies an analysis of er as a dummy subject. R-pronouns, including er, are PPs that may be arguments. It i.s proposed that in those cases in which er is generally taken to be a dummy subject er only has a semantic/pragmatic function. This analysis of er provides the means to explain the well-known problem of complementizer_trace phenomena in Dutch.

In chapter 4 some of the consequences of the theory introduced i.n the preceding chapters are investigated. The fully endocentric 
subject conception has far-reaching consequences for the analysis of languages with an apparent NP-INFL-VP structure, such as English, French, Italian and Spanish. It is suggested that in these languages the preverbal subject occupies a derived position. Differences between Old English and Modern English are shown to support this analysis. It is claimed that the postverbal subject in Romance languages in so-called (stylistic) inversion constructions indicates the underlying position of the subject. With respect to the occurrence of apparent dummy pronouns in other languages it is shown that German es and English it may be analysed in a way which is similar to het in DutCh in most respects. It will be evident that the proposals in this chapter are relatively tentative and that further detailed research remains to be done to fathom all the implications for the theory as a whole. 

Chapter 1

\section{Gaps and Parasitic Gaps}

\subsection{Introduction}

Recently, the phenomenon of parasitic gaps has become one of the most widely discussed topics in generative grammar. Their relevance to linguistic theory derives on the one hand from their systematic distribution, as pointed out by Engdahl (1983), and on the other hand from the fact that their appearance is so peripheral that "it is highly unlikely that new and independent principles need be invoked" to determine their distribution "or that rules of particular grammars are involved" (Chomsky 1982,39). In Some Concepts and Consequences (Chomsky 1982), it is demonstrated that the distribution of parasitic gaps in English can in fact be made to follow from independent principles of Government and Binding Theory, without any stipulations specific to parasitic gaps.

In this chapter, the distribution of parasitic gaps in Dutch is investigated. It will be demonstrated that this distribution varies quite substantially from the distribution in English. Given the reasoning above, this difference should follow from independently existing differences between the two languages. As we shall show, this is in fact the case.

* As pointed out in the introduction, this chapter contains work written jointly by Teun Hoekstra and myself. It is composed of the article Gaps and Parasitic Gaps (Bennis \& Hoekstra 1984b) supplemented by a revised version of the final chapter of The Distribution and Interpretation of Gaps (Bennis \& Hoekstra 1984a) and a part of our GLOW_paper A parametrized Gap Condition (Bennis \& Hoekstra 1985). 
This demonstration requires a discussion of the distribution of gaps in general. In section 2, we provide an account of the distribution of gaps in terms of a general principle, which we call the Gap Condition. This condition, which is modeled on Kayne's (1984) Connectedness Condition, replaces the standard ECP of Chomsky (1981). In section 3, it is demonstrated that the Gap Condition adequately accounts for differences with respect to P_stranding in Dutch and English. Section 4 illustrates the application of the Gap Condition to parasitic gap constructions in English.

These three sections provide the background for the discussion of parasitic gaps in Dutch in section 5. In 5.1 it will be seen how the Gap Condition explains the much more restricted distribution of parasitic gaps in Dutch compared to English. In 5.2 we discuss the surprising phenomenon of gaps which have all the properties of parasitic gaps except for the apparent absence of a licensing gap. We shall argue that there is in fact a licensing gap and explain why this particular phenomenon can be found in an OV language like Dutch, but not in a VO language like English. The relevant difference will be seen to have various ramifications, including a difference in transparency of Exceptional Case Marking constructions.

\subsection{Connectedness}

\subsubsection{Kayne's g-projection}

MUCh research in generative grammar has been directed towards restricting the class of possible transformational operations. While these restrictions used to be formulated on the application of transformational rules themselves, most of these restrictions are formulated within recent Government and Binding Theory as well-formedness conditions on representations. Among these restrictions is the Empty Category Principle (ECP), which limits the distribution of traces left by movement by requiring that the empty category resulting from movement be locally identified by a proper governor. The ECP, formulated in (1), distinguishes two different kinds of proper governors. 
(1) ECP

An empty category A must be properly governed by either

a. a category $[ \pm N, \pm V]$ (or INFL), or

b. a local antecedent

The primnry motivation for the ECP lies in subject/non-subject asymmetries of the kind illustrated by the examples in (2). The contrast in grammaticality follows from the ECP if it is assumed that the subject is governed by INFL and that INFL in English does not qualify as a proper governor.

(2)a. Who do you think that Bill likes e b.*Who do you think that e likes Bill

(3) I wonder who e likes Bill

The empty category in (2a) is licensed by the ECP because it is governed by the lexical element like. The empty category in (3), although it is not properly governed by a lexical category, is licensed by virtue of being governed by a local antecedent, who in COMP. Many similar examples of subject/non-subject asymmetries, supporting the formulation of the ECP in (1), can be found in the literature.

The ECP thus has two separate ways of licensing an empty category, a local lexical governor and/or a local antecedent. It has frequently been noted that this is in fact an unnatural combination. On the one hand, the requirement for a trace to have an antecedent follows from its very nature of being a trace. On the other hand, Kayne demonstrates that the notion of a local lexical governor makes the wrong predictions in cases like (4), where the empty category has a local lexical governor in both cases, i.e. the preposition of. Hence, the ECP predicts that they should both be grammatical.

(4)a. Which actress do you think that John likes pictures of e b. Which actress do you think that pictures of $\underline{e}$ turn Bill on 
The standard ECP thus meets with both conceptual and empirical problems. Kayne therefore proposes to replace the ECP in (1) by a condition which collapses (a) and (b) in (1) in a conceptually more attractive fashion. This condition is concerned with the relation between the gap and the antecedent, which must constitute a g-projection as defined in (5).

(5) $\mathrm{Y}$ is a g-projection of $\mathrm{X}$ iff

a. $\mathrm{Y}$ is a projection of $\mathrm{X}$ (in the usual sense of $\mathrm{X}$-bar theory) or of a $\mathrm{g}$-projection of $\mathrm{X}$

or b. $\mathrm{X}$ is a structural governor and $\mathrm{Y}$ immediately dominates

Wand $\mathrm{Z}$, where $\mathrm{Z}$ is a maximal projection of a g-projection of $\mathrm{X}$, and where $\mathrm{W}$ and $\mathrm{Z}$ are in a canonical government configuration

The ECP is thus replaced by the requirement that the gap and the antecedent be connected by a g-projection. The definition of g-projection mentions the notion of canonical government configuration. This is a linear requirement on the relation between maximal projections on the path from the gap to the antecedent and its sister. The order of these is determined by the relative order of the verb and its object, i.e. in a VG language like English, the canonical government configuration requires that maximal projections on the path be on a right branch.

The canonical government requirement is not a local requirement, like the ECP, but takes the entire structure between the gap and the antecedent as its scope. It therefore not only explains the contrast in (2), but also that in (4).

Consider the contrast in (4) first. The governor of the empty category in both examples is the preposition of. The pp headed by of is therefore a g_projection of the governor, by virtue of being

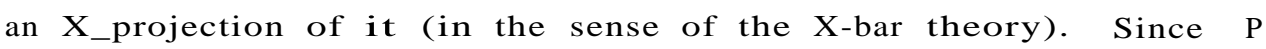
is a prOper governor in English, the g-projection can in principle be continued, if the pp and its sister stand in a canonical government configuration. This is the case in both (4a) and (4b). 
Therefore, the NP pictures of $\underline{e}$ is a g-projection. Again, the g-projection can be continued if the NP and its sister stand in a canonical government configuration. This is true only in (4a), where the NP is on a right branch. In (4b), however, the NP is on a left branch. Therefore, the g-projection stops at the level of NP, and no connection by means of a g-pl'ojectioll can be established between the gap and its antecedent.

Let us now turn to the contrast in (2). In (2b), the empty category is not embedded in a left branch, but is on a left branch itself. Again, no g-projection can be built because the governor of the gap, INFL, is not a structural governor. Although both (2b) and (4b) are therefore ungrammatical, the reasons are slightly different: in (2b) no g-projection can be built because the governor of the gap is not a proper governor, whereas in (4b) the g-projection stops because INFL and the NP subject do not stand in a canonical government configuration.

The g-projection requirement thus constitutes an improvement on the standard ECP, because it eliminates the conceptual problem encountered by the standard ECP and because it has a wider empirical scope. In section 4 we shall see that its scope is wider still (cf. Kayne 1984).

\subsubsection{Two modifications of Kayne's g-projection}

In spite of the unifying effect that the g-projection has in comparison to the standard ECP, it still distinguishes between two different notions. Every g-projection consists of two parts which can be distinguished by the different conditions that are being imposed on them in the definition in (5). The full g-projection starts with an $\mathrm{X}$-projection, which is the maximal projection of the governor of the gap. The condition that is placed on the gap and its sister is that its governing sister be a lexical category. No such condition is imposed on sisters of maximal projections on the path, i.e. on $\mathrm{W}$ in the definition in (5). Alternatively, whereas the relation between maximal projections and their sisters is subject to the linear canonical government configuration, no such linearity is imposed on the relation at the bottom of the 
g-projection, i.e. on the relation between the gap and its governor.

This differentiation lacks empirical support and is therefore conceptually undesirable. We shall demonstrate that if identical conditions are imposed on all links on the path, the notion of g-projection makes stronger predictions than the notion as defined in (S). These predictions appear to be correct.

Consider first the fact that the requirement of being lexical is not imposed on W in (S). This would allow for extraction out of adjuncts, as in (6), which would have a structure like (7).

(6)*Who did you go home after seeing $\underline{e}$

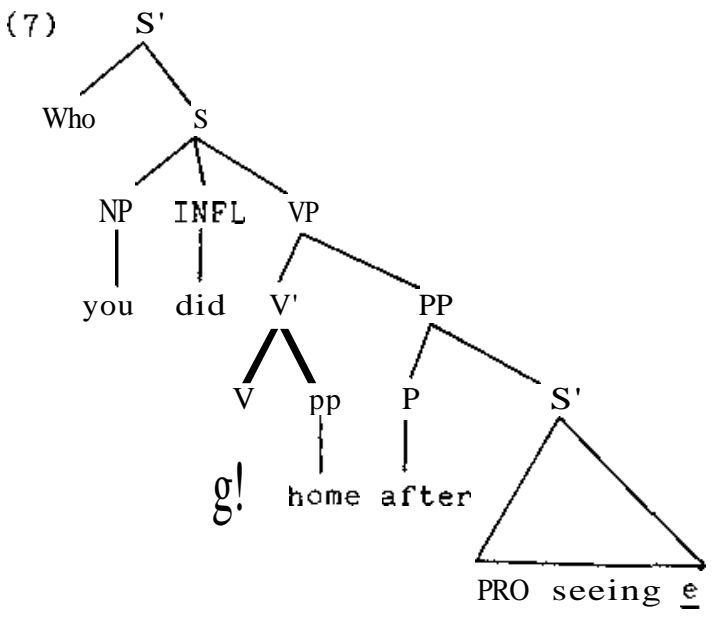

Here, the pp headed by after is a g-projection of the governor of e, seeing. Since this pp is on a right branch, VP should also be a g-projection and we would therefore expect the structure to yield a grammatical result. If, however, a maximal projection must have a lexical sister and be on a right branch, the ungrammaticality of (6) would be predicted.

The effect of imposing a linear requirement on the relation between the gap and its governor cannot be observed in a head-initial VD language like English or in a head-final OV language, but it can be observed in a language with mixed branching like Dutch. Dutch has aV-order. The canonical government 
configuration requires maximal projections to be on a left branch, rather than on a right branch as in English. PPs may generally occur both preverbally and postverbally. Adpositions are usually prepositional, but postpositions occur as well. Thus, there are four theoretical possibilities, which are depicted in (8).

(8)a.

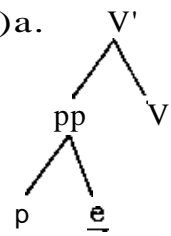

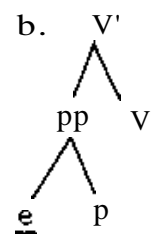

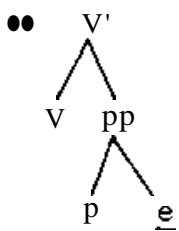

d.

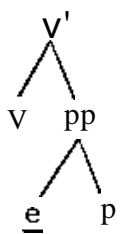

If the canonical government requirement is imposed only on maximal projections on the path, we predict that (8c) and (8d) are ungrammatical, because the $\mathrm{pp}$ is on a right branch. No distinction is made between ( $8 \mathrm{a})$ and ( $8 \mathrm{~b})$, however. If we strengthen the definition of g-projection such that the gap and its governor must also stand in a canonical government configuration (cf.Koster 1984), we predict that only ( $8 \mathrm{~b})$ is allowed. This prediction is correct, i.e. stranding of adpositions is only possible with postpositional PPs in preverbal position. P-stranding in Dutch is discussed in much greater detail in section 3. Postpositional PPs in DutCh usually have a so-called $[+\mathrm{R}]$-complement. As the examples in (9)-(12) show, extraction of these complements is possible only from preverbal PPs.

(9) a. dat Jan naar het meisje keek that John at the girl looked

b.*het meisje dat Jan naar e keek the girl who John at looked

(10)a. dat Jan daar naar keek that John there at looked

b. het huis waar Jan e naar keek the house where John at looked

(11)a. dat Jan keek naar het meisje that John looked at the girl

b.*het meisje dat Jan keek naar $\underline{e}$ the girl that John looked at 
(12)a. dat Jan een boek heeft gekocht daar over that John a book has bought there about

b.-het onderwerp waar Jan een boek heeft gekocht e over the subject where John a book has bought about

It turns out, then, that the definition of g-projection can be strengthened and unified in the following way.

\section{(13) Gap Condition}

A gap $\mathrm{Z}$ in a tree $\mathrm{P}$ is linked to its antecedent by a connected subtree of $\mathrm{P}$ which constitutes a g-projection

$\mathrm{XP}$ is a g-projection of the structural governor Wof $\mathrm{Z}$ iff the head of XP c-governs $Z$ or a g-projection of $W$

$\mathrm{X}$ c(anonically)-governs $\mathrm{Y}$ iff $\mathrm{X}$ precedes $\mathrm{Y}$ in a VO language and follows $\mathrm{Y}$ in an OV language

The requirement that the governor of a gap be a structural governor is motivated in Kayne $(1984,167)$. Whether or not a specific category is a structural governor appears to some extent to be a language particular matter, e.g. English but not French prepositions qualify as structural governors.

From the above discussion relating to the island character of adjuncts, it will be clear that our notion of government as used in (13) differs from the generally adopted definition in Aoun \& Sportiche (1983). According to their proposal a lexical category governs all phrases within its maximal projection. We assume that government is restricted to the argument projection, as in Chomsky (1979). Therefore, an adjunct phrase is not governed, although it is in the maximal projection.

Government is not a relational notion itself, but rather a domain restriction within which certain relations hold. Among these relations are Case Assignment, Theta-role Assignment to internal arguments, and the UCC (Unlike Category Condition), which is discussed in the next section. 
1.2.3 Extraction from complement clauses

One reason to distinguish (as Kayne's definition in (5) does) between the $X$-projection part of a g-projection and the higher levels of the g-projection derives from the different behavior in English of empty categories constituting a left branch themselves and empty categories embedded in a left branch. This differential behavior can be illustrated by the examples in (14). In (14a), the subject of a clausal complement is extracted, whereas a part of the subject is extracted in (14b).

(14)a. Which runner do you believe $\underline{e}$ to have won the race b. Which book do you believe the first chapter of $\underline{e}$ to be full of lies

According to Kayne $(1984,169)$, the empty category in (14a) is licit since a g-projection of the verb believe contains the antecedent. This is so, since there is no requirement that there be a node which immediately dominates both the governor and the gap. The immediate dominance requirement on higher levels of the g-projection explains the ungrammaticality of (14b), i.e. the subject NP (the first chapter of e) and believe do not stand in a canonical government configuration, because there is no category which immediately dominates both. Our proposal makes the same distinction, however, without having recourse to a distinction between $\mathrm{X}$-projection and g-projection. Consider the relevant parts of the tree structures of (14) given in (15). 


\section{Gaps and Parasitic Gaps}

(15)a.

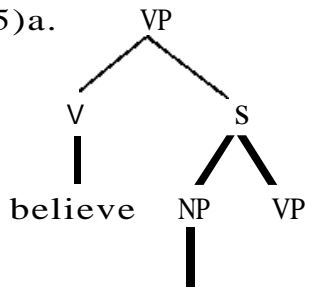

b.

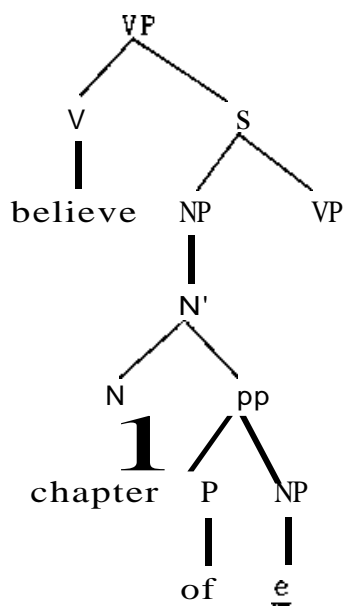

The VP in both (15a) and (15b) is a g-projection of the governor of the gap (believe in (15a) and of' in (15b)). For our purpose, the structure above this VP is irrelevant. In (15b), the pp and the NP are also g-projections. The distinguishing property resides in $\mathrm{S}$. In neither construction is Sag-projection, since the head of $S$ (INFL) does not c-govern a g-projection of the governor of the gap. In the case of (15b), this means that the maximal g-projection (i.e. the $\$^{\prime}$ which contains the antecedent) does not constitute a connected subtree, or put differently, the subtree from the governor of the gap to the antecedent is not a g-projection. In the case of (15a), the fact that $S$ is not a g-projection is irrelevant since it is not part of the relevant subtree, which starts with believe, the governor of the gap

It turns out that our Gap Condition in (13) handles extractions out of complement clauses (including small clauses) without having recourse to a separate notion of X_projection.

A problem for Kayne's approach as well as for ours arises in the case of WH-extractions out of sentential complement clauses in Dutch.

Dutch is an av language. As a result, the canonical government configuration is for the governor to occur on the right of the governee. However, although NP and AP complements have to precede the verb in Dutch, full sentential complements, finite and 
non-finite, have to follow the verb. Therefore, we expect extraction out of sentential complements to be impossible in Dutch, which, however, it is not. Consider (16) and its tree structure representation in (17). We shall assume that $S$ is the maximal projection of $V$ and that $S$ is governed from the right by INFL, which wc take to be the head of $S^{\prime}$ (see Hoel<stra 1984 for discussion).

(16) Wat dacht je dat Piet $\underline{t}$ zag?

What thought you that Peter saw?

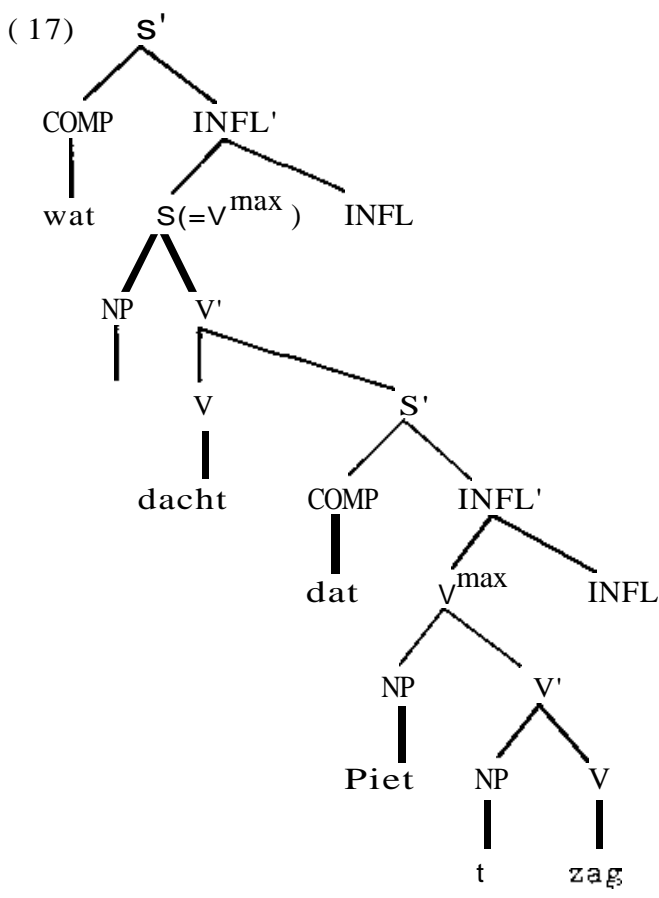

In accordance with canonical government, we can build a g-projection up to the embedded $\mathrm{S}^{\prime}$ : the $\mathrm{Y}$ zag governs the gap to the left, the ymax is also governed from the left by INFL. Hence $S^{\prime}$, being the maximal projection of INFL, is a g-projection of $V$. The matrix $\mathrm{V}^{\max }$ is not a g_projection of the embedded $\mathrm{V}$, since dacht governs the $S^{\prime}$ in the wrong direction.

We shall assume that movement from the extraction site to the 
matrix COMP does not take place in a single step, but rather by successive movement via the embedded COMP. Since the embedded $S^{\prime}$ is a g-projection of the embedded V, movement to the embedded COMP is allowed. The second extraction leaves an empty category behind. This empty category in COMP is governed by the verb dacht, but not canonically.

Essentially following a suggestion made by Van Riemsdijk (p.c.), we shall assume that licensing requirements for categories in $\mathrm{A}^{\prime}$-positions are less strict than for categories in A-positions. In this case, this means that we shall assume that the directionality of canonical government does not apply to the empty category in COMP. Therefore, the matrix S' constitutes a g-projection of the governor of this empty category in COMP. Thus, the path from the empty category in A-position to its ultimate antecedent in the matrix COMP consists of two separate subtrees, each of which constitutes a well-formed g-projection.

This analysis makes an interesting prediction. It not only explains why extraction from embedded sentential complements is possible in Dutch, in spite of the apparent violation of the canonical government requirement, but it explains at the same time why the WH-island condition is so strictly obeyed in Dutch, much more so than e.g. in English. The reason is that extraction in Dutch necessarily involves an intermediate step through COMP, whereas in English a g-projection can be built directly, i.e. without an intermediate step through COMP, given the fact that the embedded clause is canonically governed by the matrix verb.

In section 5.1. we shall discuss a further interesting corollary of our analysis of extractions out of Dutch sentential complements.

\subsection{Complex cases of PPs}

In the previous section it was shown how $\mathrm{P}$-stranding in DutCh can be explained in terms of the Gap Condition. In this section we shall present a more elaborate discussion of the problems concerning $\mathrm{P}$-stranding in general, and in Dutch in particular.

The phenomenon of P-stranding is discussed at some length in Van Riemsdijk (1978a). The account given by Van Riemsdijk focuses 
on the internal structure of PP. In 3.2 we shall discuss those aspects of the syntactic context of the $\mathrm{pp}$ which are relevant to stranding, but first, in 3.1, we shall go into Van Riemsdijk's account. The discussion in this section will prove to be relevant to the distribution of parasitic gaps in Dutch, which will be discusscd in section 5 .

\subsubsection{Van Riemsdijk's analysis of $P_{-}$stranding}

Dutch is mainly prepositional. As is indicated in (18b), extraction of the NP complement of a preposition is not allowed.

(18)a. Jan heeft op Marie/*Marie op gerekend

John has on Maryl Mary on counted

b. Wie heb je op $\underline{t}$ gerekend

Who have you on counted

If the complement of a preposition is a [-human] pronoun, it obligatorily appears in the so-called $\mathrm{R}$-form and precedes the $\mathrm{P}$ of which it is a complement. The notion $\mathrm{R}$-form refers to a set of pronominal elements that characteristically have a phoneme $/ \mathrm{r} /$ which is not found with other pronouns. The phenomenon is illustrated by the examples in (19).

$$
\begin{array}{rll}
\text { (19)a.*Jan heeft op het } & \text { gerekend } \\
\text { John has on it } & \text { counted } \\
\text { b. *Jan heeft op er } & \text { gerekend } \\
\text { John has on there counted } \\
\text { o Jan heeft er op gerekend } \\
\text { John has there on counted } \\
\text { d. *Jan heeft het op gerekend } \\
\text { John has it } \text { on counted }
\end{array}
$$

In (19c), the $P$ is a postposition and the $R$-pronoun may be extracted, either by WH-movement or by regular R-movement:

$$
\text { (20)a. Waar heeft Jan } t \text { op gerekend }
$$

Where has John on counted 
b. Jan heeft er vandaag niet $t$ op gerekend John has there today not on counted

The explanation of this set of facts given in Van Riemsdijk (1978a) can be summarized as follows. The impossibility of (18b) is explained by postulating the Head Constraint, which states that no material may be extracted from the domain of the head. In order to account for the obligatory shift of [_human] pronouns to R_forms, Van Riemsdijk invokes an R-suppletion rule Which changes the pronoun het in (19a) into er, as in (19b). Then there is a filter that excludes an R-pronoun in the complement position to the right of the preposition. A rule of R-movement has the effect of relocating the $\mathrm{R}$-pronoun to the left of the preposition and outside of the $\mathrm{P}^{\prime}$-domain in order to escape the effects of the Head Constraint. This movement is depicted in (21). Apart from the Head Constraint, Van Riemsdijk also assumes that extraction from pp is restricted by subjacency, pp counting as a bounding node. Given the binding nature of PP, WH-extraction in (20a) cannot have taken place in a single step. Therefore, the R-pronoun is first moved outside the PP to the position taken by er in $(20 b)$, thus crossing only a single bounding category, and then moved to CQMP, again crossing only a single bounding node $(S)$.

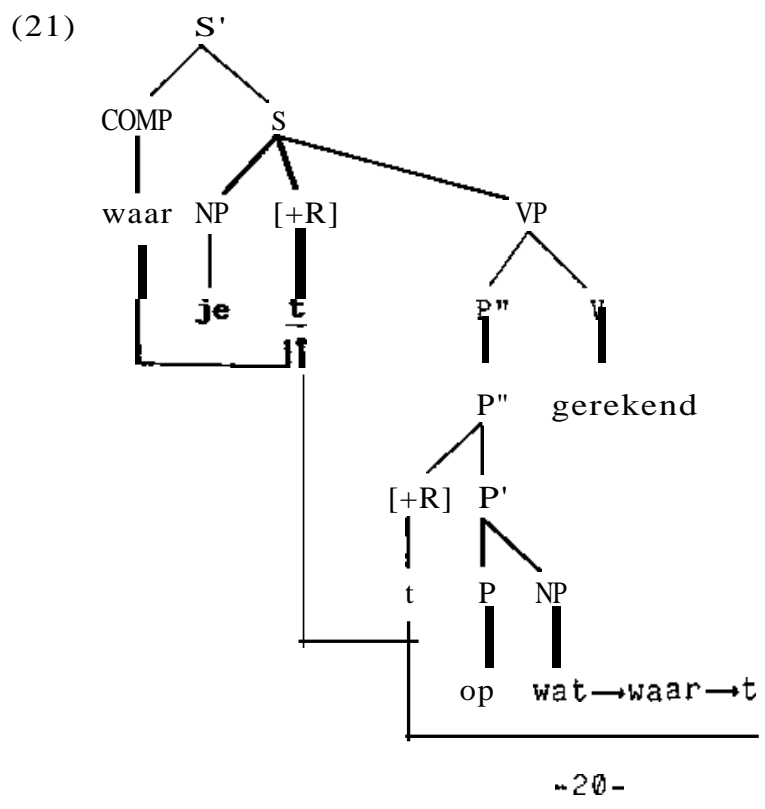


Although the R-pronouns in Van Riemsdijk's analysis originate as NPs, it is important to note that an R-pronoun can only bind empty [R]-positions, i.e. empty positions inside PP. This will become clear in our discussion of parasitic gaps in section 5. This is one of the reasons to assume that $\mathrm{R}$-pronouns do not result from suppletion, but are base-generated in front of their $P$ head. The different orientation of R-complements and non-R-complements with respect to $\mathrm{P}$ can be derived from Case Theory on the assumption that $P$ assigns Case to the right and that $R$-forms inherently resist Case. [1].

In the previous section, we demonstrated how the difference in extraction possibilities between prepositional and postpositional PPs is a direct consequence of the requirement of canonical government (cf. (8)-(12)). Although Van Riemsdijk's account is also capable of making this distinction, his analysis has nothing to say about the difference between postverbal and preverbal PPs, i.e. his analysis does not preclude extraction of R-pronouns from postverba 1 PPs. In this sense, then, Van Riemsdijk's account relates the possibility of extraction entirely to PP internal aspects.

\subsubsection{Adjacency and P-stranding}

It has previously been observed (see Hornstein \& Weinberg 1981) that the possibilities of extraction from PP seem to depend in large measure on the context in which the PP appears. Hornstein \& Weinberg point out that preposition stranding is possible if the $P$ is reanalyzed to become part of a complex verb. This reanalysis rule applies only to material contained in the domain of the verb. In this way, they can make a distinction between S-PPs and VP-PPs, only the latter of which allow P-stranding. In our terms, this distinction is an automatic consequence of the requirement that maximal projections on the path from the governor of the gap to the antecedent be canonically governed (cf. (6)). There is therefore no need for a reanalysis rule. Furthermore, we shall follow Kayne (1984, ch. 5) in assuming that the difference between French and English with respect to F-stranding is a consequence of the fact that $F$ is a structural governor in English, but not in French. 
Hornstein \& Weinberg argue that the difference between S-PPs and VP-PPs is unexpected under Van Riemsdijk's approach. Now we want to draw attention to a similar kind of problem. In Dutch, the position of a stranded preposition differs quite strikingly from the possible positions of the corresponding full PPs. This is illustrated in (22).

(22)a. dat ik over dat onderwerp met Piet sprak that I about that subject with Peter talked

b. dat ik met Piet over dat onderwerp sprak that I with Peter about that subject talked

c. ${ }^{*}$ het onderwerp waar ik over met Piet sprak

the subject Where I about with Peter talked

d. het onderwerp waar ik met Piet over sprak the subject where I with Peter about talked

The stranded preposition over in (22c) cannot occupy the same relative position as the corresponding full pp in (22a), but has to occupy the position to the immediate left of the verb. This descriptive generalization holds throughout: the stranded preposition must be left adjacent to the verb.[2]. This generalization follows from our Gap Condition, i.e. from the requirement that the pp itself is canonically governed and that the $P$ must also canonically govern its complement. Let us consider the structure of (22c). We shall assume, following Kayne (1984), that syntactic structure is binary branching. Given the linear order of the constituents in (22c), this means that the syntactic structure of the verb projection of (22c) must contain something like (23).

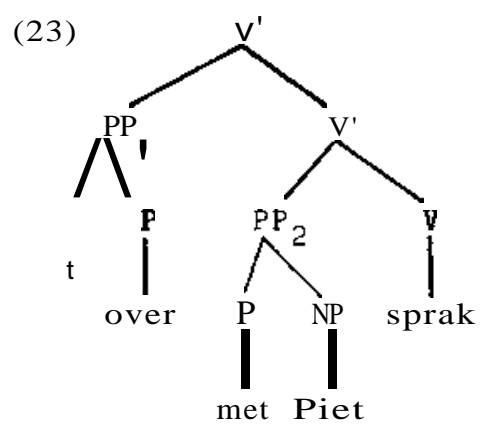


In this structure $\mathrm{PP}_{2}$ is strictly governed (in the sense of minimally c-commanded) by the lexical verb, unlike PP,. Therefore, if it is assumed that canonical government requires strict government, the ungrammaticality of (22c) is an automatic consequence.

There appears to be some variation between Dutch and English as to what counts as the government domain within which canonical government must hold. Consider (24), which is the mirror image of (22c) in the relevant respects.

(24) Which subject did you talk with Peter about $\underline{e}$

Here, the about-PP, although belonging to the V-domain, cannot be strictly governed by the verb, given the binary branching requirement. We have no explanation to offer for this variation between Dutch and English.

The requirement that a pp containing a stranded preposition must be canonically governed predicts that no extraction is possible from a PP in the complement of an NP, since PP complements to nouns follow the noun in Dutch. This is illustrated by the following examples.

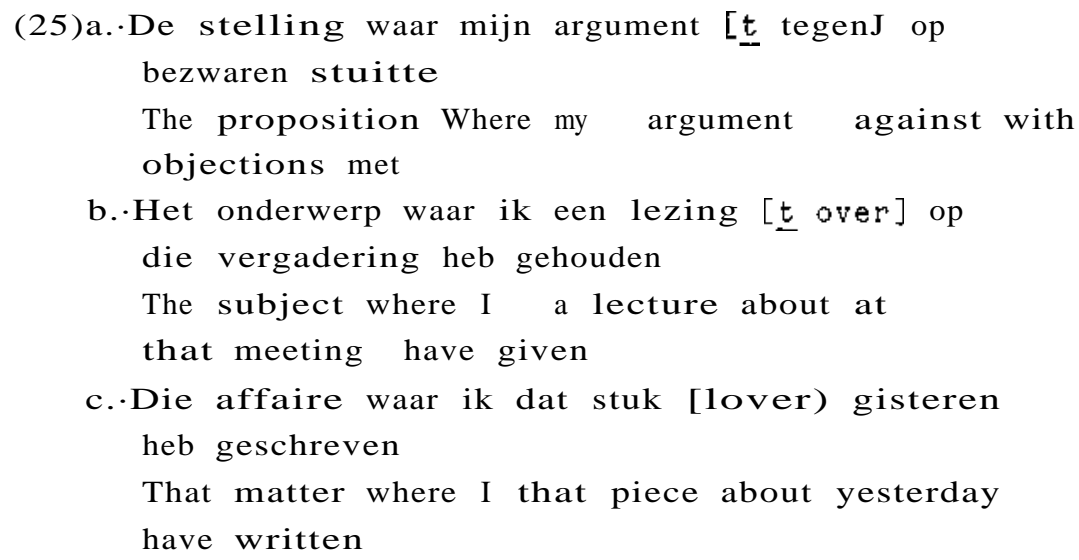

The only NPs from Which it seems possible to extract an R-pronoun from a pp complement are direct object NPs which are adjacent to the verb. 
(26)a. het onderwerp waar ik op die vergadering een lezing [t over] heb gehouden

the subject where I on that meeting a lecture

about have given

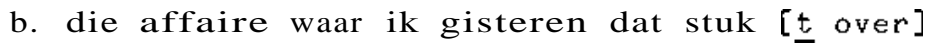

geschreven heb

that matter where I yesterday that piece about written have

These facts are reminiscent of the discussion concerning PP extraction from NP (cf. Bach \& Horn 1976, Chomsky 1977). Chomsky (1977) argues that extraction from NP as in (27) should be excluded, given subjacency with NP and $\mathrm{S}$ as bounding nodes, but proposes that the $\mathrm{pp}$ is reanalyzed as a separate constituent prior to movement into COMP. About Which book did you write a review

We could adopt a similar line of reasoning and assume that in cases like (26), where it seems that extraction takes place from inside an NP, the pp is restructured out of NP first, a process which is needed independently to account for the examples in (28).

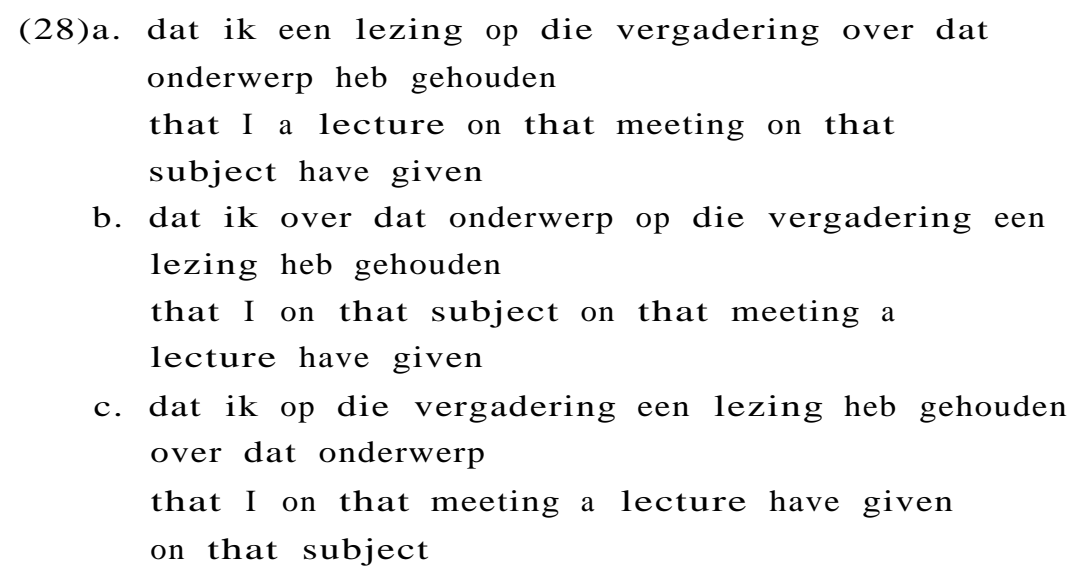

After restructuring, the $p$ is strictly governed by the verb and hence a g-projection can be built if an R-pronoun is extracted. 


\subsubsection{Extraction from complex PPs}

We now turn to more complex cases, where it will be demonstrated that our Gap Condition makes correct predictions. These cases involve adpositions which take a PP complement. Since a P may occur either as a preposition or postposition, we can distinguish between eight different situations involving a $\mathrm{P}$ with a $\mathrm{pp}$ complement from which the NP complement is extracted. Four of these involve postverbal PPs. As we explained earlier, these constructions are ungrammatical because the matrix PP is not canonically governed. The four preverbal cases are given in (29).

(29)a.

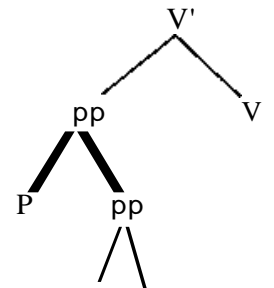

c.

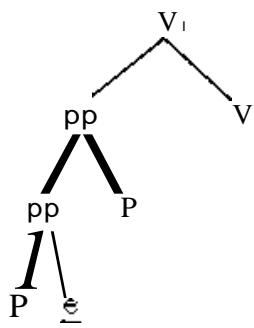

b.

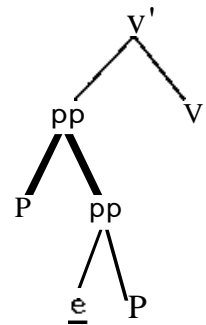

d.

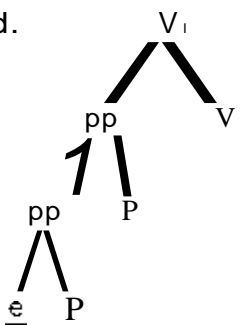

These four different combinations are instantiated by the (b) examples of $(30)-(33)$.

(30)a. dat hij de koekjes [voor [bij de koffie]] koopt that he the cookies for with the coffee buys

b. ${ }^{*}$ Ik vroeg wat hij de koekjes voor bij t kocht

I asked What he the cookies for with bought

(31)a. dat hij de koekjes [voor [daar bij]] koopt

that he the cookies for there with buys 
b. *Ik vroeg waar hij de koekjes voor t bij kocht

I asked where he the cookies for with bought

(32)a. Hij is net [[onder het hek] door] gekropen

$\mathrm{He}$ is just under the fence through crawled

b. *Ik vroeg welk hek hij net ander $\underline{t}$ door was gekropen

I asked which fence he just under through was crawled

(33)a. Hij is net [[daar onder] door] gekropen

$\mathrm{He}$ is just there under through crawled

b. Ik vroeg waar hij net $t$ onder door was gekropen

I asked where he just under through was crawled

Two factors are relevant in determining the possibility of extracting the complement of the embedded $P$ :

a. Is this complement canonically governed by $\mathrm{P}$ ?

b. Is the embedded pp canonically governed by the matrix P?

If we inspect the tree representations in (29), we see that in (29a) both the empty category and the embedded pp are not canonically governed; in (29b) the empty category is canonically governed, but the embedded $\mathrm{pp}$ is not; in (29c), the empty category is not canonically governed, although the embedded pp is; finally, both the empty category and the embedded pp are canonically governed in (29d). The grammaticality of (33b) is therefore predicted by the Gap Condition, just like the ungrammaticality of the other (b) examples. Thus, we succeed in predicting that only one out of eight possibilities yields a grammatical result without any statements specific to these constructions.

The next question concerns the possibility of extracting the pp complement of an adposition itself. In this case, there are four situations, two with the pp in postverbal position, Which again we Shall not disCUSS, and two with a preverbal PP. These two situations are depicted in (34). 
(34)a.

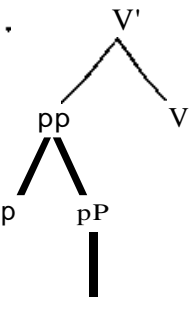

b.

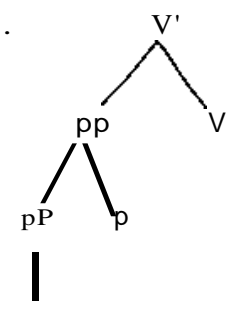

These structures are instantiated by the (b) examples in (35)-(36). It is predicted that only the structure in (34b) yields a grammatical outcome. In (34a), the embedded PP is not canonically governed. The facts are as predicted.

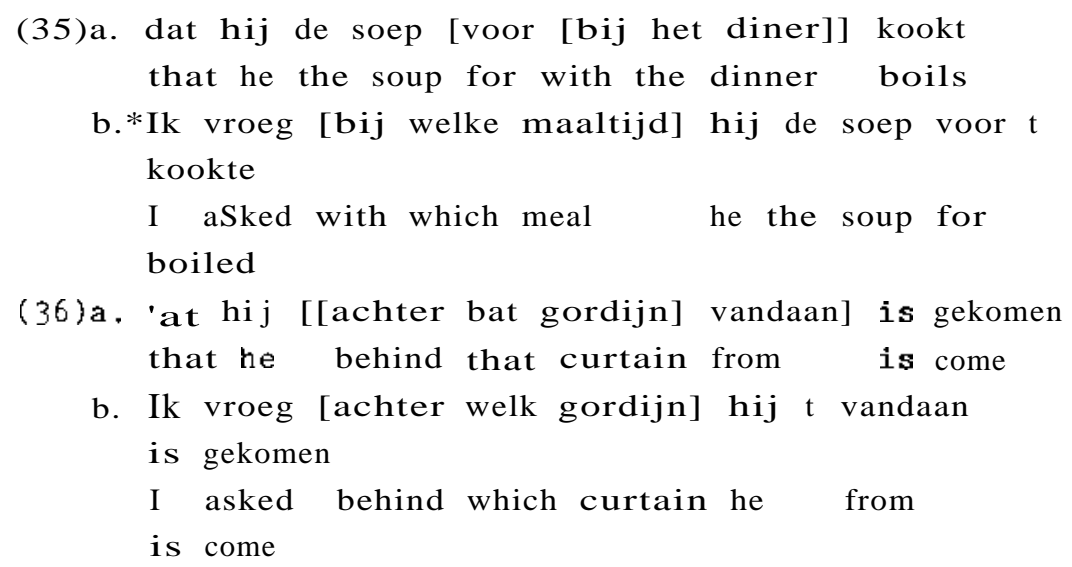

It should be noted that Van Riemsdijk's analysis cannot account for the contrast between (31) and (33). Van Riemsdijk suggests that extraction from PPs is made possible via a base generated $[+R]$-position outside the head domain, i.e. on the $\mathrm{P}^{\prime \prime}$ level (see section 3.1). Nothing would prevent the extraction of the R-pronoun in (31b) in two successive steps as depicted in (37). 
(37)

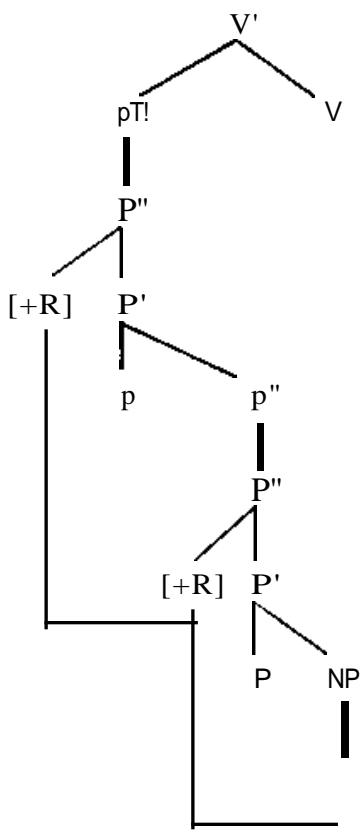

Van Riemsdijk appeals to the notion of bridge to account for the ungrammaticality of $(31 \mathrm{~b})$ : the relevant prepositions would not qualify as suitable bridges, unlike elements like vandaan and door, as in (33) and (36), which he analyzes as postpositions (cf. Van Riemsdijk 1978a,299ff). If an appeal to the notion of bridge were on the right track, we would not expect the consistent preposition-postposition asymmetry that we find in (31)-(33) and $(35)-(36)$.

Turning to comparable structures in English, we would expect extraction from a pp which is embedded in a pp to be possible, since this would constitute the exact mirror image of (29d). This expectation is borne out by the following examples.

(38)a. Fido jumped from under the table

b. Which table did Fido jump from under $t$

(39) a. Fido ran out into the meadow

b. Which meadow did Fido run out into $t$

Unexpected, however, is the fact that the embedded pp itself cannot 
be extracted, unlike the mirror image counterpart in Dutch in (36).

(40) $a . *$ Under which table did fido jump from $t$

b. Into which meadow did fido run out $t$

Sag (1982) discusses these examples and argues for an explanation in terms of a GPSG version of the A-over-A principle. Whereas the ungrammaticality of (40) is unexpected under our approach, the grammaticality of (36b) constitutes an anomaly for Sag's A-over_A account. We shall now demonstrate that the ungrammaticality of (40) is related to other phenomena, which are independent of our Gap Condition.

\subsubsection{Reanalysis in complex PPs}

Although the examples discussed in the previous section involve PPs in the complement of $\mathrm{P}$, this configuration is usually not allowed. In general, $P$ may not govern $P P$. This is in fact an instance of a much wider restriction, which states that no category may govern an element of the same category. So, N may not govern an NP, A may not take AP complements, V may not take V projections as complements, and similarly, $\mathrm{P}$ cannot take $\mathrm{pp}$ complements. This restriction, called the Unlike Category Condition (UCC), is amply discussed and illustrated in Hoekstra (1984, ch. 2). To illustrate the restriction on Ps, we can give examples like those in (41).

(41)a.*We spraken over in het huis

We spoke about in the house

b. ${ }^{*}$ Ik vertrouw op onder het bed als een goede schuilplaats

I trust on under the bed as a good hiding place

c.*Voor het opeten van de taart rekenden we op tijdens

de lunchpauze

For the eating of the cake counted we on during the lunch break

The counterexamples to this restriction in the case of Ps concern only a few prepositions, which are semantically similar for Dutch 
and English. Some examples are given in (42).
(42) van voor de oorlog
from before the war
voor na the maaltijd for after the meal
tot na die datum
until after that date

The main reason to consider these examples exceptional is that the configuration is subject to severe restrictions of a lexical nature. In order to maintain the UCC as a general principle, we shall assume that the constructions in (42) escape the effect of the UCC by being reanalyzed into a prepositional complex.

This situation closely resembles the case of $\mathrm{V}$-raising complement structures in Dutch, both in its motivation and in its effect. In Dutch, sentential complements do not occur in preverbal position, unlike APs and NPs, whereas PPs may in principle occur on either side of the verb. The reason that APs and NPs must occur preverbally can be accounted for by assuming that Case Assignment is directional.C3]. The fact that PPs, which do not require Case, may occur both preverbally and postverbally suggests that Theta-role Assignment is not directional. The obligatory postverbal occurrence of sentential complements can be derived from the UCC, if we assume that the UCC is directional, just like Case Assignment, its direction being determined by the direction of Case Assignment. A sentential complement in preverbal position will be governed by $\mathrm{V}$ from the right, which is also the direction of Case Assignment. Therefore, if a sentential complement is non-distinct from $V$ in its feature content, the preverbal occurrence is forbidden by the UCC.

Let us now turn to V-raising structures. These involve a verbal projection to the left of the matrix verb. Consider the structure in (43). This structure is rejected by the ucc. Therefore, the complement either has to occur in instverbal position, as in (44a) or V-raising has to apply, giving rise to (44b)(for discussion, se Evers 1975).

(43) *dat Jan [een artikel te schrijven] beloofde that John an article to write promised 
(44)a. dat Jan beloofde [een artikel te schrijvenJ

b. dat Jan [een artikelJ beloofde [te schrijvenJ

The rule of V-raising, by which (44b) is derived, is a rule of reanalysis which applies to a structure like (45).
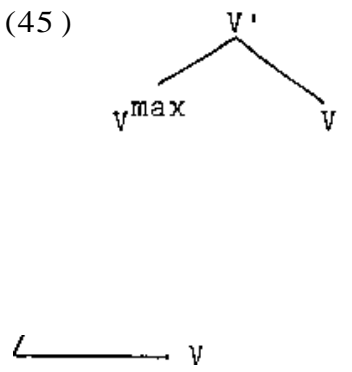

The effect of this reanalysis, which is again severely restricted by lexical factors, is that the resulting structure no longer violates the uec. In these respects, then, the reanalysis operation of Vuraising is identical to the reanalysis that we wish to invoke to account for the exceptions to the UCC in (42). One might object that there is a clear difference between $V$-reanalysis (V-raising) and the proposed P-reanalysis, since V-raising has a linear effect of reordering the matrix and the embedded verb. However, it has been established that V-raising applies in German without a similar linear effect. Recently, Huybregts (1g83) and Haegeman \& Van Riemsdijk (1984) have argued that the process of V↔raising must be broken up into two steps, one involving the actual reanalysis, which now looks even more similar to our P-reanalysis, and a second operation which realizes the linear shift in Dutch. In fact, from this perspective the reanalysis operation does not differ in any important respect from the reanalysis rule proposed by Rizzi (1982, ch. 1) for Italian. We shall formalize the reanalysis operation by assigning a cosuperscript to the head of the complement and its governor, in order to capture the fact that no actual restructuring takes place. This is evident from the fact that both heads can be separated by intervening material, as is illustrated in (46). The reanalysis operation in the case of constructions like those in 
(42) is illustrated in (47).

(46)a. van vlak veor de oorlog

from right before the war

b. van daar voor

from there before

c. van vlak daar voor

from right there before

(47)

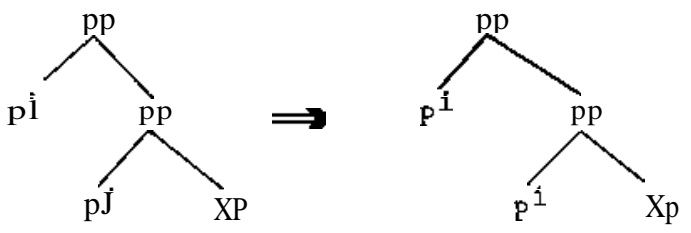

The XP in (47) may be an NP as in the examples given in (42), but also an St. This is illustrated in (48).

(48)a. Dit model dateert nog van veor dat ik geboren werd

This model dates still from before that I born was

b. Wacht maar tot na dat we gegeten hebben

Wait just until after that we eaten have

c. We bewaren de bonbons voor tot na dat we keffie

gedronken hebben

We keep the chocolates for until after that we coffee drunk have

This is in itself not surprising, but what is unexpected is the fact that an infinitival complement clause may not replace the finite complement clause. This is shown by the examples in (49).

(49)a.*Wij wilden wachten tot na gegeten te hebben

We wanted wait until after eaten to have

b.*Hij kan zich dat nog herinneren van veor te zijn geboren

He can himself that still remember from before to be born

c.*Dit is een lotion voor na te hebben gedoucht

This is a lotion for after to have showered 
Clearly, the reason for the ungrammaticality of these examples cannot be some semantic violation, since it is entirely clear what is meant. Nor can an appeal be made to a locality requirement on the control of PRO, especially not in the case of (49c), which would be an instance of PROarb.

Before this puzzle can be solved, it is relevant to introduce one further observation, which also shows an asymmetric distribution of finite and non-finite clauses in the complement of prepositions, in spite of the fact that finite and non-finite clauses in general have the same distribution in Dutch, just as they have in English (barring lexical idiosyncrasies). Infinitival clauses are found as complements to all major categories, as the examples in (50) illustrate. It is a striking fact that, whereas with other category types infinitival complements may optionally be introduced by om _(again barring leXical idiosyncrasies), the prepositional complementizer on is obligatorily absent in the complement of $\mathrm{P}$, whereas the finite complementizer dat is obligatorily present (i.e. there is no rule comparable to English that-deletion in Dutch, not with any category).[4]. This is shown in (51).

(50)a. Hij dwong mij (om) weg te gaan

$\mathrm{He}$ forced me (for) away to go

b. De belofte (om) die avond aanwezig te zijn The promise (for) that night present to be

c. Het is leuk (om) hem weer te ontmoeten

It is nice (for) him again to meet

(51)a. Zonder [dat hij het boek gelezen had]

Without that he th, book read had

b. Na [dat ik h,m ontmoet had]

After that I him $\mathrm{m}, \mathrm{t}$ had]

- Zonder (*om) het boek gelezen te hebben

Without (for) the book read to have

d. $\mathrm{Na}(* \mathrm{om})$ hem ontmoet te hebben

After (for) him met to have 
Intuitively, the two observations in (49) and (51) are clearly related: linearly speaking an infinitival clause is preceded by two prepositions. In (49), there is a combination of prepositions which normally allow reanalysis in order to avoid a violation of the UCC, whereas in (51) the infinitival complement of a preposition may not be introduced by a prepositional complementizer. Let us take seriously the notion of prepositional complementizer and assume om, which introduces infinitival clauses to be a preposition occupying the embedded COMP position. This assumption is itself without any other consequences. For instance, it does not imply that PRO should be excluded from the subject position of such infinitival complements, since COMP is the specifier of the INfL projection. Therefore, no government relation exists between $\mathrm{P}$ in COMP and the subject position of $\mathrm{S}$, which is $\mathrm{V}^{\max }$ in Dutch. We shall follow Stowell (1981) in assuming that in English, COMP is the head of $\mathrm{S}^{\prime}$, rather than INFL. This assumption allows us to explain the difference between Dutch and English in this respect. If COMP is the head of $S^{\prime}$ in English, for in COMP governs the subject position of $S$ and assigns Case to it under government. Therefore, the subject of infinitival clauses introduced by for must be lexical. Configurationally, there is no difference between the relation of COMP and the subject position on the one hand and the verb consider and the subject of its small clause complement AP, as in (52b).

\section{(52)a. for [John to leave] \\ b. consider [John foolish]}

In both cases, the relation is as in (53). We shall assume that at least $\mathrm{V}$ and $\mathrm{P}$ in the position of $\mathrm{X}$ govern the position $\mathrm{W}$ in (53).

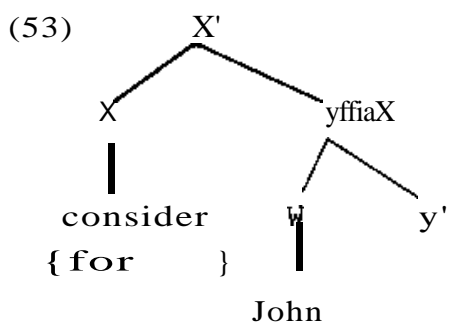


The assumption that om is a preposition in COMP position allows us to explain the fact that infinitival clauses introduced by om do not occur in the complement of a preposition. The structure of an example such as (51c), with om present, would look like (54).

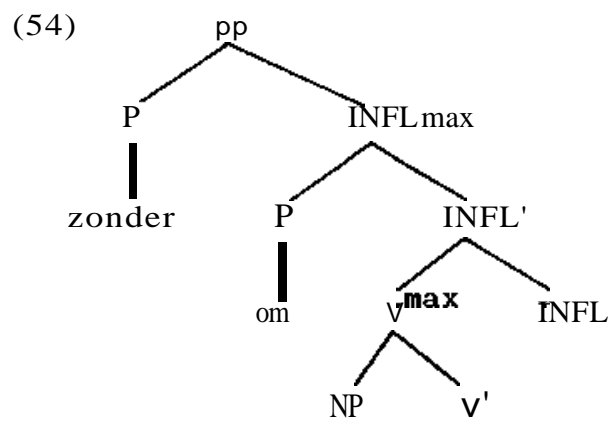

The configurational relation between zonder and om is identical to the relation between $\mathrm{X}$ and $\mathrm{W}$ in (53), i.e. zonder governs om, which is not allowed by the UCC. Therefore, the sentence is ungrammatical. It should incidentally be noted that om does not stand in a government relation to the NP subject of Vmax, as we stated above. We note here that, eVen if the combination of zonder and om fulfilled the lexical requirements for reanalysis (which it happens not to), reanalysis is inapplicable in this configuration, since om is not the head of the complement of zonder. It is a characteristic property of reanalysis rules that they apply to heads only. If the COMP position may be filled by the preposition om, other prepositions might in principle occupy this position as well. Then, zonder in (51c) could also occupy this position if om is not present, thus yielding a structure like (55) instead of (54) .

(55)

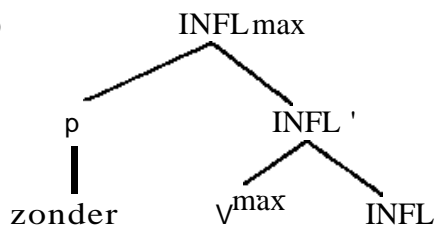

Suppose this is in fact correct. Then we can account for the 
contrast between (48) and (49). This contrast is again illustrated by the pair in (56).

(56)a. voor na dat je gedoucht hebt

for after that you showered have

b.*voor na te hebben gedoucht $\quad(=(49 c))$

for after to have showered

Their respective tree structure representations are given in (57a) and (57b), under the assumption that the preposition na projects a pp structure of its own. However, under the assumption made above, that the preposition na may occupy the COMP position of the infinitival clause, the structure of (57b) would be as in (58).

(57)
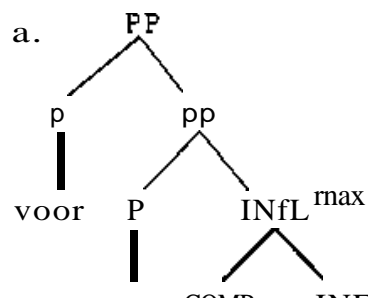

na b.
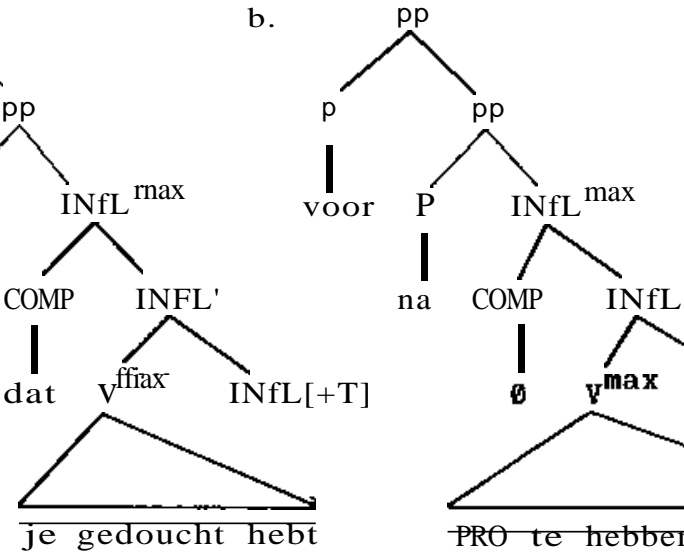

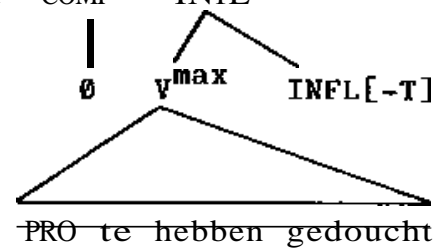

(58)

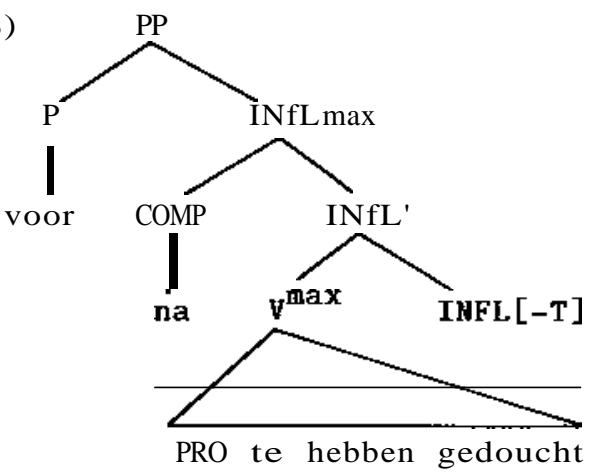


(57a) violates the UCC as it stands, but given the fact that lexical conditions are fulfilled, reanalysis of the two Ps can take place. If (57b) were the correct representation of (S6b), we would expect reanalysis to apply in this case as well, and hence expect (S6b) to be grammatical. However, (58) is the structure we are advocating in this section. Although lexical conditions are met, reanalysis cannot take place in this configuration, because the preposition na is not the head of the sister projection of the preposition voor. Since voor does govern na just as zonder governs om in (54), (58) violates the UCC.

The conclusion that the preposition introducing tenseless adjunct clauses is in COMP, so that the construction as a whole is of the category $S^{\prime}$ ( =INFL ${ }^{\text {max }}$ ), rather than $P P$, derives further support from the following observation. PPs can have specifiers like vlak, drie uur, etc., as is shown in (59). (S9a) exemplifies this with $\mathrm{P}$ taking an NP complement and $(5 \mathrm{gb})$ with $\mathrm{P}$ taking a tensed clause as complement. However, these specifiers are not allowed if the preposition introduces a tenseless clause. This follows from our analysis if it is assumed that the relevant specifiers only combine with a $\mathrm{P}$ projection, which we claim is absent in the constructions in (60).[5].

(S9)a. Vlak voor (NP de maaltijd] dronken we een glas sherry Right before the meal drank we a glass sherry Drie uur na [NP de wedstrijd] zaten de spelers nog te hijgen

Three hours after the game sat the players still to to gasp

b. Vlak Voor [SI dat we gingen eten] dronken we een glas sherry

Right before that we went eat drank we a glass sherry

Drie uur na [S' dat ze de wedstrijd gespeeld hadden] zaten de spelers nog te hijgen

Three hours after that they the game played had sat the players still to gasp 
(60)a.*Vlak alvorens te gaan eten dronken we een glas sherry Right before to go eat drank we a glass sherry b.*Drie uur na de wedstrijd gespeeld te hebben zaten de spelers nog te hijgen

Three hours after the game played to have sat the players still to gasp

One question remains to be answered, before this analysis can be considered fully satisfactory: what makes (57b) unacceptable? Let uS suppose that Dutch differs from English in that at S-structure CaMP must be filled. This is evident in the case of tensed embedded clauses, as there is no rule in Dutch comparable to English that-deletion. It is also clear in main clauses, where the sentence initial CaMP must always be filled _ by the finite verb in all cases and by a fronted constituent in clauses different from yes-no questions and imperatives. This assumption implies that there is an optional rule of om-deletion in the $\mathrm{PF}$ component of the grammar to account for the optionality of om in cases like (50).[6J.

Given the requirement of COMP being filled at $\mathrm{S}$-structure, we can explain why (57b) is ungrammatical as it stands. The UCC applies at S-structure. Consequently, since there cannot be an empty COMP at S-structure, (57b) can only have om in COMP position, but then the structure violates the UCC for the same reason as (54), i.e. om is governed by na and no reanalysis can take place. Thus, there is no way in which (57b) can be accepted. Therefore, (58) is the only possible structure, but this structure also violates the UCC, as discussed.

We are now in a position to return to the problem that we left unsolved at the end of the previous subsection. There we noted a contrast between Dutch and English with respect to the possibility of extracting the pp complement of $P$. Thus, in Dutch a pp complement to a postposition could be extracted, as illustrated by the example in (36b), repeated here, whereas the pp complement of a preposilion in English cannot be extracted, as was shown by the examples in (40), also repeated here. This contrast was unexpected, given the fact that their structures are mirror images. 
(36)b. Ik vroeg [achter welk gordijn) hij t vandaan was gekomen

I asked behind which curtain he from was come

(40) a. *nder which table did Fido jump from $t$

b. *Into which meadow did Fido run out $t$

From our perspective, it was the ungrammaticality of (40) which was unexpected, since the Gap Condition would allow it, just as it allows (36b). As we have argued in this section, pp complements to prepositions are in principle excluded by the UCC. Therefore, reanalysis must have applied to the structures in (40) in order to escape the effect of the UCC. We assume that the formation of a prepositional complex by reanalysis makes the complex inseparable. This accounts for the ungrammaticality of (40). We have argued that the UCC is a directional principle, the direction in which it applies being the direction in which Case is assigned. Since Ps in Dutch and English assign Case in the same direction, the UCC does not apply to the structure underlying (36b), since the matrix $P$ is postpositional. This accounts for the contrast between Dutch and English in this respect.

\subsection{Parasitic gaps}

After this digression on the distribution of gaps in Dutch and the comparison with that of English, we now turn to the distribution of parasitic gaps.

The parasitic gap phenomenon may be illustrated by the example in (61). Apart from the gap created by WH-extraction, indicated by $\underline{t}$, there is a second gap, indicated by $\underline{e}$, which is parasitic on the first gap.[7].

(61) Which articles did John file $t$ without reading $\underline{e}$

The reason for calling $\&$ parasitic on the trace is that its occurrence is indeed dependent on $\underline{t}$, as can be demonstrated by the examples in (62). (62a) shows that $\underline{e}$ is not licensed if its 
antecedent is in an argument position. (62b) shows that extraction from the position of $e$ itself is not allowed.

(62)a.*John filed these reports without reading $\underline{e}$ b. Which reports did John go home without reading $t$

In (61), both $\underline{t}$ and $\underline{e}$ are bound by which articles, which is in a non-argument (A') position. Therefore, both empty categories are variables according to the functional definition of empty categories in Chomsky (1982, ch.3). This qualification explains a further restriction on parasitic gaps, which is illustrated by (63).

(63) *Who do you think $\mathrm{t}$ went home without John having met $\underline{e}$

The reason for the ungrammaticality of (63) follows from the required status of $e$ as a variable: $\underline{t}$, the real gap, is coindexed with $e$ and c-commands $e$. Therefore, $e$ has $t$ rather than who as its local binder and is therefore locally A-bound. Thus, the ungrammaticality of (63) reduces to the same principle that rules out (64), viz. the requirement that variables be locally A-free.

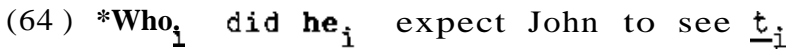

Similarly, the parasitic gap may not c-command the real gap, since in that case the parasitic " $p$ would function as the local antecedent of the real gap, so that the real gap is locally A-bound. This explains the ungrammaticality of (65).

(65) *Which girl did you present $\underline{\underline{z}}$ to $\underline{\mathfrak{t}}$ (cf. Which girl did you send a picture of $\underline{e}$ to $t$ )

The descriptive statement of a parasitic gap given by Chomsky $(1982: 66)$ is as in (66). 
(66) In the construction (A), where order is irrelevant and we assume $\underline{a}, \underline{t}, \underline{\mathbf{e}}$ to be coindexed, the parasitic gap $e$ is licensed if and only if (8);

(A).,$\ldots a$. $\ldots$ e

(B) ( i) a c-commands $t$ and $e$

( ii) $t$ does not c-command $\underline{e}$ or conversely

(iii) 只 does not head the chains $(\underline{a}, \underline{t})$ and (aㅗ, $\underline{\text { e }}$ )

( iv) $\underline{\epsilon}$ is governed (is not PRO) and heads a chain with a theta-role

Here, (iii) states in effect that the antecedent expression a must be in a non-argument position, whereas (iv) states that the parasitic gap is subject to the ECP, just like the real gap.

An interesting aspect of the parasitic gap phenomenon is that the relation between the parasitic gap and the antecedent is not subject to the bounding condition, i.e. subjacency, which is what we expect given that no movement is involved, and that subjacency is a condition on extraction operations. This fact is illustrated by the contrast between (61) and (6Zb). However, Kayne (1984,ch. 8) observes that contrasts like those in (67) and (68) are unexpected.

(67)a. The person that John described t without examining any pictures of $\underline{\underline{e}}$

b. The person that John described $t$ without any pictures of $\underline{e}$ being on file

(68)a. The books you Should read $t$ before it becomes difficult to talk about e

b.*The books you should read $\mathrm{t}$ before talking about $\underline{\underline{e}}$ becomes difficult

These contrasts cannot be explained in terms of a subjacency violation since subjacency is irrelevant for parasitic gaps. Nor can they be explained by the EC?, although there is a subject/non-subject asymmetry, since the parasitic gap is governed by a preposition in all cases. The ungrammaticality of the (b) examples in (67)-(68) cannot be attributed to the fact that the parasitic gap is embedded in a subject, since cases like the one in (69) are grammatical. 
(69) A person who close friends of $\underline{e}$ admire t

In section 2.1, we saw that Kayne replaces the standard ECP in (1) by his g-projection requirement in (5), which has a wider scope than subject/non-subject asymmetries. The contrasts between the (a) examples and the (b) examples of (67) and (68) are reminiscent of the contrast between the examples in (4), repeated here. This contrast was explained in terms of the g-projection requirement.

(4)a. Which actress do you think that John likes pictures of $\mathrm{t}$

b. Which actress do you think that pictures of $t$ turn Bill on

The contrast in (67)-(68) reduces to the g-projection requirement if it is assumed that both gaps must be related to their antecedent by a g-projection. The maximal g_projection of the governor of $\underline{e}$ in the $\mathrm{Cb}$ ) examples is the embedded subject NP, because this NP is not in a canonical government configuration. The maximal g-projection of the governors of both gaps in the (a) examples is the matrix 5', which contains their antecedent.

This simple extension of the application of the g-projection requirement does not explain the grammaticality of (69). Let us consider the tree structure of the relevant part of (69).

who

close

friends

$$
\text { of } \underline{e}^{\text {admire }} t
$$

The nodes numbered 1 represent the g_projection of the governor of 
e and the nodes numbered 2 represent the g-projection of the governor of $t_{\text {. }}$ Kayne proposes that the g-projection is extended to what he calls the Connectedness Condition, which requires that distinct g-projections that relate to the same antecedent be connected, such that the g-projections form a connected subtree. This is the case in the structure in $(70)$ : the maximal g-projection of the governor of $E$ connects directly to the g-projection of the governor of $t$ without intervening nodes. This connection requirement can be built into our Gap Condition in (13) very easily by requiring that the relation between an antecedent and its gaps forms a connected subtree.

Both in terms of the Connectedness Condition and our revised formulation of it as the Gap Condition, the contrast between the (a) and (b) examples of (67)-(68) is explained straightforwardly, as can be seen in the tree representations in (71).

(71) a.

that

John

described $t$

without

PRO

examining

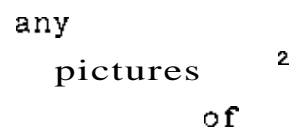

b.

that

John

described $t$ without

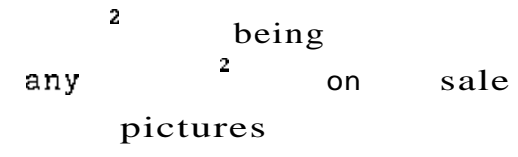

of $\underline{\mathrm{e}}$

With this background in the theory of parasitic gaps, we shall discuss the distribution of parasitic gaps in Dutch. 


\subsection{Parasitic Gaps in Dutch}

In the previous sections we have discussed the distribution of normal gaps in Dutch and explained how this distribution is adequately accounted for in terms of the Gap Condition. In this section we examine the effects of this condition on the distribution of parasitic gaps. In 5.1 we shall concentrate on the normal cases of parasitic gaps, while 5.2 focuses on an apparent problem for the theory of parasitic gaps in constructions that do not appear to have a real gap to license the parasitic gap.

\subsubsection{The distribution of parasitic gaps}

In this section we discuss the reasons why the distribution of parasitic gaps in Dutch is much more limited than in other languages, specifically English. The first reason has to do with the fact that there are two types of gaps in Dutch. As we showed in section 3, gaps inside PPs necessarily take a (+R] antecedent, while other gaps take a $[-R]$ antecedent. This fact limits the possible combinations of two gaps, one real, the other parasitic, since either both of them are of the $(+R]$ variety or both are of the (-R] variety. Thus, there is no equivalent to an English example like (72).

(72) This is the guy that I suggested to $e$ that my brother could offer $t$ a job

The reason is that $e$ requires a $(+R]$ antecedent, whereas $t$ can only take a $[-R]$ antecedent. So, both the option with the $[-R]$ relative pronoun die and the option with the $[+R]$ relative pronoun waar are ungrammatical.

(73)*Dit is de jongen die/waar ik $\underline{e}$ aan suggereerde dat mijn broer teen baan kon aanbieden

If $t$ is replaced by a pronoun, the sentence with the $(+R]$ relative 
pronoun is grammatical.

(74) Dit is de jongen waar ik $\underline{t}$ aan suggereerde dat mijn broer hem een baan kon aanbieden

If both gaps are of the [+R] variety, a construction of this type is possible, as is shown by the example in (75).

(75) Dit is het artikel waar ik e over zei dat Harry This is the article where I about said that Harry een reactie $t$ op moest schrijven a reaction to should write

It should be noted that it is impossible to have a construction of this type with two [-R] gaps. The reason for this is that the [-R] gap in the matrix clause would c-command the gap in the embedded clause and hence function as its local antecedent. Consequently, the embedded gap is not locally A-free. Therefore, an example like (76) is ungrammatical, just as its English counterpart is.

(76)*Dit is de man die ik $\underline{e}$ vertelde dat mijn broer This is the man who I told that my brother

$\mathrm{t}$ zou bezoeken would visit

In section 3. we explained why there can only be a single [+R] gap in a given clause, due to the requirement that the PP from which the R-pronoun is extracted must itself be canonically governed. Since PPs in NPs follow the noun. only PPs which are governed by V allow extraction. Since there is only one $\mathrm{V}$ per clause, there can only be one $[+\mathrm{R}]$ gap per clause. Therefore. there are no Dutch counterparts to constructions like (77).

(77) Who did you give a picture of $\underline{e}$ to $t$

Similarly, there can only be one [-R] gap per clause, since [-R] gaps cannot be COUChed in a PP and consequently will always stand in a c-command relationship. Summarizing the discussion so far, we 
have seen two restrictions on parasitic gap constructions:

a. the two gaps must be of the same type $([ \pm R])$

b. the gaps must be contained in different clauses

These restrictions follow from the theory presented thus far. It is easy to see that both requirements are fulfilled in constructions of the type exemplified in (75). The second clause in this type is a complement clause. There are two other conceivable combinations of two clauses: a) a matrix clause and a relative clause, and b) a matrix clause and an adjunct clause. Both types allow parasitic gaps in English. We shall now examine these two types in Dutch.

Let us examine clauses embedded in NPs first. An example of this type of construction in English is given in (78).

(78) This is the book [that everyone [who reads e] becomes enthusiastic about $\underline{t}]$

Constructions of this type are obviously impossible in Dutch: the clause embedded in NP is not canonically governed, since clauses follow the noun in Dutch as well as in English. These constructions are impossible, both with [-R] gaps, as in (79), and with [+R] gaps, as in (80).

(79).Dit is het boek dat iedereen [die $\underline{e}$ leest]

$t$ bewondert

This is the book that everyone who reads admires

(80).Dit is een vraag waar iedereen [die $\underline{e}$ over denkt] This is a question where everyone who about thinks een antwoord $t$ op weet an answer to knows

Let us now turn to constructions with adjunct clauses, which constitute a very productive class of parasitic gap constructions in other languages. We mentioned earlier that adjunct clauses are islands for extractions, both in EngliSh and in Dutch. The fact that they are islands in Dutch does not come as a surprise. given the proposal we made in 2.5 concerning extraction from embedded clauses. Consider (81). 
(81)*Wat is Jan [na [dat hij t zagJJ vertrokken

What is John after that he saw left

The embedded S' is a g-projection of the governor of the gap, but this $S^{\prime}$ is on a right branch. So, the maximal projection of the governor of $\mathrm{S}^{\prime}$, the $\mathrm{pp}$ headed by na, is not a g-projection. Consequently, the path breaks off at $\$^{\prime}$.

In English, adjunct clauses are islands for extraction as well, as is illustrated in (82).

$(82)^{*}$ What did John leave after he had seen $\mathrm{t}$

The ungrammaticality of (82) is predicted by our Gap Condition, just as the ungrammaticality of (81) is, but the reasons are slightly different. While in Dutch the g-projection of the governor of the gap breaks off at the level of the embedded $S^{\prime}$, it breaks off in English at the level of PP. The reason for this difference is that unlike in Dutch, the $S^{\prime}$ is canonically governed by the preposition in English. Therefore, the pp is a g-projection of the governor of the gap. The reason Why this g-projection cannot be continued is that the PP itself is not governed by V. Hence, Vmax is not a g-projection. This difference allows us to make a precise prediction. An English adjunct clause may contain a parasitic gap, if the adjunct PP is connected to the path of a real gap, but a Dutch adjunct clause should not be able to contain a parasitic gap, since the pp itself is not a g-projection. This prediction turns out to be correct, as is illustrated by the contrast between (83) and their Dutch translations in (84).

(83)a. Which book did you return $\underline{t}$ before you could read $\underline{e}$

b. A person that they spoke to $t$ because they admired e

c. This is the kind of food you must cook $t$ before you eat

d. The paper that we should destroy $t$ before someone steals a copy of $\underline{e}$ 
(84)a.*Welk boek moest je t terugbrengen voor dat je $€$ kon lezen

b.*Een persoon waar zij t. tegen spraken om dat zij bewondering $€$ voor hadden

c. ${ }^{*}$ Dit is het soort voedsel dat je $\mathrm{t}$ moet koken voor dat je e eet

d.*Het papier dat we $t$ moesten vernietigen voor dat iemand e steelt

Let us illustrate why there is a difference in grammaticality between (83) and (84) by drawing the relevant tree structures of (83a) and (84a). The point where the g-projection breaks off is boxed. It is clear that the boxed constituent connects up with the path of the real gap in the tree structure of (83a), but not in the tree structure of (84a).

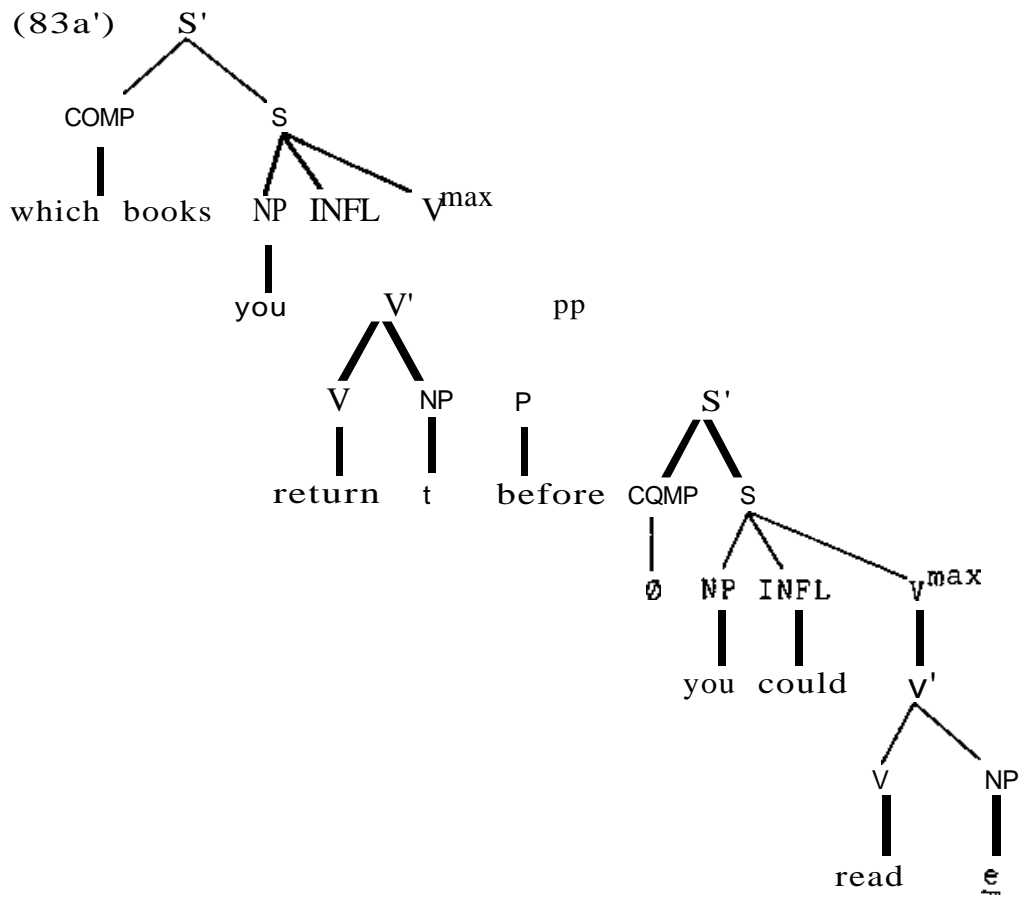


$\left(84 a^{\prime}\right)$

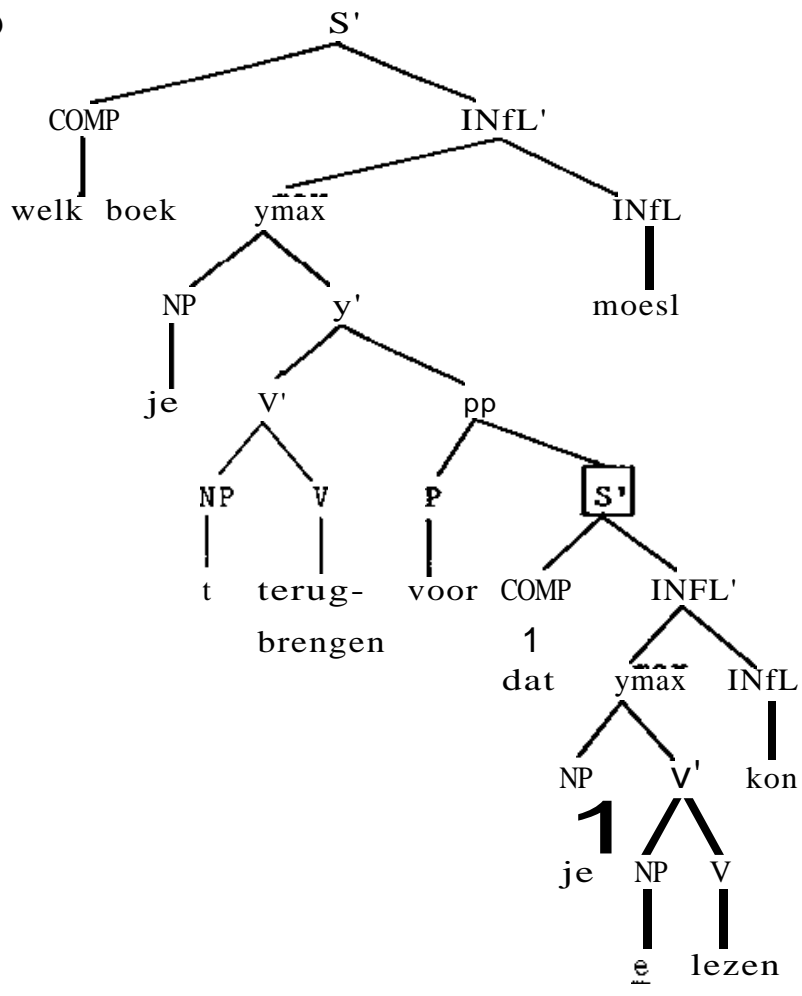

These tree structures are in accordance with the assumptions about the head of Sand $S^{\prime}$ that we made above. Although the prediction about the non-occurrence of parasitic gaps turns out to be correct in tensed adjunct clauses, parasitic gaps can be found in tenseless adjunct clauses, as has been observed by Dutch (and German) linguists since the introduction of the notion of parasitic gaps. Examples with [-R) gaps are provided in (85) and examples with [+R] gaps in (86).

(85)a. Welke boeken heb je [zonder $\underline{e}$ te bekijken] $\mathrm{t}$ weggezet Which books have you without to inspect away put

b. Dit is de oom die ik [na jaren niet e gezien te hebben] This is the uncle who I after years not seen to have gisteren weer $t$ tegenkwam yesterday again met 


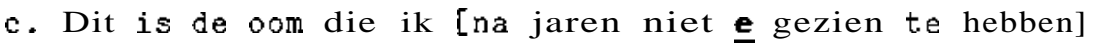
This is the uncle who I after years not seen to have hoopte dat ik in Kopenhagen $t$ zou ontmoeten hoped that $I$ in Copenhagen would meet

(86)a. Waar heb je [na twee jaar e over nagedacht te hebben] Where have you after two years about thought to have een oplossing $t$ voor gevonden

a solution to found

b. Ik hOll niet van vragen waar ik [zonder eerst rustig I love not of question where I without first quietly e over na te denken] een antwoord $t$ op moet geven about to think an answer to must give

c. Dit is het speelgoed waar ik [na jaren niet $\underline{e}$ naar This is the toy where I after years not to omgekeken te hebben] dacht dat ik Piet $t$ mee zag spelen looked-for to have thought that I Peter with saw play

The fact that these parasitic gaps are allowed is surprising given our explanation of the impossibility of a parasitic gap in a tensed adjunct clause.[B]. It will be recalled, however, that we argued in section 3.4 that the preposition introducing an infinitival clause occupies the COMP position of that clause, rather than being the head of a PP, taking this clause as its complement. As can be seen in the tree structure in $(84 a)$, it is the pp which stands in the way of connecting the g-projection of the governor of the parasitic gap to the path of the real gap. However, in the case of infinitival adjuncts, this pp structure would be absent, i.e. the tree structure of the examples in (85) and (86) would not be as in (87), but rather as in (88) (cf. the tree structures in (55) and (58)). 
(87)

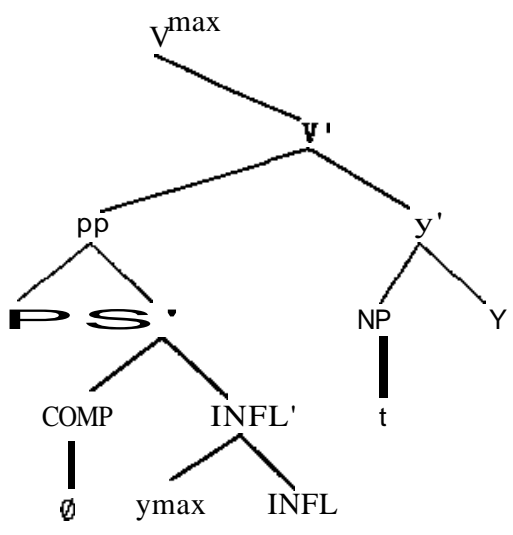

c $\underline{\mathbf{e}}$

(88)
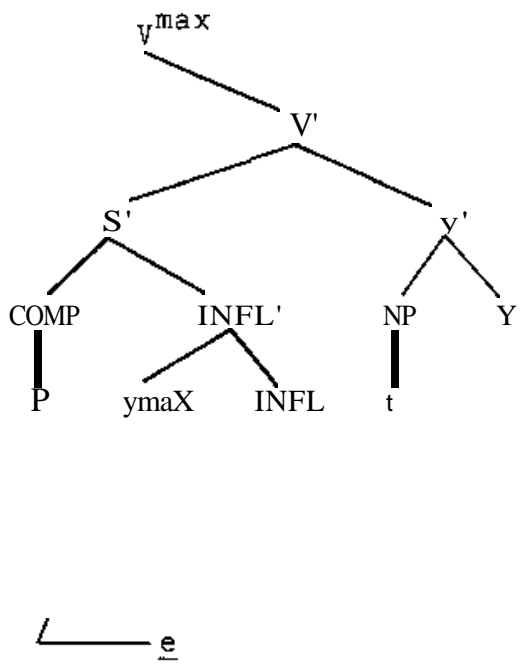

It should be stressed that the distribution of parasitic gaps in Dutch is entirely as predicted by the constraints that are relevant for normal gaps. Therefore, it would be counterproductive to provide an alternative analysis to account for these second gaps if 
this alternative were non-consequential for the distribution of real gaps. In that case the theory would redundantly allow for an analysis of these second gaps as parasitic gaps as well.

Before we turn to a discussion of the surprising phenomenon that we announced at the beginning of this section, we want to discuss an issue that is relevant for the debate of the derivational status of parasitic gaps. In Chomsky (1982), parasitic gaps are assumed to be empty categories at D-structure, their status of variables being determined at S-structure or LF by the functional definition of empty categories. Their status of variable, then, does not result from movement of the content from the position of the parasitic gap to an $\mathrm{A}^{\prime}$-position, as is the case with normal variables, but rather from their local binding by an antecedent in an $\mathrm{A}^{\prime}$-position. More recently, this non-derivational approach to parasitic gaps has been called into question (Chomsky, class lectures where he refers to work by Longobardi). Parasitic gap constructions appear to be sensitive to Complex Noun Phrase Constraint effects, something which is unexpected under the approach taken in Chomsky (1982). It is therefore proposed that parasitic gaps do result from movement to $\mathrm{A}^{\prime}$-position, thus creating an operator-variable relation independently. It turns out that the latter approach conflicts with the situation found in Dutch.

In section 2, we argued that extraction from sentential complements in Dutch is possible by successive cyclic movement only. Therefore, it is predicted by the derivational approach to parasitic gaps that a parasitic gap could be found in a complement clause within an adjunct clause. This situation is depicted in (89). 
(89)

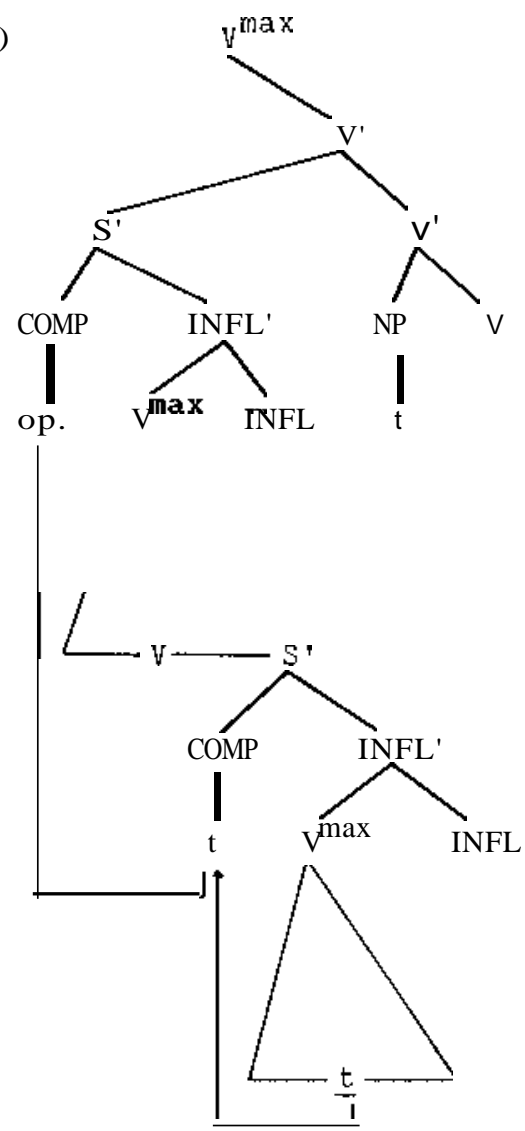

The most deeply embedded $t$ would be the extraction site of the parasitic gap. The $t$ in COMP results from successive cyclic movement of the operator op. into the matrix COMP, which connects to the path of the real gap.

Under the non-derivational approach, there is no movement, hence no successive cyclic movement, and we therefore predict that the g-projection of the governor of a parasitic gap contained in a complement clause inside the adjunct breaks off at the level of this complement clause, as this clause itself is not canonically governed. Therefore, the derivational approach predicts sentences of the type exemplified in (90) to be grammatical, whereas the non-derivational approach adopted here predicts them to be ungrammatical. The latter prediction turns out to be correct. 
(90)*Welke boeken heb je [zonder te weten [dat je e

Which books have you without to know that you

mocht bekijkenJ $t$ doorgebladerd

were allowed to inspect browsed-through

This evidence thus favors the original approach to parasitic gaps taken in Chomsky (1982).

\subsubsection{Parasitic gaps without real gaps}

Up to this point, the discussion of the differential distribution of parasitic gaps in Dutch and English has been in accordance with the methodological requirements that follow from the peripheral nature of the parasitic gap phenomenon. The differences were all shown to follow from independently existing differences between the two languages. Therefore, no language specific statements are needed either in the grammar of Dutch or the grammar of English to account for the phenomenon.

It was pointed out above, however, that Dutch appears to have gaps which look like parasitic gaps, since they occur in positions from which no extraction seems possible, but which do not seem to be licensed by the presence of a real gap. Such gaps are found in the examples in (91).

(91)a. Jan heeft die boeken [zonder $\underline{e}$ te bekijken]

weggelegd

John has those books without to inspect away put

b. Ik ben mijn oom [na $\underline{e}$ jaren niet gezien te hebben] I have my uncle after years not seen to have gisteren weer tegen gekomen yesterday again against come

c. Het is een schande dat de arts de patient [zonder e It is a disgrace that the doctor the patient without behandeld te hebben] vijftig gulden liet betalen treated to have fifty guilders let pay 
d. Ik heb deze scriptie [alvorens definitief $\underline{e}$ te

$\mathrm{T}$ have this term paper before definitively to

beoordelenJ eerst aan Jan voorgelegd

judge first to John shown

The gaps are interpreted as coreferential with die boeken, mijn oom, de patient, and deze scriptie, respectively. However, if no movement is involved, these gaps are bound by a category in an A-position, which is generally excluded as a consequence of the Binding Theory (i.e. principle $\mathrm{C}$, which requires that variables are locally A-free). The English counterparts of the examples in (91) are indeed excluded:

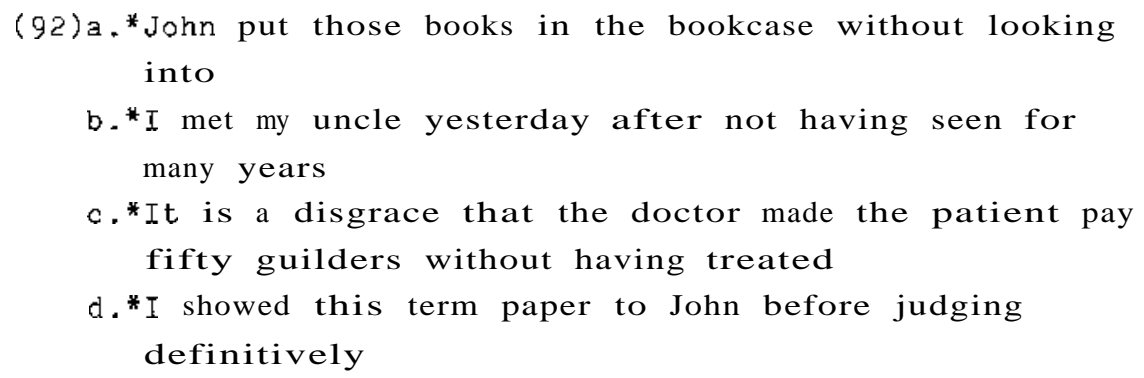

It would be counterproductive at this moment to assume that the requirement that the parasitic gap be A-free does not hold in DutCh, since such a step would not only introduce language specific stipulations with respect to the parasitic gap phenomenon, but would also make the wrong predictions. Thus, if it is assumed that the antecedent of a parasitic gap may be in an A-position in Dutch, the sentence in (93) would be predicted to be grammatical, contrary to fact.

(93) Ik vertelde Jan dat ik [zonder hem ${ }^{*} \mathrm{e}$ te willen I told John that I without him to want beledigen] anders had besloten insult differently had decided

Since the understood PRO-subject of the adjunct clause is obligatorily controlled by the subject of the embedded clause ik, 
the nearest antecedent for e would be Jan, which c-commands e. Nevertheless, the sentence is ungrammatical. It would be highly unattractive to assume that in Dutch, unlike in English, parasitic gaps are subject to some sort of locality requirement in order to account for the ungrammaticality of (93), since, as we have seen above, parasitic gaps in the examples that we discussed earlier are not subject to such a requirement.

In the case of R-gaps, it can be demonstrated quite clearly that a real gap, as well as a path with which the path of the parasitic gap can be connected, are required. The element er can have a number of distinct functions, some of which can coalesce in a given structure. We can distinguish between a locative er as in (94a), a presentative er which appears in sentences with indefinite subjects as in (94b), a prepositional er, of which several examples have already been given (cf.(94c) and a quantitative er, which is in most respects similar to the quantitative use of ne in Italian and en in French (cf.(94d).

$$
\begin{aligned}
& \text { (94)a. ik heb *(er) jaren gewoond } \\
& \text { I have there years lived } \\
& \text { b. dat *(er) een jongen loopt } \\
& \text { that there a boy walks } \\
& \text { c. ik heb *(er) niet e over gesproken prepositional er } \\
& \text { I have there With Peter about talked } \\
& \text { d. ik heb *(er) gisteren twee gezien } \\
& \text { I have there yesterday two seen }
\end{aligned}
$$

Even if in a given construction the conditions for the appearance of er are met more than once, only a single er is present at surface structure (cf.ch.3 for an analysis and qualification of this statement), as is shown in the following examples.[9].

(95)a. quantitative and prepositional;

Ik heb er twee e e van

I have there two of

b. presentative and prepositional:

Toen kwamen er verscheidene mensen e naar kijken

Then came there various people at look 
c. presentative and locative:

Er woont niemand

There lives nobody

d. presentative, quantitative, and prepositional:

Hoe er drie e e van kunnen samenvallen

How there three of can coincide

If a parasitic R-gap is present, it cannot be licensed by a presentative er, as is shown in the examples in (96a) and (96b). A parasitic R-gap can only be licensed by an R-pronoun in the matrix clause, if this R-pronoun is extracted from a position more deeply embedded than the adjunct clause containing the parasitic gap. An example is given in (96c)

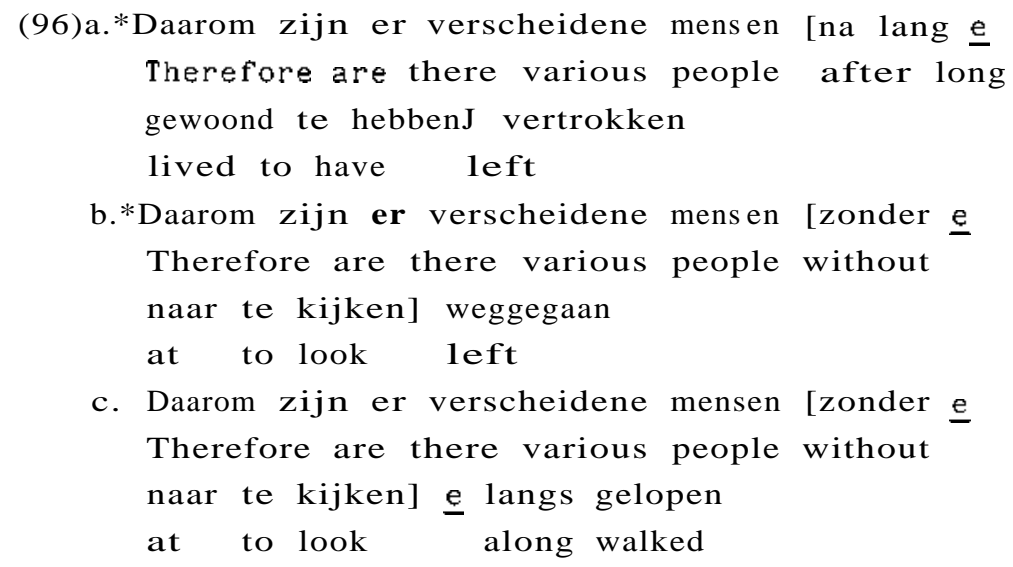

In (95b) and (96b) er should have both a presentative function and an antecedent function with respect to the prepositional R-gap. The grammaticality of (95b) shows that both functions can be combined in one occurrence of er. Therefore, the ungrammaticality of (96b) must be related to the fact that the prepositional $R$-gap is contained in an adjunct clause. Given the fact that the adjunct clause is an island in this case as well, the prepositional R-gap in (96b) must be parasitic. The grammaticality of (96c) indicates that a parasitic R-gap in the adjunct clause is indeed possible. The main difference between (96b) and (96c) is the fact that, although in both sentences er occupies an $\mathrm{A}^{\prime}$-position, in (96c) er 


\section{Gaps and Parasitic Gaps}

binds an R-gap that is more deeply embedded than the adjunct clause. Therefore a path is created with which the path of the parasitic R-gap can connect. In (96b), on the other hand, there is no such path and consequently no connection can be made. These R-gap phenomena thus illustrate quite nicely that not only an antecedent in $\mathrm{A}^{\prime}$-position, but also a path in the matrix clause, is required in order to license a parasitic gap.

Returning to the examples in (91), we observe that in these sentences the gap is contained in an island (i.e. the adjunct clause). Therefore, these examples pose two related, though logically independent, problems:

a. the antecedent of the gap is in an A-position

b. the gap is contained in an island and there does not seem to be a path with which the g_projection of the governor of the gap can connect

Both problems would be solved at the same time if the structure of the sentences in (91) were comparable to (96c), rather than to (96a) or (96b), i.e. if the antecedent NP originated in a position more deeply embedded than the adjunct. This would lead us to postulate (97) as the tree representation of (91a), with $t$ indicating the A-position from which the antecedent NP is extracted. A similar analysis is independently proposed in Felix (1983). The antecedent (die boeken) is attached to the V-projection by Chomsky-adjunction, and is consequently in a non-argument position.

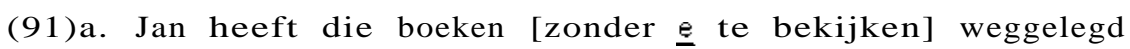
John has those books [without to inspect] away put 
(97)

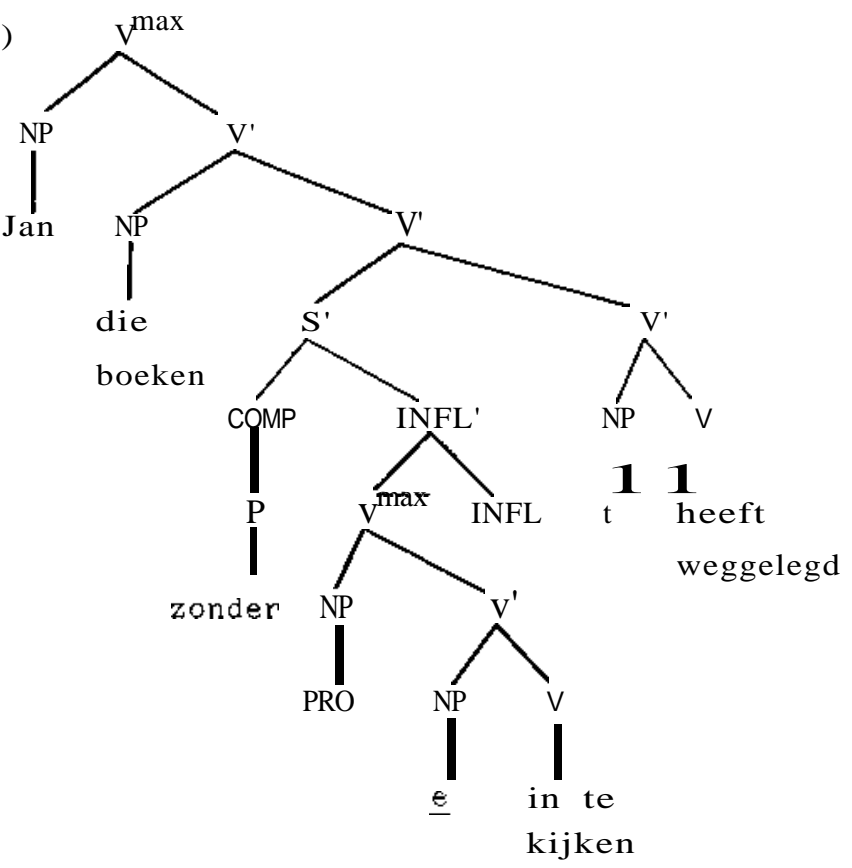

This representation fulfills all the requirements for the two gaps. Both gaps are canonically governed by their respective V-heads and the matrix clause $\mathrm{V}$-projection belongs to the path of $\underline{t}$ with which the path in the adjunct $S^{\prime}$ is properly connected. This $S^{\prime}$ is itself a g-projection of the governor of the parasitic gap. Both gaps are bound by a c-commanding NP in a non-argument position and neither gap c-commands the other.[10].

The relevant question at this point is how the existence of the real gap in (97) can be motivated. The first principle which gives us the position of $t$ as the base position of the direct object is the $\mathrm{X}^{\prime}$-principle according to which modifiers are attached at a higher level of structure than complements (cf.Jackendoff 1977). On the assumption that Dutch is QV, this implies the order adjunct-NP-V, rather than NP-adjunct-V.

A further pertinent consideration is the adjacency requirement on Case Assignment proposed in Stowell (1g81). If such adjacency is required for the verb to assign Case to its direct object, there must be an NP-position adjacent to the verb, as in (97).

In his discussion of the universality of the adjacency requirement 
on Case Assignment, Stowell develops two hypotheses to take apparent violations into account. The first hypothesis is specifically designed to cope with such violations in Dutch. The relative order of NPs and optional adverbials within the traditional VP-domain is essentially free. Thus, in constructions with an object NP and an optional adverbial pp, both orders are allowed:

(98)a. dat Jan zijn vriendin in Amsterdam ontmoette that John his girl friend in Amsterdam met

b. dat Jan in Amsterdam zijn vriendin ontmoette that John in Amsterdam his girl friend met

Given these examples, one would be inclined to assume that Case is assigned to the NP in the position in (98b), under adjacency with the verb. However, Stowell assumes that the VP in Dutch is double headed, i.e. has two head positions, one of which is VP-initial. He also assumes that Case is assigned by the V-head in initial position under adjacency. His two principal reasons for these assumptions are the following:

a. in main clauses the verb obligatorily appears in VP-initial position, in this way motivating the double headed character of the Dutch VP;

b. the direct object must appear in VP-initial position Both assumptions are wrong. The verb_second position of the finite verb in Dutch and German main clauses is not a position within VP, but rather in COMP (see Den Besten 1983). As the example in (g8b) shows, direct objects do not have to appear in VP-initial position. (For more detailed criticism of Stowell's proposal, see Hoekstra 1984,109ff.) Apart from these general deficiencies of Stowell's proposal, we do not quite see how he would be able to account for those constructions in Which the direct object does not occupy the VP-initial position, but rather a VP_medial position.

A variant of Stowell's analysis is presented in Koopman (1984). She does not assume that the Dutch VP is double headed, but nevertheless agrees with Stowell in assuming that Case is assigned from VP-initial position under adjacency. According to Koopman, Case is assigned from a VP-initial clitic position by the Case 
features of the verb. It will be evident that this analysis meets with the same problems as Stowell's: adjacency is not met at surface structure, neither with the Case assigning position initially in VP, nor with the Case assigning position at the end of VP. The main reason for Koopman to assume Case assignment from VP-initial position is her hypothesis that Case is always assigned in the same direction by the various categories in a particular language. Since Dutch is (mainly) prepositional, this harmony would not exist if verbs in DutCh assigned Case from right to left. Although such a cross-categorial harmony, at least as far as the direction of Case Assignment of $\mathrm{V}$ and $\mathrm{P}$ is concerned, seems to be fairly widespread among languages of the world, it is clearly not a necessary requirement.[11].

In our analysis, Case is assigned by the verb under government from right to left. With respect to adjacency, we assume that, rather than being subject to a linear adjacency requirement, Case assignment is subject to strict government. Under the additional assumption of binary branching, this has the effect of linear adjacency between the Case assigning category and its complement NP. In English, this is not only true for object NPs but also for subjects of (small) clauses. for Dutch, however, this hypothesis has a different effect on objects than on subjects. This can be illustrated by the tree structures for small clause complements in (99), where (99a) represents English and (99b) Dutch constructions of this type.

(99)a.

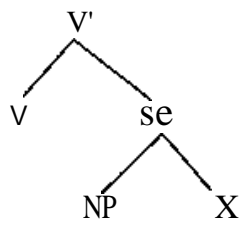

b.

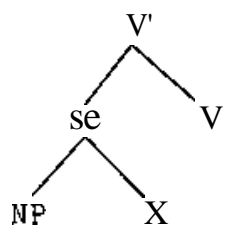

The NP is structlJrally governed by $\mathrm{V}$ in both cases, but while $\mathrm{V}$ and NP are string adjacent in English, the NP is separated from $V$ in Dutch by the predicative part of the small clause complement. The same situation obtains in the case of subjects of full clauses under our analysis: the subject in Dutch is governed by INFL, which appears on the right of the Vmax, whereas the subject itself is the 
leftmost constituent within Vmax. In conclusion, then, it turns out that Stowell's adjacency requirement can be made to follow from government and binary branching, i.e. it is not a primitive of the theory.

The cases in which the direct object is not (structurally) adjacent to its Case assigner, as in (g8a), are then accounted for by optional movement. Since movement must be upgrading, this has the linear effect of movement to the left. The movement leaves behind a Case marked trace, which is therefore a variable according to the inherent definition of empty categories. The landing site of the movement operation must be a non-argument position, which can be created through adjunction (see Belletti \& Rizzi 1981). As a result, the extraction site is also a variable according to the functional definition of empty categories, since it is in an A-position and locally bound by an antecedent in $\mathrm{A}^{\prime}$-position.

It should be noted that the choice of applying this leftward NP-movement is determined by pragmatic rather than by strictly syntactic considerations: definite NPs are more likely to be moved than indefinites, clitics are obligatorily moved. It is interesting to note that the operation is formally identical to Heavy-NP-Shift in EngliSh. Since the nature of branching is the mirror image of Dutch, this movement will always have a rightward moving effect. This explains why types of NPs that are likely to be moved by Heavy-NP-Shift are precisely those which are not likely to be moved in Dutch, whereas Heavy-NP-Shift of clitics is essentially excluded again, not for syntactic but rather for pragmatic reasons.[12).

Let us now turn to Stowell's second hypothesis for dealing with apparent counterexamples to the adjacency condition. This hypothesis is invoked to account for cases of non-adjacency at surface structure in Italian, where the object may be separated from the verb by an intervening adverb of manner. Stowell proposes that there may be a level of argument projection, at which the adverb does not appear. Then, adjacency may be met either at S-structure itself, resulting in strict adjacency as in English, or at the level of the argument projection, the latter option being the marked one chosen in Italian. We shall not dwell on the merits of this proposal for Italian, but shall concentrate on a possible application of this idea to account for cases of non-adjacency in 
Dutch. When this idea is applied to the examples in (98), the S-structure of each of the sentences might directly correspond to its surface manifestation, i.e. without traces. Adjacency of the verb, now taken to occupy the VP_final position, would in both cases be met at the level of argument projection, since at that level the pp in Amsterdam would not appear. If this explanation is maintained, we would be at a loss with respect to the parasitic gap constructions in (91), since under this proposal there is no need to assume the existence of a real gap which is required in order to make the connection with the g-projection of the governor of the parasitic gap. In fact, the notion of argument projection, as it is used here, obscures the hierarchical relation between the NP, the adverbial, and the verb, just as it obscures the linear relation. Essentially, these relations appear to vanish into thin air, since, just as one can say that the required adjacency on Case Assignment is met at the level of argument projection, it might be argued that the local relation between verb and object Which follows from X'-theory (or Chomsky's 1965 sister condition on strict subcategorizationl is defined at the level of argument projection. The contrast between (91) and (10) makes it crystal clear, however, that both the linear and the hierarchical relation of the adjunct and the $\mathrm{NP}$ are relevant, since the reason for the ungrammaticality of the examples in (100) will ultimately be the lack of c-command of the parasitic gap by an antecedent in A'-position.

(91) a. Jan heeft die boeken [zonder ze/e te bekijken] $\underline{t}$ weggelegd

John has those books without them to inspect away put

(100) a. Jan heeft [zonder ze/*e te bekijken] die boeken weggelegd

John has without them to inspect those books away put

(91) b. Ik ben mijn oom [na hem/e jaren niet gezien te I am my uncle after him years not seen to hebben gisteren weer $\underline{t}$ tegen gekomen have yesterday again against come 
(100)b. Ik ben [na hem/*e jaren niet gezien te hebbenJ I am after him years not seen to have gisteren weer mijn oom tegen gekomen yesterday again my uncle against come

(91) c. Het is een sChande dat de arts de patient [zonder It is a disgrace that the doctor the patient without hem/e behandeld te hebbenJ $\underline{\mathbf{t}} \mathbf{v i j f t i g}$ gulden him treated to have fifty guilders liet betalen let pay

(100)c. Het is een sChande dat de arts [zonder hem/*e It is a disgrace that the doctor without him behandeld te hebben] de patient vijftig gulden treated to have the patient fifty guilders liet betalen let pay

(91) d. Ik heb deze scriptie [alvorens hem/e definitief te I have this term paper before it definitively to beoordelen] eerst aan Jan $t$ voorgelegd jUdge first to John submitted

(100)d. Ik heb [alvorens hem/*e definitief te beoordelenJ I have before it definitively to judge eerst aan Jan deze scriptie voorgelegd first to John this term paper submitted

It turns out that the predictions made by our analysis are clear in this case, and what is more, they appear to be correct.

Evidence for the correctness of the hypothesis that NPs may be moved upward to the left in Dutch can also be derived from Exceptional Case Marking constructions. These constructions are illustrated by the following examples.[13]

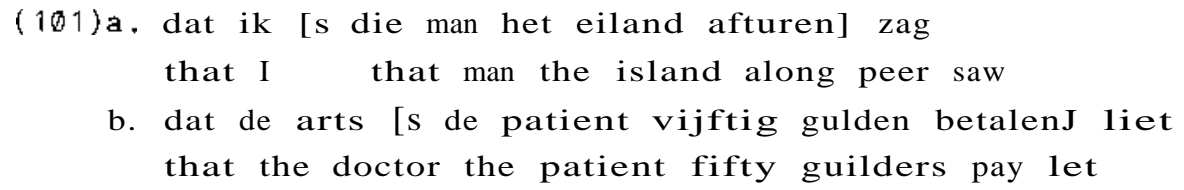


We shall assume an analysis of these constructions which does not differ in any important respect from the analysis of believe-type constructions: the representation in (101) assumes S'-deletion (alternatively, the relevant matrix verbs select a Vmax, rather than a full $\mathrm{S}^{\prime}$ ), and Case is assigned to the subject of the embedded clause by the matrix verb under government. The relevant evidence for the upgrading movement derives from the interaction with the scope of adverbials. In (102a), the person using the binoculars is the referent of the matrix subject. This is expected, of course, since the adverbial pp is contained in the matrix clause. Let us assume that the scope of an adverbial is restricted to the clause within which it is contained. Then (102b) poses a problem, since it can be either the referent of the embedded subject or the referent of the matrix subject who is using binoculars. Nevertheless, it would be untenable to assume that the embedded clause is transparent for the scope interpretation of adverbials, since in (102c) it can only be the referent of the embedded clause who is using binoculars.

(102)a. Ik zag met een verrekijker dat iemand het eiland aftuurde

I saw with binoculars that someone the island along peered

b. Ik zag iemand met een verrekijker het eiland afturen I saw someone with binoculars the island along peer

c. Ik zag iemand het eiland met een verrekijker afturen I saw someone the island with binoculors along peer

How can we account for the ambiguity of (102b)? It will be clear that no explanation is likely to emerge if the structures of (102b) and (102c) are as in (103a)-(103b) respectively.

(103)a. Ik zag [s iemand met een verrekijker het eiland afturen] b. Ik zag [s iemand het eiland met een verrekijker afturen]

No appeal can be made to the opacity effect induced by the subject, since the adverbial is contained in the domain of the subject in both structures. The resolution of the ambiguity could be sought by 
appealing to a rule of raising to object, but such a rule is inconsistent with some of the basic assumptions of the GB_framework, specifically the theta-criterion and the related Projection Principle. However, nothing prevents a movement rule in Dutch which is in its effect quite similar to raising to object, if the preceding account of possible non-adjacency of verb and object is correct. That rule differs from raising to object in that the landing site is an $\mathrm{A}^{\prime}$ _position, created via Chomsky-adjunction, rather than an A-position. The ambiguity of (102b) can be accounted for by the $S$-structure representations in (104). In (104a), the adverbial is part of the embedded clause and can only be linked to the embedded subject; in (104b), the embedded subject is attached to a higher level than the adverbial, which is now part of the matrix clause, thus allowing linking to the matrix subject.

\section{(164)a. Ik zag [s iemand met een verrekijker het eiland afturen] b. Ik zag iemand ${ }_{i}$ met een verrekijker $\left[s \underline{t}_{i}\right.$ het eiland afturen J}

The non-ambiguity of $(102 \mathrm{c})$ follows from the fact that, given the position of the adverb after the object, it must be contained in the embedded clause, since the object itself may not be moved to a position outside the embedded $S$, because of the opacity induced by the subject. A similar kind of argument can be based on the relative scope of two adverbials. In a simple sentence like (105), niet (not) takes scope over met opzet (deliberately), i.e. the sentence has the implication that John sang out of tune.

(105) Jan zong niet met opzet vals

John sang not deliberately out of tune

In the biclausal construction in (106), on the other hand, niet may either take scope over the proposition expressed by the complement of the perception verb or over met opzet only. This would be hard to explain if the only possible structure of (106) were (107a), since then we would expect the reading with niet taking scope over met opzet only, as in (105), with the necessary implication of John singing out of tune. The second reading would follow from (107b) as 
an alternative structure for (106), on a par with (107a).

(106) Ik hoorde Jan niet met opzet vals zingen

I heard John not deliberately out of tune sing

(107)a. Ik hoorde [S Jan niet met opzet vals zingen]

b. Ik hoorde Jan ${ }_{i}$ niet $[S \underline{\mathbf{t}}$, met opzet vals zingen]

There is even a third reading for (106). In this reading both niet and met opzet take scope over the matrix clause. This reading is accounted for by the structure in (107c).

(107)c. 1k hoorde $\operatorname{Jan}_{i}$ niet met opzet $\left[S \underline{t}_{i}\right.$ vals zingenJ

The interpretation of (106) correponds to the following three sentences:

(108)a. I heard that John did not deliberately sing out of tune

b. I didn't hear that John deliberately sang out of tune

c. I didn't hear deliberately that John sang out of tune

It should be noted that a similar analysis is not available for English or VO languages in general. To illustrate this, let us examine the tree structure in (109), which would represent the configuration relevant for English perception verb constructions and ECM-constructions.

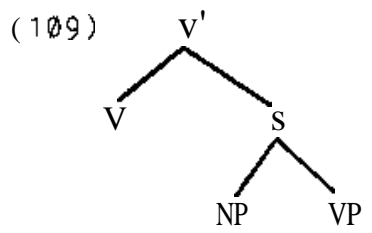

If we want to promote the NP subject of the complement clause, there are three logical possibilities, which are depicted in (110). 

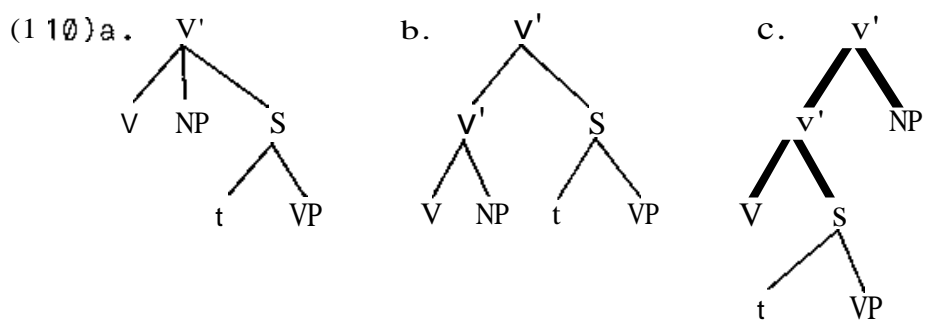

The tree structure in (110a) violates the theta-criterion and/or the Projection Principle. There are two possibilities. First, the landing site is available at D-structure, in which case it should be assigned a theta-role. If so, the derived structure would violate the theta-criterion, since the NP would receive two thematic roles. If not, the D-structure would be ill_formed because there is an internal argument position which is not assigned a theta-role. Secondly, the landing site is not present at D-structure, in which case the Projection Principle is violated, since the representation at D-structure crucially differs from the representation at $\mathrm{S}$-structure. The structure furthermore violates the restriction of syntactic structures to binary branching, which has been proposed recently in the literature (Kayne 1984, ch.7). This argumentation is of course the argumentation against traditional proposals involving Subject Raising to Object (cf.Chomsky 1981, ch.2)

A similar line of reasoning applies to (110b). Again, the landing site constitutes a problem for the Projection Principle and/or the theta-criterion. (110b), while not violating the binary branching requirement, furthermore does not accord with the requirement that a trace be c-commanded by its antecedent, while it is not clear how the empty category would fare under the ECP. The only possibility left is (1100), but apart from the hierarchical effect of the raising, there is also a linear effect, i.e. the NP subject would end up on the right hand side of the clause from which it is extracted. This is precisely the effect of Heavy-NP-Shift, which we claimed earlier to be the mirror-image operation of the 'raising' or 'Light-NP-Shift' we claim to be operative in Dutch. As is to be expected, therefore, the result of Heavy-NP-Shift under these circumstances yields grammatical reSUlts, as can be seen in (111). 
Moreover, Heavy-NP-Shift licenses parasitic gaps, just like 'raising' does in Dutch. This is exemplified in (112).

(111) They'd believe [ $\mathrm{t}$ to be foolish] any candidate who would take the trouble to run in every primary

(112) John offended $\underline{t}$ [ by not recognizing e immediately his favorite uncle from Cleveland

The following examples illustrate that it is indeed impossible to have an adverb after an NP that is the subject of a perception verb complement, if it is linked to the matrix subject (as is possible in Dutch).

(113) I put the books secretly back in John's drawer

(114) I forced John unintentionally to commit suicide

(115) I saw John secretly put the paper back in my desk

The example in (113) shows that adverbs of the class secretly, unintentionally may follow an object NP and be linked to the subject. The same is illustrated in (114), where John is the matrix object controlling the embedded PRO subject. The relevance of (115), then, is that the adverb secretly cannot be linked to matrix subject position. Therefore, the structure representing (115) cannot be as in (116); of. $(104 b)$. This is precisely as predicted.

(116) I saw John $n_{i}$ secretly $\left[s \underline{t}_{i}\right.$ put the paper back in my desk]

A related matter concerns the possibility of adverbial modification inside small clause constructions. Stowell (1981,258) argues for the constituency of small clause complements by pointing out the impossibility of separating the subject of the small clause from its predicate by an intervening adverb. Relevant examples are given in (117).

(117)a.*1 consider John myself to be very stupid

b.*1 expect that sailor sincerely off my ship by midnight c.*We feared John with great concern killed by the enemy 
It should be noted that adverbial modification may be found in this position in small clauses, but only if the modifier is linked to the subject of the small clause and not to the matrix subject, exactly as in (115). This restriction is a consequence of the hypothesis suggested earlier that adverbs take their scope in the propositiona1 domain Which contains them.

(118) I thought Mary unconsciously in love with Peter

By now, it should no longer be surprising that Dutch differs in this respect from English. In Dutch, adverbial modifiers intervening between the subject and the predicate of a small clause may not only be linked to the small clause subject, but also to the subject of the matrix clause. This is exemplified in (119).

(119)a. Ik maakte de tafel onbedoe1d kapot

I made the table unintentionally broken

b. Ik vond Jan opzettelijk onaangenaam

I found John deliberately unpleasant

The representation of (119a), where the adverb is linked to a constituent outside the small clause domain, would be as in (120).

(120) Ik maakte de tafel. onbedoeld $\left[\underline{\mathbf{t}}_{\mathbf{i}}\right.$ kapotJ

This possibility is available in Dutch because of its aV-nature, which allows the NP sUbject to be moved tc a c-commanding position created through adjunction. As discussed earlier, this possibility is available in English only in the case of rightward movement.

We assume that the analysis according to which the direct object originates in the position left adjacent to the verb, from where it may be moved and adjoined in an $\mathrm{A}^{\prime}$-position, has been satisfactorily motivated on the basis of the predictions it makes with respect to differences between Dutch and English. If the analysis is indeed correct, the structure in (97) is also the correct representation of (91). This is a desirable result, since on this basis, the parasitic gap phenomenon in Dutch has all the properties we expect, given the overall structure of the GB-theory. 


\subsection{Chains and features}

In this section we shall discuss a particular kind of parasitic-gap construction which appears to have some consequences for the present version of the GB-framework. We shall propose a modification that solves the problem posed by the relevant parasitic-gap construction and examine the consequences of this proposal. Let us first exemplify the problematic kind of construction.

(121)a. Jan heeft zich [zonder PRO $\underline{e}$ te bedenken) $t$ John has himself without to consider

in het water gestort into the water thrown

b. Jan heeft $\underline{\text { zich }}$ [na PRO verscheidene malen e John has himself after various times vergist te hebben] toch weer $\underline{t}$ gerehabiliteerd mistakes-made to have yet again rehabilitated

c. De sprinter heeft zich [zonder PRO e te bekommeren The sprinter has himself without to worry om de afstand) $\underline{t}$ ingeschreven voor de marathon about the distance registered for the marathon

d. Het leger heeft zich [zonder PRO e te verzetten) The army has itself without to resist aan de vijand $t$ overgegeven to the ennemy surrendered

In these examples both $\mathrm{t}$ and $\mathrm{e}$ are bound by zich, which is an anaphor. In these sentences the matrix clause Subject, zich, PRO, $\underline{e}$ and $t$ carry the same referential index.[14). The problem, then, is that $\underline{e}$, which is a variable, is bound by PRO in the adjunct, hence by a local antecedent in an A-position, so that the construction should be ruled out (cf.1.4). The problem shows some resemblance to cases such as (122), where the variable t should be coindexed with the subject, hence be A-bound.

(122) Himself he did not like $t$ 
This problem has received several different solutions in the literature. According to one proposal, the Binding Theory applies at LF after reconstruction: the antecedent is first moved back to its original position where the reflexive is bound by its antecedent in accordance with the Binding Theory for anaphors. An alternative version of the proposal is to let the Binding Theory apply via the trace. Van Riemsdijk \& Williams(1981) argue against this proposal, because of the difficulties involved in cases such as (123), Which would require the device of layered traces.

(123) Pictures of themselves they do not like $t$

Van Riemsdijk \& Williams propose a more drastic alternative: they suggest a linear model of grammar in which there is a separate level, called NP-structure, which results from the application of NP-movement to D_structure and Which forms the input to WH-movement. In their model, the Binding Theory is supposed to apply at NP-structure. At that level, the representation of (122) and (123) would have the phrases himself and pictures of themselves in their base positions, so that no difficulties would arise with the Binding Theory for reflexive anaphors.

It should be pointed out that this proposal meets with severe prOblems in the case of parasitic-gap constructions in general, if, as was argued above, the parasitic gap does not result from movement. Therefore, at the level of NP-structure, the parasitic gap is an empty category the status of which is unclear, as the notion of variable does not seem to be of relevance in their model. Van Riemsdijk \& Williams might propose to interpret Case-marked empty positions only after the application of WH-movement, but then either no coreference relaticn would be stipulated between PRO and $\underline{e}$ in the examples in (121), or the variable would be A-bound. The latter state of affairs should not be permitted, since this would make it impossible to account for violations of the Strong-Crossover-Constraint, i.e. cases like (124).

(124) *Who, did he, see $\mathbf{t}_{1}$ 
In fact, all derivational solutions of the problem illustrated in (122) will experience problems in accounting for the phenomenon illustrated in (121), if there is no derivational link between the parasitic gap and its antecedent. A non-derivational approach to the interpretation of empty categories is also available in GB-theory, viz. the chain-algorithm proposal made in Rizzi(1983). Rizzi argues that instead of forming a chain in a derivational way, i.e. constructing a chain of positions which are linked by movement, chains might be read off from S-structure directly. He refers to this as the representational way of chain formation. In principle, this way of forming chains might solve the problem of parasitic gaps, since antecedent and parasitic gap may constitute a chain representationally. However, the chain algorithm must also be subject to certain restrictions. One of the restrictions that Rizzi proposes is that no intervening local binder may be skipped in the formation of a chain. A further restriction derives from the Q-criterion, which must now be formulated so as to apply to chains rather than to arguments directly, viz. the uniqueness requirement between chain and $\theta-r o l e$. Applying the chain algorithm constrained in the way described just now to the constructions in (121), we immediately observe that the problem cannot be solved in this manner. The PRO subject of the adjunct is a local binder intervening between $\underline{e}$ and its antecedent zich and may therefore not be skipped in forming a chain including zich and e. The chain thus receives two thematic roles, one assigned to PRO and the other to e. Therefore, the theory of the representational formation of Chains is incapable of accounting for the grammaticality of the sentences in (121).

Let us now introduce our own proposal with the help of a comparison of the examples in (125).

\section{(125)a. John was seen $\mathrm{t}$ \\ b. Who did John see $t$}

The trace in (125a) is an NP-trace: the movement of John is forced by the lack of Case at the position of $t$ and the movement is possible because of the fact that no thematic role is assigned to 
the surface position of John. We may therefore represent (125a) in terms of the features $[+\mathrm{C}($ ase $)]$ and $[+\theta]$ as in (126). The trace in (125b) is a WH-trace. Movement of who is not strictly forced in any sense, since Case and a thematic role are assigned to the position of t. (125b) can be represented as in (127).

(126)

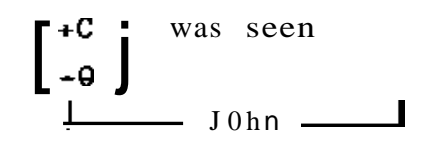

(127) $\left[\begin{array}{l}-C \\ -\theta\end{array}\right]$ John see

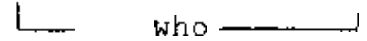

In (128) we describe the unmarked situation for an NP: it represents a position occupied by a lexical expression which has the features $[+\mathrm{CJ}$ and $[+\theta] \cdot[15 \mathrm{~J}$.

\section{John}

It should be observed that any node that is different in feature composition from (128) requires the existence of a complementary node elsewhere in the tree, normally in a one-to-one relation. If we interpret the feature $[+\theta]$ as 'having a thematic role' and $[+\mathrm{C}]$ as 'licensing a lexical expression of the type NP', this one-to-one correspondence represents the content of the Q-criterion: each referential expression must have a function. The notion that it is the Case feature which licenses an expression may perhaps need further clarification. What we mean is that on the one hand each lexical NP must have a Case feature and on the other hand that each lexical element has referential potential, either inherently (names and optionally pronouns) or indirectly via binding (anaphors and optionally pronouns). We shall say therefore that Case identifies the referent, which recalls the visibility requirement proposed in the literature. The selection of the particular referent is a different matter of course, Which is determined by the name itself rather than by Case. The main reason for us to tie the notion of 
Case so strictly to the notion of referent lies in the well-known difference between instances of NP-movement and WH-movement: the latter is subject to a crossover constraint, unlike the former, as is shown in (129).

(129)a. They socmed to each other [ $\underline{t}$ to be quite friendly] b.*Who did John tell to him that Peter had met $\mathrm{t}$

The representations in (127) have the lexical expressions in between two positions as it were. This essentially represents what one might want to call a chain. However, the chain does not make it clear in what position the expression actually is. Assuming that an expression can be at only one place on a particular level, we should specify what the position of the expression is. The position of a positively specified -featire is the position where the expression is present when functional or relational aspects are checked (i.e. checking of subcategorization and the aSSignment of Q-roles). The position of the Case feature is the position where the expression resides when referential relations between elements in the structure are checked. Before we consider the consequences of this proposal, let us demonstrate how it deals with the problematic examples in (121). We shall assume that chain formation is representational, as proposed by Rizzi(1g831, and furthermore that it is entirely free (i.e. local binders may freely be skipped). In addition to the chains in (126),(127) and (128) another type of chain must be allowed in order to account for the parasitic-gap construction. This Chain is presented in (130).

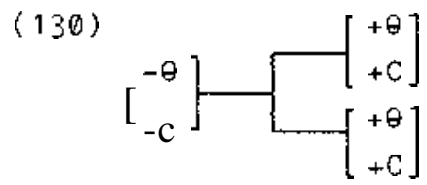

(130) can be considered identical to (127), apart from the fork in the chain. The situation in (121) instantiates the pattern in (130). A representation of the relevant positions and configurations of example (121a) is given in (131). 
(131)

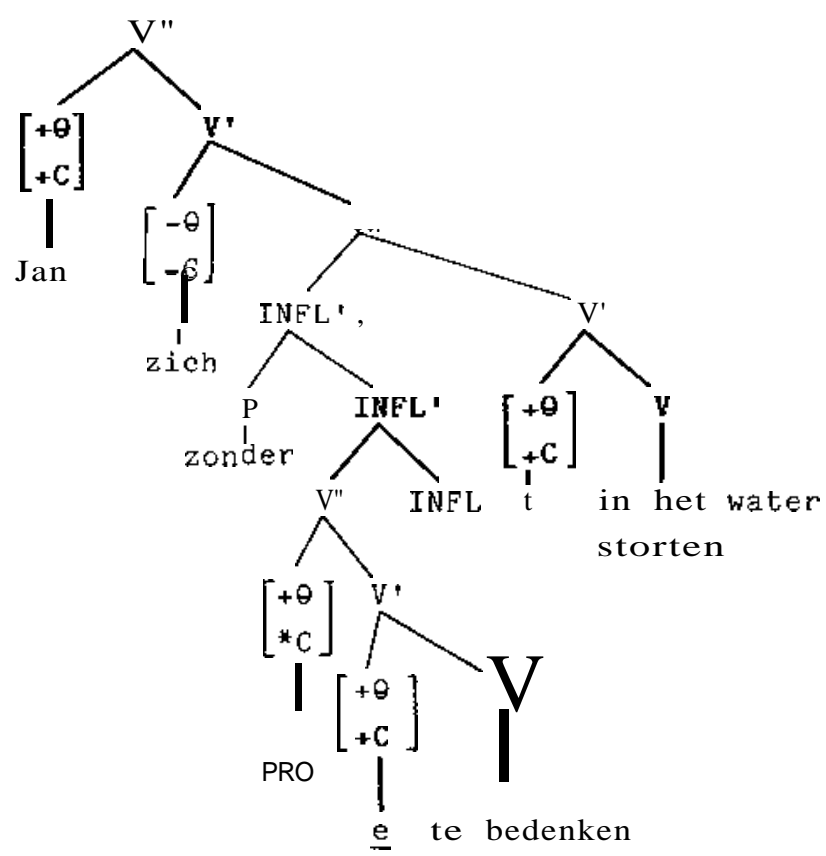

Two and only two chains can be formed in this tree: the chain (zich, es) and the chain (zich, $\underline{t}$ ), which are connected. The requirement that they are connected is a consequence of the Gap Condition. If these chains are formed and the interpretation of the feature $[+C)$ is as we have proposed, the binding between Jan and zich in the position of $t$ and that between PRO and zich in the position of e can be established in accordance with principle $A$ of the Binding Theory.

Let us now examine how the claim that only the correct chains can be built is a consequence of the interpretation of the features mentioned above. We have seen that the chains in (132) are correct.

$$
\begin{aligned}
& \text { ( 132)a. }\left[\begin{array}{l}
+\theta \\
+\mathrm{C}
\end{array}\right] \\
& \text { b. }\left[\begin{array}{l}
-\theta \\
\neq \mathbb{C}
\end{array}\right] \quad\left[\begin{array}{l}
+\theta \\
-\mathbb{C}
\end{array}\right] \quad \text { NP_movement } \\
& \text { c. }\left[\begin{array}{l}
-\theta \\
-\mathbb{C}
\end{array}\right]\left[\begin{array}{l}
+\theta \\
+\mathbb{C}
\end{array}\right] \quad \text { WH-movement }
\end{aligned}
$$




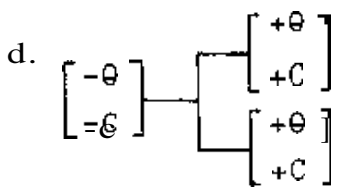

parasitic gaps

All other imaginable pussibilities are ruled out. To see this, let us examine a number of impossible chains, such as those in (133).

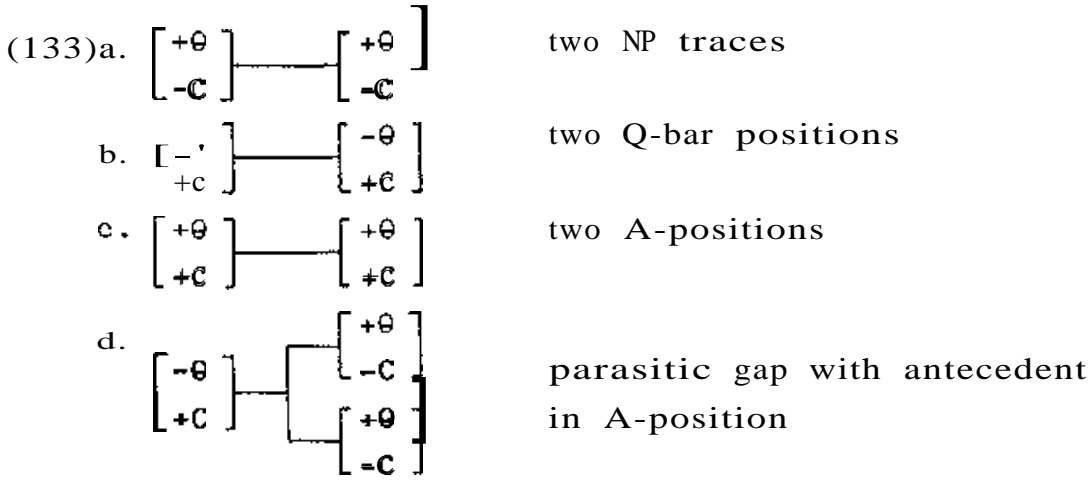

Under standard assumptions of GB-theory, the ungrammaticality of constructions involving (133a) results from the Case filter (i.e.the visibility requirement) and from the $Q$-criterion, because the chain is not visible and receives two thematic roles. The ungrammaticality of (133b) again results from the Q-criterion, since the chain does not receive a thematic role. The chain in (133c) violates the Q-criterion, since the chain has two roles, while (133d) is ungrammatical because of the requirement that variables are A-free (i.e. are subject to principle $C$ of the Binding Theory).

If functions are signalled by the feature $[+\theta]$ and referents by $[+C]$, all four structures in (133) are dismissed for the same reason: they violate the condition in (134), which we call the Theta-Referent Condition, and which is in fact a reformulation of the $\mathrm{Q}$-criterion, with the Gap Condition built in. 
(134) TR-Condition

A chain is well-formed iff

a. it contains a unique function (i.e. $[+Q]$ )

b. it contains a unique referent (i.e. $[+\mathrm{C}]$ )

c. the members of the chain are connected in accordance with the Gap Condition

With respect to multiple gap structures, the difference between (132d) and (133d) is that, although the two chains which combined each have the two relevant features, the feature $[+\mathrm{C}]$, i.e. the referent feature, is shared by the two chains in (133d). Hence, it is not unique. From (134) it follows that we build chains of more than two members only if these chains involve at least one position which has only minus values. For three member chains, this allows for the three possibilities in (135), each of which indeed yields grammatical results, as is demonstrated in the corresponding sentences in (136).

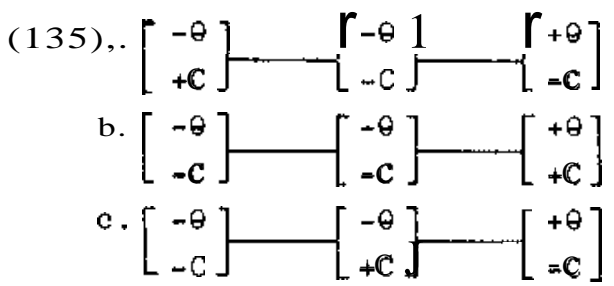

(136)a. John appeared [ $\underline{t}$ to be likely [ $\underline{t}$ to win]]

b. Who did you think [ $\underline{\mathrm{t}}$ [John saw $\underline{\mathrm{t}}]]$ ?

c. Who $t$ appeared [t to be the winner]?

A different instantiation of (135c) seems marginally possible, viz. those sentences where case is assigned in the intermediate COMP-position, as appears to be the case in a construction discussed by Kayne (1984,Ch.5), exemplified in (137).

(137) Quel garşon crois tu [t [ $\underline{t}$ être le plus intelligent]]

The chain in (13?) does not violate any of the requirements on chains in (134), but the construction is nevertheless quite restricted in its distribution. We shall not discuss this type of 
construction here.

Apart from the unificatory effect of the TR-condition in the explanation of the illformedness of (133), it appears that we no longer need the notion of variable. As NP-traces are considered anaphors, hence subject to principle A of the Binding theory, traces left behind by WH-movement are held subject to principle $\mathrm{C}$ of the Binding Theory and are thus considered to be on a par with names. The reason for this differential status of the two types of traces with respect to the Binding Theory is that it explains the difference in the locality that is required between extraction and landing site and that it also explains the requirement that WH-traces are A-free.

With respect to this latter requirement, it Should be obvious how our proposal accounts for this. Consider a case of Strong Crossover, as in (138).

(138) * Who did he see $t$ ?

The only chain allowed in this construction is the chain (Who, $\underline{t}$ ). The $[+C]$ position of this chain is the position of $t$. Therefore, for the purposes of the Binding Theory, who occupies the position of $t$. Since who is identical to names in all relevant respects (i.e. who is not a dependent element as it cannot take an antecedent), it must be free. Given the fact that the Binding Theory does not impose locality restrictions on the distance between gap and its antecedent in the case of WH-movement, it appears that the notion of variable can be dispensed with in the grammar, or, formulated slightly differently, that its status derives from the TR-condition $[16 \mathrm{~J}$. Our proposal achieves what proposals involving reconstruction or a level of NP-structure aim at. Our proposal is superior, however, since it is non-derivational and can therefore take parasitic gaps into account as well.

\subsection{An alternative approach to parasitic gaps in Dutch}

In the preceding discussion it was shown that the occurrence and the distribution of parasitic gaps in DutCh can be accounted for by 
assuming that the following three claims are correct.

a) the distribution of parasitic gaps should be covered by the theory of normal gaps enriched by the concept of connectedness as developed by Kayne. We have seen that the Gap Condition is able to provide an explanation for both normal and parasitic gaps.

b) there is a rule of $\mathrm{S}$-internal leftward adjunction. This rule is independently motivated. It was seen to be necessary to account for the apparent free word order in the Dutch middle field and the transparency of Small Clauses and Exceptional Case Marking constructions. Further motivation for this rule was derived from Heavy-NP-Shift in English as the structural mirror-image of leftward adjunction

c) prepositions introducing infinitival complements occupy the COMP position. This assumption, which enables us to account for the contrast between parasitic gaps in finite and in infinitival clauses, is independently motivated as well.

In the final part of this chapter we shall concentrate on the comparison of our theory and an alternative analysis proposed in Huybregts and Van Riemsdijk(1985) (henceforth H\&vR).

The discussion will be structured as follows. First, we will present the alternative analysis of H\&vR. Then we shall discuss their arguments against our analysis, which is followed by a discussion of their arguments in favour of their approach. Finally we will present some evidence in favour of our analysis.

\subsubsection{The analysis of Huybregts and Van Riemsdijk}

In their view the difference between Dutch and English with respect to parasitic gaps is that in Dutch parasitic gaps have a distribution which is identical to the distribution of real gaps, while in English this distribution is different. Given independent restrictions on the parasitic-gap construction in general, it is predicted that the distribution of parasitic gaps in Dutch is extremely limited. In their view, a parasitic gap shows up only in sentences such as (139). 
(139) Dit is een boek [waar ik $\underline{e}_{1}$ van denk [dat Jan This is a book which I of think that John e. naar verlangtJ)

for longs

The tWQ gaps ill (139) are potentially real gaps. If a gap is present in an adjunct clause, it cannot be a real gap and, as a consequence, they hold that it cannot be a parasitic gap either. In their view the gap e in (140) is not parasitic.

(140)a. Welke boeken heb je [zonder $\underline{\mathbf{e}}$ te lezen) $\underline{\mathbf{t}}$ weggezet? Which books have you without to read put away

b. Ik heb deze boeken [zonder e te lezen) $\underline{\mathbf{t}}$ weggezet I have these books without to read put away

Cases like (140) are argued to be derived in such a way that (140a) can be seen as an instance of across-the-board(ATB) application of wh-movement, and (140b) as an instance of across-the-board application of NP-adjunction, which they regard as the leftward equivalent of Right Node Raising, i.e. Left Node Raising. Their analysis of $(140)$ is represented in (141) schematically.

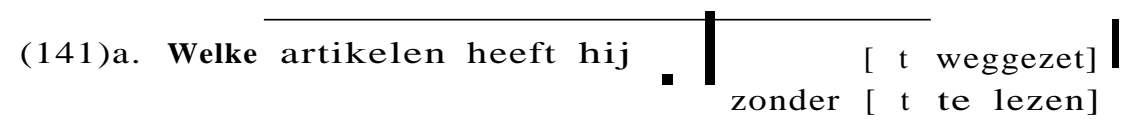

b. Ik heb deze boeken *

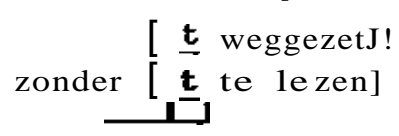

(the indicates the position in which the lower sentence is inserted). In (141) the NP is extracted from the two coordinated VPs simultaneously. It will be clear that they have to attribute to the preposition introducing the adjunct clause the status of a coordinator. In fact, they argue that these prepositions are subordinators that can also be analysed as coordinators, which phenomenon they refer to as insubordination.[17J. The crucial difference between our analysis and theirs is the status of the preposition intrOducing infinitival adjunct Clauses. Both analyses depend on a general theory of gaps and parasitic gaps and both assume leftward NP-adjunction. If our assumption that the 
introductory prepositions appear in COMP is correct, everything follows from the theory of gaps without additional assumptions. If their claim that these prepositions are insubordinators is correct, they have to make additional assumptions in order to show that these parasitic-gap constructions are basically similar to across-the-board phenomena.

Moreover, in our account differences between Dutch and English in the range of possible parasitic-gap constructions follow from other, independent differences between Dutch and English. In their account the class of Dutch constructions corresponding to English parasitic-gap constructions divides into real parasitic-gap constructions (as in (139)), for the extremely limited distribution of which they have to provide an explanation as well, and ATE-constructions (as in (140))

From this we would like to conclude that our analysis is to be preferred conceptually. However, if it should turn out that there are serious counterarguments against our theory and that there are striking similarities between the construction with a gap in infinitival adjuncts and regular across-the-board constructions, their analysis might have to be preferred.

\subsubsection{An argument against our analysis}

H\&vR present two potential problems for our analysis. One problem will be discussed in the next section. The second one is concerned with sentences like (139). Our analysis forces us to assume that e1 is a parasitic gap whereas $\mathrm{e} 2$ is the real gap. $H \& v R$ argue as follows "If correct, their analysis predicts a grammatical outcome if an appropriate pronoun substitutes for the parasitic gap but an ungrammatical result if the real gap is replaced by a pronoun. Both predictions are wrong, falsifying their account." It is indeed the case that these predictions are wrong, as is shown in (142).

(142)a. ${ }^{*}$ Dit is een boek waar ik er van denk dat Jan e naar verlangt

b. Dit is een boek waar ik e van denk dat Jan er naar verlangt 
However, the grammaticality of (142b) is irrelevant to our analysis. Since either gap in (139) is accessible for extraction, no problem arises if a pronoun replaces the most deeply embedded gap. As far as the Gap Condition is concerned, (142a) is predicted to be grammatical as well. Their conclusion that in (139) el is the real gap, which they base on the variants in (142), is completely unmotivated and seems to be based solely on intuition. The substitution test provided by $H \& v R$ has no theoretical status and does not lead to any prediction or conclusion. With respect to the ungrammaticality of $(142 \mathrm{~b})$ we would like to claim that it results from a Strong Crossover violation. Even if er belongs to PP, which is not clear at all, a strong-crossover violation is predicted. It is well-known that strict c-command is insufficient in cases of prepositional complements. This is true for anaphora, control, binding and, apparently, strong crossover, as Shown in (143).

$$
\begin{aligned}
& \text { (143)a. Ik vertelde [aan Jan] een verhaal over zichzelf] } \\
& \text { I told to John a story about himself } \\
& \text { b. Jan vroeg [aan mij] om PRO een liedje te zingen } \\
& \text { John aSked to me for a song to sing } \\
& \text { c. } \text { Ik vertelde [aan hem) dat Jan geslaagd was } \\
& \text { I told to him } \\
& \text { d.*Wie vertelde } \mathbf{j i j} \text { aan hem dat jij } \underline{\mathrm{t}} \text { gezien had? } \\
& \text { Who told you to him that you seen had }
\end{aligned}
$$

These facts indicate that strict c-command is insufficient. The ungrammaticality of (143d) is due to strong crossover, on a par with the ungrammaticality of (142a). Thus, the counterargument of H\&vR is without force.

\subsubsection{Parallelism between across-the-board and parasitic-gap constructions}

To support their analysis, $H \& v R$ point to a number of parallelism requirements on the structures containing the two gaps. It follows from their analysis that parallelisms as required by the Coordinate 
Structure Constraint should be obeyed. If there are indeed such parallelism requirements on dual gap structures, they may constitute an argument against our analysis. However, any instance of non-parallelism in principle constitutes a strong argument against their proposal. We shall argue that such problems indeed arise. The Coordinate Structure Constraint excludes asymmetric extraction from one of the conjuncts. This explains the ungrammaticality of (144).

(144)a.*Wat heb je gewande1d en $t$ gekocht?

What have you walked and bought

b. *Ik heb dat boek zowe1 gewande1d a1s $\underline{t}$ gekocht

I have that book both walked and bought

In what follows we shall provide examples of asymmetric extraction with parasitic gaps in adjunct clauses that are a) perfectly grammatical in our judgement and b) undoubtedly much more acceptable than sentences of the type in (144) for all speakers of Dutch.

H\&vR consider (145a) to be an instance of a dual-gap structure arising from ATB r-movement, schematically represented in (14Sb).

(145)a. Hij heeft er [zonder echt [ẹ naar] te ver1angen] $\mathrm{He}$ has there without really for to long mij [e om] gevraagd

me for asked

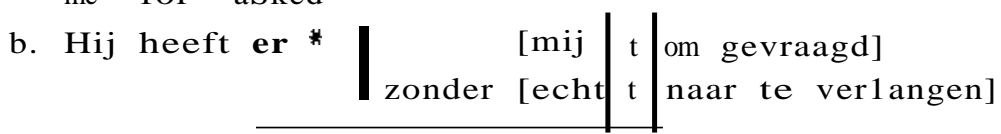

Extraction of mij would constitute an instance of asymmetric extraction and is thus predicted to be ungrammatical. (146a) is a case of asymmetric wh-extraction and (146b) an instance of asymmetric NP-adjunction.

(146)a. Wie heeft hij er [zonder echt [e naar] te verlangen]

Who has he there without really for to long

$\underline{\mathrm{t}}$ [e om] gevraagd

for asked? 
b. Hij heeft mij er [zonder echt [e naar] te verlangen] He has me there without really for to long

$\underline{\mathbf{t}}[\mathrm{e}$ om] gevraagd

for asked

In their view these sentences are just as ungrammatical as the completely ungrammatical sentences in (144), which they present as an argument against our analysis. They reject (146a), a judgement we do not share. However, if they want to reject (146a), they must also reject $(146 \mathrm{~b})$, but in our opinion there is no contrast at a11 between (145a) and (146b). What is unfortunate for them is that (146b) seems preferable. Similar cases of asymmetric extraction resulting in grammatical sentences are provided in (147).

(147)a. Wat heeft Jan er [zonder [e over] na te denken] What has John there without about to think tegen jou $\underline{\mathbf{t}}$ [t over] gezegd

to you about said

b. Dit is de kast waar Jan deze boeken [zonder e This is the bookcase where John these books without

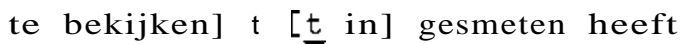
to inspect in thrown has

The parallelism requirement that follows from the ATB analysis also runs into trouble with respect to verb second, as they observe themselves. In regular instances of ATB, Verb Second applies in an ATB fashion, as expected. This is shown in (148).

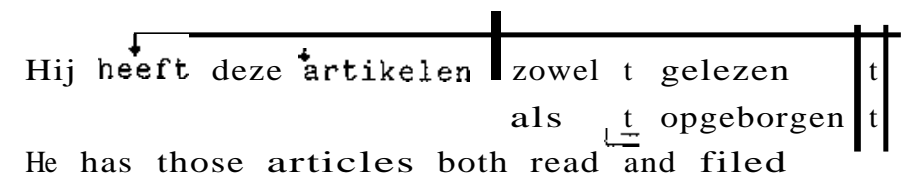

An ATB derivation for V2 in case of parasitic gaps in adjunct clauses is not available. The finite verb is only part of the matrix conjunct and not of the adjunct. In those cases the parallelism breaks down. H\&vR suggest two possible derivations, represented in (149). 
Gaps and Parasitic Gaps

( 14g)a. Welke artikelen héft $\left.y_{1 J}\right|_{\text {zonder }}\left|\frac{t}{t} \frac{\text { opgeborgen }}{\text { te lezen }}[\underline{t}]\right|$

Which articles has he without to read filed

b. Welke artikelen heeft

r
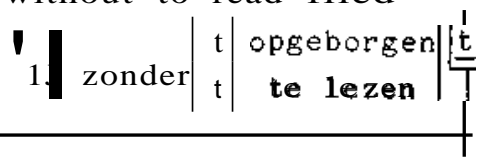

Since (14ga) "violates the very core of the ATB theory", they argue for $(14 \mathrm{gb})$ as the correct representation. This has the undesirable side effect that the upper conjunct does not correspond to a syntactic constituent at all. They accept this consequence. This implies that not constituency but rather the linear string is relevant in establishing the delimitation of the conjuncts. As far as we can see, it is far from obvious that constituency is irrelevant in coordination. In order to show that their theory on dual gap structures is correct, they have to provide a theory on coordination. In the absence of such a theory, the derivation depicted in (14gb) is not very attractive.

A further problem for their theory arises in constructions with long extraction from the conjunct(s). In regular ATB constructions long extraction from each or both of the conjuncts seems to be allowed, as is illustrated in the sentences in (150).

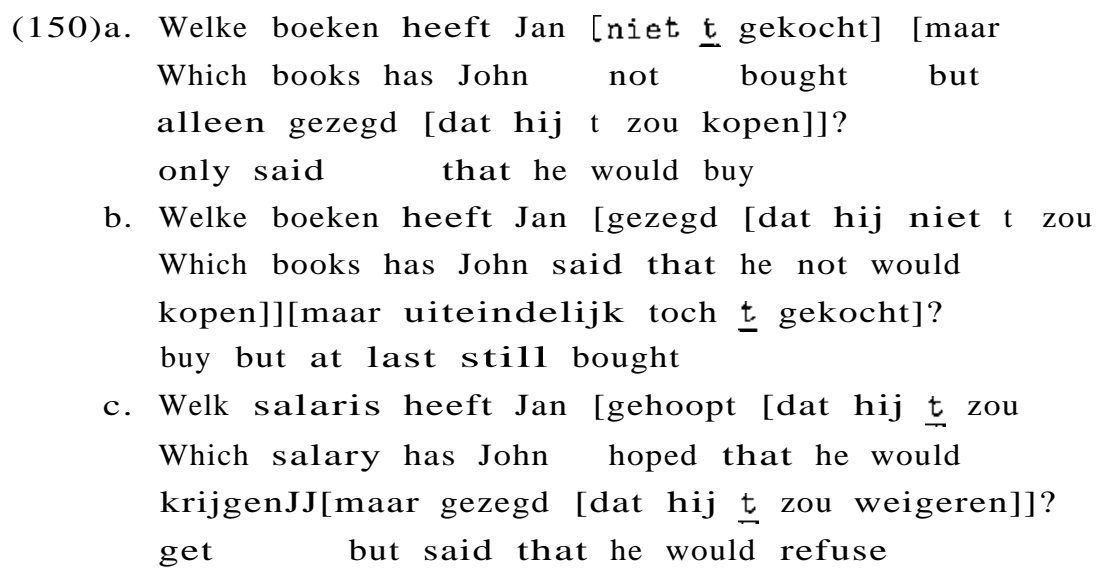

If adjunct clauses containing a gap are to be analysed as instances of ATE extraction, we expect the same pattern to emerge in long extraction. However, it turns out that long extraction is 
not allowed from the adjunct clause but only from the matrix clause, as is shown in (151) (see Ch.1.5.1,(90».

(151)a. Dit is het speelgoed waar ik [na jaren niet

This is the toy where I after years not

[t naar] omgekeken te hebben] dacht dat ik Jan

to looked-for to have thought that I John

[t mee] zag spelen

with saw play

$a^{\prime}$.Welke boeken heb je [zonder ooit $\underline{t}$ ingekeken te

Which books have you without ever looked-in to

hebben] gezegd dat je leerlingen $t$ moesten lezen?

have said that your pupils had to read

b.*Welk boek heb je [zonder te zeggen dat je zelf nooit

Which book have you without to say that you self never

$\underline{t}$ ingekeken hebt] je leerlingen $\underline{t}$ aangeraden?

looked-in have your pupils recommended

c.*Welke boeken heb je [zonder te zeggen dat je zelf

Which books have you without to say that you self

nooit $\underline{t}$ ingekeken hebt] gezegd dat je leerlingen

never looked-in have said that your pupils

$\mathrm{t}$ moesten lezen?

have to read

The ungrammaticality of the b. and c. examples is due to the fact that no long extraction is allowed from adjunct clauses. Given the fact that regular ATB sentences allow this kind of extraction, there seems to be no explanation within an ATB approach. In our analysis the ungrammaticality of $(151 \mathrm{~b}, \mathrm{c})$ follows from the fact that the gap within the adjunct clause is a parasitic gap. As argued in 1.5.1, the g-projection of these embedded parasitic gaps cannot be connected to the g-projection of the real gap.

In view of the problems concerning the necessary parallelisms and given that $H \& v R$ have not succeeded in providing any decisive counterargument to our parasitic-gap analysis, we conclude that their proposal should be rejected in favour of a parasitic-gap approach. 


\section{NOTES}

1. A problem arising with R-pronoun complements of prepositions concerns the impossibility of regular pronouns in the complement position of prepositions if they are [-human], as shown by example (19a). Van Riemsdijk accounts for this in terms of suppletion together with the application of the rule of R-movement, which is made obligatory in its effect in terms of an output filter. Below we shall argue against other instances of a specific rule of $\mathrm{R}$-movement. We believe it is correct to state that the problem of [-human] pronouns is solved by stipulation in Van Riemsdijk's analysis. We shall solve this problem equally stipulatively by assuming that pronouns like het etc. may not occur in the complement of $\mathrm{P}$.

2. There is a class of apparent exceptions that involve adjacency of the $\mathrm{P}$ to something more than the basic lexical verb. These include inherent adverbs of place or direction and predicative complement constructions. Examples are provided in (i)

(i) a. het middel waar ik de kamer $\mathrm{t}$ mee schoon mak the material where I the room with clean make

b. de trein waar ik t mee naar Groningen ga the train where I- with to Groningen go

We shall assume that the verb and the immediately preceding constituent constitute a verbal complex of some sort. They are impenetrable units and, although PPs can normally appear in postverbal position, including subcategorized PPs, the directional PP in (ib) must be immediately left adjacent to the verb, as is illustrated in (ii).

(ii) a.*dat we naar Groningen gisteren gingen that we to Groningen yesterday went

b.*dat we gisteren gingen naar Groningen that we yesterday went to Groningen

In this respect, these constructions resemble idiomatic expressions which also behave as syntactic units.

It seems that to some extent, non-inherent place adverbials as well as indirect objects with the preposition aan (to) may intervene between the verb and the stranded PP. These cases produce a milder ungrammaticality than other intervening material. We can tentatively assume that these elements are optionally incorporated into the verbal complex.

3. As is clear from the examples in (18), prepositions in Dutch assign Case to the right. This would lead to the prediction that postpositions cannot take NP-complements, although this in fact appears to be possible in Dutch.

(i) dat hij [de boom in] klom that he the tree in climbed

However, these postpositional PPs may never be moved from their preverbal position, as is illustrated in (ii).

(ii) a.*[Welke boom in] ben jij t geklommen Which tree in are you climbed 
b.*dat jij bent geklommen [die boom in]

that you are climbed that tree in

We shall therefore assume that Case is provided by the verb - in which case the postposition would really be a particle and the NP a direct object or indirectly via the postposition. This approach tallies with the analysis adopted by Van Riemsdijk (1978a).

4. There are some exceptions to this generalization in Dutch. In the complement of the prepositions voor 'before' and tot 'until' the appearance of dat is optional, whereas dat is obligatorily absent in the case of sinds (temporal 'since'). These options are clearly idiosyncrasies of these prepositions, and we shall not go into them here.

5. It is interesting to note that infinitival clauses cannot be introduced by the preposition voor: voor must be replaced by alvorens, which can never take an $\mathrm{NP}$ or a tensed clause as complement. This amounts to saying that it must occupy the COMP position in our analysis. Thus the complementary distribution of voor and alvorens can be described in our analysis in terms of a difference in structural position.

6. The deletion of om is subject to recoverability, of course. Om also introduces infinitival purposives, as in (i), in which case it cannot be deleted.

(i) Jan zei dat*(om) mij te overtuigen

John said that for me to convince

An optional deletion rule in the PF-component can also be invoked to account for the absence of dat after for (see note 4).

7. In general, sentences with parasitic gaps are not fully acceptable, which might be attributed to a violation of the Bijection Principle (Koopman \& Sportiche 1981). What is relevant for the discussion, however, is the contrast between 'acceptable' parasitic gap constructions and completely unacceptable ones. The judgments of native speakers are relatively uniform in this domain. This should also be born in mind with reference to the examples from Dutch. When we consulted Dutch native speakers about these constructions, we invariably presented them with the 'acceptable' parasitic gap construction first. Native speakers' judgments varied from completely to marginally acceptable. However, without exception, all informants were clearly aware of the contrast between the licensed parasitic gap construction and its non-licensed counterpart.

At this point, it might be useful to note that in all the relevant Dutch examples offered to our informants, the verb governing the parasitic gap is clearly'obligatorily transitive. In Van Geijn-Brouwers (1982), it is argued that there are no parasitic gaps in Dutch and that in all examples which appear to contain perasitic gaps the verb is pseudo-transitive. This explanation is not available for the examples we provide. It would furthermore leave entirely unexplained why there should be a difference with respect to licensed and non-licensed parasitic gap constructions.

8. The careful reader might have noticed that apart from the difference in finiteness between (84) on the one hand and (85) and (86) on the other, there is a further difference, viz. the relative position of the verb and the adjunct. It must be admitted that sentences like (85) and (86) become slightly less acceptable if the adjunct clause occupies a postverbal position. This difference 
is a relative matter, however, whereas the differential grammaticality of tensed versus tenseless adjunct is very sharp. The ungrammaticality of the examples in (84) cannot be salvaged by placing the adjunct in preverbal position. Therefore, we conclude that the account given here, viz. the difference in position of the preposition introducing the clause, is the correct one.

9. Examples such as (95), which involve two gaps with only one single overt binder in $A^{\prime}$-position, should not be considered parasitic gap constructions, because these constructions have completely different properties.

10. The idea that the order NP-ADV-VERB in Dutch should be accounted for by postulating a rule that moves the NP to the left has been proposed many times in the literature for various reasons which have nothing to do with parasitic gaps (cf. Kerstens 1978, De Haan 1979). Felix (1983) makes a similar proposal for German in order to account for parasitic gaps. The analysis we present here is adopted in Koster (1984).

11. From the perspective of language acquisition, it is difficult to see the advantages of a uniform direction of Case assignment in a particular language, or at least to see the reason for assuming that this must be the case by virtue of a universal principle. The direction in which Case is assigned can be established quite easily on the basis of positive evidence. The simplest way to go about constructing a grammar compatible with primary data like in je stoel 'in your chair' and flesje drinken 'drink a bottle' is to assume that P assigns Case to the right and $V$ to the left. Of course, such evidence is abundantly available.

12. It is to be expected that the adjunction proposed here would give rise to weak crossover effects, but it turns out that this is not the case. In this respect, the adjunction involved in Heavy-NP-Shift in EngliSh, which we claim to be formally identical to the leftward adjunction in Dutch, is similar in that it does not yield any weak crossover effect either. This is illustrated in (i) and (ii).

(i)a. Ik heb [zonder het ${ }_{j}$ in te kijken] het boek terug gebracht I have without it into to look the book back brought

b. Ik heb het boek [zonder het in te kijkenJ terug gebracht

(ii)a. John offended his favourite uncle from Cleveland [by not immediately recognizing him.]

b. John offended [by not immediately rè cognizing him ${ }_{i}$ ] his favourite uncle from Cleveland;

The absence of these crossover effects might be due to the fact that the coreferential pronominal element is contained in an $S^{\prime}$. In such cases, weak crossover can never be observed (cf.Van Riemsdijk \& Williams 1981, Chomsky 1982).

If no $S^{\prime}$ intervenes, crossover effects are not only absent, but rather we find What we may call anti-crossover effects, again both in those constructions that involve leftward adjunction in Dutch and rightward adjunction in English. This is illustrated in (iii) and (iv).

(iii)a.?Ik heb in zijn. tuin de buurman gezien

I have in his 1 garden the neightor seen

b. Ik heb de buurman in zijn tuin gezien

(iv)a.?I introduced his. teacher to John.

b. I introduced to IJOhn his new teacher for English literature 
In this respect, then, these adjunctions seem to behave differently from movements to COMP. This difference might be explained in terms of the distinction between operators and non-operators in $\mathrm{A}^{\prime}$-positions (cf.Kayne 1984, ch.10), in such a way that only operators give rise to weak crossover effects. In any event, the difficulties with respect to weak crossover are not specific for the adjunction analysis for Dutch, given the parallelism with Heavy-NP-Shift in English.

The same is true for another question that is raised by our proposal. Why is there no Heavy-NP-Shift to the right in Dutch and Light-NP-Shift to the left in English? It turns out that the landing site of the adjunction is always at the same side of the governor of the extraction site as the extraction site itself, at least in the cases we are considering. Moreover, these adjunctions violate the principle of external adjunction proposed by Van Riernsdijk (1918a, Ch.1), in that the moved phrase is adjoined to the projection line of the governor of the extraction site. It seems, then, that the type of 'internal' adjunction under discussion has some quite specific properties, which, in the optimal case, derive from some principles reason. It would take us too far afield to investigate this matter in detail, but it should be clear that these questions, which have never been raised before with respect to Heavy-NP-Shift, do not discredit the analysis that we propose for Dutch.

13. The order of constituents in these examples reflects the order assumed for their underlying structure, i.e. a structure with the matrix verb taking a preverbal sentential complement. V-raising must be applied to these constructions, which has the linear effect of changing the order of matrix and embedded verb in Dutch.

Further examples like (101)-(104), and related discussion can be found in Coppen et a1. (1983).

14. These constructions show a similarity to constructions of the type in (i).

(i) John only has himself [PRO to consider e]

These constructions will be left out of consideration here, since it is clear that they do not involve parasitic gaps. For a discussion of this type of construction, see Van Haaften (1983).

15. PRO is not an empty NP. This is evident from the fact that it is not subject to the Gap Condition, and also from the fact that it need not have an antecedent (PROarb). We therefore take PRO to be an expression, unlike empty categories, which are merely positions. In the context of our proposal, the fact that PRO does not need to be linked to an antecedent can be taken as a consequence of PRO's intrinsic features, e.g. apart from referential features it has an inherent Case feature which need not be satisfied by a Case assigner. This aspect will be represented below by assigning the value * to the Case feature in the position occupied by PRO. This is tantamount to saying that a chain headed by PRO is visible for the thematic criterion.

16. The necessity of a COMP to COMP movement can no longer be made to follow from the status of the WH-trace as a variable. In our system, almost all conceivable violations of the COMP to COMP requirement can be accounted for by other independent principles. Prime candidates are the TR_condition and the Binding Theory. 
Gaps and Parasitic Gaps

17. The reason for the impossibility of a second gap in a finite adjunct clause follows since the subordinating complementizer dat forces the preposition to be analysed as a subordinator. 
Chapter 2

\section{$H E T$ as a Referential Expression}

\section{1 Introduction}

In this chapter it will be argued that Dutch het is not a dummy pronoun when it functions as the subject of a weather verb, or when it is in construction with an extraposed sentential complement. In the latter structure het may appear in subject and in object position. I shall provide arguments for the correctness of this hypothesis and discuss some of its implications.[1J.

We can distinguish two different instances of the dummy pronoun het. Dutch het is similar to English it in this respect. The first instance concerns its use as a subject in construction with a weather verb, as in (1). This construction will be discussed in section 2. The second case involves a wide range of constructions in which the subject or object does not seem to have a thematic role but where it is clearly related to a postverbal sentential complement, as in (2).

(1) Het regent

It rains

(2)a.Het schijnt dat Jan ziek is

It seems that John ill is

b.Het is vervelend dat Jan ziek is

It is annoying that John ill is

c.Het wordt beweerd dat Jan ziek is

It is said that John ill is 
d.Jan betreurde het dat hij ziek was

John regretted it that he ill was

In addition to the so-called "dummy" use of the pronoun het, it can also be used as a neuter. personal pronoun. In view of what has just been said, it should be clear that I shall argue in favour of an analysis in which the pronoun het is a referential pronoun in all instances. In section 3 , it will be argued that the "dummy pronoun" het displays several properties that are characteristic of referential expressions. such as the fact that it may be the antecedent for reflexives. PRO and parasitic gaps. This implies that we need no longer make a distinction between three different uses of one pronominal element, but rather that. given the properties of the pronominal element het, we expect het to occur in different construction types. In section 4 . it is demonstrated that an analysis in which dummy het is considered to be a referential expression leads to correct predictions with respect to extraction from sentential complements. In section 5, I shall discuss the occurrence of het as the subject of raising verbs. It will be argued that het is the D-structure object of the raising verb which is raised to subject position for reasons of Case. I shall discuss the relation between het and $S^{\prime}$ in section 6 . There it is argued that het is similar to regular NPs in that it needs both a Q-role and Case. but that het differs from other NPs in that it may be bound by an $S^{\prime}$ in adjunct position. The requirement that a related $S^{\prime}$ must c-command het places several restrictions on th, distribution of het. In particular it follows that het cannot appear as an external argument if it is related to a postverbal $S^{\prime}$. Apparent counterrexamples to this consequence of the theory can be found in constructions with adjectives, as in (2b), in constructions with ergative verbs and in constructions with "psychological" verbs. These constructions are discussed in sections 7,8 and 9 , respectively. The final part of this chapter is devoted to the problem of NP-Inversion. The analysis of this construction will support the central claims that there is no structural subject position in Dutch and that NP-movement is an instance of the independently motivated rule of Adjunction. Some aspects of the discussion in this chapter have already been 
presented in Bennis (1985).

\subsection{Weather-HET}

Chomsky(1981) extensively discusses the occurrence of it in construction with weather verbs. He argues that weather-it is not referentIal, in the sense that it does not denote a designated member of D, D being a domain of individuals that serve as values of variables and as denotata. On the other hand, weather-it may behave as an argument in control structures. in which case it may serve as an antecedent for PRO. This is indicated in (3).

\section{(3) It sometimes rains after [PRO snowing]}

To account for the grammaticality of (3), Chomsky argues that "weather-it is similar to arguments in that it can control PRO but unlike them in that it denotes no member of $D$, as a matter of grammatical principle"(Chomsky 1981:325). Therefore he proposes to consider weather-it a 'quasi-argument'. In his view. it can be a true argument (it is on the table), a quasi-argument (it rains) and a non-argument (it seems that ...).

According to Chomsky, the main reason for the distinction between true and quasi arguments is that the non-wellformedness of (4) and (5) is different in nature.

(4) *Which rock thinks?

(S) What rains?

Chomsky claims that the ungrammaticality of (S) is caused by grammatical principle, whereas the non-wellformedness of (4) is caused by other considerations, factual or conceptual, that constrain D.

I would like to claim that weather-it always denotes a member of D. Given that only one member of $D$ (it) may serve as an individual in the domain $D$ that satisfies the conceptual requirement that is imposed on the subject by the weather verb, (5) is ungrammatical for the same reason as (4). In this sense, 
weather-it is similar to NPs in idiom chunks, where likewise only one element from $D$ satisfies the requirements imposed by the verb and where simple wh-extraction is not allowed. Given the fact that the idiom chunk may be the antecedent of a pronoun (it in (6c)), the idiom chunk must be an argument.

(6)a. John took care of the orphans

b. What did John take of the orphans?

c. Care was taken of the orphans. but it was insufficient

On the basis of this paradigm, Chomsky argues that idiom chunks like the one in (6) are also quasi-arguments. However. given the grammaticality of (6d), the ungrammaticality of (6b) does not seem to arise from the fact that the moved expression $\mathbf{i}$, a quasi-argument whereas the variable left behind by wh-movement must be a true argument, as Chomsky suggests.

(6)d. How much care did John take of the orphans?

The difference between (6b) and (6d) seems to be a consequence of the fact that in these idiomatic expressions the set of individuals of $D$ is very restricted. In this case. only those NPs that have the noun care as a head(care, how much care, no care etc.) are possible.

Let us now return to weather verbs and turn to Dutch. There are several arguments in favour of the true argument status of het in this construction. Note that in Dutch too, weather-het may appear as the antecedent of PRO, as can be seen in (7).

(7)a. Het is na PRO drie weken geregend te hebben

It is after three weeks rained to have uiteindelijk toch weer mooi weer geworden finally after all again beautiful weather become b.*De $z \circ n$ is na PRO drie weken geregend te hebben The sun is after three weeks rained to have uiteindelijk toch weer doorgebroken finally after all again broken through 
c.*Het is na PRO drie weken geregend te hebben

It " after three weeks rained to have

duidelijk dat de oogst zal mislukken

clear that the harvest will fail

The grammaticality of (7a) indicates that PRO may be controlled by weather-het, whereas the ungrammaticality of (7b) and (7c) shows that PRO in this construction must be controlled by weather-het. Note that the ungrammaticality of (70) demonstrates that het with an extraposed sentential complement differs from weather-het, since it cannot function as the antecedent of PRO. PRO being the subject of a weather verb from a thematic point of view.

Furthermore, although the set of conceivable arguments that are able to function as the subject of weather verbs is normally restricted to het, other individuals of $\mathrm{D}$ may function as a subject as well, as can be seen from the examples in (8).[2).

(8)a. Het/Het bolletje sneeuwt

It Ithe little ball snows

b. Het/De douche druppelt

It Ithe shower drips

c. Het/De wind waait hard

It IThe wind blows strongly

Thus, even in the case of regular weather verbs subjects other than het are possible. In addition, weather-het can also be used in other constructions, with verbs that do not exclusively refer to weather conditions, as shown in (9).

(9)a. Het/mijn neus/het huis is koud

It Imy nose Ithe house is cold

b. Het/de wond trekt dicht

It Ithe wound closes

'It is clouding over'I'The wound is healing'

c. Het/de kamer wOrdt donker

ItI the room becomes dark

From these facts we may conclude that in principle the occurrence 
of weather-it is optional in the sense that true arguments may appear in its position as well. There seems to be no real reason then to argue that it differs from other referential expressions as far as its argument status is concerned.

Another argument that indicates that weather-het is not a dummy pronoun is the fact that it cannot be left out, as is possible if het is a dummy pronoun in construction with an extraposed S'. In these cases, which will be discussed in more detail below, the occurrence of het is optional.

$$
\begin{aligned}
& \text { (10) ... dat (het) duidelijk is dat Jan ziek is } \\
& \text {... that (it) clear is that John ill is } \\
& \text {... dat (het) gebleken is dat Jan ziek is } \\
& \text {.. that (it) appeared is that John ill is }
\end{aligned}
$$

If weather-it was a dummy pronoun along with the dummy het, we would expect it to be optional. too, at least if we argue for a syntactic solution with regard to the occurrence of empty dummy pronouns in Dutch, along the lines of a weak pro-drop parameter(cf.Pesetsky 1982a) or of the ECP (cf.Hoekstra 1983).

From now on, I shall assume that weather-het is a true argument in all relevant respects.

\subsection{Referential properties of the dummy pronoun het}

In this section it will be argued that dummy het displays three properties that might be called characteristic of referential expressions: het in its dummy use can function as an antecedent for reflexives, PRO and parasitic gaps. This would be surprising if het were just a dummy pronoun filling a structural position. If we consider het a referential expression in all instances, these facts are precisely as one might expect.

Just like other referential expressions 'dummy'-het shows one of the most salient sentence-internal referential properties, i.e. it can be the antecedent for (inherent) reflexives, as can be seen in (11). 
(11)a. Het spreekt voor zich(zelr) dat ik kom It speaks for itself that I come 'It is self-evident that I will come'

b. Het doet zich vaak voor dat Jan ziek is It does itself often for that John i/l is

'It often occurs that John is 111'

Het is not part of the idiomatic expressions, since it can be replaced by other referential expressions, as shown in (12).

(12)a. Dit rapport spreekt voor zichze1f

This report speaks for itself

b. Die situatie doet zich vaak voor

That situation does itself often for

'That situation occurs frequently'

It is interesting to note that while het is optional with complement clauses, in sentences such as (11) the occurrence of het is obligatory, Which indicates that het is indeed the antecedent of the lexical anaphor.

A further argument in favour of the hypothesis that 'dummy'-het is a referential expression can be found in the fact that 'dummy'-het may be the antecedent of PRO. For obvious reasons het cannot control the subject of the clause with which it is coindexed, as in (13).

$$
\begin{aligned}
& \text { (13) *Het is leuk om PRO duidelijk te zijn dat Jan } \\
& \text { It is nice for clear to be that John } \\
& \text { tot hoogleraar zal worden benoemd } \\
& \text { as professor will be appointed }
\end{aligned}
$$

In order to be related to the matrix clause, i.e. to receive a thematic role or,more precisely, to become part of a chain with a thematic role the postverbal infinitival clause containing PRO must be coindexed with het. On that assumption, no coindexation between het and PRO is possible, since it is quite natural that het cannot be coindexed with a constituent that is part of another constituent with which het is also coindexed. This condition is known as the 
i-inside-i condition. Although it is clear that PRO in (13) cannot be controlled by het, we may wonder why no arbitrary interpretation of PRO is possible either. The construction in (13) is typically a construction in which arbitrary PRO occurs, as is illustrated in (14).

(14) Het is leuk om PRO hoogleraar te worden It is nice for professor to become

'It is nice to become a professor'

As has been observed in the literature, the interpretation of arbitrary PRO is not completely arbitrary. Whereas the verb vallen(to fall) in (15) can have both human and non-human subjects, only a human interpretation is possible for PRO in (16).

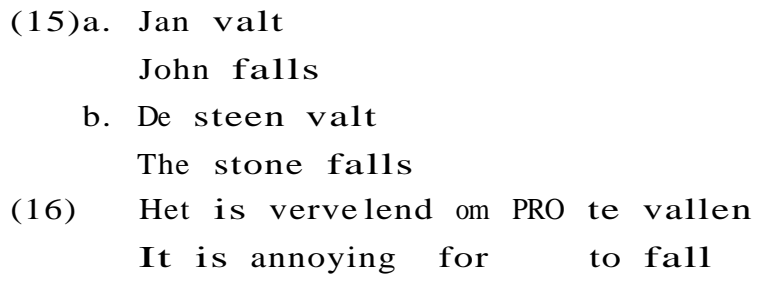

Whatever the explanation for the restriction on the interpretation of arbitrary PRO, it will be clear that this explanation should also cover the ungrammaticality of (13), in that it minimally explains the non-occurrence of arbitrary PRO in (13).

However, het may be the antecedent of PRO, if this PRO is contained in an unrelated adjunct clause, as in (17).

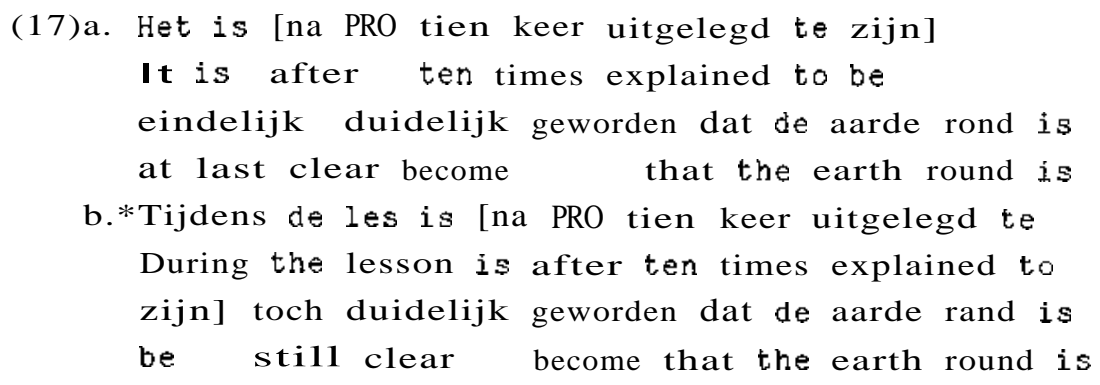


The ungrammaticality of (17b) indicates that the occurrence of het -which is optional if the adjunct clause is finite or can be left out altogether, as in $(18 \mathrm{a}, \mathrm{b})-$ is obligatory to control the PRO-subject of the adjunct clause. It is thus impossible to analyse PRO in (17a) as arbitrary PRO, which analysis would moreover be in conflict with the restrictions on the interpretation of arbitrary PRO as discussed above.

(18)a. Tijdens de les is (het) duidelijk geworden dat During the lesson is (it) clear become that de aarde rond is the earth round is

b. Tijdens de les is (het) na dat het tien keer is During the lesson is (it) after that it ten times is uitgelegd duidelijk geworden dat de aarde rond is explained clear become that the earth round is

There is no other possibili.ty then to assume that 'dummy'-het is the antecedent of PRO in a configuration of obligatory control. This fact constitutes a serious objection to the analysis of het as a dummy pronoun.

The next argument for the referential status of the 'dummy' pronoun het concerns the fact that het can be the antecedent for a parasitic gap. As has been argued in ch.1.5. parasitic gaps are licit if the g-projection within the adjunct clause properly connects with a g-projection in the matrix clause and both gaps are allowed by the Gap Condition. The sentences in (19) are in all relevant respects structurally similar to the parasitic gap sentences discussed in ch.1.5.2. What is relevant here is the fact that the antecedent of both gaps is the 'dummy' pronoun het.

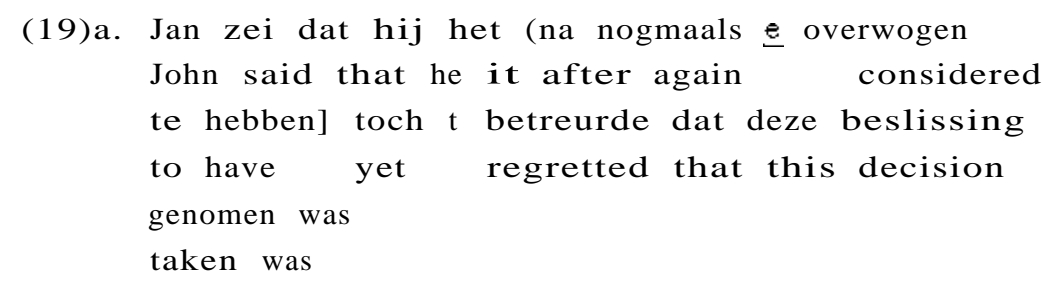


b. Jan zei dat hij het [na een keer e beleefd te John said that he it after one time gone-through to hebben] nooit meer $\underline{t}$ wilde meemaken dat de minister have never again wanted experience that the minister een prijs weigert uit te reiken

a prize refuses to present

The occurrence of het is obligatory in these cases, while it is optional if there is no parasitic gap present. furthermore, het must appear to the left of the adjunct clause containing the parasitic gap. If it is assumed that het is indeed the antecedent of the parasitic gap, this is precisely what we expect.

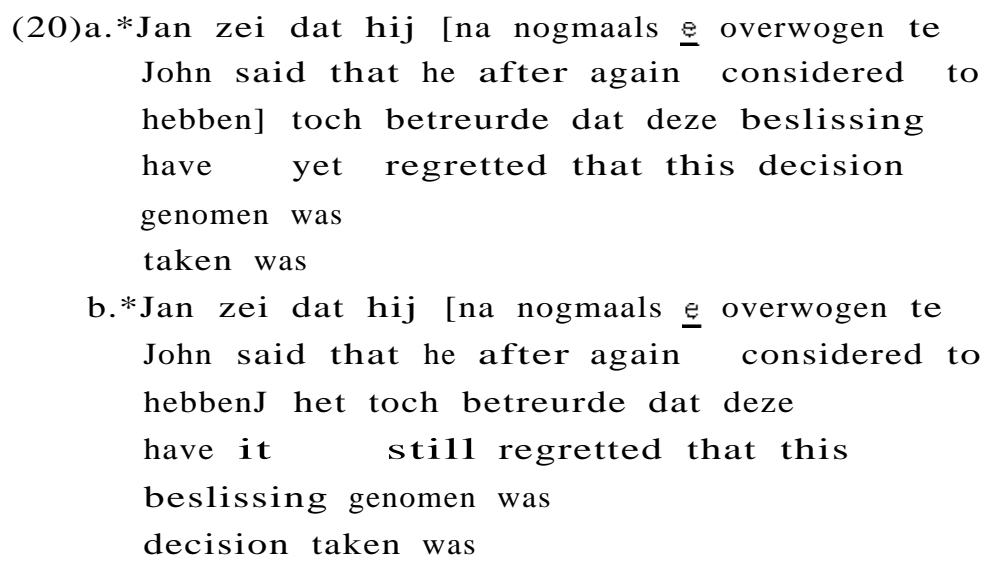

The obligatory presence of het in an $\mathrm{A}^{\prime}$-position c-commanding the parasitic gap would seem to imply once more that 'dummy'-het needs to be analysed as the antecedent. Aside from the antecedenthood of het in these cases, which is an argument for the referential status of het in itself, it is interesting to observe that the parasitic gap itself cannot be assigned a dummy interpretation. Unquestionably, the empty category in the adjunct clause occupies the thematic object position. It would be very awkward to assume that het is the antecedent of a non-thematic position in the matrix clause, and the antecedent of a thematic position in the adjunct clause. In that case het would be a dummy pronoun with respect to the matrix clause and a referential pronoun with respect to the 
adjunct clause. This asymmetry disappears if het is interpreted as a referential pronoun in the matrix clause as well. Again we observe that the plausibility of the assumption that het is a dummy pronoun, which is based on intuition rather than on a well-motivated argumentation, vanishes if the data are considered in more detail.

In the next section, other syntactic arguments will be provided that support the hypothesis that het is always referential.

\subsection{HET and sentential complements}

\subsubsection{HET in object position}

In this section I shall argue that het in object position in construction with a postverbal $S^{\prime}$ is not a dummy pronoun but rather a referential expression in argument position carrying a propositional thematic role. It is a well-known fact that het may appear optionally in object position in construction with a postverbal sentence. This occurrence of het yields the so-called factive interpretation that is virtually obligatory with some verbs (haten (to hate)), optional with others (betreuren (to regret)) and rather marginal elsewhere (zeggen (to say)).

$$
\begin{gathered}
\text { (21)a... dat ik ?(het) haat dat Jan ziek is } \\
\text { that I it hate that John i11 is } \\
\text { b... dat ik (het) betreur dat Jan ziek is } \\
\text {... that I it regret that John ill is } \\
\text { c... dat ik (?het) zeg dat Jan ziek is } \\
\text {... that I it say that John il1 is }
\end{gathered}
$$

Obviously, the selection of het is dependent on semantic and pragmatic factors that do not concern us here, except that some interpretation of the notion factivity is involved (cf.Kiparsky \& Kiparsky 1970 and Van den Hoek 1970). What is relevant, however, is the question of the syntactic status of het in these sentences. It is generally assumed that the sentential complement is extraposed 
and that het is optionally inserted in the position of the trace, as a resumptive pronoun. If this was the correct derivation het would not be a referential expression, since it would violate the theta-criterion. The thematic role is assigned to the $S^{\prime}$ by the verb. and not to het.

In what follows I will adopt Hoekstra's(1g83) proposal that if het is present, it is a referential expression base-generated in object position. This implies that in those cases the postverbal $S^{\prime}$ cannot be a direct argument of $\mathrm{V}$, but only an 'indirect' argument by virtue of coindexation with the preverbal object het. $S^{\prime}$ must thus be an adjunct clause.

In addition to the arguments presented in the previous sections. there is another argument in favour of the hypothesis defended here, concerning extraction from the postverbal S'. As has been observed by several people (e.g.Hoekstra 1983, Groos 1983), extraction from sentential complements is excluded if a corresponding het is present. This is illustrated in (22).

(22)a. Wat betreurde jij dat hij gezegd had?

What regretted you that he said had

b. Wat betreurde jij het dat hij gezegd had?

What regretted you it that he said had

In an analysis that is based on extraposition of the sentential complement, (22a) and (22b) differ only with respect to the insertion of het in the position of the trace. The only way to account for the difference in grammaticality would then be to postulate a completely ad-hoc filter which excludes extraction if het is present. If het in (22b) is a referential expression in argument position, and not a resumptive pronoun, then the ungrammaticality of (22b) follows immediately. In that case. the postverbal 3' must be an adjunct clause, since there is no thematic role available. If this is correct, the ungrammaticality of (22b) is on a par with the ungrammaticality resulting from extraction out of other adjunct clauses. as in (23).

(23)*Wat heb jij de beslissing betreurd nadat je gehoord hebt What have you the decision regretted after you heard have 
Under this analysis the grammaticality of (22a) does not immediately follow. If the sentential complement is extraposed, the $S^{\prime}$ will be moved from an A-position to an $\mathrm{A}^{\prime}$-position. Again, the $S^{\prime}$ will be in a position that is structurally similar to the position of adjuncts, and extraction is thus predicted to be impossible, contrary to fact. Let us suppose that instead of being extraposed the $S^{\prime}$ can be base-generated in postverbal position. If that is correct, the postverbal S' may occupy an argument position. In that case, we can relate the difference between (22a) and (22b) to the fact that in (22a) the $S^{\prime}$ occupies an A-position, whereas it cannot occupy such a position in (22b) since the referential pronoun het must occupy the A-position. If het in (22b) does not occupy the A_position, but $S^{\prime}$ does, then there arises a violation of the theta-criterion, since there is a referential expression without a thematic role. The difference between (22a) and (22b) is then that in (22a) the verb betreuren assigns its propositional thematic role to the postverbal $S^{\prime}$, whereas it assigns this role to the NP het in (22b). The relevant parts of the structures in (22) are given in (24).

(24)a.

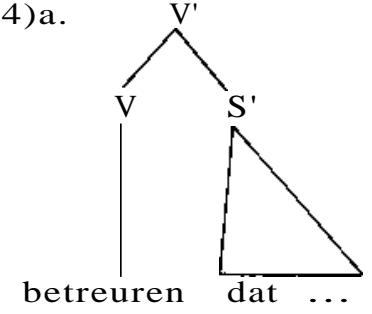

b.

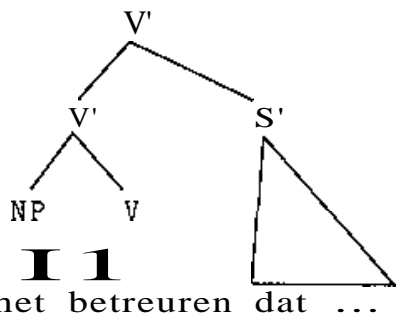

As far as extraction from $\mathrm{S}^{\prime}$ is concerned, the theory concerning extraction from $S^{\prime}$ put forward in ch.1.2.3 predicts that only configurations in which the verb (minimally) governs the sentential complement, as in (24a), allow extraction. Otherwise, no g-projection can be built from the governor of the gap up to the minimal maximal projection containing the antecedent, which results in a violation of the Gap Condition.

The rather controversial assumption that sentential complements may be base-generated in postverbal position might need 
some further elaboration. [3J. This assumption is based on the idea that the assignment of thematic roles is non-directional. The order of constituents must then be based on other principles of the grammar. Let us assume that Case assignment is directional. In Dutch. the verb assigns Case to the left, which explains why NP-complements have to appear preverbally. Since S' does not need Case, $S^{\prime}$ is allowed to appear postverbally, just like PP-complements. The question may then be asked why S'_complements do not appear preverbally, whereas PPs do. This might be explained in terms of the Unlike Category Condition, which essentially claims that no category XP may be governed by a category X (cf.Hoekstra 1984). If the Unlike Category Condition is also assumed to be a directional principle its direction being identical to the direction of Case assignment, it follows that $S^{\prime}$, which is non-distinct from $\mathrm{V}$ in its feature composition, cannot appear preverbally, while PP (and NP) can. For a discussion motivating these assumptions I refer to ch.1.

A further argument that seems to support the analysis of the differential position of the postverbal $S^{\prime}$ being dependent on the presence or absence of het is provided by those cases in which the postverbal $S^{\prime}$ is related to the complement of a subcategorized preposition. It is then predicted that in those cases the $S^{\prime}$ cannot be in a postverbal A-position, since it is not the verb that assigns a thematic role in this case, but the preposition or rather the combination of verb and preposition. Given the fact that a preposition as head of a preverbal pp cannot govern the postverbal $S^{\prime}$, the $S^{\prime}$ must appear in $A^{\prime}$-position. We therefore predict that a pronoun has to occur in the A-position, i.e. het is not optional as it was in the cases of V-complementation in (21). Furthermore, it is predicted that no extraction from $S^{\prime}$ is possible. Both predictions turn out to be correct, as will be demonstrated below. There is a further difference between these constructions and the direct object constructions discussed above. This concerns the fact that for some reason it is impossible for het to appear as a complement to a preposition. In those cases it is necessary to use the adverbial pronoun er, which appears to the left of the preposition (cf.Van Riemsdijk 1978a \& ch.1.2 \& 1.3). Other 
referential expressions have to appear to the right, as a consequence of the fact that $\mathrm{P}$ assigns Case to the right. Given the fact that these phenomena are not specific to the construction under discussion, I shall not go into the discussion of complements of $\mathrm{P}$ and the related issue of preposition stranding here. For an exhaustive discussion, I refer to Van Riemsdijk 1978 and chapter 1. What is relevant, however. is the fact that if the preverbal preposition has a postverbal sentential complement, er is obligatorily present, as can be seen in (25).

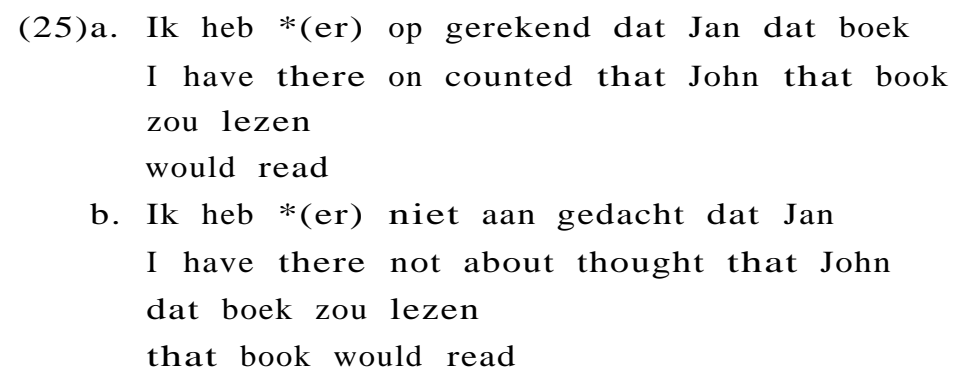

These facts are predicted by the theta-criterion, since there has to be a referential expression that carries the thematic role assigned by the (verb +)preposition. Given the fact that the $S^{\prime}$ cannot occupy a postverbal A-position at D-structure, er is necessarily present to carry the thematic role. Along the same lines, we predict extraction to be impossible because the $5^{\prime}$ is in an $\mathrm{A}^{\prime}$-position or adjunct position. This is shown in (26).

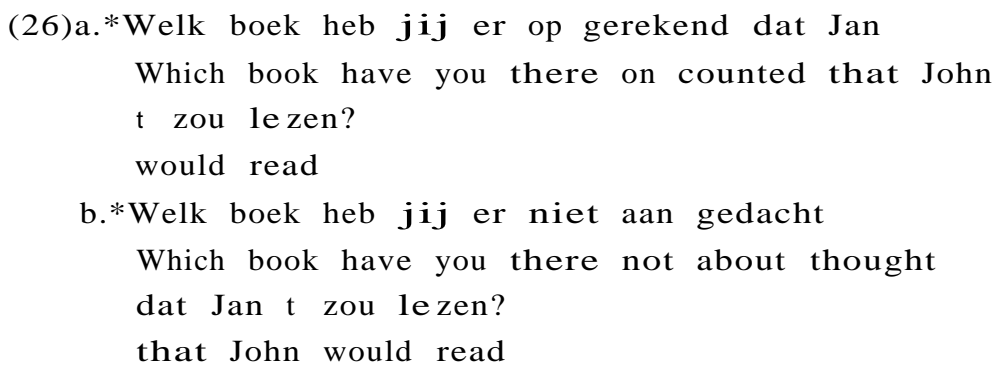

That er behaves like a referential expression in these cases can again be illustrated by the fact that it can be the antecedent of a 
parasitic gap. This is shown in (27).

(27) Ik heb er [zonder PRO $\underline{e}$ over na te denken] I have there without about to think $\mathrm{t}$ mee ingestemd dat Jan naar huis zou gaan with agreed that John home would go

\subsubsection{HET in subject position}

$A$ full discussion of all the relevant instances of 'dummy'-het in subject position requires an investigation into the properties of a variety of constructions. Therefore I shall initially restrict my attention to a discussion of het in the passive counterpart of the sentences in (21).

We have seen in (21) that het is optionally present in object position if there is a postverbal sentential complement. This fact was argued to be related to the position of $S^{\prime}$, i.e. S' can be either in argument position or in adjunct position. If the sentences in (21) are given passive variants, we can either passivize the construction with het as direct object, in which case het behaves like a normal object, which has to be moved to the non-thematic subject position in order to receive Case, or we may passivize the construction without het. in which case there is no NP-object but only an $\mathrm{S}^{\prime}$-object. Because an $\mathrm{S}^{\prime}$-object need not receive Case, the resulting sentence will then show all the characteristics of passives of intransitive verbs, since nothing need be moved to sUbject position. The first type of passive construction is illustrated in (28a) and the seCond in $(28 b, c)$.

(28)a. Het wordt betreurd dat Jan ziek is

It is regretted that John il1 is

b. Er wordt betreurd dat Jan ziek is

There is regretted that John $i 11$ is

c. Door iedereen wordt betreurd dat Jan ziek is By everyone is regretted that John $i 11$ is

If we assume the existence of dummy pronouns, the paradigm in 
(28) raises several complicated questions. Three different dummy pronouns appear to show up: het in (28a), er in (28b) and the empty dummy pronoun $\underline{e}$ in $(28 \mathrm{c})$. What is it that governs the distribution of dummy pronouns? What is the difference between het and er? In view of the fact that it is certainly not the case that dummy het can always be replaced by dummy er, nor vice versa, as can be seen in the following examples, this approach would give rise to serious problems.

\section{(2g)a. Het/*er schijnt dat Jan ziek is It/there seems that John ill is \\ b. Er/*het wordt gelachen \\ There/it is laughed}

If het in (28a) is considered to be a referential expression, (28a) is an ordinary instance of a passive sentence. In that case, the fact that $(2 \mathrm{gb})$, in which an intransitive verb is passivized, is ungrammatical does not come as a surprise, as this would result from a violation of the theta-criterion. There is then no theta-role available for het. The question that arises now is what the status of er is. I shall not discuss this matter in any detail here. In chapter 3 it will be argued that er is not a dummy pronoun either. Er can have various functions, one of Which is an adverbial with a pragmatic function. In (28b) and $(2 \mathrm{gb})$ it is this function that is carried by er. If we pursue this line of reasoning, it will be clear that there are no empty dummy pronouns either. which is a desirable result since the notion of empty dummy is fairly aWkward: it implies that there are categories that have no surface realization and no interpretation either. These assumptions would naturally lead to the position that there may be sentences without a structural subject (like 28b,c), which is in conflict with Chomsky's Extended Projection Principle (Chomsky 1982), which requires sentences to contain a structural subject. However, I think that too much has been made of the Extended Projection Principle and that we should go back to the Projection Principle. For an extenSive discussion of this matter, I have to refer to 2.9.

Let us assume that it is in fact correct to consider het in (28a) as a referential expression that is moved from object to 
subject position in order to receive Case. In that case, the $\mathrm{S}^{\prime} \mathbf{i}$, an adjunct and not an argument, and consequently we predict extraction from $S^{\prime}$ to be impossible. However, in $(28 \mathrm{~b}, \mathrm{c})$ the $S^{\prime}$ is an argument of the verb, and should thus allow extraction. This prediction is borne out, as $i$, shown in (30).

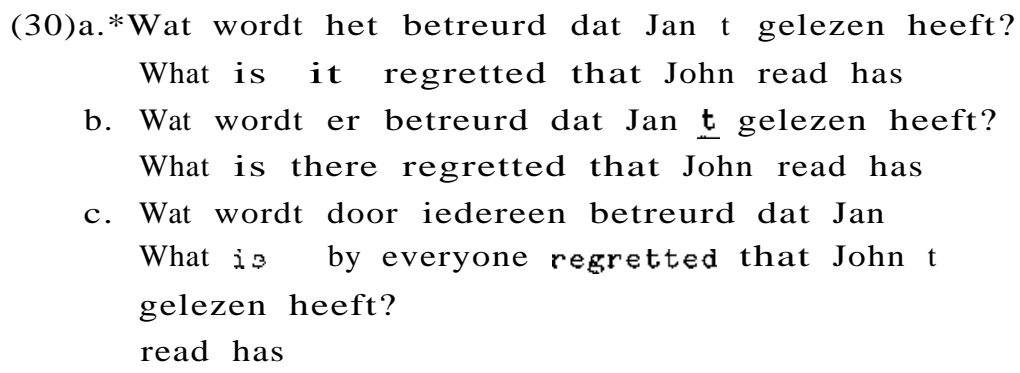

In a dummy-pronoun analysis the contrast between (30b) and (26) would be very difficult to account for, as there is a dummy pronoun er and an extraposed sentential complement in the two sentences. There is no reason to suppose that something like coindexing between dummy and S' blocks extraction only in (26) and not in (30b).

\subsection{HET-Raising}

The evidence presented thus far of the referential status of het in subject position leads quite straightforwardly to a similar analysis in the case of het appearing as the subject in Raising constructions, as in (31).

(31) Het is gebleken dat Jan ziek was It is appeared that John ill was

Just as in the case of the passive sentences discussed in the previous section (cf.(28)), the appearance of het is optional, as is illustrated in (32). 
(32)a. Er is gebleken dat Jan ziek is

There is appeared that John $i 11$ is

b. Gisteren is gebleken dat Jan ziek is

Yesterday is appeared that John 111 is

Similarly, extraction from the sentential complement turns out to be impossible if the subject position is filled with het.

(33)a.*Wat is het gebleken dat Jan gezegd heeft?

What is it appeared that John said has

b. Wat is er gebleken dat Jan gezegd heeft?

What is there appeared that John said has

c. Wat is gisteren gebleken dat Jan gezegd heeft?

What is yesterday appeared that John said has

In all relevant respects these sentences are similar to the ones in which het optionally appeared in object position, and their corresponding passives. The explanation in those cases was dependent on the possibility for het to occupy a direct-object argument position. If we postulated that het was a referential pronoun base-generated in subject position in (31) and (33a), we would be confronted with at least two serious problems. First, we would be forced to assume that a raising verb such as blijken ha' a thematic subject in those cases, whereas it lacks such a position in regular raising sentences, as in (34).

\section{(34) Jan blijkt ziek te zijn}

John appears il1 to be

This would be a very unfortunate consequence of this analysis. The second problem concerns the extraction cases in (33). Given the line of argumentation in the previous sections, we are led to expect that the external thematic role of blijken is either assigned to het (cf.31), in which case the $S^{\prime}$ would be an adjunct or to the $\mathrm{S}^{\prime}$ directly (cf.32). In 2.4.1 it was argued that extraction from $S^{\prime}$ is possible only if $S^{\prime}$ is an (internal) argument of V. Under this analysis, this is not the case in (31) and (32), which would predict extraction to be entirely impossible, contrary 
to fact. In view of these problems I will consider this analysis to be incorrect.

If we consider het to be a dummy pronoun only in these cases, we are left with the same problems that were discussed in section 3. It would be hard to explain the distribution of dummy pronouns and the extraction facts in (33). Furthermore, it would be completely counterproductive to assume that het is a dummy pronoun in (31), but not in the comparable cases discussed in the previous section.

However, if we assume that the factual similarity between the passive sentences in (28) and (30) and the raising-verb sentences under discussion is an immediate consequence of a structural similarity, all problems vaniSh. This implies that het, if present, is a D-structure direct object, which is moved to subject position. This analysis is rather attractive since raising verbs have the same characteristics as passive verbs, i.e. they do not assign a thematic role to the subject position nor Case to their object position (cf.Burzio 1981).[4J. This is the standard analysis of raising in sentences such as (34). If we consider het in (31) to be a referential expression that needs a thematic role as well as Case, het must be base-generated as object to receive a thematic role, and must be moved to the subject position in order to get Case. Therefore, nothing has to be changed in the lexical specification of raising verbs to account for these cases. Furthermore, the extraction facts follow automatically. If het is present, the $S^{\prime}$ cannot be an argument of the verb and extraction is thus impossible. If het is not selected, the $S^{\prime}$ is an argument and extraction is predicted to occur. The facts in (31) and (32), which have been a problem for some time and have led to analyses that argued for the existence of two verbs blijken, can now be accomodated quite easily without construction-specific statements.

The proposed raising analysis of het into subject position shows not only a structural similarity with movement in passive constructions but also with movement in the case of ergative verbs. If the analysis provided in Hoekstra(1984) is correct, one of the diagnostic properties of verbs that do not assign Case to their object nor an external thematic role is that their perfective auxiliary is the verb zijn, whereas verbs that are regularly 
transitive in Hoekstra's sense, i.e. assign an external thematic role, select the auxiliary verb hebben. From this point of view, it is expected under our analysis that these raising verbs select the perfective auxiliary zijn. This seems indeed to be the case as can be seen from the following example.

(35) Het is/*heeft gebleken dat Jan ziek is

It is 1 has appeared that John is i11

Unfortunately, it turns out that the analysis of these raising-verb constructions is not always as simple as this. If we take a different raising verb such as schijnen (to seem), the facts are quite different. If schijnen is followed by a (finite) sentential complement, the occurrence of het is obligatory and no extraction from the sentential complement is allowed at all. This is Shown in (36) and (37).

(36)a. Het scheen dat Jan ziek was

It seemed that John ill was

b. ${ }^{*} \mathrm{Er}$ scheen dat Jan ziek was

There seemed that John ill was

c.*Gisteren scheen dat Jan ziek was

Yesterday seemed that John il1 was

(37)a.*Wat scheen het dat Jan gezegd had?

What seemed it that John said has

b. Wat scheen er dat Jan gezegd had?

What seemed there that John said has

c. Wat scheen gisteren dat Jan gezegd had?

What seemed yesterday that John said has

How can the difference between blijken and schijnen be explained? If we assume that there are two different verbs blijken and only one verb schijnen, we would base our account of the differences between these two verbs on mere stipulation. On the other hand, the dummy pronoun account runs into serious problems. It would be rather infelicitous to assume that the selection of dummy pronouns is lexically determined in such a way that blijken selects both het and er, while schijnen selects het only. More seriously, it would 
follow that the appearance of empty dummy pronouns is not licensed by syntactic principles like the ECP or some version of weak pro-drop, but has to be lexically determined too, since schijnen does not allow an empty dummy pronoun, as is shown in (36c).[5J.

In the account proposed here these problems do not arise, since there are no dummy pronouns. I would like to argue that the differences between schijnen and blijken are a consequence of a difference in subcategorization. Whereas blijken allows the propositional thematic role to be expressed by NP (het), S or St, schijnen does not take an $\mathrm{S}^{\prime}$-complement. If this is correct, it is clear that het is obligatorily present in (36), while it explains at the same time that extraction is entirely impossible, since $S^{\prime}$ has to appear in adjunct position. Thus, the differences between the two raising verbs can be accounted for by making use of the independently necessary mechanism of subcategorization, which is possible only if het is analysed as a referential expression originating in object position.

That subcategorization is necessary to account for the distribution of complements to raising verbs is also manifest in case of other complements of these verbs. Both blijken and \$chijnen take S-complements in the standard raising sentences such as (34). However, only blijken, and not \$chijnen, takes small-clause complements (cf.Stowell 1983), as is shown in (38).

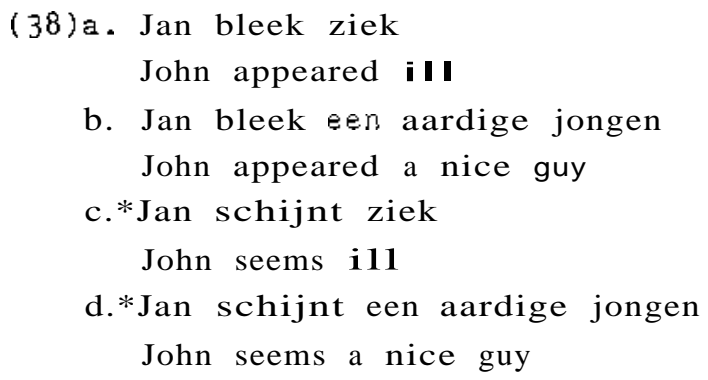

Whereas blijken takes all types of propositional complements, i.e. $S^{\prime}$, NP(het), Sand S(mall)C(lause), schijnen subcategorizes for NP and $S$ only. In this context, it is interesting to note that there is a third raising verb lijken (to seem) that differs from the other two subcategorization schemata in that it allows 
NP-complements, as in (39a), S-complements, as in (39c), and Se-complements, as in (39d), but not $\mathrm{S}^{\prime}$-complements, as is shown in (39b).

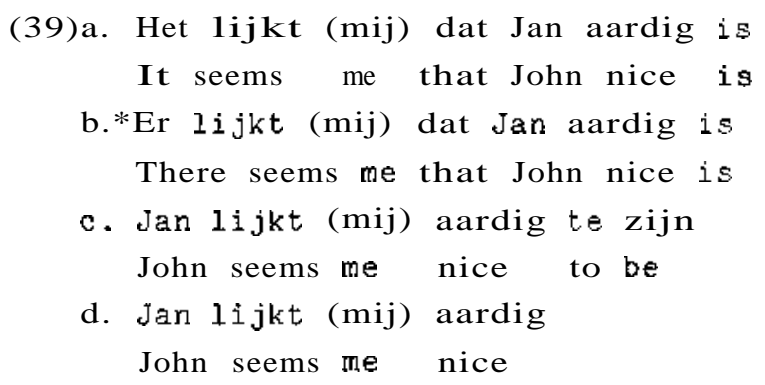

If this analysis is correct we expect that the verbs dealt with in this section may occur with an NP-complement only, i.e. without an adjunct $S^{\prime}$. Given the fact that these verbs select a propositional theta-role, only a small class of NPs is able to appear as argument of these verbs. Instances are het and dat. Although the resulting sentences are rather uninformative, they appear to be grammatical.

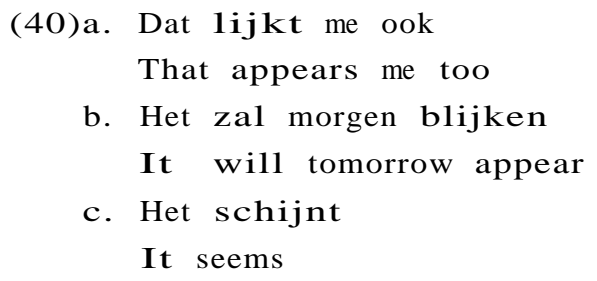

The grammaticality of these sentences illustrates once more that het is a referential expression carrying a thematic role.

With respect to the verb blijken two more remarks can be made. The fact that het is a referential expression can again be made to follow from the fact that (400) is grammatical whereas substitution of het by er or leaving the subject position empty, as is possible in case the verb is followed by a sentential complement (cf.(32)), results in ungrammaticality, as is shown in (41). 
(41)a.*Er zal morgen blijken

There will tomorrow appear

b.*Morgen zal blijken

Tomorrow will appear

The ungrammaticality of (41) follows from the fact that the verb in (41) cannot assign its propositional thematic role to a referential expression, whereas it can be assigned to het in ( $4 \emptyset \mathrm{b}$ ).

A further observation relates to the fact that contrary to lijken and schijnen, blijken may appear with a non-propositional thematic role. This is shown in (42).

(42) Zijn onnozelheid blijkt telkens

His stupidity appears again and again

In the same way as above, we can relate this difference to different lexical properties of the three raising verbs. In addition to a propositional thematic role, blijken is clearly to be specified for a non-propositional internal thematic role.[6J.

The fact that in the analysis presented here these three raising verbs are completely similar in their syntactic properties, which are fully predictable on the basis of independent principles of grammar, and different in their lexically determined \$ubcategorization properties, seems a desirable result, preferable to an analysis in which construction-specific claims have to be introduced. It should be stressed again that this analysis is dependent on the assumption that het is a referential pronoun. This assumption is supported by the fact that het shows referential properties because it can function as the antecedent for PRO, lexical anaphors and parasitic gaps.

\subsection{Bisentential verbs}

Before continuing our survey of the so-called dummy pronoun het in subject position, we may wonder whether the relation between a sentential complement and a coreferential pronoun is subject to syntactic restrictions. If the pronoun is present it occurs in an 
A-position or is moved from an A-position, while the $S^{\prime}$ is an adjunct and thus in At-position at all levels of representation. Since the Binding Theory is a theory that applies to coreference relations between constituents in A-positions only, it has nothing to say on this issue. Formally, the relation between $S^{\prime}$ and het is similar to the relation between an operator in $A^{\prime}$-position and a trace. The major syntactic constraint on this relation is that the phrase in $\mathrm{A}^{\prime}$-position must c-command the trace. Therefore, we may expect that a similar constraint holds in the cases under discussion. In the constructions discussed thusfar this seems indeed to be the case, since it was argued that in all cases the pronoun was generated in a position c-commanded by the $S^{\prime}$. This is obvious when the pronoun appears as the direct object, as in (43). The same is true if het occurs as the subject of a small clause, as in (44). From both positions the pronoun might be moved upwards in order to receive Case, as was the case in the passive counterparts of (43), in raising constructions and in constructions involving raising of the subject of a small clause, as will be discussed in the next paragraph. Relevant instances are illustrated in (45).

Ik betreur het dat jij ziek bent

I regret it that you sick are

(44) Ik vind het vervelend dat jij ziek bent

I consider it annoying that you sick are

(45)a. Het wordt $\mathrm{t}$ betreurd dat jij ziek bent

It is regretted that you siCk are

b. Het schijnt $t$ dat Jan ziek is

It seems that John ill is

c. Het is [t vervelend J dat jij ziek bent

It is annoying that you sick are

From this we may conclude that the SI in $\mathrm{A}^{\prime}$-position must c-command the pronoun, as in (43) and (44), or at least the head of the chain containing the pronoun, as in (45). If this is correct, we would not expect to find sentences in which the pronoun is the D-structure subject of a sentence containing a coreferential SI in $A^{\prime}$-position. This seems indeed to be the case. There are verbs that may select a propositional external thematic role. Examples are 
verbs like bewijzen (to prove), aantonen (to demonstrate) and impliceren (to imply). Given the fact that these verbs have a regular passive counterpart and have the perfective auxiliary hebben, they are transitive and select an external thematic role.

(46)a. Dit argument bewijst mijn gelijk

This argument proves my right

b. Mijn gelijk wordt door dit argument bewezen

My right is by this argument proved

c. Dit argument heeft mijn gelijk bewezen

This argument has my right proved

Koster(1978bl has shown that these verbs are problematical for an extraposition analysis. Koster shows that an extraposition analysis gives the wrong result in case both arguments of these verbs are sentential. While (47a) is grammatical, just as in English, (47b) is ungrammatical.

(47)a. Dat Jan bloed aan zijn handen heeft bewijst dat That John blood on his hands has proves that Marie onschuldig is

Mary innocent is

b.*Het bewijst dat Marie onschuldig is dat Jan bloed

It proves that Mary innocent is that John blood aan zijn handen heeft

on his hands has

If the sentential subject is extraposed and the subject position is filled with the dummy pronoun het, we expect (47bl to be grammatical. Koster argues that subject sentences do not exist and that in (47a) the introducing sentence is a satellite that binds the empty NP subject of the main clause. According to Koster the double $S$ problem in (47b) does not arise, since $S^{\prime}$ cannot be extraposed, because Koster claims that there is no rule of extraposition. I agree with Koster as far as the explanation of the grammaticality of $(47 a)$ is concerned. Topicalization moves a constituent with a thematic role (either a structurally assigned thematic role or an inherent thematic role) to COMP. The subject 
sentence in (47a) cannot be moved from subject position to COMP, since it cannot be generated in that position. This is not because of the base rules, as suggested by Koster, in which case we would have to argue that NP-VP is the obligatory expansion of $S$ and NP cannot be rewritten as S', but rather on account of the UCC, as argued in Hoekstra(1984). In the theory proposed here, a subject NP-position is not required, so we cannot rely on the base rules to exclude subject sentences. If we assume that subject sentences are excluded by the UCC, (47a) must be the result of movement of the subject NP to COMP, followed by a deletion under identity with the satellite $\mathrm{S}^{\prime}$. A strong argument in favour of an analysis along these lines is the fact that this deletion is optional, as is illustrated in (48).

(48) Dat Jan bloed aan zijn handen heeft (dat) bewijst That John blood on his hands has that proves dat Marie onschuldig is that Mary innocent is

Koster argues that (47b) does not appear since the satellite stays where it is in (47a). However, in the approach defended here, nothing seems to exclude a construction in which the propositional external thematic role is assigned to the NP het. In that case it should be possible to add an adjunct clause which is coreferential with the NP in subject position and thus we expect (47b) to be grammatical. However, if it is assumed that the relation between $S^{\prime}$ in $\mathrm{A}^{\prime}$-position and het in A-position is subject to the same conditions as the relation between operator and trace, this problem is solved, since in (47b) the $S^{\prime}$ does not c-command the subject or its trace.[7J. The implication of this proposal is that the ungrammaticality of sentences like (47b) has nothing to do with the presence of two sentential complements, as is suggested in the literature e.g. by Ross(1973), who proposes the Same Side filter or by Emonds(1970). The ungrammaticality is caused by an improper A'-binding relation between the pronoun in subject position and the adjunct $S^{\prime}$. Evidence that this solution is to be preferred can be derived from sentences in Which the internal argument of the verb is non-sentential, as in (49). 
(49) *Het bewijst mijn gelijk dat deze voorspelling uitkomt It proves my right that this prediction comes true

It should be noted that in this analysis the relation between $S^{\prime}$ and the pronoun is in most relevant respects similar to an analysis in which het is considered to be a resumptive pronoun. The only difference is that in these cases it can be argued that the resumptive pronoun is not inserted in the extraction site. Instead. it is an ordinary pronoun in an A-position or it is moved from an A-position, and is related to an $\mathrm{A}^{\prime}$-antecedent by interpretation. In such CaSeS the $S^{\prime}$ is optional, but if it is present it has to be properly connected to the pronoun in order to be part of a chain, i.e. to receive a thematic role under coindexation. If no such coindexation can take place, the $S^{\prime}$ in adjunct position has no thematic role, neither structurally nor inherently, and consequently the sentence cannot be interpreted.

It might be the case that what has been said here about het can be extended to resumptive pronouns in general, i.e. they are base-generated pronouns in A-positions. interpretively related to a c-commanding constituent in an $\mathrm{A}^{\prime}$-position. Interestingly, Safir(1985) argues that the defining property of resumptive pronouns is that they are pronouns which are $A^{\prime}$-bound. If this is true in general, it would constitute a strong argument in favour of the analysis proposed here. At this point, however, it would take us too far afield to discuss this idea in more detail.

\subsection{HET in Small-Clause constructjons}

A further construction in which het can occupy the subject position is given in (50).

(50)a. Het is duidelijk dat Jan ziek is

It is clear that John ill is

b. Het lijkt waarschijnlijk dat Jan ziek is

It seems probable that John ill is 
This construction is generally analysed as a typical instance of S'-extraposition. It will be clear that such an analysis is not compatible with the theory presented thusfar. Our theory predicts that

a. het is a referential expression

b. $S^{\prime}$ is in adjunct position

c. S' must c-command het or its trace

d. het cannot be a subject at D-structure, as a consequence of $\mathrm{c}$.

In what follows I shall argue that these predictions can be motivated for such examples as (50) as well. This will involve a discussion of the Small-Clause theory. I shall not take a stand in the discussion of the merits of the Small-Clause theory. I shall assume that the theory as has been developed in Stowell(1g81) is basically correct. What is relevant for our purpose here is those constructions in which the head of the Small Clause selects an external argument that is propositional. An example is given in (51) .

(51) Ik vind het vervelend dat Jan ziek is

I consider it annoying that John ill is

There seems to be no problem in this case. [het vervelend] constitues a Small Clause of which het is the subject. The $S^{\prime}$ is an adjunct, which c-commands het. Het is a referential expression that carries a thematic role assigned by the head vervelend and is assigned Case by the matrix verb vinden.

More complex instances of the Small-Clause construction involve constructions in which the subject of the Small Clause cannot be assigned Case by the matrix verb. This situation arises when the matrix verb is a passive or a raising verb. In Stowell (1981) for English and Hoekstra (1984) for Dutch, it is argued that, just like a raising verb, the verb to be or zijn is not able to assign Case and, following Burzio's generalization, is not able to assign an external thematic role. In these three cases the subject of the Small Clause has to be moved to the subject position of the matrix clause in order to receive Case. Some instances are exemplified in (52), in which the subject of the SC is Jan. 
(52)a. [e] wordt [Jan intelligent] gevonden

$a^{\prime}$. Jan wordt $[[\underline{t}]$ intelligent $J$ gevonden

John is intelligent found

b. [e] blijkt [Jan intelligent]

$b^{\prime}$. Jan blijkt [ [t] intelligent]

John appears intelligent

c. [e] is [Jan intelligent]

$c^{\prime}$. Jan is [ [ $\left.\underline{t}\right]$ intelligent]

John is intelligent

On the assumption that this analysis is correct, the question arises as to what would happen if the subject of the SC is propositional. As in (52), the subject of the $\mathrm{SC}$ is governed from outside the SC, since the SC itself does not include a category that is able to govern the subject position.[8]. If the SC subject is an MP, it Should be assigned Case by the external governor, as in (51). If the NP cannot receive Case, due to properties of the matrix verb, the $\mathrm{NP}$ has to be moved and the trace must be canonically governed. In both cases the SC must appear preverbally because the structural governor $V$ assigns Case to the left and because canonical government, which is necessary for the Gap Condition, is from right to left as a consequence. From this it follows that we do not expect to find SCs with a preverbal sentential subject, since this would constitute a violation of the uec, as in the case of preverbal sentential complements. The verb governs a non-distinct maximal projection to its left, in the direction of Case assignment. The ungrammaticality of such sentences is illustrated in (53).

$$
\begin{aligned}
& \text { (53)a.*Jan zei dat hij [[dat Piet komt] vervelendJ vindt } \\
& \text { John said that he that Peter comes annoying considers } \\
& \text { b. *Jan zei dat [[dat Piet komt] vervelend] is } \\
& \text { John said that that Peter comes annoying is }
\end{aligned}
$$

If the propositional external argument of the se is the NP(het) and the related S' a base-generated adjunct, the NP can get Case, either directly or after NP-movement, and the sentences are 
grammatical.

(54)a. Jan zei dat hij [het vervelendJ vindt dat Piet komt John said that he it annoying considers that Peter comes

b. Jan zei dat het [t vervelendJis dat Piet komt John said that it annoying is that Peter comes

In the preceding paragraphs it was argued that subjectless sentences in Dutch appear if the verb does not assign an external thematic role and there is no internal NP-argument that has to be moved to subject position to receive Case. In addition to the passives of intransitive verbs, this situation occurs if the verb (passive, raising or ergative) selects an internal sentential complement. In those cases the postverbal S' occupies an argument position and since $S^{\prime}$ doesn't need Case, there need be no movement to subject position. The question now arises whether subjectless sentences appear in the SC-constructions under discussion. This issue reduces to the question as to whether it is possible for the $S^{\prime}$ to occupy an argument position in the SC-construction. At first sight this would seem to be impossible, since the propositional thematic role is not assigned by the verb, but by the head of the SC. The relevant structure is illustrated in (55).

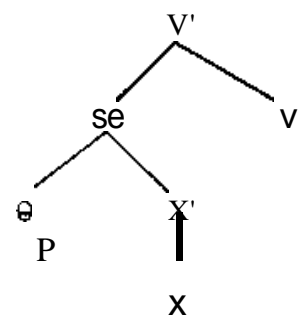

As was argued above, the UCC prevents the $S^{\prime}$ from appearing in the preverbal SC-subject position. There is no possibility for a postverbal S' to occupy an argument position in this structure, since the A-position is located within the se. Therefore we do not expect to find sentences of this type without het nor do we expect to find sentences that show extraction from the postverbal 5'.[9]. 
The facts, however, seem to suggest the contrary. Although some of these sentences are slightly marked, it is possible to leave out het in these constructions, as is shown in (56)and (57).

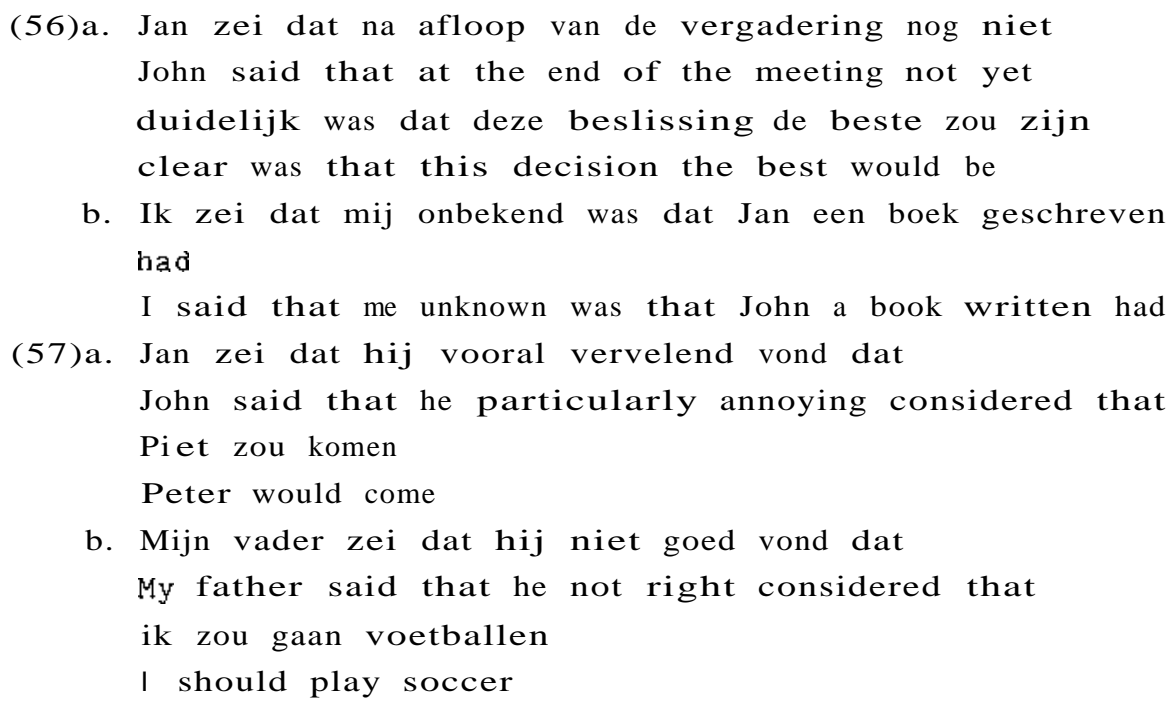

In (57) there is no lexical structural subject of the se, While in (56) the embedded clause contains no apparent lexical subject at al1.

In both (56) and (57) it is possible to extract a wh-phrase from the most deeply embedded $\mathrm{S}^{\prime}$, while extraction appears to be impossible in the corresponding sentences containing het $($ cf. $(54)) \cdot[10]$.

(58)a. Wat is duidelijk dat Jan $\underline{t}$ zal gaan zeggen?

What is clear that John will go say

b. Wat is het duidelijk dat Jan $t$ zal gaan zeggen?

What is it clear that John will go say

(59)a. Wat vond Jan vervelend dat hij $\underline{t}$ gezegd heeft?

What considered John annoying that he sai.d has

b. Wat vond Jan het vervelend dat hij $\underline{t}$ gezegd heeft?

What considered John it annoying that he said has

The theory put forward in 1.2 .3 claims that extraction from 5' 
is possible only if $\mathrm{S}^{\prime}$ is governed by V. Given that government is upward bounded to the argument projection of the governor, it follows that from a structural point of view $S^{\prime}$ should be analysed as an internal argument of the verb. This approach was confirmed by the extraction facts discussed in the previous sections. If the same line of reasoning is applied to the extraction facts in (58) and (59), it seems to force us to give up the se analysis as shown in (55) in those cases where het is absent. The grammaticality of extraction in (58a) and (59a) requires a structure like (60), in which the $\mathrm{S}^{\prime}$ is structurally an argument of $\mathrm{V}$.

(60)

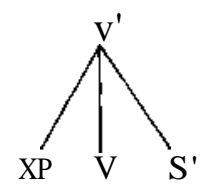

Such a structure is apparently in conflict with the se theory, since the external argument of the XP (i.e. $S^{\prime}$ ) is not located within the maximal projection of the theta-assigning head (XP). Eventually this would lead us to give up the se theory altogether. In view of the fact that the se theory makes a fair number of interesting predictions and is conceptually to be preferred to other theories dealing with the same range of constructions, this would be an unfortunate result. There seems to be only one way to reconcile the theory of extraction motivated in the preceding sections with the Small-Clause theory, with respect to the facts under discussion. We shall have to assume that a structure such as (60) is in some way derived from a se structure. At first sight, it seems to be unattractive to be forced to adopt such a derivational approach. However, there are a number of independent arguments in favour of a rule that reanalyses the verb and the predicative part of a SC as some kind of verbal unit. After the application of this rule the external argument of the SC is structurally the internal argument of this verbal complex. The effect of this reanalysis rule is illustrated in (61). 
(61)a.

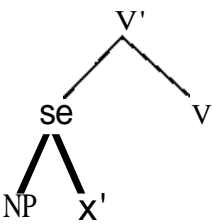

b.

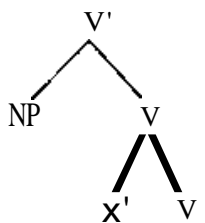

If such a reanalysis rule can be motivated, the relevant structure of the problematic sentences discussed in this section is as depicted in (62).

(62)

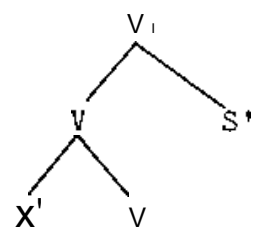

If this is the correct structure, we can account for the optionality of het in (54), (56) and (57) and for the possibility of extraction in case het is absent (cf.(S8)\&(59)).

There are at least three arguments in favour of the reanalysis rule indicated above.

-As was discussed in ch.1, preposition stranding in Dutch is restricted to configurations in which the stranded preposition is left-adjacent to the verb. This was argued to be a consequence of the Gap Condition, since the pp containing the stranded preposition must be canonically governed in order to build a well-formed g-projection to the antecedent of the gap contained within PP. However, there are counterexamples to the claim that the stranded preposition must be left-adjacent to the verb (cf.ch.1, note 2). If the verb is preceded by a se, the preposition that is stranded must be left-adjacent to the predicative part of the se. This is shown in $(63) \&(64)$.

(63)a. Hij heeft met een ladder [dat boek op de kastJ gelegd $\mathrm{He}$ has with a ladder that book on the bookcase put b. Waar heeft hij $t$ mee dat boek op de kast gelegd? Where has he with that book on the bookcase put 
c. Waar heeft hij dat boek op de kast $\underline{t}$ mee gelegd? Where has he that book on the bookcase with put

d. Waar heeft hij dat boek $\underline{t}$ mee op de kast gelegd? Where has he that book with on the bookcase put

(64)a. Jan zei dat hij [[alle argumenten tegen deze stelling]

John said that he all argument against this thesis onjuistJ vindt incorrect considers

b.*De stelling waar hij $\underline{\mathrm{t}}$ tegen alle argumenten The thesis where he against all arguments onjuist vindt incorrect considers

c.*De stelling waar hij alle argumenten onjuist

The thesis where he all arguments incorrect

$\underline{t}$ tegen vindt against considers

d. De stelling waar hij alle argumenten $\underline{t}$ tegen The thesis where he all arguments against onjuist vindt incorrect considers

These facts constitute an argument both for the SC analysis and for the reanalysis rule. If the bracketed part of the a-examples were not a se, we would predict the c-examples to be grammatical, since no difference is predicted to occur between these cases and sentences like (65).

(65)a. Hij heeft over dit onderwerp met Harry gepraat He has about this subject with Harry talked b.*Het onderwerp waar hij $t$ over met Harry gepraat heert The subject where he about with Harry talked has c. Het onderwerp waar hij met Harry $t$ over gepraat heeft The subject where he with Harry t about talked has

In (65) there is no se and consequently the stranded preposition appears adjacent to the verb, as required by the Gap Condition. The difference between (63)\&(64) and (65) can be explained on the basis of the assumption that the sentences in (63)\&(64) contain a SC, 
while there is no se in (65).

It is not enough to assume that the sentences in (63)\&(64) contain a se. The contrast between the b,c-examples and the d-examples indicates that stranding of the preposition is restricted to the position immediately preceding the verb and the predicative part of the SC. The Gap Condition requires the pp containing a stranded preposition to be canonically governed by $\mathrm{V}$. This can only be the case if the verb and predicative part of the pp constitute a verbal unit that governs the PP. Consequently, both a se analysis and a standard non-Se analysis fail to account for the stranding facts in (63)\&(64) and (65). What is needed is a rule that creates a verbal unit. This rule cannot be free, to the extent that every constituent preceding the verb may be incorporated. It must be formulated in such a way that it applies to the predicative part of se's only. That is precisely the reanalysis rule we need in order to provide an account of the problematical sentences in this section.

-The second argument is related to the fact that the ordering of constituents in the so-called middle-field of the Dutch sentence (the part between subject and verb) is relatively free. In 1.5 .2 the relative freedom within the middle-field was argued to be a consequence of $\mathrm{S}$-internal adjunction. However, the position of the predicative part of a se is not free at all. It has to appear left-adjacent to the verb. This is shown in (66).

(66)a. Ik heb (gisteren) over dit onderwerp(gisteren)

I have yesterday about this subject yesterday

met Harry (gisteren) gesproken

with Harry yesterday talked

b. Ik heb (gisterenl dit boek (gisteren) in de kast

I have yesterday this book yesterday in the bookcase

(*gisteren) gezet

yesterday put

c. Jan zegt dat hij (altijd) mijn argumenten

John says that he always my arguments

(altijd) onjuist (*altijd) vindt

always incorrect always considers 
While the position of the adverb gisteren is completely free in (66a), it is clear from $(66 b, c)$ that no adverb can appear between the predicative part of the SC and the verb. This suggests that the verb and the predicative part of the SC constitute an impenetrable unit. [11].

- A further argument in favour of reanalysis is taken from Hoekstra(19841. Hoekstra argues for a reanalysis of verb and predicative part of the SC in order to account for observations regarding the formation of verbal compounds in Dutch. Contrary to English, Dutch allows the formation of verbal compounds if the left-hand member is the predicative part of a SC. Examples are given in (67).

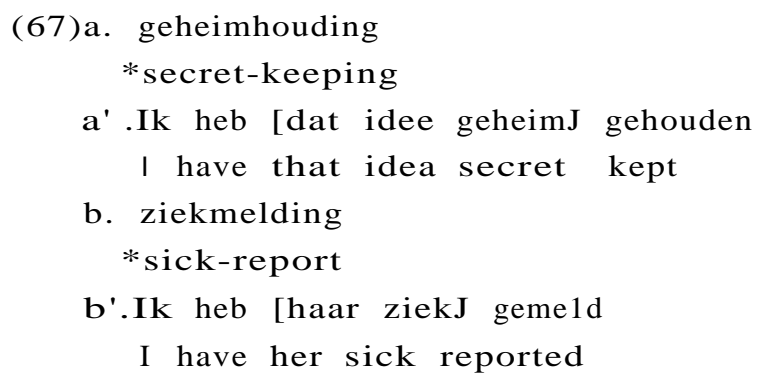

Roughly, the impossibility of such verbal compounds in English can be accounted for by claiming that verbal-compound formation is restricted to arguments of $\mathrm{V}$. Within the se theory the predicative part of the se is not an argument of V, but the whole SC is. To account for the grammaticality of such verbal compounds in DutCh, Hoekstra argues that the se is broken up by reanalysis, which creates a complex consisting of the verb and the predicative part of the SC. After reanalysis a verbal compound can be formed. Such a reanalysis operation is not possible in English, since this operation requires adjacency of verb and predicative part of the se, which requirement is met in Dutch, but not in English.

Given this argumentation, it seems to be correct to assume that in Dutch a rule of reanalysis is able to create a verbal unit consisting of the verb and the predicative part of a se. When we 
turn back to the subject of se's with a propositional external thematic role, a contradiction between theory and facts is no longer apparent. After reanalysis, a postverbal $S^{\prime}$ can be an argument of the complex V. If that is the case, we expect subjectless sentences of the type as exemplified in (56) and (57) to occur and we expect wh-extraction from $S^{\prime}$ to possible only if $S^{\prime}$ appears in A_position, i.e. if het is not present (cf.(58)\&(59)).

Up to this point it has been argued that the occurrence of het is optional in the following configurations:

passives of verbs with a sentential object

- raising verbs with a sentential object

raising verbs with a SC containing a propositional subject

Consequently, it is predicted that the same range of phenomena can be observed in a configuration where a passive verb takes a SC complement that has a propositional subject. This is indeed the case. Het may be present as the SC subject. In that case it has to be moved to the subject position of $S$ in order to get Case, as shown in (68). If the postverbal $S^{\prime}$ is an argument of the reanalysed verbal complex, the subject position of $S$ will remain empty, as in (69). Wh-movement from the $S^{\prime}$ is predicted to be possible only if het is absent, i.e. if $S^{\prime}$ occupies an A-position. This is illustrated in (70) and (71).

(68)a. Het wordt door iedereen vervelend) gevonden It is by everyone annoying considered

dat Jan dat gezegd heeft

that John that said has

b. Het wordt [ $\underline{t}$ geheim] gehouden dat Jan dat

It is secret kept that John that

gezegd heeft

said has

(69)a. Door iedereen wordt vervelend gevonden dat Jan By everyone is annoying considered that John

dat gezegd heeft

that said has

b. Er wordt geheim gehouden dat Jan dat gezegd heeft

There is secret kept that John that said ha 
(70)a.* Wat wordt het door iedereen vervelend gevonden What is it by everyone annoying considered dat Jan $t$ gezegd heeft? that John said has

b.*Wat wordt het geheim gehouden dat Jan $t$ gezegd heeft? What is it secret kept that John said has

(71)a. Wat wordt door iedereen vervelend gevonden Wat is by everyone annoying considered dat Jan $t$ gezegd heeft? that John said has

b. Wat wordt er geheim gehouden dat Jan $t$ gezegd heeft? What is there secret kept that John said has

This concludes our discussion of het in the SC-construction. The facts discussed in this section can be brought into line with the general theory developed in this chapter if we assume that there exists a rule of reanalysis in Dutch that is able to construe a verbal complex consisting of the verb and the predicative part of a se. Independent evidence in favour of such a reanalysis rule has been presented.

In the next section, I shall turn to the presence or absence of 'dummy'-het in constructions with ergative verbs.

\subsection{HET and ergative verbs}

It has been argued that the class of intransitive verbs is not a coherent class, but rather a class that has to be divided in 'unergative' and 'unaccusative' verbs (cf.Perlmutter 1978, Burzio 1981). Roughly, unergative verbs are verbs that assign an external thematic role, while unaccusative verbs do not. Given the generalization that verbs that do not assign an external thematic role are not able to assign Case to their object -the well-known Burzio Generalization- the internal NP-argument of unaccusative verbs has to be moved to subject position in order to receive Case. The Burzio generalization not only applies to a subclass of the intransitive verbs but also to passive and raising verbs. The various subtypes of verbs within the class of intransitive verbs 
can be motivated on the basis of their differential properties. With reference to Dutch, this subject is dealt with in Den Besten(1g82) and Hoekstra(1g84).

I shall not discuss the subject of the ergative hypothesis in any detail, but rather concentrate on those aspects of this construction that are relevant to the topic under discussion. Hoekstra argues convincingly that there are four properties that distinguish the unaccusative verbs from unergative ones. Unaccusative verbs can have no agentive subjects, they cannot be passivized, they select the perfect auxiliary zijn (to be) and they allow participle-adjective conversion. Unergative verbs may have an agentive subject, they can be passivized, they select the perfect auxiliary hebben (to have) and they do not allow participle-adjective conversion. As far as these aspects are concerned unergative intransitive verbS are in all relevant respects similar to regular transitive verbs. These properties are illustrated in (72).

(72) unergative verbS:

a. agentive subject

Jan lacht

John laughs

b. passive

Er wordt gelachen

There is laughed

c. perfective auxiliary hebben (to have)

Jan heeft gelachen

John has laughed

d. no participle-adjective conversion

* de gelachen jongen

the laughed boy 
(73) unaccusative verbs:

a. non-agentive subject

Jan sterft

John dies

b. no passive

*Er wordt gestorven

There is died

c. perfective auxiliary zijn (to be)

Jan is gestorven

John is died

d. participle-adjective conversion

de gestorven jongen

the died boy

These properties divide the class of intransitive verbs in two. The subject of the unergative verb is in all relevant aspects similar to the subject of transitive constructions whereas the subject of unaccusative verbs has several properties in common with the object of transitive verbs and is in most respects similar to the subject of passive or raising constructions. This difference is structurally accounted for by assuming that subjects of unergative and transitive verbs are D-structure subjects while subjects of unaccusative verbs are D-structure objects.

It will be clear that the latter construction, i.e. the construction with an unaccusative verb, is relevant our purposes. We expect the 'resumptive pronoun' het to show up as the surface subject and we expect corresponding subjectless sentences. The pattern that we expect to emerge in these cases is exactly the same as in the raising construction and the passive construction discussed in the preceding sections. If an unaccusative verb selects a propositional thematic role, it may optionally be assigned to NP or S'. If it is assigned to NP, the pronoun het will appear, which has to be moved to subject position in order to get Case. If the propositional role is assigned to $\mathrm{S}^{\prime}$, the sentence will be subjectless since there is no NP that has to be moved to subject position. Accordingly, wh-movement from $S^{\prime}$ is allowed only if the $S^{\prime}$ appears in an A-position. I shall demonstrate that this is indeed the case. The verb bevallen (to please) is an 
unaccusative verb according to all the criteria presented above. It does not have an agentive subject (74a), it cannot be passivized (74b), it selects the perfect auxiliary zijn (74c) and it allows adjective-participle conversion (74d).

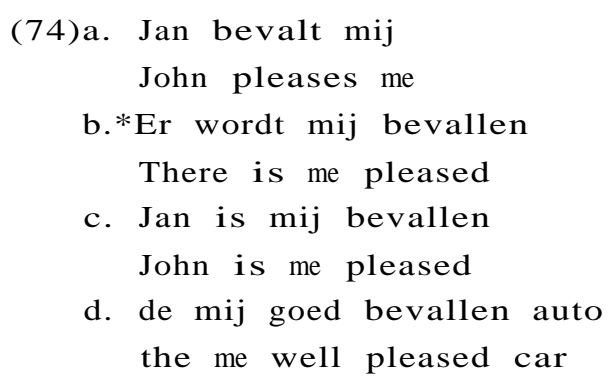

The verb bevallen may also select a propositional internal argument and should therefore be able to display the predicted properties. This is illustrated in (75) and (76)

\{75)a. Mij bevalt het niet dat Jan dat gezegd he eft Me pleases it not that John that said has

b. Mij bevalt niet dat Jan dat gezegd heeft Me pleases not that John that said has

(76)a.*Wat bevalt het jou niet dat Jan $t$ gezegd heeft? What pleases it you not that John said has

b. Wat bevalt jou niet dat Jan $\underline{t}$ gezegd heeft? What pleases you not that John said has

From this we may conclude that, as predicted, these constructions do not differ in any significant way from the constructions discussed in the preceding sections and thus corroborate our analysis.

\subsection{Psychological verbs}

The analysis presented in the previous section seems to be contradicted by the fact that the same range of data can be observed with verbs that do not satisfy all the criteria fOl being 
unaccusative. In particular, there is one class of verbs in Dutch, the so-called 'psychological verbs' (Den Besten 1982), that appear to contradict the analysis presented thusfar. Some instances of this class are verbazen (to surprise), verwonderen (to astonish), interesseren (to interest) and ergeren (to irritate). These verbs allow the appearance of het, the occurrence of subjectless sentences and extraction from $S^{\prime}$ if het is not present. In these respects they are similar to the unaccusative verb bevallen. This is illustrated in (77) and (78).

$$
\begin{aligned}
& \text { (77)a. Mij ergert het dat Jan dat gezegd heeft } \\
& \text { Me irritates it that John that said has } \\
& \text { b. Mij ergert dat Jan dat gezegd heeft } \\
& \text { Me irritates that John that said has } \\
& \text { (78)a.* Wat ergert het jou dat Jan } t \text { gezegd heeft? } \\
& \text { What irritates it you that John said has } \\
& \text { b. Wat ergert jou dat Jan } t \text { gezegd heeft? } \\
& \text { What irritates you that John said has }
\end{aligned}
$$

Moreover, these verbs do not have an agentive subject, which is a property of unaccusative verbs. This is illustrated in (79).

(79)a. Zijn gedrag ergert mij

His behaviour irritates me

b. Dat boek interesseert mij

That book interests me

On the other hand, these verbS show three properties of unergative verbs.

- they select the perfective auxiliary hebben instead of zijn, as shown in $(80)$.

(80)a. Zijn gedrag heeft/*is mij geergerd His behaviour has/is me irritated

b. Dat boek heeft/*is mij geinteresseerd That book has/is me interested 
- with respect to participle-adjective conversion they pattern with unergative, transitive verbs, as is illustrated in (81)-(83)

(81) unergative verbs

a. De jongen koopt een boek

The boy buys a book

b. Het gekochte boek

The bought book

c. ${ }^{*}$ De gekochte jongen

The bought boy

(82) unaccusative verbs

a. Het experiment bevalt de studenten goed

The experiment pleases the students well

b. \#e goed bevallen studenten

the well pleased students

c. het goed bevallen experiment

the well pleased experiment

(83) psychological verbs

a. Zijn gedrag ergert de leraar

His behaviour irritates the teacher

b. de geergerde leraar

the irritated teacher

c.*het geergerde gedrag

the irritated behaviour

the third argument in favour of an unergative status of psychological verbs is that these verbs appear to allow passivization, as shown in (84).[12 J.

(84)a. Ik wordt daardoor geergerd

I am that-by irritated

b. Ik wordt daardoor gelnteressserd

I am that-by interested

The data in (77)-(84) appear to be contradictory. From (80)-(84) it seems to follow that psychological verbs are unergative, whereas the data in (77)-(79) can only be explained if they are unaccusative verbs. 
It is important to observe that these psychological verbs show up in another, completely different, configuration. The objects in (79) may become subjects not only by the application of passive, as is illustrated in (84), but also in the construction in which an inherent reflexive pronoun shows up. In this configuration the S-structure subject of (79) appears as a prepositional object. This is shown in (85).

(85)a. Ik erger mij aan zijn gedrag

I irritate me to his behaviour

b. Hij interesseert zich voor dat boek

$\mathrm{He}$ interests himself for that book

In the optimal case, (79) and (85) Should in some way be relatable to each other. If the sentences in (79) were just regular transitive structures, we would require two different operations that both have the effect of absorbing the external thematic role. Since -in accordance with the Burzio generalization- the effect of the absorption of an external role is that the verb is no longer able to assign Case, the object must be moved to subject position. One of these operations is passive (cf.(84)) and the other results in sentences like those in (85). There are various objections to such a proposal. First, it is not clear why the operation that applies to (79) in order to derive (85) would be restricted to psychological verbs only, i.e. why is (86b) ungrammatical as an alternative to $(86 a) 7$

(86)a. Jan wordt door mij geslagen

John is by me hit

b.*Jan slaat zich aan/voor/... mij

John hits himself to/for me

A further argument against a passive-like derivation of (85) can be found in the fact that in sentences such as (85) the corresponding subject of (79) is contained in a PP, which itself shows all the characteristics of a subcategorized PP and thus of a constituent belonging to the argument projection. The selection of the 
preposition in (85) is fully determined by lexical properties of the verb, whereas in the case of passives the original external argument can only be contained in a by-phrase. For instance, ergeren selects a pp headed by the preposition aan (to), interesseren selects voor (for) and verbazen selects over (about).

What I would like to suggest is that these verbs are unergative with respect to Case marking and unaccusative with respect to $\mathrm{Q}$-selection. This idea is in some way reminiscent of Den Besten's proposal concerning these verbs. It may seem as if $I$ am trying to solve a contradiction by postulating another. However, if it can be shown that it is structurally possible for a verb to be unaccusative and unergative, we are able to relate the apparently contradictory behaviour of these verbs to this apparently contradictory structure. One important point of the analysis is that it allows us to relate the sentences in (85) to those in (79).

Suppose the D-structure configuration of a psychological verb and its two arguments is as depicted in (87). The crucial point is that the verb does not assign an external role, but two internal roles only.

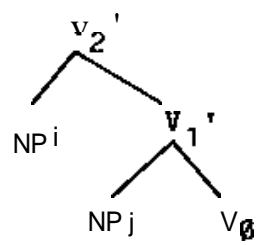

The unergative and the unaccusative properties of psychological verbs can be accounted for on the basis of (87). Suppose that the verb $\left(V_{\emptyset}\right)$ is able to assign structural Case to $\mathrm{NP}_{j}$ and that $\mathrm{NP}_{i}$ has no inherent case. If this is true, sentences of the type in (79) can be derived by movement of $\mathrm{NP}_{\mathrm{i}}$ out of the argument projection in order to receive Case from INFL. The derived structure of (79a) is depicted in (SS). 
$(88)$

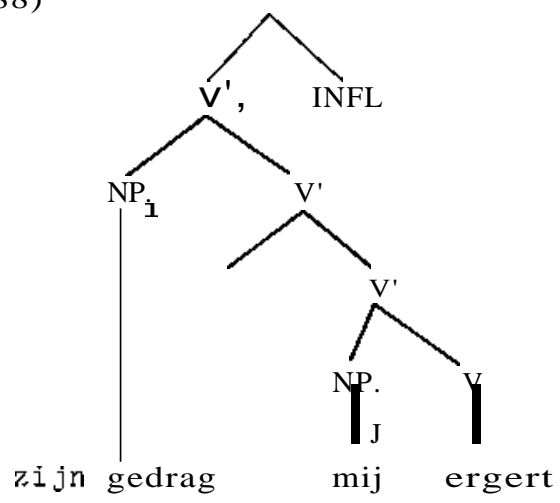

Given the fact that $\mathrm{NP}_{\mathrm{J}}$ is a regular object in all relevant respects, we expect participle-adjective conversion to be possible if the participle is an adjective with respect to $\mathrm{NP}_{j}$, as in (83b), just as in regular transitive constructions, as in (81b).

The occurrence of het and the related phenomena presented in (77)-(78) follow from this analysis. In (77a) \& (78a), het is an internal argument, c-commanded by a postverbal $S^{\prime}$ in adjunct position. In (77b) \& (78b) $S^{\prime}$ is assigned an internal thematic role by the verb directly. As extraction takes place from $S^{\prime}$ in argument position only, the contrast in (78) can be explained.

If we assume Hoekstra's(1984) theory that the auxiliary verb zijn is selected if the verb does not assign an external thematic role, while hebben is selected otherwise, it is predicted that these psychological verbs select zijn, contrary to fact. However, if zijn is selected, a Case problem arises. Neither the verb zijn nor the participle are able to assign structural Case to the object. We are left with a construction with two NPs and only one Case (nominative) available. In order to solve the Case problem it is necessary to select hebben. This problem with respect to the selection of the auxiliary verb is exactly the same as the problem with respect to Burzio's generalization. The verb in (87) is able to assign structural Case, although it does not select an external thematic role. With respect to Case marking these verbs are unergative, whereas with respect to $Q$-selection they appear to be unaccusative. As a tentative solution to this problem I would like to suggest that these verbs are unergative in the sense that they 
are able to assign Case to their structural object (NP $\left.{ }_{j}\right)$, and assign a thematic role external to the minimal argument projection $\left(V_{1}\right)$. They are unaccusative in the sense that these verbs are unable to assign Case to $\mathrm{NP}_{\mathrm{i}}$, which is internal to the maximal argument projection $\left(\mathrm{V}_{2}\right)$. In order to solve the Case problem mentioned above and in accordance with their unergative property these verbs select the perfective auxiliary hebben.

A strong argument in favour of (87) as the D-structure representation of (79) can be derived from the phenomenon of NP-inversion, which will be discussed in more detail below. As observed by several people (e.g. Den Besten 1982, Hoekstra 1984) NOM-DAT Inversion is possible only if the nominative NP is a D-structure object. If the S-structure subject in (79) is a D-structure external argument we do not expect Inversion to be possible. However, if (87) is the correct D-structure configuration we expect Inversion to occur. It is indeed the case that Inversion is possible in these constructions, as is shown in (89).

(89)a. dat hem dat gedrag irriteerde that him that behaviour irritated

b. dat mij dat boek interesseert that me that book interests

The occurrence of inversion with these psychological verbs is particularly interesting since it does not seem to involve NOM-DAT inversion, but rather NOM-ACC inversion, as becomes clear from the German counterparts of the sentences in (8g) (cf.Den Besten 1982, Lenerz 1977).

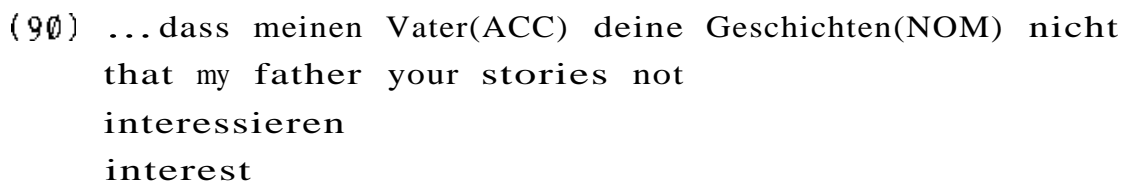

On the basis of these inversion phenomena Den Besten argues that psychological verbs select two internal arguments and assign Case only once. This is exactly what has been proposed in (87).

If (87) is the correct representation of sentences of the type 
in (79), it is somewhat unexpected to find passive variants of the type in (84), since passivization involves two related properties. The external thematic role is absorbed and the verb is not able to assign Case. In this case it is not obvious that an external thematic role is present. There are two ways to deal with this problem. First, we may claim that one of the internal arguments is to some extent external, i.e. external to the minimal argument projection. If this argument ( $\mathrm{NP}_{\mathrm{i}}$ in (87») can be absorbed, the sentences in (84) can be regarded as passives. Alternatively, it can be argued that the sentences in (84) are not really passives. One argument in favour of such an analysis follows from the fact that the passive auxiliary worden(to be) can be paraphrased by the verb raken(to get, to become), as in (91), which is a copula verb.

(91) Ik wordt/raak daardoor geergerd I an/get that-by irritated

An additional argument in favour of a non-passive analysis of and (91) concerns the fact that the door(by)-phrase is not a regular passive door-phrase. The occurrence of this $p p$ in this construction is unrelated to the fact that the sentence is passivized, as is shown in (92).

(92) Hij ergert mij door zijn gedrag He irritates me by his behaviour

If it is true that the passive auxiliary is in fact a copula and the passive door-phrase is an adverbial pp with a regular causal interpretation, not much evidence in favour of passive construction is left. They are just instances of a copula verb followed by a Small Clause, the head of which is an adjective (geergerd). I shall assume that this approach to the sentences in (84) is the correct one.

This analysis allows us to provide an explanation for the related construction with a reflexive pronoun, given in (85), repeated here. 
(85)a. Ik erger mij aan zijn gedrag

I irritate me to his behaviour

b. Hij interesseert zich voor dat boek

$\mathrm{He}$ interests himself for that book

This construction shows many similarities with the impersonal construction in FrenCh (impersonal se) and Italian (impersonal si) (Belletti 1980, Chomsky 1981, Burzio 1981 a.o.). If we assume that the reflexive pronoun absorbs objective Case, the object has to be moved in order to receive Case. If this is the correct derivation, no Case is available for the other internal argument. A preposition has to be selected in order to assign Case. Because the NP is internal, the selection of the particular preposition can be made dependent on the verb, i.e. the pp will show up as a subcategorized PP. This is shown in (93).
(93)a. Hij verbaast zich over mij
He surprises himself about me
b. Hij ergert zich aan mij
$\mathrm{He}$ annoys himself to me

As was indicated above the selection of the preposition is indeed determined by the choice of the particular psychological verb.

The question might be raised why the impersonal construction shows up with all psychological verbs, and why it is not productive with regular transitive verbs. I would like to suggest that the lexical rule inserting zich is able to absorb Case. but differs from passive in that it is not able to erase the external argument. If this is correct, we expect the impersonal construction to show up only in those configurations in which the verb assigns structural Case, but does not project an external argument.

In this respect it is interesting to note that the regular middle construction in Dutch differs from the construction in (85). A weak reflexive or reflexive clitic is required in the construction under discussion, as in (95), whereas the strong reflexive (or no reflexive at all) is present in middles of the type illustrated in (94). 
(94) Dit boek verkoopt zichzelf/*zich This book sells itself

(95) Jan ergert zich/*zichzelf aan mij John irritates himself to me

In middle constructions of the type in (94), the external argument is erased as a consequence of a lexical operation. If the construction with psychological verbs in (79) were similar to regular unergative verbs, we expect the construction of the type in (85) to be a middle construction, in which case it would pattern with the middle construction in (94). We would have no explanation for the strong/weak reflexive distinction illustrated in (94)-(95). Moreover, we would have no explanation for the possibility of the supposed external argument to appear in a pp in (95) but not in (94), as is shown in (96).

(961*Dit boek verkoopt zichzelf door/voor/aan/... mij

This book sells itself by/for/tal ... me

I shall conclude this section with a survey of the different construction types in which the psychological verb interesseren occurs. This verb differs from the other psychological verbs in that it appears in a regular unergative pattern. An example is given in (97).

(97) Zijn vrienden hebben hem voor meisjes geinteresseerd His friends have him for girls interested

It is clear that zijn vrienden in (97) is an external argument. Contrary to the constructions in (89), NP-Inversion is impossible, as shown in (g8).

(98)*dat hem zijn vrienden voor meisjes hebben geinteresseerd that him his friends for girls have interested

The presence of an external argument can be integrated in the theory presented above quite easily. The only thing we have to add 
to the structure in (87) is an external argument. It follows that the underlying structure of (98) can be represented as in (99).

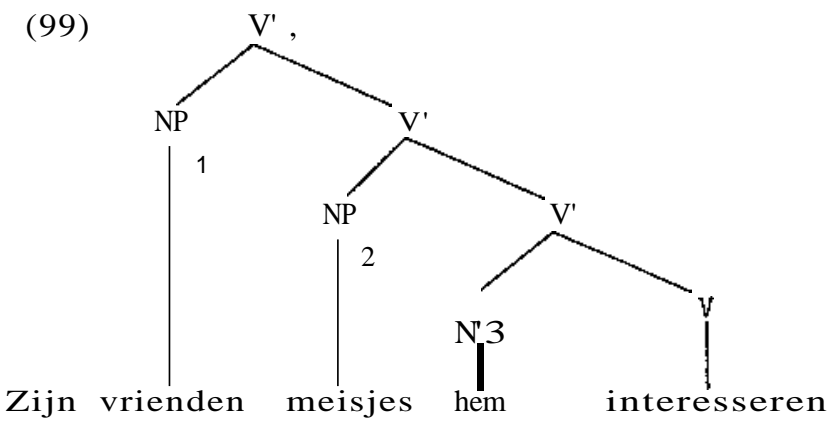

Given the fact that there are three NPs and only two structural Cases the structure has to be saved by the insertion of a preposition, as in (97). As expected, this structure can be given a normal passive variant, as in (100).

(100) dat hij door zijn vrienden voor meisjes was/werd geinteresseerd

that he by his friends for girls was interested

If the external argument (NP1) is absent, which appears to be a lexical property of psychological verbs, $\mathrm{NP}_{2}$ can receive nominative Case by movement to a position in which it is governed by INFL. Given the fact that Inversion is possible, two orders, NP2-NP3 and $\mathrm{NP}_{3}-\mathrm{NP}_{2}$, appear, as is shown in (101).

(101)a. dat meisjes hem interesseren that girls him interest

b. dat hem meisjes interesseren that him girls interest

Given that the external argument may be absent, the reflexive pronoun zich can be inserted. In that case structural Case assigned by the verb is absorbed. $\mathrm{NP}_{3}$ has to be moved outside the argument projection to receive nominative Case and the preposition voar appears, as in (97), to assign Case to $\mathrm{NP}_{2}$, as in (lrli2). 
(102) dat hij zich voor meisjes interesseerde that he himself for girls interested

Finally, the participle geinteresseerd may be the head of a small clause AP. In that case $\mathrm{NP}_{3}$ has to be moved out of argument projection to receive Case. In exceptional Case marking constructions NP3 remains within the small clause, as in (103a). If the governing verb is not able to assign Case, as in copula constructions, $\mathrm{NP}_{3}$ has to be moved out of the small clause to a position in which it may receive Case, as in (103b).

$$
\begin{aligned}
& \text { (103)a. dat hij hem in meisjes gelnteresseerd vindt } \\
& \text { that he him in girls interested considers } \\
& \text { b. dat hij in meisjes gelnteresseerd is } \\
& \text { that he in girls interested is }
\end{aligned}
$$

It is interesting to observe that the preposition introducing NP2 is in in these cases. Obviously, the adjective geInteresseerd selects a different preposition from the verb interesseren, which selects voor as in (97) and (102). This difference allows us to present a minimal pair, as in (104).

$$
\begin{aligned}
& \text { (104)a. Hij is (door mij) voor meisjes gelnteresseerd } \\
& \mathrm{He} \text { is (by me) for girls interested } \\
& \text { b. Hij is (*door mij) in meisjes geinteresseerd } \\
& \mathrm{He} \text { is (by me) in girls interested }
\end{aligned}
$$

(104a) is a passive sentence, whereas (104b) is a copula construction. This difference corresponds to a difference in interpretation. In (104a) an agent is implied and can be added in a door-phrase, while no such implication is present in (104b).

In the following section, I shall discuss the so-called Nominative-Dative Inversion. This construction provides further eVidence that psychological verbs belong to the class of ergative, raising and passive verbs. 


\subsection{Inversion phenomena}

As has been noted in the literature (Koster 1978a. den Besten 1981,1982, Everaert 1982 and Hoekstra 1984), an indirect object may precede a subject in subordinate clauses in Dutch. [13J. This phenomenon is illustrated in (105).

(105) Jan zei dat hem(IO) die zaak(Subj) niet beviel John said that him this matter not pleased

As will become clear, this phenomenon is restricted to specific constructions. We might propose a rule of indirect object preposing to account for sentences like (105) (cf.Koster 1978a), but the application of this rule must then be restricted to specific configurations. For instance. nominative-dative inversion is not allowed in ordinary constructions with a bitransitive verb, shown in (106).

(106) *Jan zei dat hem Marie een boek had gegeven John said that him Mary a book had given

As has been observed in Den Besten(1982) and Hoekstra(1984) nominative-dative inversion is possible only in those constructions in which there is no external argument. Consequently, this construction shows up in passives of bitransitive verbs. as in (107), raising constructions, as in (108). and with ergative verbs allowing an indirect object, as shown in (109).

(107)a. Jan zei dat hem een boek gegeven zou worden John said that him a book gi.ven would be

b. De minister wil niet dat hem een prijs The minster wants not that him a prize overhandigd zal worden presented will be

(108)a. Jan zei dat hem die film leuk leek John said that him that movie nice seemed

b. Jan zei dat hem het probleem duidelijk was John said that him the problem clear was 
(169)a. Jan zei dat hem dat boek niet beviel John said that him that book not pleased

b. Jan zei dat hem een ongeluk was overkomen John said that him an accident was happened

In all these cases the D-structure direct object may appear after the indirect object carrying nominative Case.[14J. Interestingly, the same possibility arises with the psychological verbs introduced in the preceding section, as is illustrated in $(110)$.

\section{(110)a. Jan zei dat hem dat boek niet interesseerde John said that him that book not interested \\ b. Jan zei dat hem dat amuseerde John said that him that amused}

If we want to maintain the generalization that can be derived from $(197)-(109)$, i.e. inversion occurs only if there is no D-structure subject, in other words if the verb does not assign an external thematic role. we are forced to assume that the psychological verbs in (110) do not assign an external themati.c role either. This would be a fortunate result in the light of the appearance of het in these constructions as discussed above.

\section{10.1 Previous proposals}

Any account of the inversion construction has to consider the status of the nominative NP in order to explain the contrast between (106) and $(105),(107)-(110)$. Given that the surface subject. the nominative NP, is conceivably a D-structure object in all possible inversion structures, both Den Besten and Hoekstra argue that in these cases the j.nternal argument is left in its original position. This implies that they have to argue in favour of a special procedure in order to allow the structural object of the verb to receive nominative Case. Obviously the nominative NP may receive Case either by movement to subject position, as can be seen i.n the non-inverted counterparts of the sentences given above, or by a special mechanism that makes it possible to assign 
nominative Case to the direct object in its D-structure position. Although both Den Besten and Hoekstra argue that the structural subject position is left empty in inversion structures, their analyses differ with respect to the mechanism that is responsible for the exceptional nominative Case assignment.

In Den Besten (1982) a principle called 'chain-government' is introduced. The definition is given in (111).

(111) Chain Government (Den Besten 1982)

a. If $\mathrm{NP}_{\mathrm{i}}$ is governed by a category $\alpha$ which cannot or may not assign Case, $\mathrm{NP}_{\mathrm{i}}$ will acquire Case from the first Case-assigner up which it is chain governed by

b. $\alpha$ chain-governs $B$ iff $\alpha$ governs y 1 Y1 governs $\mathrm{Y}^{\prime}, \cdots, \mathrm{y}_{\mathrm{n}-1}$ governs $\mathrm{Y}_{\mathrm{n}}{ }^{\prime}$ and $Y n$ governs $\beta \quad(n>11$

This principle implies that the verb that has no Case-assigning property of itself may inherit this property from its governor.

Hoekstra on the other hand argues that the NP in object position gets Case by coindexation with a dummy pronoun in subject position. By means of a co-superscripting device the object $\mathrm{NP}$ in inversion structures is co-superscripted with the empty dummy in subject position.

I shall present a different solution to the inversion problem, which requires no exceptional case-marking procedure at all. Before presenting this analysis, I shall discuss some of the consequences of Den Besten's and Hoekstra's analyses. In his discussion of Den Besten's proposal Hoekstra points out that chain-government cannot cope with a comparable Case problem in the case of an er(therel-insertion construction in which the subject is 'demoted'. as in (112),

(112) Hij zei dat er hem niemand/*Marie een zoen heeft gegeven $\mathrm{He}$ said that there him nobody/Mary a kiss has given

In this sentence the subject niemand (nobody) follows the indirect object hem. The verb geven (to give) assigns an external thematic 
role. If the subject carrying this role is indefinite. it may appear after the indirect object. Although the two constructions differ to the extent that in the inversion cases discussed above the nominative NP remains in object position whereas in (112) the indefinite $\mathrm{NP}$ is adjoined to $\mathrm{V}^{\prime}$ according to Hoekstra, the Case-assigning problem in the two constructions can be generalized by making use of a co-superscripting device. Such an analysi.s is not available in Den Besten's approach. At the same time, co-superscripting allows a straightforward account of the agreement in number between subject and verb in inversion constructions. Hoekstra proposes the following formulation of co_superscripting:

(113) Co-superscripting (Hoekstra 1984)

Co-superscribe er and an NP c-commanded by

er if this NP has phonetic features and no Case.

Copy the number of the NP in the feature matrix of er.

If we use this version of co-superscripting. an explanation can be given for the problems of Case assignment and subject-verb agreement in the following two contexts.

(114)a... dat er ${ }^{\mathrm{i}}$ mij [iets leuks]i overkwam

... that there me something funny occurred

b.... dat er ${ }^{\mathrm{i}}$ mij [enkele mensen]i hun boek geven

...that there me some people their book give

In (114a) the NP iets leuks is in direct object position, its D-structure position in which it cannot be assigned Case by the verb directly. Nominative Case assignment and subject-verb agreement are determined by co-superscripting. In (114b) the NP enkele mensen is the external argument which is adjoined to $\mathrm{V}^{\prime}$. Again nominative Case assignment and agreement are determined by co-superscripting.

In view of the fact that the occurrence of er is optional in both sentences in (114). Hoekstra haa to assume that co-superscripting is not restricted to sentences with er in subject position, but is also applicable if there is no lexical subject in 
sUbject position. In that case there is co-superscriptine between an empty dummy pronoun and the subject NP. Hoekstra's approach has three advantages: he is able to relate the two inversion structures to one exceptional nominative Case-marking procedure; in his theory there exists an explicit relation between nominative Case and subject verb agreement: finally, it allows him to define the notion subject structurally as $[\mathrm{NP}, \mathrm{S}]$ in all cases.[15J. On the other hand, his approach forces him to postulate the occurrence of dummy pronouns in all instances in which the lexical subject is not the first constituent in $\mathrm{S}$. This assumption is not independently motivated but is forced by theoretical considerations only.

In Den Besten's approach there is no such problematic claim regarding empty dummy pronouns. If er is present. as in (114), er occupies the subject position, whereas in case er is left out the subject position is filled by the indirect object. However, in his account the relation between nominative Case and agreement can be stated only indirectly. Whereas the subject in inversion structures is governed and Case-marked by the verb via chain-government, the agreement relation between INfL and subject is not formally expressed. Nevertheless, it seems to be clear that agreement in Dutch is determined by Case only. If there is a nominatIve NP in the sentence it agrees with the finite verb. Neither position of the NP nor thematic role are relevant in this respect. This can be seen very clearly from the occurrence of indirect object passives. If the indirect object retains its inherent oblique Case, it does not trigger agreement (115a). If the indirect object is assigned nominative Case in the same sentence. the verb agrees with the indirect object (115b).

$$
\begin{aligned}
& \text { (115)a. ...dat ons werd/*werden verzocht om weg te gaan } \\
& \text {... that us was/were requested for away to go } \\
& \text { b. ...dat wij *werd/werden verzocht om weg te gaan } \\
& \text {...that we was/were requested for away to go }
\end{aligned}
$$

(11521) and (115b) are structurally alike. They only differ with respect to the fact that the inherent oblique Case of the indirect object is overruled by the structural nominative Case in (115b). The exceptional nature of this "overruling Case" may then account 
for the rather marginal status of (115b), which is constrained by several superficial factors and subject to individual variation (cf.Den Besten 1981, Everaert 1982, Hoekstra 1984). What is relevant here is the fact in (115a) the unmarked third person singular is required while the nominative Case in (115b) forces agreement to take place.

In summary, an optimal theory of inversion phenomena should have the following properties:

- the class of verbs that allow inversion to take place is structurally different from the class that does not allow inversion.

- there is a uniform proces of nominative Case assignment in all instances of inversion structures.

- the theory allows us to express the fact that nominative Case assignment and subject-verb agreement are closely related.

- the theory does not force us to adopt the existence of empty dummy pronouns.

\subsubsection{Inversion and the Extended Projection Principle}

In what follows I shall argue that the theory put forward in the preceding chapters can deal with the inversion phenomena without having recourse to additional principles. There is no need for either chain-government or co-superscripti.ng. Crucial to the theory developed so far is the assumption that there is no structural subject position. A subject is present only if the verb (or the predicate) projects an external thematic role. From this perspective there is no longer an asymmetry between subject and object. Depending on lexical properties, the verb mayor may not project an internal or external thematic role. If this can be shown to be correct, we are one step further in the elimination of the base rules, whi.ch is a desirable result since it reduces the degree of stipulation necessary within the grammar. This also implies the elimination of the Extended Projection Principle (Chomsky 1982). If the subject is treated just like the object. the Projection Principle is sufficient. The question is then how to account for 
those properties that gave rise to the Extended Projection Principle. With respect to Dutch this question has already been partially answered. We have seen in the preceding sections that there are lots of sentences without a lexical subject. They can be found in those cases in which the verb does not select an external argument and there is no internal NP-argument that has to receive nominative case. Given this regularity it seems to be rather unproductive to assume the existence of empty dummy pronouns, a category that is not visible nor interpretable. If it is correct that het is not a dummy pronoun, as has been extensively motivated in this chapter, this approach reduces the strength of a theory in which the subject position is considered to be a universal property of sentences even further. The most compelling argument in favour of the Extended Projection Principle is the fact that a dummy SUbject is required if there is no external argument. If in the relevant cases the dummy pronoun can be shown to be a referential expression, the argument loses its force. In the following chapter I shall argue that er(there) is not a dummy pronoun either. If this is correct, there are no lexical dummy pronouns in Dutch. This would make the claim of the existence of empty dummy pronouns extremely weak.

Returning now to the inversion sentences under discussion, I shall assume with Den Besten and Hoekstra that they occur in those cases in Which the verb assigns no external thematic role. In accordance with the Burzio generalization, these verbs are not able to assign Case structurally. However, contrary to both Den Besten and Hoekstra, I do not consider these objects to occupy their original D-structure position in inversion sentences. I shall assume that structural Case-marking always takes place under structural government. Therefore, the nominative $\mathrm{NP}$ in inversion structures, as in $(107)-(110)$, has to be governed by the category that assigns nominative Case. i.e. by INFL. How can this be achieved? Note that it was argued above that there is no structural subject position. This implies that there is no fixed position to which nominative Case is assigned. As soon as the D-structure object is governed by INFL it may get nominative Case. The consequence of having no structural subject position is that there can be no rule moving a constituent into such a position. As a 
consequence NP-movement rules cannot be viewed as moving an object into subject position. From this it follows that derivationally there is no difference between NP-movement and movement to an $A^{\prime}$-position. If this is true, we would expect NP-movement to pattern with adjunction to $A^{\prime}$-position. These processes are similar with respect to their derivation but different with respect to the assignment of Case. This is precisely what I would like to propose. Differences between A-binding and $\mathrm{A}^{\prime}$-binding follow from the fact that in A-binding constructions Case is assigned at a derived position whereas in the case of A'-binding Case is assigned at D-structure position. A theory that is able to capture this distinction has been presented in 1.6. There it has been argued that the referential properties of an NP are determined by Case, in such a way that the position in which an NP gets Case is the position relevant to the referential interpretation. This was called the TR-condition. Let me illustrate this proposal with a simple passive construction.

In the D-structure corresponding to (116). i.e. (117), there is no subject position since no external argument is assigned by the verb (or the predicate).

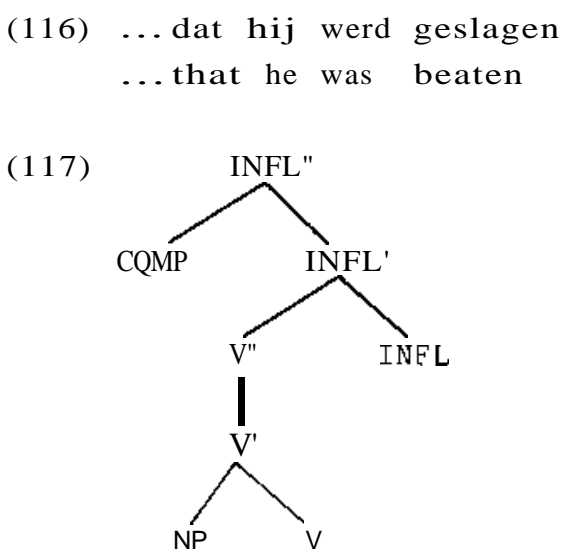

Given its passive properties the verb is not able to assign Case to its structural object. In order to receive Case the NP has to be moved to a position in Which it is governed by a category that is able to assign Case. Since INFL assigns nominative Case, the NP 
will be moved into the domain of government of INFL. It is assumed throughout that government is upward bounded at the level of argument projection ( $\left.X^{\prime}\right)$, while it reaches downward to a domain of another governor (cf.1.2.2). Therefore. any movement of NP out of $\mathrm{V}^{\prime}$ in (117) brings the $\mathrm{NP}$ out of the government domain of $\mathrm{V}$. If the $\mathrm{NP}$ is moved to a position within $\mathrm{V}^{\prime \prime}$, but outside $\mathrm{V}^{\prime}$, it appears in the government domain of INFL. If there was an NP subject position in (117) ([NP. $\left.\mathrm{V}^{\prime \prime}\right]$ ), movement of the NP in these passive sentences could be substitution. However, if we assume that there is no subject position, the NP should be adjoined to a position higher in the tree. In ch.1.5.2 it has been argued extensively that in Dutch such an adjunction operation to an $A^{\prime}$-position $j, s$ independently motivated in order to account for the occurrence of parasitic gaps and the transparency of Small Clauses and Exceptional Case marking constructions. Suppose that in these passive sentences the same adjunction operation can be applied. The object NP will be moved into a position in which it is governed by INFL, in the direction in Which INFL assigns Case to regular subjects that are generated as external arguments. In these cases the object NP has to be moved in order to receive Case. while in the case of regular adjunction movement is optional and is triggered by pragmatic factors or the licensing of parasitic gaps.

The theory expounded in the previous sections allows us to get rid of the asymmetric notion of argument position or A-position. This notion is defined as a position "in which an argument such as a name or a variable may appear in D_structure; it is a potential theta-position. The position of the subject mayor may not be a theta-position, depending on the properties of the associated vr. Complements of $X^{\prime}$ are always theta_positions. with the possible exception of idioms"(Chomsky 1981,p.47). Why should there be an asymmetry between subject and object? Only if a lexical category selects a complement is there an A-position, the object position, while the subject position is always an A-position whether or not the VP selects an NP subject. This asymmetry is Considered to be necessary to account for passives and raising constructions since in those cases the subject position (A-position) is necessarily not a thematic position. However, if the preceding analysis of the derivation of a passive construction is correct, we may identify an 
A-position with a theta-position, thereby reducing the redundancy within the theory considerably. Given the fact that the notion theta-position is necessary in any theory to account for the lexically determined selection properties of lexical categories, we do not need the notion argument position any longer. All diferences between A-movement and $\mathrm{A}^{\prime}$-movement, which is a distinction that cannot be made anymore, should follow from other principles of the theory. In fact. all these differences can be made to follow from the only relevant difference between these operations, the position in which Case is assigned to the NP or rather to the chain containing NP and its trace.

A further consequence of this theory is that the notions subject and object do not have any intrinsic content. They may be instantiated to refer to the notion external or internal argument, respectively, but since the latter notions are necessary anyway these grammatical relations are completely superfluous. This implies that grammatical relations cannot be taken as primitives of the theory, a position which is also defended in Williams $(\lg 81, \lg 84)$.

A final consequence is that it is no longer possible to formulate the Extended Projection Principle along the lines of Chomsky(lg82). It has been argued before that there is empirical evidence that the stipulation that clauses contain a subject is unnecessary and leads to awkward concepts like empty dummy pronouns. In the theory defended here, the notion subject is no longer present as a notion Which is distinct from the notion external argument. Either we have to formulate a new principle replacing the Extended Projection Principle in a way compatible with the proposed theory or we may dispense with the Extended Projection Principle in favour of the conceptually more attractive Projection Principle. Given both conceptual and empirical considerations I shall opt for the latter. In that case, the analysis of the occurrence of the so-called dummy subject pronouns will be crucial. If we succeed in showing that there are no dummy subjects, or at least that it is not a general property belonging to Universal Grammar that clauses have a SUbject, we have rather strong evidence favouring the theory defended here.

There arises a potential problem for this analysis, however. 
It appears to predict that extraction from adjuncts is possible. It was argued above that an NP occupying a position outside the argument projection of $\mathrm{V}$ is structurally governed by INFL. This was seen to be a consequence of the government definition adopted here and was argued to be necessary to account for the assignment of nominative Case. Given the fact that INFL governs that NP to the left and canonical government is assumed to be government from right to left in Dutch (cf.ch.1.2.2), the NP moved from the argument projection by adjunction is canonically governed by INFL. An advantage of this consequence of the theory is that it allows us to explain the fact that 'demoted' subjects in er_insertion contexts can be moved by wh-movernent, as shown in (118).

(118)a. Jan zei dat er gisteren niemand in de tuin liep

John said that there yesterday nobody in the garden walked

b. Wie zei Jan dat er gisteren $t$ in de tuin liep Who said John that there yesterday in the garden walked

The indefinite external argument occupies a position outside the argument projection of $\mathrm{V}$, from which posItion it can be extracted since that position satisfies the requirements imposed by the Gap Condition. However. if this is correct it follows that all adjuncts are canonically governed by INFL. That might lead us to expect that extraction from adjuncts is possible. How can we then provide an explanation for the fact that both stranding of prepositional adjuncts and wh-extraction out of sentential adjuncts impossible, as is illustrated in (119)?

(1191a.*De winkel waar ik [t_ in] een boek gekocht heb The shop where I in a book bought have b. *Wat ben je [zonder PRO $\underline{t}$ te zeggen) weggegaan What are you without to say left

Given the fact that the adjunct itself is a g-projection of the governor of the gap and the adjunct is canonically governed by INEL as required by the Gap Condition, the matrix $\$$ ' is a g-projection 
of the governor of the gap. Nothing seems to prevent this movement. In ch.1.5 it was argued that extraction from adjunct clauses is impossible because adjuncts are not governed. It is clear that such an explanation does not hold. Another explanation is called for. Fortunately, such an explanation can be provided without any additional stipulation. Structurally the sentences in (119) are parallel to the English sentence (14b) in 1.2 .3 , repeated here in $(120 \mathrm{~b})$.

(120)a. Which runner do you believe $t$ to have won the race?

b.*Which book do you believe the first chapter of $t$ to be full of lies?

With respect to $(120 \mathrm{~b})$ it was argued that although the matrix $S^{\prime}$ is a g-projection of the governor of the gap, the Gap Condition is violated since the collection of g-projections does not constitute a connected subtree. The reason is that the $S$ in the complement of believe is a maximal projection on the path from the governor of the gap to the antecedent that does not belong to the subtree. It separates the path into two subtrees. In (120a) there is one connected subtree since the lowest maximal projection on the path is the VP dominating believe. In that case it is irrelevant that $S$ does not belong to the path, since the g-projection is a connected subtree anyway. The same line of reasoning is applicable to (119). $S$ is a g-projection of the governor of the gap only if the head of $S$ (i.e. V) is the governor of the gap or the governor of a g-projection of the governor of the gap. Given the fact that adjuncts are not governed by $\mathrm{V}$ since they do not belong to the argument projection of $\mathrm{V}, \mathrm{S}$ can never be a g-projection of the governor of a gap in an adjunct clause. Adjuncts may be canonically guverned only from outside $\mathrm{S}$ by INFL. Any extraction from an adjunct thus violates the requirement that the path from governor of the gap to antecedent must be a connected subtree. At the same time it is predicted that adjuncts themselves may be extracted since the first constituent that belones to the collection of g-projections is the maximal projectiorJ dominating the (external) governor of the gap. The difference between extraction of an adjunct and extraction from an adjunct is represented in (121). 

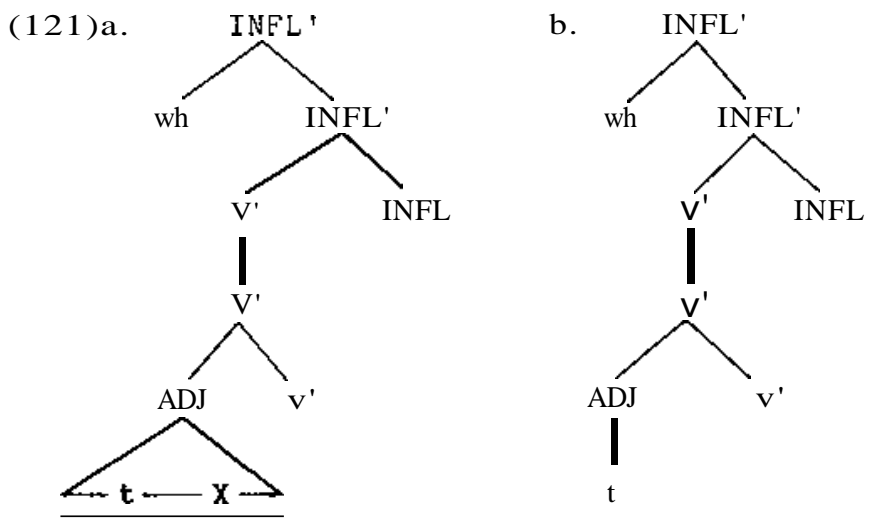

In (121a) ADJ is a g-projection of the governor of the gap (i.e. $\mathrm{X})$. This g_projection is canonically governed by INFL and consequently INFL" is a g-projection. The subtree which is the collection of g-projections is not a connected subtree, since there is a maximal projection on the path that does not belong to that collection, i.e. V"(S). This structure therefore violates the Gap Condition. In (121b) the first g_projection on the path is INFL' '. The collection of g-projections thus consists of one member only or, in case of long extraction, of INFL" and all relevant maximal projections dominating INFL". The status of $\mathrm{V}^{\prime \prime}$ is completely irrelevant. In this case the subtree is connected.

Let us now return to the adjunction analysis of NP_movement. Apart from the theory-internal advantage discussed above, this analysis has the advantage of accounting for the inversion phenomena without recourse to additional principles. It has been pointed out above that the inversion phenomenon only occurs in those constructions in which the surface SUbject, or rather the nominative NP, is a D-structure internal argument. This observation led Den Besten and Hoekstra to analyse the nominative NP structurally as an internal argument in inversion cases. It will be clear that this analysis does not fit the theory advocated here. I have to assume that the internal argument has to be moved out of the argument projection of $\mathrm{V}$ in order to receive nominative Case. However. since this movement is not substitution in the sense that the internal argument is moved to a peripheral structural subject 
position, but adjunction to a position outside the argument projection, we expect both orderings (Nom/Obl and Obl/Nom) to appear.

As was shown above, the ordering in the Dutch 'Mittelfeld', i.e. the part of the sentence between CaMP and $V$, is relatively free. This freedom was seen to be a consequence of (multiple) application of adjunction. With respect to the ordering of NPs there are principally two restrictions on this ordering. First, all NPs precede an objective NP (direct object).[16]. Second, a definite external argument precedes all other NPs. I have no syntactic explanation to offer for these restrictions. Especially the second restriction seems to be dependent on semantic and pragmatic factors, i.e. semantic restrictions to determine which NPs may count as indefinite (cf.Barwise \& Cooper 1980 and Zwarts 1981) and pragmatic restrictions with respect to the ordering of presupposition and focusCcf.ch.3 and Lenerz 1977). Although these restrictions provide the descriptive generalization as to which external arguments may appear in the middle field and which ones may not, and possibly the motivation of 'scrambling' as part of the pragmatic ordering in this middle field, they do not explain why an indirect object may not precede a definite external argument. Let us therefore provisionally assume that external arguments are base_generated as daughters of the maximal projection of the theta_assigning head and that indefinite external arguments may be adjoined to $\mathrm{X}^{\prime}$, subject to semantic and pragmatic conditions.[17]. This is in fact assumed in most analyses concerning the 'er-insertion' construction in Dutch. If this is correct, the demoted external argument is syntactically precisely the same as the internal argument that has to be moved to get Case. Both are nominative and both are in between the external argument position, i.e. the position in which an external argument is generated if there is one, and the argument projection of V. This would explain why these two sets of nominative NPs show the same behaviour, as demonstrated in (122).

(122)a. dat hem een kado gegeven was that him a present given was 

b. dat hem dat kado gegeven was that him that present given was
c. dat hem niemand een kado gegeven heeft that him nobody a present given has
d.*dat hem deze jongen een kado gegeven heeft that him this boy a present given has

The a.- and the b.-examples demonstrate that with passives the indirect object may precede the nominative internal argument irrespective of the definiteness of that NP. In c. , but not in d., the indirect object may precede the nominative external argument subject to the definiteness restriction. In constructions of the type in a.-c. other constituents such as adverbials and PPs may precede the nominative NP as well. This similarity can easily be accounted for under the assumptions made above. The nominative NP belongs to the middle field and can be preceded by all kinds of constituents through adjunction of those constituents to a position in front of the NP. There is no need for exceptional Case marking procedures like Chain-government or co-superscripting since nominative Case can be assigned structurally in all relevant cases. We do not need to assume the existence of an empty dummy position in the examples (122 a-cl. Thus, this analysis meets all the criteria for an optimal explanation of the inversion cases, as put forward above.

\subsubsection{HET and Inversion}

If het patterns just like the NPs in the preceding paragraph with respect to the inversion construction, it would constitute strong corroboration for the non-dummy analysis of het. If het were a (definite) dummy pronoun in subject position, we do not expect inversion to appear. If het in the relevant construction is a regular pronoun we expect it to pattern with other NPs in inversion contexts. Unfortunately, however, this test is not immediately decisive, for independent reasons. As was pointed out in note 16, the order of unstressed pronouns differs from the order of NPs in the case of object and indirect object. The order of NPs \{i.e. 
10-00) is a marked order in case of pronouns and arises only if both pronouns are stressed, as is shown in (123) (W stands for weak and $\underline{\underline{S}}$ for strong).

$$
\begin{aligned}
& \text { (123)a. ...dat Jan ut urn niet zou geven } \\
& \text {...that John it(W) him(W) not would give } \\
& \text { b.*...dat Jan urn ut niet zou geven } \\
& \text {...that John him(W) it(W) not would give } \\
& \text { c. ...dat Jan het hem niet zou geven } \\
& \text {...that John it(S) him(S) not would give } \\
& \text { d.? .. dat Jan hem het niet zou geven } \\
& \text {... that John him(S) it(S) not would give }
\end{aligned}
$$

With the inversion construction there is another complicating factor. For some reason a pronominal internal argument that has to be moved from the argument projection of $\mathrm{V}$ in order to receive Case has to precede the indirect object, contrary to what is to be expected under any analysis of the inversion construction. This is illustrated in (124).

(124)a. dat hem deze assistent goed beviel that him this assistent well pleased

b.*dat hem hij goed beviel that him he well pleased

The ungrammaticality of (124b) is problematic for the inversion theory. Following Den Besten(1983) we may assume that (weak) personal pronouns cliticize onto COMP and that they do so in a particular order. We may even go one step further and argue that nominative pronouns are in fact an expansion of pronominal features in COMP, which would make the analysis of COMP-inflection in Dutch dialects and in particular in West-Flemish(cf.Bennis \& Haegeman 1984) more general. Along those lines we may explain the ungrammaticality of $(124 \mathrm{~b})$ and the potential argument regarding inverSion of het cannot be made. The facts, however, are even more complicated than indicated above. It seems to be the case that if het is the internal argument that has to be moved, inversion is not impossible. In that case the judgements are entirely parallel to 
the judgements given with respect to the order of pronouns in (123).

$$
\begin{aligned}
& \text { (125)a .... dat ut urn niet verteld was (dat ...) } \\
& \text {... that it }\{\mathrm{W}) \operatorname{him}(\mathrm{W}) \text { not told was (that ...) } \\
& \text { b.*...dat urn ut niet verteld was (dat ...) } \\
& \text {...that } \operatorname{him}(\mathrm{W}) \text { it(W) not told was (that ...) } \\
& \text { c.... dat het hem niet verteld was (dat ...) } \\
& \text {...that it(S) him(S) not told was (that ...) } \\
& \text { d.? .. dat hem het niet verteld was (dat ...) } \\
& \text {...that } \operatorname{him}(S) \text { it }\{S\} \text { not told was (that ...) }
\end{aligned}
$$

As expected, the non-inverted sentences in $(125 \quad a, c)$ are grammatical, whether utlhet is a personal pronoun without complement clause or a resumptive pronoun related to a complement clause. There are two potential explanations of the ungrammaticality of (125b). The ungrammaticality may follow from a restriction on the order of pronouns, on a par with the ungrammaticality of (123b), or it may follow from a restriction on inversion of pronouns, on a par with (124b). However, the marked acceptability of (125d), which is undoubtedly much better than the completely ungrammatical (124b), indicates that we should opt for the former explanation. It then follows that it is not the distinction pronominallnon-pronominal that is relevant with respect to the distinction inversion/non-inversion. A distinction between human personal pronouns and other NPs including het has to be made in this case.[18J.

Whatever the exact explanation of these facts, it is clear that the acceptability of (125d) and (126) constitutes an argument against the analysis of het as a dummy pronoun in (peripheral) subject position.

(126) a.?Jan zei dat hem het nog niet duidelijk was John said that him it not yet clear was dat de paus zou komen that the pope would come 
b.?Jan zei dat hem het niet beviel dat de paus

John said that him it not pleased that the pope

zou komen

would come

c.?Jan zei dat hem het gebleken was dat

John said that him it appeared was that

de paus zou komen

the pope would come

d.?Jan zei dat hem het irriteerde dat de paus

John said that him it irritated that the pope

zou komen

would come

In all unaccusative constructions, passive (125d), raising( 126c), ergative verbs(126a,b), and psychological verbs $\{126 \mathrm{~d})$, the indirect object may precede the nominative NP het. This is unexpected if het is a dummy pronoun occupying the structural subject position. If het is not a dummy pronoun, these facts are predicted by the theory.

\subsection{Summary}

In this chapter it has been argued that the pronoun het should be analysed as a referential expression in all its occurrences. Given the fact that it is an NP, it follows that it Should receive a thematic role and Case. It was demonstrated that a dummy-pronoun analysis of het would be ad-hoc and counterproductive, in particular since het displays referential properties such as the possibility to be an antecedent for PRO, parasitic gaps and reflexives. The constructions in which het is generally taken to be a dummy pronoun involve constructions in which het is related to an (extraposed) S'. In our approach, the referential pronoun het may appear if a propositional thematic role is selected. This pronoun may be related to an $S^{\prime}$ in an adjunct position. In these cases het is a resumptive pronoun in such a way that it is a pronoun in a theta-position c-commanded by an (optional) $S^{\prime}$ in non-theta position. If het is absent, $S$ ' may occupy the theta-position. On the baSis of this difference we are able to provide an account of a 
contrast in extraction from $\mathrm{S}^{\prime}$.

From this analysis of het it follows that we do not assume an empty dummy pronoun to be present in the absence of het. One major consequence is that there are subjectless sentences in Dutch. This is in conflict with the Extended Projection Principle, which requires that every clause contains a subject. It has been argued that we should reject the Extended Projection Principle and return to the Projection Principle.

It has been demonstrated that the analysis of het as a referential expression has important consequences for the analysis of various constructions, such as raising constructions, inversion constructions and constructions with psychological verbs.

In the next two chapters, I shall investigate the apparent dummy-pronoun status of er and the occurrence of dummy pronouns in other languages. It will once again be demonstrated that there is no reason to assume the existence of dummy pronouns that appear in order to fill the subject position as a consequence of the requirement that clauses must have a SUbject. An interesting consequence of such a theory is that the presence of a subject is determined by lexical properties of the verb (i.e. the assignment of an external argument) or by Case (i.e. the presence of a D-structure object requiring Case) only. This allows us to get rid of a curious subject/object asymmetry within the theory. This asymmetry concerns the fact that the object position is always a theta-position, whereas the subject position mayor may not be a theta-position. In this chapter it was argued that we should identify an A-position with a theta-position. It follows that the subject position is an A-position if the verb selects an external argument only, just like the object position. A consequence is that NP-movement can no longer be analysed as A-movement or movement to an A-position. Differences between NP-movement and wh-movement should follow from other principles. One major difference between these two types of movement rules involves the position in which the moved NP receives Case. The TR-Condition introduced in chapter 1 allows us to derive the differences between the two types of movement rules from the position in which Case is assigned, without having to rely on the notion of (non-)argument position. 
1. A proposal that is similar in several respects is made in Hoekstra (1983).

2. The little ball in the a-example refers to a souvenir ball in which it appears to be snowing when the ball is shaken.

3. A similar proposal with respect to the D-structure position of sentential complements is made in De Haan(1979), although for different reasons and with different consequences.

4. Hoekstra(1984) argues that the thematic role in these raising constructions is either assigned internally, in which case the $S^{\prime}$ is an argument of $V$, or externally in which case the subject position has to be occupied by the referential expression het and the $\mathrm{S}^{\prime}$ is in an $\mathrm{A}^{\prime}$-position. This analysis is not very attractive since it forces us to assume that these verbs may assign one thematic role to subject or object position.

5. In fact, sentences like the ones in (37), which are given as ungrammatical, seem to be marginally acceptahle to many speakers of Dutch. It is interesting to observe that whereas there exists a clear-cut distinction in gramrnaticality between (ia) and (ib) no such difference is found in (ii).

(i) a. Wat blijkt dat Jan $t$ gezegd heeft? What appears that John said has

b.*Wat blijkt het dat Jan $t$ gezegd heeft?

What appears it that John said has

(ii)a.?Wat schijnt dat Jan t gezegd heeft?

What seems that John-said has

b.?Wat schijnt het dat Jan $\frac{t}{\text { gezegd heeft? }}$

What seems it that John said has

If we follow the argumentation presented in this chapter, the sentences in (ii) are ungrammatical, although for different reasons. (iia) is ungramrnatical since, as was argued, the verb schijnen does not subcategorize for an 'S', while (iib) is ungrammatical because the wh-phrase is extracted from $S^{\prime}$ in adjunct position.

According to the intuitions of native speakers (iib) is slightly better than (iia), while both are more acceptable than (ib) and clearly less acceptable than (ia). These facts are problematic for the theory presented here. I have no genuine explanation to offer. I would like to suggest that it is in keeping with the theory that the two sentences in (ii) are ungrammatical, because extraction from ' $S^{\prime}$ is impossible. If we do want to extract from the sentential complement, possibly on the analogy of extraction from the complement of blijken, a grammatical principle must be violated. Either we have to change the subcategorization specification of the verb schijnen in such a way that it allows an $\mathrm{S}^{\prime}$-complement or we have to extract from an adjunct clause. Since no grammatical alternative is present, I shall tentatively assume that these violations may lead to marginally acceptable sentences. Obviously, the extraction from $S^{\prime}$ in adjunct position, as in (iib), leads to a somewhat better result, which suggests that the lexical properties of verbs are more strictly obeyed than the principles that govern extraction, which is in line with the Projection Principle. 
6. Hoekstra\{1984,note 81) relates this property of blijken to the fact that blijken, but not the other two raising verbs, may appear with an $\mathrm{S}^{\prime}$-complement without het. He claims that only blijken can take a G_subject, as in (42), and that the presence of er in sentences such as (32a) indicates the absence of this external thematic role. Since both schijnen and lijken do not take a a-subject, these verbs do not allow er in subject position, as in (36b) and (39b). Although Hoekstra is able to relate two phenomena that are left unrelated under the analysis presented here, there are several problems with Hoekstra's proposal. First, his proposal is in conflict with his own theory on unaccusatives. According to his criteria, blijken belongs to the class of unaccusative verbs (cf.(35) and related discussion). This implies that in (42) blijken does not project a G-subject, but rather an internal argument. It then folloWS that the supposed similarity between the occurrence of er in passives and in sentences containing blijken is absent. Another incompatibility in his proposal is the fact that he argues that not only blijken but also lijken and schijnen take G-subjects. This follows from the fact that he assumes that het is a referential expression in argument position. Apparently, the raising verbs differ in allowing a non-propositional - subject. If that is so, we should expect er to appear with schijnen and lijken, indicating the absence of the propositional G-role.

7. It is assumed throughout that an $S^{\prime}$ in adjunct position occupies a position within Vmax. It is even crucial to the analysis presented here. However, there is no principled reason for this assumption. If the adjunct 5' occupies a position outside Vmax, this 5' c-commands het in subject position and we expect (47b) to become acceptable. (47b) is ungrammatical with a normal intonation pattern. However, the sentence improves considerably if there is a clear break in intonation right before the adjunct 5'. In that case, the adjunct appears to be a kind of afterthought. This observation does not weaken our claim regarding the explanation of the ungrammaticality of $(47 \mathrm{~b})$. It is to be expected that a difference in position of the adjunct corresponds to a difference in interpretation. In this section, I shall be concerned only with sentences that display a normal intonation pattern.

8. This is true only if we accept the definition of government discussed in ch.1. It was argued that the domain of government is upward bounded to the minimal argument projection of the governor. This excludes government of the external argument of a lexical category by that lexical category itself.

9. In this respect this construction seems to be similar to constructions in which $5^{\prime}$ is related to a prepositional object, as discussed in ch.2.4.1. In those cases er has to appear in A-position.

10. It is interesting to observe that sentences like the ones in (57) are somewhat marginal in comparison with the corresponding sentences with het. (59a), however, is impeccable. The reason is that it is the only possibility to extract from 5'. This indicates that the rule of reanalysis that will be proposed below represents a marked option.

11. There is one major problem with the reanalysis proposal adopted here. This concerns the fact that the unit consisting of predicative part of the se and the verb is not completely impenetrable. In particular stranded prepositions may occur in between se and verb, as is illustrated in (i).

(i) de stelling waar Henk alle argumenten onjuist van vindt the thesis Where Henk all arguments incorrect of considers 
It is to be expected, then, that reanalysis of verb and predicative part of the se is impossible in (i), given the lack of (structural) adjacency. However, it turns out that we have to assume that reanalysis is possible in (i), given the acceptability of (ii).

(ii) het boek waar ik (het) vervelend van vindt dat het niet vertaald is the book where I (it) annoying of consider that it not translated is

If het is absent, the postverbal $S^{\prime}$ is the external argument of the head of the se (vervelend). It thus follows that reanalysis is required in our analysis. The acceptability of (i) is also rather surprising for other reasons. (i) differs from the ungrammatical sentence (640) only in the choice of the preposition. Moreover, the stranded preposition in (i) cannot be replaced by a full PP, as in (iii).

(iii)*dat Henk alle argumenten onjuist van deze stelling vindt that Henk all arguments incorrect of this thesis considers

I have no solution to offer for the unexpected gramrnaticality of (i). Facts of the type in (i) appear to weaken the reanalysis proposal and the theory on P-stranding proposed in ch.1.

Any analysis of (i) should also account for the fact that a stranded preposition may even occur between particle and verb. In that position no other constituents are allowed. Although the relevant sentences are marginally acceptable, there is a contrast between a particle followed by a stranded preposition, as in (iva), and a particle followed by a full PP, as in (ivb).

(iv)a.?de tentamens waar zij de helft over van moesten maken the examinations where they the half again of must make

'the examinations the half of which they have to do again'

b. ${ }^{*} \mathrm{Zij}$ moesten de helft over van de tentamens doen

They must the half over-again of the tentamination do

A similar contrast can be observed in the case of idiomatic expressions. If the verb and its object constitute an idiomatic expression, nothing can intervene between object and verb. Only stranded prepositions are marginally possible, as in (va).

(v)a.?het antwoord waar hij door de mand mee viel

the answer where he through the basket with fell

'the answer which showed him up for what he was worth'

b.*dat hij door de mand met dat antwoord viel

that he through the basket with that answer fell

It appears that there is a kind of P-float to the right. The exact status of such a rule and the conditions under which it applies are unclear to me at present. I shall leave these phenomena for further research.

12. It is not immediately clear that (84) is an instance of regular passivization. For a discussion on this issue, see below and Den Besten $\{\lg 82)$.

13. The phenomenon of Inversion is present in main clauses as well. However, the data are obscured by the phenomenon of topicalization. from a sentence such as (i), it cannot be deduced whether Inversion has been applied or not. 
(i) Hem bevie1 die zaak niet

Him pleased this matter not

The indirect object hem may be preposed by topica1ization from both sides of the nominative NP die zaak. In order to demonstrate the phenomenon of inversion in main clauses another constituent has to be topicalized, as in (ii).

(E) Ondanks de goede recensies was hem dat boek niet bevallen

In spite of the good reviews was him that book not pleased

14. Although the process of inversion is optional in principle, the actual appearance of one of the two options is to some extent determined by principles of a non-syntactic nature. For instance, if the indirect object hen in the examples (107)-(109) is replaced by an indefinite indirect object such as niemand(nobody), most of the sentences are acceptable in the non-inverted order only. Similar phenomena will be discussed in ch.3, where it is argued that in those cases in which multiple orders can be derived by the application of optional syntactic rules, the actual order of the middle field is determined by semantic and pragmatic criteria.

A different observation pertains to inversion with psychological verbs. It is clear that under the analysis proposed in the preceding section sentences such as (110) are not instances of nominative-dative inversion, but rather of nominative-objective inversion. In those cases the verb is able to assign Case structurally to only one of the two internal arguments. This difference in Case-marking between psychological verbs and other constructions in which inversion is allowed can be observed quite clearly in German. Psychological verbs show nominative-accusative inversion, whereas the other inversion cases are instances of nominative-dative inversion. As argued above, these German data are strong arguments in favour of the presented analysis of psychological verbs.

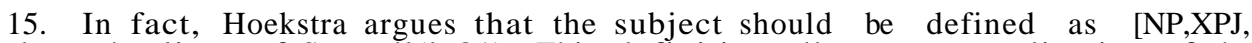
along the lines of Stowell(lg81). This definition allows a generalization of the notion subject across categories.

16. An exception to this empirical generalization is the fact that in case of unstressed pronouns the order is $\mathrm{Obj} / \mathrm{Obl}$.

17. A different analysis will be presented in ch.3.

18. Interestingly, there is further evidence that the pronoun het in both uses, i.e. independent pronoun and resumptiv 2 pronoun, has to be distinguished from the other pronouns. In exceptional case marking constructions with an embedded definite external argument only het may precede the subject.

(i) dat ik [het(int.arg.) hem/de minister(ext.arg.) zeggenJ hoorde (dat $\bullet \bullet$ ) that I it him/the minister say heard (that -..)

(ii) *dat ik [haar(int.arg.) hem/mijn vader(ext.arg.) slaanJ zag that I her him/my father beat saw

The sentences in (ii) are grammatical only if the first NP (haar) is the external argument of the embedded verb.

A second distinguishing property is that het does not appear as complement of a preposition. In both cases het differs in distribution from all other NPs including human pronominals.

A further difference between het and the other pronominals concerns the fact 
that the distinction between the weak pronoun ut and the strong pronoun het, which was seen to be relevant with respect to the mutual order of pronouns (cf. (123)), does not seem to be relevant with respect to topicalization. Neither Het nor ut can be topicalized, as is illustrated in (iii). In those cases the pronoun dat(thatl must be selected.

(iiila.*Het heb ik gezegd It $(S)$ have I said

b.*Ut heb ik gezegd It(W) have I said

c. Dat heb ik gezegd

That have I said

Other pronominals show a distinction between weak and strong forms with respect to topicalization. It looks as if non-human pronouns show a three-way distinction in relative strength. Het patterns with ut with respect to topicalization, and with dat with respect to the mutual order of pronouns. The precise status of these observations is unclear to me at present. 

Chapter 3

\section{The Adverbial Pronoun ER}

\subsection{Introduction}

In the previous chapters. the pronoun er and the class of R-pronouns was introduced at several points. In this chapter I shall focus on the pronoun er mainly in relation to its so-called dummy-pronoun status. The dummy-pronoun appearance of er is only one of the many possible functions of er. I shall argue that in all its uses er is an adverbial pronoun that may enter tnto a variety of syntactic relations. In some sense the spirit of this chapter is similar to that of the preceding one. Het was argued to be a referential NP in all cases. This was seen to be particularly relevant with respect to its so-called dummy use. The analysis of er as an adverbial pronoun is in fact the traditional view. as put forth in the Bech's(1952) article 'Ueber das njederländische Adverbialpronomen er'. Thi.s analysis differs from most. if not all. recent analyses of er. These generally take the different syntactic functions of er as an indication or motivation for the existence of several distinct pronouns which may vary in their categorial status and inherent syntactic properties. A different view in a completely different framework is expressed in Kirsner (1979). Basing his account on the conception that one form should correspond to one function/meaning. he argues in favour of a unificatory analysis of er that is based on the idea that the meaning of er is constant and can be described as presentational. I agree with Kirsner that an optimal theory of er should relate all occurrences of er. I do not agree with him that such a unificatory 
approach should necessarily be based on a particular meaning of er that is present in all specific instances. It can be argued that er possesses inherent properties which allow er to appear in a variety of syntactic constructions. Differences between distinct occurrences of er should then be considered to follow from the distinct syntactic relations and not from the appearance of different pronouns which happen to have the same surface realization. Paradigmatical as well as syntagmatical differences can be observed, such as the possibility of substitution of er by other R-pronouns and the maximal domain within which the syntactic relation in which er participates holds.

As pointed out above, the main purpose of this chapter is to provide evidence that er Should not be analysed as a dummy pronoun in subject position if there is no thematic subject or if the indefinite subject is 'demoted'. If this can be shown, or if it can at least be shown that it is not necessary to analyse er as a dummy pronoun in these instances, we can maintain our claim that there are no dummy pronouns in Dutch to fill the subject position and that a clause does not require a subject to be present. as is required by the Extended Projection Principle. By eliminating the stipulation that clauses should contain a subject, we are able to get rid of another unattractive asymmetry within the theory i.e. the difference between argument position and theta position. In the case of objects every theta position is an argument position and vice versa. In the case of subjects, however. each theta-position is an argument position but it is not the case that each argument position is a theta-position. Non-thematic argument positions appear crucially whenever the subject position is occupied by a dummy pronoun. If there are no dummy pronouns and there is no necessity for a subject position (i.e. argument position) to be part of the structure. the set of argument positions is then properly contained within the set of theta-positions (but cf.ch.3.3.31.

Such a theory thus possesses the following advantages:

- no stipulative requirement to the effect that sentences should contain a subject is necessary.

- argument positions are always theta positions, which implies that subject and object are similar in this respect. 
- the actual appearance of a subject in D-structure is completely determined by lexical properties of the verb, just as with objects. - the appearance of a subject in S-structure in a construction without a subject in D-structure is largely dependent on considerations of Case assignment (Burzio's generalization).

- there is no need for the notions subject and object. At D-structure level subject and object can be identified with external and internal argument respectively (their Q-position). At S-structure subject and object can be identified with nominative and objective Case respectively (their Case-position). Since both Q-assignment and Case assignment are independently motivated mechanisms within the theory, the notions subject and object are redundant (cf.Williams 1981,1984).

- there is no reason to postulate the appearance of empty dummy pronouns.

It will be clear that it is important to argue against the existence of dummy pronouns that fill the subject position. This does not necessarily imply that there are no dummy pronouns at all. It might be the case that there are languages that make use of dummy elements to fill specific positions in order to satisfy a particular principle that would be violated otherwise. In this chapter and in chapter 4 it will be argued that in Dutch. German and other languages instances of 'dummy elements' can be found, not as a consequence of the Extended Projection Principle. but rather because they derive from other independently motivated principles within the theory. The importance of the extensive discussion of het and er in Dutch is that it can be argued that there appears to be no real reason why they should be dummy subjects at all. If this turns out to be correct, the theory as sketched above. which is conceptually to be preferred to a theory that includes the Extended Projection Principle, is supported by empirical evidence.

In order to demonstrate that it is indeed the case that er does not function as dummy subject. I shall first provide an overview of the different constructions in which er shows up. I shall then present a solution to some of the many intriguing puzzles that are associated with er. 


\subsection{The distribution of er}

It is customary to distinguish four different constructions in which er occurs. I shall briefly describe these four constructions and their properties for expository purposes. They are respectively, existential and/or expletive er, prepositional er, quantitative er and locative er (cf.Bech (1952), Bennis (1980a».

\subsubsection{Existential/expletive er}

The expletive use of er has the greatest relevance for our purposes. It is generally assumed that this type of er fills the subject position or binds an empty subject position if the indefinite subject has been moved into the verb phrase. Examples are given in (1) and (2), in which the a-examples are the sentences without er and the corresponding b-examples contain er.

(1)a. Een jongen loopt in de tuin

A boy walkS in the garden

b. Er loopt een jongen in de tu in

There walks a boy in the garden

(2)a. Een muis liep gisterenavond bij ons toch op een

A mouse walked yesterday-evening with us yet on a

gegeven ogenblik op tafel

certain moment on table

b. Er liep gisterenavond bij ons toch op een

There walked yesterday-evening with us yet on a gegeven ogenblik een muis op tafel (cf.Paardekooper 1971) certain moment a mouse on table

One of the diagnostic properties of expletive er is that within $S$ er appears before the subject, if there is one.

This construction shows some similarity to the existential/expletive constructions in languages such as English, french and German. One obvious similarity is that the construction appears only if the subject is indefinite. as shown in (3). I shall not be concerned here with the exact definition of the term 'indefinite' and the semantic conditions under which it is possible 
to demote the subject. For a discussion on this topic I refer to Zwarts (1981) and Barwise \& Cooper (1980), among others. [1].

(3)a.*Er loopt de jongen in de tuin

There walks the boy in the garden

b.*Er zitten deze twee meisjes op de tafel

There sit these two girls on the table

There are also some striking differences between Dutch and German and between Dutch and English, which will be discussed below (cf.ch.4). It is sometimes argued that a further restriction on the occurrence of expletive er is that it appears only if the verb is intransitive. Although there seem to be some restrictions on the use of expletive er, it is certainly not correct to say that er is not allowed if the verb is transitive. Instances of transitive constructions with expletive er are given in (4).

(4)a. Er kocht niemand een boek

There bought nobody a book

b. Er heeft nog nooit iemand een boek geschreven

There has yet never anybody a book written

over de tweede wereldoorlog

about the second world war

I shall return to this issue in section 5. Finally, we may observe that this type of er shows up in passives without a logical object, $\operatorname{asin}(5)$.

(5)a. Er wordt gevoetbald

There is played soccer

b. Er werd hard gelachen

There was loudly laughed

In all these cases er has been regarded as a dummy pronoun occupying the non-thematic subject position. It will be clear that in our approach the occurrence of er in these sentences should receive a different explanation. 


\subsubsection{Prepositional er}

Prepositional R-pronouns, including er. have been an important topic in Van Riemsdijk(1978) and in chapter 1 of this book. In ch.1 it has been argued that R-pronouns are base-generated within pp as arguments of $\mathrm{P}$, carrying a structurally assigned thematjc role, as in (6). These R-pronouns can be moved out of PP, leaving the preposition stranded, as shown in (7). P-stranding turned out to be possible with R-pronouns only, since R-pronouns are base-generated to the left of P, whereas other arguments follow the head of PP. as illustrated in (8). Given the Gap Condition it follows that P-stranding in Dutch is possible only if the complement of $P$ is moved from a position to the left of P. Because R-pronouns carry a structurally assigned thematic role they are obligatorily present, as is shown by the sentences in (9).

(6)a. Ik heb met hem [er over] gesproken

I have with him there about talked

b. Ik heb enkele boeken [er over] gelezen

I have some books there about read

(7)a. Ik heb er met hem [t over] gesproken

I have there with him about talked

b. Ik heb er enkele boeken [t over] gelezen

I have there some books about read

(8)a. Ik heb [ er/* dat onderwerp over] gesproken

I have there/that subject about talked

b. Ik heb [over *er/dat onderwerp] gesproken

I have about there/that subject talked

c. *Ik heb dat onderwerp met hem [ $\underline{\mathrm{t}}$ over] gesproken

I have that subject with him about spoken

(9)a.*Ik heb met hem over gesproken

I have with him about talked

b. *Ik heb enkele boeken over gelezen

I have some books about read 


\subsubsection{Quantitative er}

The quantitative use of $\mathrm{er}$ is found when there is a quantified NP containing an empty head or an empty $N^{\prime}(c f . B l o m$ 1977, Bennis 1979). It is in many respects comparable to one of the functions of the French clitic en (cf.Hulk 1982) and the Italian clitic ne (cf.Belletti \& Rizzi 1981). A comparison between these constructions in different languages $\boldsymbol{W}$ presented in Bennis \& Hulk( 1979). The occurrence of quantitative er " obligatory if the head of a quantified NP in the sentence is empty. as can be seen in (10). There are no R-variants. i.e. there is no paradigm of the type in (11). The ungrammatical examples in (12) constitute evidence that er cannot occur in first position in $S^{\prime}$.

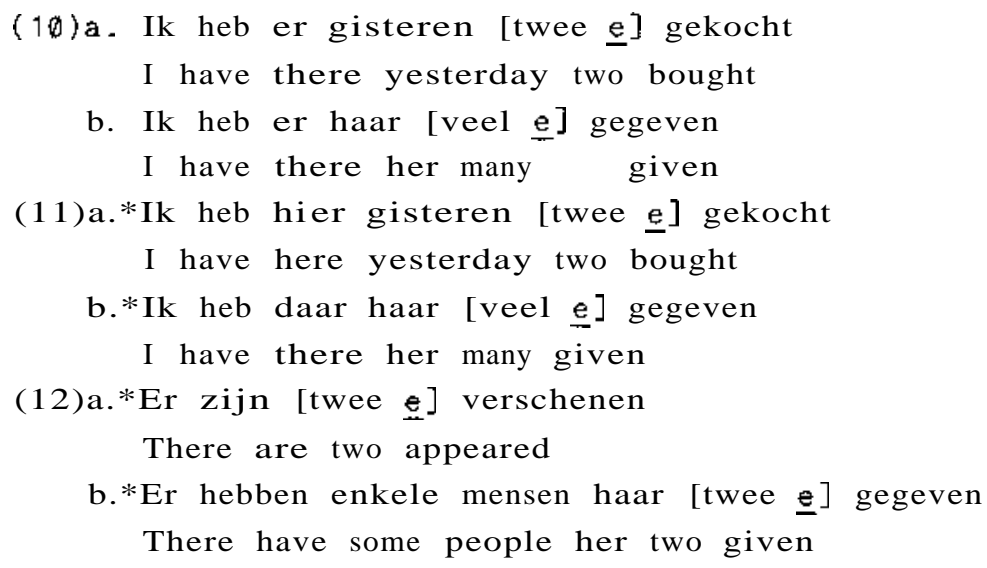

\subsubsection{Locative er}

In (13) and (14) er functions as an adverbial with a weak locative interpretation. It can optionally be added to sentences which allow a locative phrase, such as in (13a). It is obligatorily present if the verb requires a locative phrase, as shown in (14).

\footnotetext{
(13)a. Jan koopt er een boek

John buys there a book

b. Jan koopt een boek

John buys a book
} 


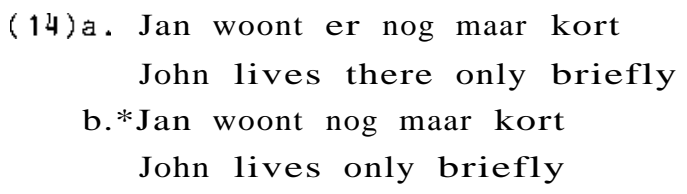

In these cases er can be replaced by other R-pronouns and other locative constituents.

\subsubsection{Co-occurrence of syntactic functions of er}

A peculiar property of er is that one surface realization may have more than one syntactic function. Since we distinguished four different functions of er we should be able to find $\mathbf{1 1}$ different possibilities of the pronoun er having more than one distinct function. Seven of these combinations can be found quite easily. For reasons to be discussed below, the co-occurrence of prepositional er and locative er is rather restricted.

a. expletive + prepositional

$$
\begin{aligned}
& \text { (15) ... dat er twee jongens }[\underline{t} \text { op] zaten } \\
& \text { that there two boys on sat }
\end{aligned}
$$

In (15) er is expletive since it appears before the indefinite subject. (16a) shows that if the subject is definite, the sentence becomes ungrammatical. Er is prepositional since the preposition requires a complement, as shown in (16b).

$$
\begin{gathered}
\text { (16)a.*... dat er deze jongens [t op] zaten } \\
\text { that there these boys on sat } \\
\text { b.*... dat dez€ jongens [e op] zaten } \\
\text { that these boys on sat }
\end{gathered}
$$

b. expletive + quantitative

(17) ... dat er niemand [twee $\underline{e}$ ] gekocht heeft that there nobody two bought has 
That er is quantitative follows from the fact that in (18) er is obligatorily present.

(181*...dat niemand [twee e] gekocht heeft that nobody two bought has

c. expletive + locative

(19) ... dat er niemand meer woonde that there nobody anymore lived

$\mathrm{Er}$ is locative since the verb wonen requires a locative complement, as follows from (20).

(20)*... dat Jan woonde

that John lived

d. prepositional + quantitative

(21) ... dat Jan er [twee e][t over] gelezen heeft that John there two about read has

Er is prepositional since the object of the stranded preposition must be an R-pronoun. In (21) er is quantitative because the replacement of er by another R-pronoun, which is possible with respect to $\mathrm{P}$-stranding. results in ungrammaticality, as is illustrated in (22). Quantitative er cannot be replaced by other R-pronouns.

(22)*...dat Jan hier [twee $\underline{e}][\underline{t}$ over) gelezen heeft that John here two about read has

e. quantitative + locative

(23) Jan zou drie we ken van zijn vakantie in Italië doorbrengen John would three weeks of his hollidays in Italy spend maar uiteindelijk heeft hij er maar [twee e] t doorgebracht but eventually has he there only two spend 
In (23) er is quantitative since the empty head of the quantified NP must be bound by er. Er is locative since the verb doorbrengen requires a locative complement, as is illustrated in (24).

(241*... dat hij zijn vakantie had doorgebracht that he his hollidays had spend

f. expletive + quantitative + prepositional

(25)a... dat er niemand [drie $\underline{e}][\underline{t}$ over] geschreven heeft that there nobody three about written has

b. Hoe er [drie e][ $\underline{t}$ van] kunnen samenvallen How there three of can co-occur

g. expletive + quantitative + locative

(26) ... dat er nog maar [twee $\underline{\mathrm{e}}] \underline{\mathrm{t}}$ woonden that there yet only two lived

To conclude this section, I would like to discuss briefly the question whether er may also have the same function twice. In principle we expect this to be possible. With respect to the quantitative function of er, it is possible to construct a sentence in which er is related to more than one quantified NP containing an empty head. This is shown in (27).

(27) ...dat er [twee e][één e] gekocht hebben that there two one bought have

Combining sentences of the type in (25)-(26) with a sentence of the type in (27), we are able to construct a sentence in which er has four functions. An example is given in (28).

(28) ... dat er [één $\underline{e}]$ [twee é] [ţ over] gelezen heeft that there one two about read has

If all these relations are indicated by subscripts, the structure 
of (28) would be as in (29).

(29) ... dat eri,j,k,1 [één $\left.\underline{e}_{j}\right]_{i}\left[\right.$ twee $\left.\underline{e}_{k}\right]\left[\underline{t}_{-1}\right.$ over] gelezen heeft In (29) $\mathrm{er}_{\mathrm{i}}$ is expletive and, at least according to a widely accepted analysis, coindexed with the demoted subject. $\mathrm{Er}_{\mathrm{j}}$ and $\mathrm{er}_{\mathrm{k}}$ are quantitative and coindexed with the empty heads of the relevant NPs, the subject and the object, respectively. $\mathrm{Er}_{1}$ is prepositional and moved from PP.

\subsubsection{An analysis of co-occurrence}

Before turning to other er-phenomena that are relevant to our discussion of the non-dummy status of er, 1 shall present an analysis of the phenomenon discussed in the previous section. This analysis is in most respects similar to the analysis presented in Bennis(1980a). In (29) the relations in which one occurrence of er may participate are represented by different indices expressing the distinct relations. However, it follows from the Projection Principle and the theta-criterion that one constituent can have only one referential index. If this is correct. we should replace (29) by $(30)$.

(30) ... dat er $\mathbf{r}_{\mathbf{i}}$ [één $\left.\underline{e}_{\mathbf{l}}\right]_{1}$ [twee $\left.\underline{e}_{\mathbf{i}}\right]\left[\underline{t}_{\mathbf{i}}\right.$ over] gelezen heeft

This structure shows some similarity with parasitic-gap constructions. A parasitic-gap approach to this multiple gap structure leads to several problems. One problem concerns the fact that the subject NP (een e) c-commands three of the four gaps. This implies that these gaps are A-bound. To circumvent this problem it might be suggested that there is no coindexation between er and the indefinite subject. A further obvious problem is that none of the empty categories is parasitic in the sense that they require a licensing gap. This is not a problem in itself. since there is no prohibition against parasitic-gap structures in which both gaps are licit gaps themselves (cf.ch.1). However, the fact that in the case of quantitative er the gap within $N P$ is a legitimate gap is 
surprising. In the literature this gap is analysed as $\mathrm{N}, \mathrm{N}^{\prime}$ or $\mathrm{N}^{\prime \prime}$ (cf.Blom 1977, Bennis 1979, Coppen 1985). Without further qualification I shall assume that the categorial status of the gap is $\mathrm{N}[-\max ]$. The question arises as to whether the empty category is the result of movement of er or a base-generated empty category. [2J. Arguments in favour of a non-movement analysis of quantitative er will be presented in section 3.3.4. If the empty category within $\mathrm{NP}$ is indeed base-generated, the parasitic-gap approach to (30) cannot be maintained.

A further argument against a parasitic-gap analysis of (30) is the fact that the gaps, although coindexed with the same antecedent, are not coreferential themselves. A sentence like (30) might be interpreted as (31).

(31) ... dat één student twee boeken over Vestdijk gelezen heeft that one boy two books about Vestdijk read has

All gaps are interpreted differently. This property of constructions of the type in (30) cannot be due to a property of er, for example the lack of reference potential of er, since in regular parasitic-gap constructions in which er is the antecedent of both gaps. as in (32), coreferentiality is implied.

(32) Jan heeft er [zonder e over na te denkenJ $\underline{t}$ mee ingestemd John has there without about to think with agreed

A final argument against a parasitic-gap analysis of (30) concerns the ungrammaticality of (33).

$$
\text { (33)*.. dat Jan er } \left.\mathbf{r}_{i} \text { er }{ }_{j} \text { [twee } \mathbf{-}_{-1}\right]\left[\mathbf{t}_{-}\right. \text {over] gelezen heeft }
$$
that John there there two about read has

(33) becomes grammatical if one occurrence of er is left out, as in (34a), or if the second er is turned into another R-pronoun. as in $(34 b)$. [3].

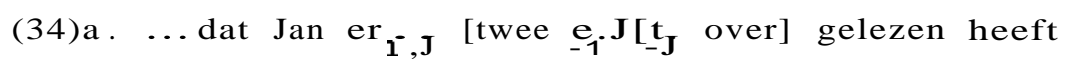
that John there two about read has 


\section{b.... dat Jan er ${ }_{1}$ daar $_{J}\left[\right.$ twee $\left.\underline{e}_{\mathbf{1}}\right][\mathbf{t}$ over] gelezen heeft that John there there two about read has}

Given the grammaticality of (34b) we expect (33) to be grammatical as well. In a parasitic-gap approach this would be difficult to account for. We may try to circumvent this problem by postulating an ad-hoc rule to the effect that for some reason it is impossible to have more than one occurrence of er per clause. Si.nee the alternative strategy of a parasitic-gap construction is available, we can use that strategy to avoid ungrammaticality. Unfortunately, such a rule does not help, since it is possible for more than one er to occur in one clause, as is illustrated in (35) (cf.Coppen 1985).

(35)a. Er wonen er drie

There live there three

b.... dat er niemand hem er iets [t over] wilde vertellen that there nobody him there something about wanted tell

The generalization that seems to hold is that apparently two occurrences of er cannot be adjacent. This rule seems to be a minor, local rule. We may obtain the desired effect by a local deletion rule, as has been proposed by Den Besten (1983), or by a filter excluding two adjacent er's. As Den Besten argues, this rule or filter has to follow movement rules. Otherwise we would expect sentences like (36) to be ungrammatical.

(36) $\mathrm{Er}_{1}$ lopen $t_{-1}$ er $\mathrm{J}$ [twee $\left.\underline{-}_{-}\right]$

There walk there two

Given this ordering argument and the fact that the rule is a minor rule that has to be formulated in a strictly local manner, it is typically a rule belonging to the PF-component of the grammar. Furthermore, such an analysis is confirmed by the fact that this rule/filter shows a striking similarity with a rather general phonological process in Dutch. As has been argued by Smith (1976) and Booij(1977), sequences of the type exemplified in (37) are generally excluded. 


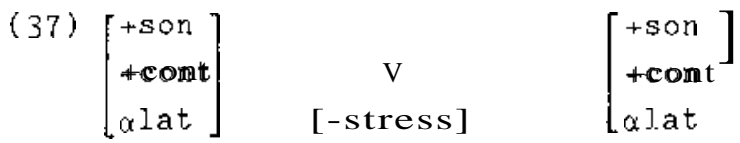

A phonological constraint designed to account for the non-existence of sequences of the type in (37) motivates the appearance of several phonological rules, among which we find d-insertion, as in (38a,d), schwa-strengthening, as in $(38 \mathrm{~b}, \mathrm{e})$ and schwa-consonant deletion, as in $(38 \mathrm{c}, \mathrm{f})$. These processes are illustrated with respect to agentive formation, as we see in (38a-o) and formation of 'inhabitatives', i.e. derived nouns with the meaning 'inhabitant of a place', as illustrated in (38d-f). [4J.

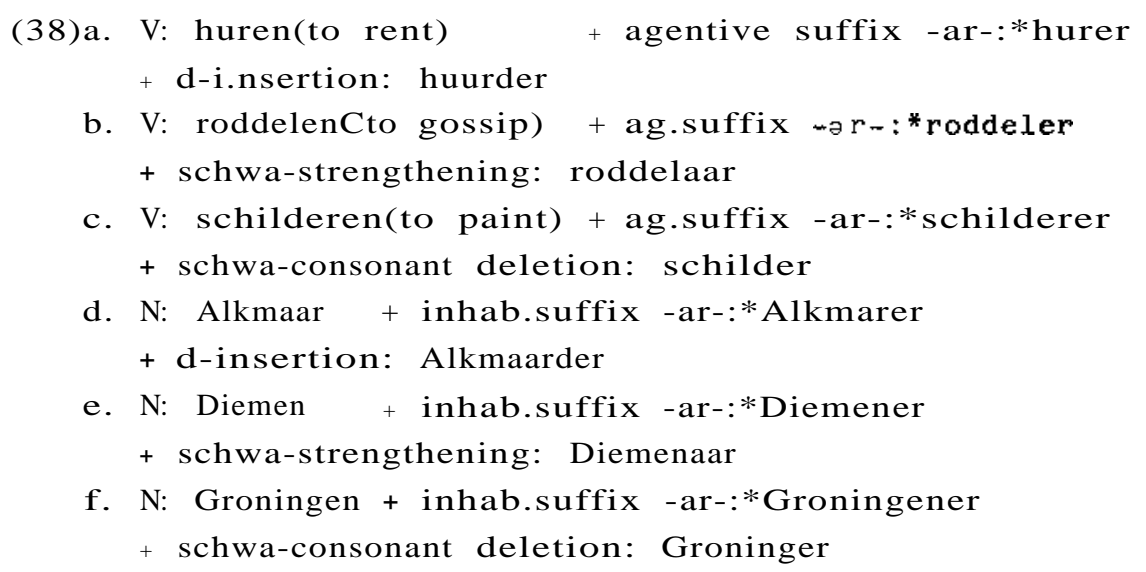

We thus may assume that er-contraction/deletion is similarly motivated by the filter based on (37). Although the filter and the related phonological rules apply to morphological operations, it is not very surprising that clitic-like weak pronouns are to some extent subject to the same rules. Obviously, the word boundaries in between the two er's may be neglected. The application of er-deletion must be restricted to those circumstances in which the two words are er, In other cases in which the filter is applicable, i.e, if er is preceded by a word ending on $/ r /$, the rule of d-insertion applies.

There seems to be enough motivation then to consider the 
deletion of er, when adjacent to er, a phonological rule in $\mathrm{PF}$ which is motivated by (37). If this is correct, no problems arise with respect to multiple gap structures such as (30). At the level of S-structure we may assume that all instances of er that are structurally required are actually present. The S-structure can be represented as in (39).

(39) ... dat er er, [één PRO..][twee PRQ.][t, over] heeft gelezen

With respect to the interpretation and binding conditions there is no problem at all, since these apply at the level of LF, at which each er with its own index is present. The apparent coalescence of various er's is the result of an independently motivated deletion rule without consequences for the interpretation. [5].

Although this analysis is able to account for the co-occurrence of er's, it does not follow that prepositional er and locative er do not co-occur, as is illustrated in (40).

\section{(40)*... dat hij er de helft [ $\underline{t}$ van] t gezet heeft that he there the half of put has}

The verb zetten requires an object and a locative complement, as is illustrated in (41a). The locative phrase can be an R-pronoun, as in (41b), and the object of a pp can be an R-pronoun as well, as in (41c). However, these two R-pronouns cannot be present in one sentence, as in $(41 \mathrm{~d}, \mathrm{e})$.

(41)a.... dat hij een boek over taalkunde*(in de kast) gezet heeft

that he a book about linguistics in the bookcase put has

b.... dat hij daar een boek over taalkunde $t$ gezet heeft

that he there a book about linguistics put has

a... dat. hij daar een boek [t over] in de kast gezet heeft

that he there a book about in the bookcase put has 


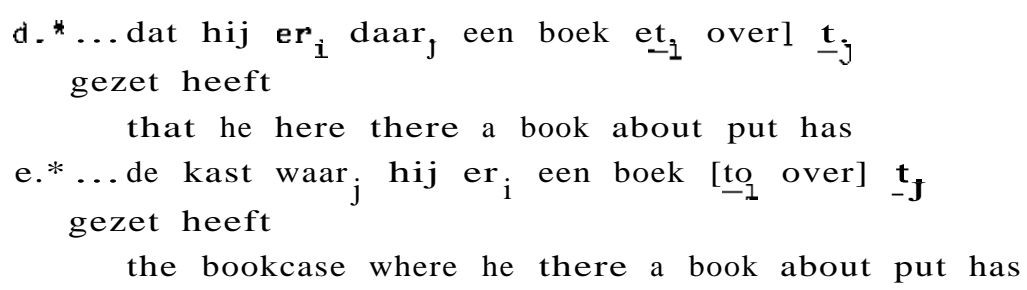

Given these facts, the ungrammaticality of (40) appears to be due to a restriction on the extraction of two R-pronouns. This restriction follows from the Gap Condition. In chapter 1, it was argued that extraction from $\mathrm{pp}$ is subject to the requirement that the pp is canonically and minimally governed by $\mathrm{V}$ (or P). In order to account for apparent counterexamples to this claim, we argued that inherent directional or locative PPs can be reanalysed as a part of a complex verb. This accounts for the grammaticality of $(41 \mathrm{~b}, \mathrm{c})$. In both cases the trace is minimally governed by $\mathrm{V}(41 \mathrm{~b})$ or the complex $\mathrm{V}(41 \mathrm{c})$. In $(41 \mathrm{~d}, \mathrm{e})$ the verb minimally governs the locative complement. This implies that reanalysis cannot take place. A consequence is that the pp cannot be minimally governed by V. This analysis is confirmed by the unacceptability of the following sentences.

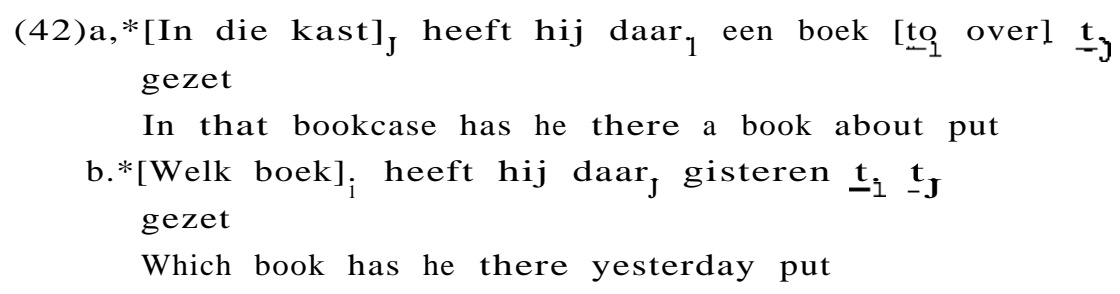

In these cases the first trace $\left(\underline{t}_{i}\right)$ is not canonically governed and so does not meet the requirements of the Gap Condition. It thus follows that the ungrammaticality of (40) is an instance of a more general prohibition. Another instantiation of this condition can be observed in the case of two stranded PPs, as in (43).

(43) *De kast waar ${ }_{j}$ hij er ${ }_{i}$ een boek [to gverjet. in] gezet heeft

The bookcase where he there a book about in put haS 
This explanation of the ungrammaticality of (40) does not exclude all potential co-occurrences of prepositional and locative er. It does not apply to those cases in which the locative $\mathrm{R}$-pronoun is not a complement to $\mathrm{V}$ but an adjunct. However, given the optionality of locative adjuncts and the weak pronoun character of er, it is very difficult to find sentences in which er is demonstrably locative and prepositional. The rather complicated example in (44b) is an illustration of the co-occurrence of locative and prepositional er in a construction with a parasitic gap.

(44)a. Jan heeft in Amsterdam [alvorens er te gaan wonen] om een John has in Amsterdam before there to go live for a vergunning gevraagd license asked

b. Jan heeft er (alvorens e te gaan wonen] $t$ om gevraagd John has there before to go live for asked c.*Jan heeft [alvorens e te gaan wonen] er om gevraagd John has before to go live there for asked d.*Jan heeft daar [alvorens e te gaan wonen] $t$ om gevraagd John has there before to go live for asked

- Jan heeft daar (alvorens e t. gaan wonen] eerst John has there before to go live at first drie jaar gewerkt three years worked

(44b) is a regular parasitic-gap sentence at first sight. Er is the antecedent of $\underline{t}$ and $\underline{e}$. However, $\underline{t}$ is a gap within pp from which it follows that er is a prepositional R-pronoun. The empty category within the adjunct is a locative phrase for which the verb wonen is subcategorized. To explain the contrast between (44b) and (44c) as a regular case of a parasitic-gap construction we would have to assume that prepositional R-pronouns may be the antecedent for locative parasitic gaps. However, the contrast in $(44 \mathrm{~d}, \mathrm{e})$ illustrates that locative parasitic gaps require locative antecedents. The relative acceptability of (44b) implies that er is locative to bind $\underline{e}$ and prepositional to bind $t$. The contrast 
between (44b) and $\{44 d\}$ is caused by the fact that co-occurrence is restricted to er.

A second instance in which it is possible to observe the co-occurrence of locative and prepositional er involves constructions in Which a locative adjunct er must be present as a resumptive pronoun. In (45a) er is required as a resumptive locative pronoun. It then follows that er in (45b) is prepositional since it binds the trace within $\mathrm{pp}$ and locative because it is used as a resumptive pronoun.

(45)a. Dit is the boekwinkel waarvan het hem tegenviel This is the bookstore Where-of it him disappointed dat hij ??(er) geen boek over taalkunde kon vinden that he there no book avbout linguistics could find

b. Dit is de boekwinkel waarvan het hem tegenviel

This is the bookstore where-of it him disappointed dat hij er geen boek [ $\underline{t}$ over] kon vinden that he there no book about could find

\subsection{Categorial status and derivation}

The questions we have to address now concern the categorial status of er, the position $\{s)$ in which the different er's are generated and how they obtain their surface positions. Let us restrict our attention in this section to prepositional, locative and quantitative er. Expletive er will be discussed in section 3.5. I shall discuss the status and derivation of these three occurrences of er in turn.

\subsubsection{The categorial status of prepositional R-pronouns}

With respect to the categorial status of prepositional R-pronouns, one might be inclined to consider them NPs since they are arguments bearing a thematic role structurally assigned by $P$ (or a $P-V$ combination). For this reason, they appear in complementary distribution with regular NP-complements. However, with respect to their internal properties and their distribution R-pronouns differ considerably from NPs. 
The generally adopted analysis in which prepositional R-pronouns are derived from NPs is proposed in Van Riemsdijk (1978a). His analysis of the occurrence and distribution of R-pronouns involves the following three steps.

1. there is a suppletion rule that changes [-human] pronouns into R-pronouns.

2. there is a filter of the form ${ }^{*} \mathrm{P}-[+\mathrm{PRO},-\mathrm{H}]$, which excludes [-human] pronouns, including R-pronouns, in a position immediately preceded by $P$.

3. there is a rule of R-movement that moves an R-pronoun to an $\mathrm{R}$-position. One of these $\mathrm{R}$-positions is generated within the $\mathrm{pp}$ to the left of $P$.

It will be clear that such an analysis does not fit the general framework adopted here. Movement of R-pronouns from a complement position on the right side of $\mathrm{P}$ would violate the Gap Condition, as has been observed in chapter 1. If R-pronouns are generated to the left of $P$ they cannot receive Case given that Case-assignment is directional. It then follows that R-pronouns are not NPs. I will argue that R-pronouns are PPs which may be assigned a structural thematic role by $P$ (cf.Hoekstra 1984. note 36). Before preSenting arguments in favour of such an analysis I shall discuss the NP-analysis of R-pronouns first.

As Van Riemsdijk observes himself, there are several problems for the NP-analysis sketched above. His analysis is designed to account for the following paradigm.

$$
\begin{aligned}
& \text { (46) a. *op dat } \\
& \text { on that } \\
& \text { b. 'op daar } \\
& \text { on there } \\
& \text { c. *dat op } \\
& \text { that on } \\
& \text { d. daar op } \\
& \text { there on }
\end{aligned}
$$

In (46a) the preposition is followed by a [-human] pronoun. It is excluded by the filter presented above. Application of the suppletion rule which changes the $[-\mathrm{R}]$-pronoun into a $[+\mathrm{R}]$-pronoun 
results in (46b). (46b) is ungrammatical for the same reason as (46a). (46c) illustrates a case of illegal movement. Only R-pronouns can be moved from the domain of the head (P). This follows from the Head Constraint. The grammaticality of (46d) illustrates a case of suppletion followed by R-movement. Neither the filter on [-human] pronouns nor the Head Constraint are violated.

One of the most attractive points in this analysis is that the ungrammaticality of (46a) and (46b) follows from the same meChanism, i.e. the filter on [-human] pronouns. Unfortunately, this filter constitutes the weakest part of the analysis. There are basically two objections. first, there are [-human] pronouns that escape the filter and second, there are [+human] pronouns that should fall under it. The first problem involves two cases.

Several [-human] pronouns which may be subject to the suppletion rule appear to the right of $P$, as is illustrated (47) .

$$
\begin{aligned}
& \text { (47)a. met alles } \\
& \text { with everything } \\
& \text { b. *met overal } \\
& \text { with everywhere } \\
& \text { c. *alles mee } \\
& \text { everything with } \\
& \text { d. overal mee } \\
& \text { everywhere with }
\end{aligned}
$$

from (47a) it follows that the suppletion rule which changes alles into the R-pronoun overal and the filter Should apply optionally. If the filter does not apply in (46a), Why does it apply to (46b)? Van Riemsdijk's account of these cases is that "the conditions under Which neither rule (8) [i.e. the suppletion rule, H.B.] nor filter (16) apply are quite idiosyncratic and subject to stylistic variation." (Van Riemsdijk 1978a, p.42). However, it seems to be the case that [-R,-human] pronouns like alles(everything), niets(nothing) and iets are never subject to the filter, whereas their [+R] counterparts are always subject to it. This generalization cannot be captured under this analysis. 
The second instance of [-human] pronouns that are not subject to the filter, involves cases in which R-movement is impossible. As Van Riemsdijk observes, several prepositions, such as zonder(without), do not allow R-movement. In those cases [-R. -human] pronouns, such as dat(that), which are subject to the filter otherwise, may appear as complement of $P$, as is illustrated in (48).

$$
\begin{aligned}
& \text { (48)a. zonder dat } \\
& \text { without that } \\
& \text { b. *zonder daar } \\
& \text { without there } \\
& \text { c. *dat zonder } \\
& \text { that without } \\
& \text { d. *daar zonder } \\
& \text { there without }
\end{aligned}
$$

Again, the [-R]-pronoun is not subject to the filter, while the $[+\mathrm{R}]$-pronoun is. These facts indicate that there is a general prohibition against $[+R]$-pronouns to the right of $P$ Which differs from the relative prohibition against [-R,-human] pronouns in the complement of $\mathrm{P}$.

A further problem for the filter concerns cases in which a [+human] pronoun cannot appear to the right of P. [-R,+human] pronouns may always appear in the complement of $\mathrm{P}$. However, it is not true that R-pronouns are inherently [-human]. It is indeed the case that prescriptive grammar requires $\mathrm{R}$-pronouns to be [-human]. On this view the perfectly grammatical a-examples of (49) and (50) should be replaced by the $[-\mathrm{R}]-\mathrm{variants}$ in the b-examples.

(49)a. de jongen waar zij [ț naar] keek

the boy where she at looked

b. de jongen [naar wie] zij t keek

the boy at whom she looked

(50)a. Als Jan een leuk meisje ziet, wil hij [er mee] uit If John a nice girl sees wants he there with out

b. Als Jan een leuk meisje ziet, wil hij [met haar] uit If John a .nice girl sees wants he with her out 
The acceptability of the a-examples indicates that $\mathrm{R}$-pronouns are not inherently [-human]. The same phenomenon can be illustrated with infinitival relatives, as in (51).

(51) Ik zoek een meisje om [t mee] uit te gaan

I look for a girl for with out to go

'I am looking for a girl to go out with'

In infinitival relatives the relative pronoun is obligatorily deleted. For reasons of recoverability pied piping is impossible. It is clear that (51) involves movement of an R-pronoun. This follows from the fact that $P$-stranding appears only in case of R-movement; from the form of the preposition, i.e. the postpositional form mee instead of the prepositional form met; and from the fact that replacement of mee by zonder results in ungrammaticality, which is due to the fact that R-movement is not allowed in case of zonder (cf.chapter 4, note 11). Again, it is clear that the deleted R-pronoun must be [+human]. Given the formulation of the filter we expect these [+human] R-pronouns to appear to the right of $P$. This is not the case, as is shown in (52).

(52) ${ }^{*}$ De jongen [naar waar] zij keek

The boy to where she looked

From these data it follows that the correlation between the non-occurrence of R-pronouns to the right of $P$ and the non-occurrence of [-R,-human] pronouns in the complement of $P$ is fairly weak. furthermore, the NP-analySis is not able to express the general non-occurrence of $R$-pronouns to the right of $P$ (but see below). In order to account for these facts two filters are necessary, one to account for the relative impossibility of [-R,-human] pronouns in the complement of $\mathrm{P}$ and $\mathrm{a}$ second one to account for the general impossibility of $[+R]$-pronouns to the right of $P$. If we allow this, the attractiveness of the NP-analysis of R-pronouns is lost. The second filter expresses only that R-pronouns do not occur to the right of $P$, without offering an explanation why this should be so. 
Let us investigate whether a PP-analysis of R-pronouns is more attractive. A first indication that $R$-pronouns should be analysed as pp, derives from the fact that they appear a, locative constituents, just like PPs. In chapter " it ha' been argued that the assignment of an (internal) thematic role takes place under government and is non-directional. Case assignment was assumed to be directional. from these claims it follows that NP-objects of $P$ should follow $\mathrm{P}$ in order to receive Case. If $\mathrm{R}$-pronouns are PPs, they are predicted to appear on both sides of $\mathrm{P}$. The reason is that PPs are not required to be Case-marked. It has also been argued in chapter 1 that the Unlike Category Condition (UCC) is directional and that the direction of application is similar to the direction of Case-marking. This independently motivated assumption allows us to explain the non-occurrence of R-pronouns to the right of $\mathrm{P}$. The order F- $[+R]$ would be ruled out by the UCC as an instance of the general prohibition of P-PP. $[+R]-P$ is allowed on a par with PP-Po If $[+R]-P$ is not a derived order as in the NP-analysis but the underlying order, we expect $\mathbf{P}$-stranding to take place in accordance with the Gap Condition. The gap which results from movement of the R-pronoun is canonically governed by $\mathrm{P}$. Given the assumption that R-pronouns are PPs that may be arguments, we are able to account for the distribution of R-pronouns within PP and their availability for movement out of PP. Let us see whether there is additional evidence in favour of this analysis.

In chapter 1 it has been observed that the prohibition against P-PP is not fully general. A few prepositions, among which van and tot, exceptionally allow PP-complements to the right. It is interesting to observe that the same class of prepositions allows $[+\mathrm{R}]$ complements to the right of $\mathrm{P}$, in conflict with the general condition discussed above. An example is provided in (53).

\section{Deze weg loopt [van hier] [tot daar] \\ This road runs from here to there}

It has been argued that in P_PP configurations reanalysis applies, with the effect that the two Ps involved are coindexed. We may adopt the same analysis for the PPs in (53). The preposition van and the intransitive preposition hier are reanalysed into a 
prepositional complex. From the position of the R-pronoun with respect to $\mathrm{P}$, and from the reanalysis of the two prepositions to escape the UCC, it follows that F-stranding is not allowed in these cases, as is shown in (54).

(54) *De stad waar deze weg [tot/toe t] loopt The city where this road to runs

A second consequence of the analysis of R-pronouns presented here is that it allows us to explain the ungrammaticality of the occurrence of R-pronouns in the absolute met(with)-construction, as is illustrated in (55).

(55)a. [Met de deur open] With the door open

b.*[Daar mee open] There with open

The absolute met-construction has recently been subject to much debate (Van Riemsdijk 1978a, Klein 1983, Beukema \& Hoekstra 1983. Van der Lubbe 1985, Smits \& Vat 1985). Although the analyses differ quite substantially, they have in common that the NF following met in (55a) is not analysed as the argument of P. This is sufficient to account for the ungrammaticality of (55b) under our approach. If not the NP in (55a) but rather the whole phrase following met is the argument of $\mathrm{P}$, there is no way to derive (55b). It is not immediately clear how the ungrammaticality of (55b) would follow in an NP-analysis of R-pronouns along the lines of Van Riemsdijk. [6].

A final point which is relevant to this discussion involves the referential properties of R-pronouns. In chapter 1 it has been argued that Case should be related to reference and thematic role to function. This is expressed by the TR-condition. If our analysis of R-pronouns is correct, we expect R-pronouns not to have reference since they are not Case-marked. It appears to be the case that R-pronouns are not specified for the so-called F-features or $\phi$-features (Chomsky 1981). These are the features of gender, number and person. These features, which are typical of pronominals, are absent in the case of R-pronouns, at least if we assume that 
R-pronouns are not [-human]. The choice of a particular R-pronoun does not restrict the domain of possible antecedents, as other pronouns do. The only features for which R-pronouns can be specified are non-referential features of the type [twh] and [ \pm proximate]. The observation that prepositional R-pronouns refer as a consequence of the fact that they are arguments, i.e. carry a structurally assigned thematic role, but do not show any further referential property, follows directly from the analysis developed here.

Summarizing this discussion, we have argued for the following two assumptions. [7 J.

(56) a. prepositional R-pronouns are PPs

b. prepositional $\mathrm{R}$-pronouns are arguments

It has been demonstrated that an analysis based on (56) can account for the distribution of prepositional R-pronouns. Under such an analysis we cannot explain the non-occurrence of [-R,-human) pronouns in the complement of $\mathrm{P}$. We have seen that a correlation between this fact and the non-occurrence of $\mathrm{R}$-pronouns to the right of $\mathrm{P}$ is only apparent. An analysis based on this supposed correlation, such as the NP-analysis proposed by Van Riemsdijk, leads to several complicated problems and missed generalizations. In our approach an additional mechanism is required to exclude the occurrence of some [-human] pronouns in the complement of most prepositions. I have no insights to offer with respect to the formulation of such a mechanism.

\subsubsection{Movement of prepositional R-pronouns}

According to Van Riemsdijk, prepositional R-pronouns including er originate on the right-hand side of $P$ in $N P$ position, where their $\mathrm{R}$-form results from a suppletion rule. After that, a rule of R-movement moves the R-pronoun from the right-hand complement side to the left-hand specifier position of $\mathbf{P}^{\prime \prime}$. The reason behind the adoption of the rule of R-movement is partly based on the observation that R-pronouns may occupy two different positions 
within PP to the left of the head. This is shown in the examples in (57).

(57)a. [Vlak er voor] stand een man

Right there before stood a man

b. [Er vlak voor] stand een man

There right before stood a man

Van Riemsdijk accounts for this phenomenon by allowing the rule of R-movement to move the R-pronoun from one base-generated $[+\mathrm{R}]$-position to another. His analysis is depicted in (58).

(58)

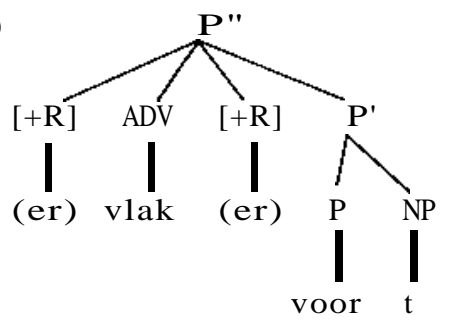

It was argued above that $\mathrm{er}$ is a complement of $\mathrm{P}$, base-generated on the left-hand side of $P$, rather than being moved from the right-hand side. The Gap Condition allows movement from the left-hand side position under canonical government. In view of the independently motivated rule of leftward adjunction, the optional shift of er from the position in (57a) to the position in (57b) does not require any stipulated landing site or a specific rule of R-movement. Er may be adjoined PP-internally to a higher level, as is the case in $(57 \mathrm{~b})$.

It will be clear that a similar analysis applies in case the $\mathrm{R}$-pronoun is moved from PP, leaving the preposition stranded. All conditions on adjunction, in particular the Gap Condition, are satisfied. This implies that the landing site of R-pronouns outside PP does not have to be base-generated. They are moved to the left according to the principles that govern leftward adjunction in general. As was argued in ch.2, leftward adjunction in Dutch is primarily motivated by pragmatic principles. 'Light' constituents are more readily moved than 'heavy' ones. Pronouns, and weak 
pronouns in particular, are almost obligatorily moved to the left. Because R-pronouns are (non-referential) pronominals and er is a weak $\mathrm{R}$-pronoun, it is in no way surprising that $\mathrm{R}$-pronouns may be subject to leftward adjunction and that er is almost obligatorily moved from PP. On this account, R-movement is just an instance of the general process of leftward adjunction, which is pragmatically motivated and syntactically constrained by principles such as the Gap Condition. Once we assume the existence of syntactic principles like the Gap Condition and the availability of leftward adjunction as a consequence of the branching nature of Dutch, the analysis of P-stranding follows without construction-specific statements.

This approach to P-stranding is quite different from the approach taken in Van Riemsdijk\{1978a,b). He argues that $\mathrm{P}$-stranding requires both one or two PP-internal $\mathrm{R}$-positions and a further R-position outside $\mathrm{pp}$ as a landing site ror H-pronouns. An argument in favour of the PP-external R-position is the so-called 'double R constraint'(Van Riemsdijk 1978b). I shall return to this phenomenon below and argue that a PP-external R-position is not required. If this is correct, there is no motivation whatsoever in favour of these base-generated R-positions. Dispensing with these $\mathrm{R}$-positions has the advantage that we are able to reduce the amount of stipulation necessary to account for the phenomenon of P-stranding in Dutch.

\subsubsection{The syntax of locative er}

With respect to the categorial status and the derivation of locative R-pronouns not much needs to be added to what has been said in the previous section. Locative R-pronouns are PPs that appear as optional PPs with a locative interpretation or if the verb (or the preposition) requires a locative complement. This is illustrated in (59).

\footnotetext{
(59)a. Ik heb (er) gewandeld

I have there walked

b. Ik het *(er) gewoond

I have there lived
} 
In this use, er behaves in all respects like a .'egular PP. It differs from prepositional R-pronouns in that it is not an argument.

The base position of locative er is either an adjunct position, freely inserted, or a subcategorized position within the complement domain of a lexical category. In these two cases er has a thematic role which is either inherently or structurally assigned.

The surface position of locative er within $S$ is again determined by adjunction.

\subsubsection{Quantitative er as a non-thematic argument}

Quantitative er differs in several respects from both prepositional and locative er. A major difference is the fact that this use of er is not related to a paradigm of $\mathrm{R}$-pronouns. Er obligatorily appears if the head of a quantified NP remains empty. [8J.

A further difference is concerned with the fact that quantitative er must remain within $S$, i.e. cannot appear in CaMP. contrary to locative and prepositional er, as is demonstrated in (60) .

(60)a. Er zit niemand [t $\underline{t}$ opJ

There sits nobody on

b. Er woont niemand $t$

There lives nobody

c. ${ }^{*}$ Er lopen [twee e] op straat

There walk two on street

The empty category within the quantified NP is either the result of movement of er or a base generated empty category. If er is moved from NP, as is argued by Kayne(1975) and Belletti \& Rizzi(1981) for similar constructions in French and Italian, it can be movement of a partitive PP, an $\mathrm{N}[-\max ]$ or a Det. I will not discuss the latter proposal (Coppen 1985) (cf.note 2 of this chapter). Suppose er is a PP, generated within the NP. One argument in favour of such an approach is the fact that quantitative er is obligatory unless the 
empty $\mathrm{N}[-\mathrm{max}]$ is followed by a partitive $\mathrm{PP}$, as is shown in (61). [9].

(61)a. [Twee e] heb ik *(er) gisteren gekocht Two have I there yesterday bought

b. [Twee e van die boeken] heb ik (*er) gisteren gekocht Two of those books have I there yesterday bought.

PPs, including partitive PPs, can be moved from NP. If er is a partitive pp we expect er to be absent when the partitive PP is moved. However, it turns out that as soon as the partitive PP is no longer part of the NP, quantitative er is obligatory, as is illustrated in (62).

(62) Ik heb van die boeken *(er) gisteren Ltwee e] gekocht I have of those books there yesterday two bought

On the assumption that $e r$ is a partitive PP, the grammatical variant of (62) contains two partitive PPs both related to the same NP. The fact that such a construction with two partitive PPs related to the same NP is otherwise impossible makes the partitive PP analysis of quantitative er highly unlikely.

The absence of quantitative $e r$ if the empty $N[-\max ]$ is followed by a partitive PP allows us to construe an interesting argument in favour of the theory of P-stranding developed in chapter 1. The argument is based on sentences such as (63).

(63) Ik heb er gisteren [twee $\underline{e}][\underline{t}$ van] gekocht I have there two of bought

At first sight this sentence appears to be derived from (61b) by movement of the prepositional R-pronoun er. However, such a derivation would be in conflict with the Gap Condition, since the pp from which extraction takes place is not canonically governed by $\mathrm{N}$. In chapter it was argued that $\mathrm{pp}$ should be canonically governed by $\mathrm{V}$ (or P) in order to allow movement. This implies that PP-complements to nouns must be moved from NP before stranding can occur. Such a derivation is not incompatible with (63). If the pp 
is moved from NP in (63) stranding can take place and quantitative er should appear, as in (62). In that case er in (63) is both quantitative and prepositional. This prediction can be tested quite easily since there is no paradigm of R-pronouns in the case of quantitative er. (64) illustrates that the stranded pp cannot be a subpart of the NP.

(64) Ik heb * (er) daar gisteren [twee e][t van] gekocht I have there there yesterday two of bought

Since daar in (64) can be interpreted as the prepositional R-pronoun the obligatory presence of quantitative er indicates that the pp is no longer part of the NP.

Let us return to the categorial status of quantitative er under a movement analysis. We have seen that DET and PP[+partitive] are unlikely candidates. Suppose $\mathrm{er}$ is a category of the type N[-max] which can be moved from a quantified NP. There are several theoretical objections to such a rule.

-the rule would involve movement of a non-maximal category, for which there is no independent evidence;

-the movement rule is obligatory. The only feasible reason to account for this obligatory movement is to stipulate that er is a c1itic and that clitics must be moved from NP;

-it is not clear that the empty category within NP is allowed in accordance With the Gap Condition;

Aside from these theoretical objections an N[_max]_movement analysis would have to consider the occurrence of an R-pronoun in this construction completely accidental. $[10]$. furthermore, there is sufficient evidence that a base-generated empty category within $\mathrm{NP}$ is required anyway. In Dutch, such an empty category of the type $\mathrm{N}$ [-max] is present in constructions with a partitive $P P$, as in (61b). In Italian and french such a category can be found in preverbal quantified NPs (cf.chapter 4.5), and in languages like English, Spanish and German such an empty category can be found in all constructions. Given the independent necessity for a base-generated empty $\mathrm{N}[-\mathrm{max}]$ and in view of the problems for a movement analysis mentioned above, it appears to be more attractive to assume that quantified NPs may contain a base-generated empty 
category in general. [11].

Assuming that the empty category is base-generated, we have to answer the following questions:

-what is th, status of the empty category?

-what is th, status of quantitative er?

-what is the nature of th, relation between er and th, empty category?

It is clear that the empty category is not a trace. Given the inventory of empty categories proposed in the literature it Should be PRO or pro. The latter empty category is an empty pronominal. As far as I can see there is no evidence that the empty $N$ [-max] is a pronominal. It cannot be replaced by pronominals; it is not clear that the empty category should be specified for pronominal features such as gender, number and person; there are no other instances of pro in Dutch. If the empty category is not pro, it should be PRO. However, it is not clear at all that it is PRO. If we assume that non-predicative NPs are opaque to government (cf.Stowell 1981), $\mathrm{N}$ [-max] is ungoverned and can thus be PRO. However, labelling this empty category PRO does not provide us with any insight in the properties of this empty category nor does it lead to empirical predictions. A complete and satisfactory answer to the first question would require a separate study, in particular if we consider the empty $\mathrm{N}[$-max $]$ from a comparative point of view. A variety of interesting semantic and syntactic questions would arise, such as the question why English allows an empty, unbound $\mathrm{N}[-\max ]$ in quantified expressions of the type [two e] but not in expressions of the type *[a red e], while the situation in Dutch is precisely the reverse, i.e. [twee e] is ungrammatical without er, but [een rode $e]$ is acceptable. This seems to suggest that adjectives might be used as nouns in Dutch but not in English, whereas numerals might be used as nouns i.n English but not in Dutch. There are indications that such an analysis is indeed correct. I will leave these and related questions for further research. Without further qualifications I shall refer to the empty CAtegory wit.hin puantified NPs as PRO.

More important for us is the answer to the second question. This question can be factored out into several related questions: what is the categorial status of quantitative er? why is an 
$R$-pronoun selected to bind or control PRO? why can only er and no other R-pronoun appear in this construction?

With respect to the categorial status of quantitative er we can assume that $\mathrm{er}$ is a PP, just as the locative and prepositional R-pronouns. The difference between locative and prepositional $\mathrm{R}$-pronouns was argued to be their argument-status. Given the fact that under our analysis quantitative er binds an empty category it is an argument, just as prepositional R-pronouns. It differs from locative $\mathrm{R}$-pronouns in that it has no inherent thematic role, and from prepositional $\mathrm{R}$-pronouns in that it does not receive a thematic role structurally. If this is correct, quantitative er is a PP which has the status of a non-thematic argument. From the non-thematic status it follows that there is no R-paradigm in the Case of quantitative er. It is present for syntactic reasons only, i.e. to bind the empty category within NP. In this sense it is a dummy pronoun. Since it does not receive an interpretation, it is not surprising to find that only the least specified member of the $\mathrm{R}$-paradigm functions as a non-thematic argument. A further question is why an R-pronoun is selected as the binder of the empty category. Obviously, this is related to the PP-status of er given that in French and Italian the binder in the quantitative construction is a PP-clitic as well. The binder cannot be an NP for reasons of Case. There is no Case available for the binder and even if it could be Case-marked, such an NP would not be suitable as a binder for $\mathrm{N}[-\mathrm{maxJ}$. Referentiality is a property of $\mathrm{NP}$ and not of N[-maxJ. No such problem arises in the case of PP-arguments. Er is non-referential as a consequence of its PP-status.

The third question which was raised above involves the properties of the relation between er and the empty $\mathrm{N}[-\mathrm{max}]$. One formal characteristic of this relation is that the binder must c-command the empty category. Given the availability of S-internal adjunction in Dutch, this is rather difficult to test. This condition can be observed more clearly in Italian and French, as will be demonstrated in chapter 4.5. More complicated is the question as to when the empty category must be bound. It appears to be the case that in Dutch the empty category must always be bound. We can formulate a condition to this effect. However, if we take Erench and Italian into consideration as well, it turns out that 
the empty $\mathrm{N}[-\mathrm{max}]$ must be bound if the NP is canonically governed. A condition to this effect is formulated and motivated in ch.4.5.3. The most complicated question in this connection involves the locality requirement on this relation. It appears to be the case that quantitative er and the NP containing the empty category must belong to the same projection. This can be observed in (65).

(65)a. *Er heeft [s niemand [twee PRO] gekocht]

There has nobody two bought

$\mathbf{a}^{\prime}$. Niemand heeft [s er [twee PRO] gekocht]

b. *Hij rekent er altijd [pp op [twee PRO]]

He counts there always on two

c. Ik vind [SC dat er ook [één es]

I consider that there also one

$c^{\prime} * \mathrm{Ik}$ vind er [SC dat ook [één e]]

d. met [se er nog steeds [twee e] in zijn handen] ... with there still two in his hands

d' *er mee [se nog steeds [twee e] in zijn handen] ...

In $\left(65 \mathrm{a}, \mathrm{b}, \mathrm{c}^{\prime}, \mathrm{d}^{\prime}\right)$ er does not belong to the minimal projection containing the quantified NP. In particular the difference between (65a) and (65a') is difficult to understand. What prevents er from being moved to the first position in main clauses? If it is claimed that the binding relation is subject to a locality constraint, the binding in (65a) may proceed via the trace within S. Movement of er to COMP cannot be excluded since all other types of er allow movement to COMP. I shall suggest a tentative solution to this problem. Suppose the relation between er and PRO is subject to a locality constraint in such a way that only one maximal projection may separate er and PRO. Such a constraint is reminiscent of the locality found in control structures (Williams 1978, Manzini 1983). If we assume this to be correct, the main problem is to account for the ungrammaticality of movement of er to a position in which it cannot bind PRO directly, as in (65a). Given that we cannot prevent er from being moved to CaMP, I shall suggest that the resulting configuration is ungrammatical since the trace is not a licit binder for PRO. In fact, it might be claimed that movement of quantitative er does not leave a trace. In chapter 1 it was argued 
that empty categories are defined by the features $+\theta$ and + Case. It was argued above that quantitative er is a PP without a thematic role. Movement of er results in an empty category without a thematic role and without Case, which is not an empty category according to the definition of empty categories. If it is correct that movement of quantitative er leaves no recoverable trace, binding in (65a) should proceed in one step, which is in violation of the binding condition introduced above. Other types of R-pronouns behave differently, since prepositional R-pronouns and locative R-pronouns are specified as $+\theta$.

This analysis also predicts that there are no parasitic R_gaps with quantitative er. As was demonstrated in ch.1.5, parasitic R-gaps are possible with prepositional R-pronouns, as is shown in (66a). Parasitic R-gaps show up with locative R-pronouns as well, as in (66b). The theory of parasitic gaps predicts that these constructions occur. In the case of the quantitative er no parasitic gap is expected to be possible for the same reasons that exclude movement to COMP. The correctness of this prediction is shown in (66c).

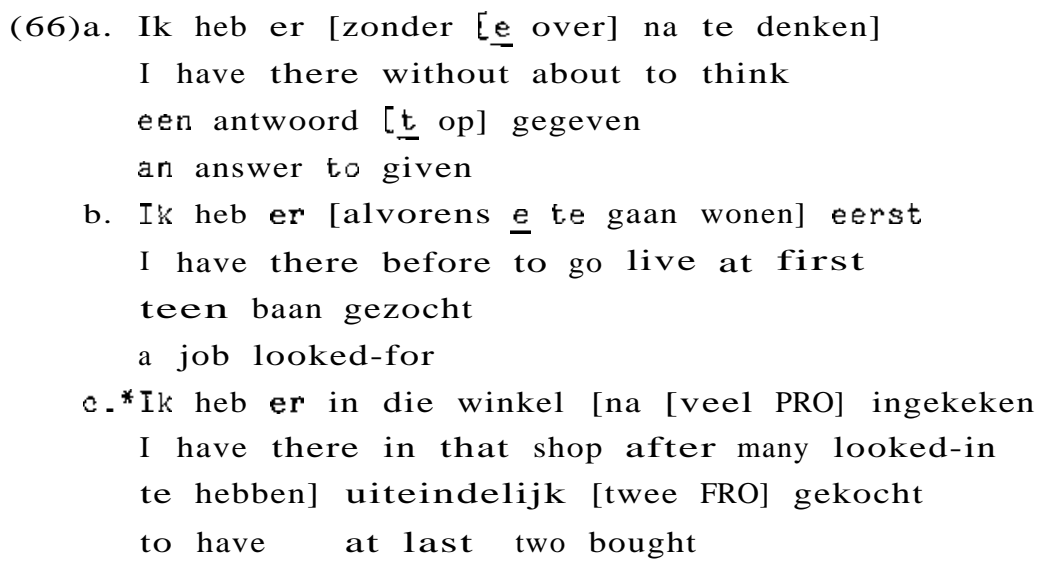

It might seem somewhat strange that $I$ argue in favour of a kind of dummy pronoun analysis of quantitative er, while I have argued at length against a dummy pronoun approach of het in the previous chapter. However, what I intended to show there was that het should not be analysed as a dummy pronoun as a consequence of 
the Extended Projection Principle only. The argument was not directed against the existence of constituents that have a purely syntactic function. In fact, it is predicted by the theory developed thus far that another dummy pronoun er should be available. In the preceding sections it has been argued that R-pronouns might be [+Argument]. In this section it has been shown that quantitative er could be analysed as $[+A,-\theta]$. If $R$-pronouns can be characterized as in (67), R-pronouns of the type $[-\theta,-A]$ are predicted to be possible.

(67) R-pronouns: pp

[+Thematic]

[tArgument]

In section 3.5, I shall argue that these R-pronouns do indeed occur, and that they show no syntactic property at all. Before going into this, however, I shall discuss the matter of R-movement in more detail, especially with respect to the so-called double-R-phenomenon.

\subsection{R-movement and the double-R-constraint}

Most linguists who have dealt with the R-phenomena in Dutch, in particular Van Riemsdijk(1978 a,b), have argued in favour of an R-position which is either the first position within VP or in between the subject and the VP. The rule of R-movement moves an R-pronoun to that position, as an instance of a structure-preserving operation. In section 3.2, I have argued against a PP-internal R-position for prepositional R-pronouns. In this section $I$ shall argue that there is no need for an R-position outside pp either. In both cases the independently motivated rule of S-internal adjunction is sufficient. If correct, this would be a desirable result since it reduces the amount of stipulation in the base component and makes the stipulation of the rule of $\mathrm{R}$-movement superfluous. In order to show that there is no need for a base-generated R-position I shall have to provide an alternative account of the so-called double-R-phenomenon (Van Riemsdijk 1978b), 
which is in fact the only and apparently rather strong argument in favour of an R-position.

\subsubsection{Van Riemsdijk's double-R-constraint}

Van Riemsdijk's(1978b) strongest argument in favour of an $\mathrm{R}$-position is based on the observation that preposition stranding by wh-movement is impossible if the R-position outside pp is occupied by a locative er. [12J. The relevant data are given in (68).

(68)a. Waar ${ }_{i}$ heeft zijj vaak $\underline{t}_{i}$ over] gesproken?

Where has she often about talked

b. Zij heeft er vaak over de oorlog gesproken?

She has there often about the war talked

c.*Waar ${ }_{i}$ heeft zij er. vaak [to over] gesproken

Where has she there often about talked?

d. Waar ${ }_{j}$ heeft zij er. vaak ${ }_{i}$. [ [to over] gesproken?

Where has she there often about talked

In (68a) it is shown that R-movement of a wh-pronoun is allowed. In (68b) the optional locative er is inserted. Given the grammaticality of $(68 \mathrm{a}, \mathrm{b})$ the ungrammaticality of (68c) is not expected. Van Riemsdijk explains the ungrammaticality of (68c) in the following way. Movement rules are subject to Subjacency. Given the fact that both $\mathrm{pp}$ and $\mathrm{S}$ are bounding nodes for SUbjacency in Dutch, movement from a PP-internal position to COMP in one step would violate Subjacency. If there is an intermediate R-position into which R-pronouns can be moved, such a position would allow the wh-R-pronoun in (68a) to escape a Subjacency violation. The required movement to COMP may proceed in two steps. If the R-position is filled by a weak locative R-pronoun, as is the case in (68c), movement would have to proceed in one step and the resulting structure would violate Subjacency. The grammaticality of (68d) follows since neither of the two movement operations violates Subjacency. The strong locative wh-R-pronoun waar can be moved to COMP in one step and the prepositional $\mathrm{R}$-pronoun can be moved into the PP-external R-position, crossing only one boundary. 


\subsubsection{R-movement and adjunction}

Although Van Riemsdijk's argument in favour of an R-position seems to be rather elegant, there is evidence that this analysis cannot be maintained. As indicated above, I shall try to argue that movement of R-pronouns is merely an instance of adjunction. R-pronouns, and in particular er, are relatively 'light' and consequently show a tendency to be moved leftwards, in a way similar to the leftward shift of NP-pronouns. In this light, the ungrammaticality of $(68 \mathrm{c})$ is completely unexpected. There is no clear reason as to why the appearance of an $R_{-}$pronoun should block the adjunction of another. It seems therefore necessary to provide an alternative account of the data discussed in the former section, without making use of an R-position. (13J.

There are two types of arguments against the Subjacency approach to (68c). First, there are cases in which a Subjacency violation does not seem to induce ungrammaticality. Second, there are sentences without a Subjacency violation that appear to be unacceptable for the same reason as (68c).

A problem for the Subjacency account is the fact that quantitative er does not block wh-movement of an R-pronoun to COMP, as is illustrated in (69).

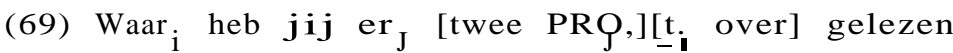
Where have you there two about read

In order to account for the acceptability of (69) it has to be assumed that there are two R-positions, one of which is exclusively reserved for quantitive er. A consequence of such an assumption is that in Van Riemsdijk's account the explanations of the ungrammaticality of $\left(7 \emptyset_{a}\right)$ and $(7 \emptyset b)$ would have to differ.

(70)a.*Zij heeft er ${ }_{i}$ er ${ }_{J}$ vaak t. [to overJ gesproken

She has there there often about talked

b. *Jij hebt er ${ }_{i}$ er ${ }_{j}$ [twee PRO $\left.{ }_{j}\right]\left[_{i}\right.$ over] gelezen

You have there there two about read 
Van Riemsdijk argues that the ungrammaticality of (70a) follows from the assumption of an R-position because the position can be filled only once (cf.note 12). There is no room for a locative er in (70a). However, given the independent necessity of a second R-position for quantitative er, the ungrammaticality of (70b) cannot be accounted for in the same way. Apparently a filter on the occurrence of two adjacent er's is necessary to account for the ungrammaticality of $(70 \mathrm{~b})$. If such a filter -similar to the one proposed in section 2- is adopted, the argument in favour of the R-position based on (70a) is severely weakened. The filter on two adjacent occurrences of er accounts for the ungrammaticality of both sentences in $(7 \emptyset)$.

A further problem involves the fact that the ungrammaticality of the crucial sentence in (68c) is not as strong as one might expect of a Subjacency violation. In particular if we force the $\mathrm{R}$-pronoun in COMP to be interpreted as a prepositional $\mathrm{R}$-pronoun, sentences of the type in (68c) improve considerably. We can achieve this effect by turning (68c) into a relative clause, as in (71).

(71)a. Dat $1 \mathrm{~S}$ het boek waar, ${ }_{1} \mathrm{zij}$ er $\mathrm{J}_{\mathrm{J}}$ vaak [to over] That is the book where she there often about gesproken heeft talked has

b. Het onderwerp waar $_{\mathrm{i}} \mathrm{ik}$ er $\mathrm{J}_{\text {en }}$ ezing [to The subject where I there a lecture about zal geven shall give

The grammaticality of the sentences in (71) indicates that a Subjacency account of the unacceptability of (68c) cannot be maintained. In fact, I do not agree with the judgement concerning $(68 \mathrm{c})$. It is true that the sentence receives the interpration indicated in (68d) in the unmarked case. However, if a suitable context is provided (68c) may become acceptable.

A different problem for the Subjacency approach involves sentences such as (72)-(75). In all these cases there is a contrast between the a- and the b-example which is similar to the contrast between (68c) and (68d). However, in these cases Subjacency fails 
to account for the observed contrast.

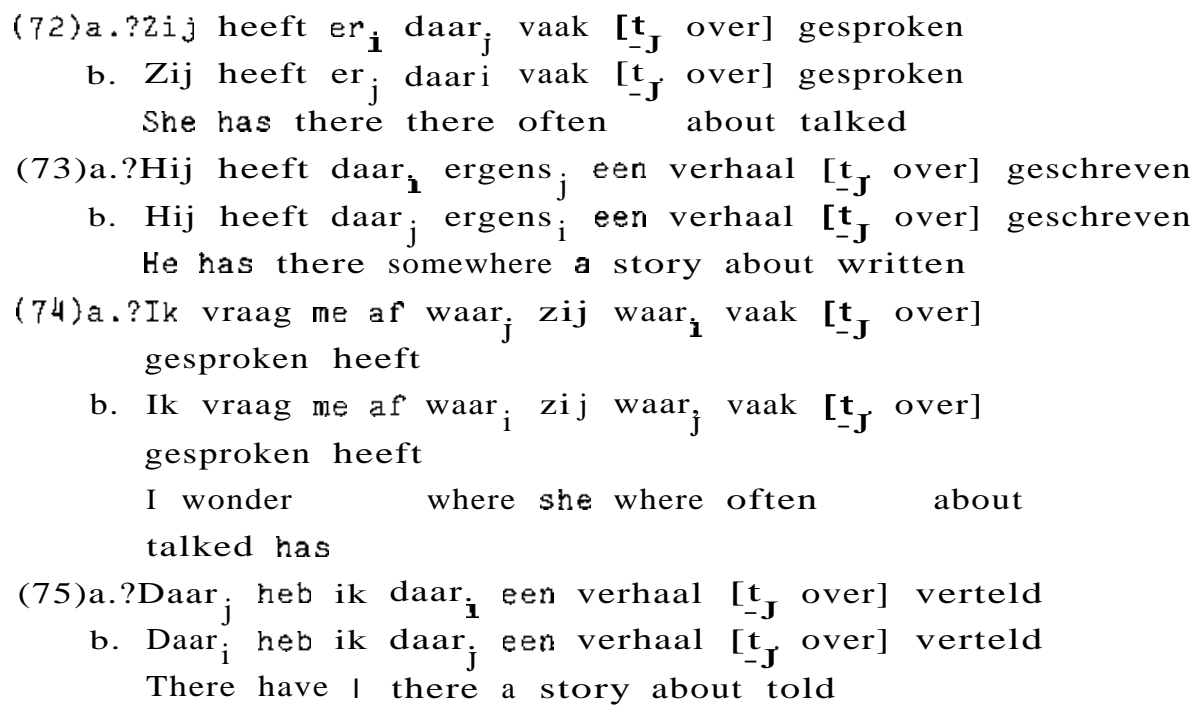

The Subjacency approach predicts (72a) to be fully ungrammatical and the other a-examples to be acceptable. The reason for this ungrammaticality of $(72 a)$ is that the weak locative pronoun er is obligatorily moved to the R-position. The same position has to be the landing site for the prepositional R-pronoun daar as well. Since this position can be filled only once, (72a) is predicted to be completely ungrammatical, which it is not. In the other a-examples the locative pronoun is not the weak pronoun er. Other locative R-pronouns do not have to be moved to the R-position. They can remain in their base position or be moved to COMP in one step. In these cases the $R$-position is free as the landing site for prepositional R-pronouns. Thus it is predicted that there is no contrast at all between the $a-$ and the b-examples, which is clearly false.

Summarizing, the analysis based on Subjacency and R-movement to a designated $\mathrm{R}$-position predicts too strong a contrast in sentences of the type (68) and (72) while it incorrectly predicts no contrast at all in sentences like (73)-(75). Furthernore, it predicts sentences such as (71) to be ungrammatical, contrary to fact. 
In the approaCh adopted here no contrast is expected at all. Movement of $\mathrm{R}$-pronouns is an instance of the general process of adjunction. There is no rule of $\mathrm{R}$-movement, there is no $\mathrm{R}$-position and Subjacency is irrelevant. With the exception of the sentences in (70), all sentences presented in this section are predicted to be grammatical. Let us investigate how we can account for the contrast in (68) and (72)-(75). A first observation concerns the fact that a purely syntactic solution to this contrast would be confronted with the problem that the contrast appears only if the two R-pronouns both qualify as possible antecedents for both gaps. Given the fact that the relative unacceptability disappears in relative clauses such as (71), a non-syntactic solution seems to be preferred.

It turns out that there are two strategies to disambiguate sentences with a locative and a prepositional R-pronoun. The first strategy involves the relative strength of $\mathrm{R}$-pronouns. It appears to be the case that the more a particular R-pronoun is specified for locative features, the less it is able to be an argument. Or put differently, the more an R-pronoun is specified for locative features, the more likely it is that it will be interpreted as a locative PP. On the basis of data such as (72) and (73) we may postulate a three-way distinction: weak R-pronouns (er), regular R-pronouns (daar (there), waar (where) and hier (here)) and strong R-pronouns (overal (everywhere), nergens (nowhere) and ergens (somewhere)). The relative unacceptability in (68c), (72a) and (73a) may then be the consequence of the fact that the weaker R-pronoun is taken as a locative PP. This strategy can be overruled quite easily if the stronger R-pronoun is prepositional for independent reasons, as in the relative clauses in (71). It is interesting to observe that the same classification of $\mathrm{R}$-pronouns is relevant with respect to the distribution of prepositional R-pronouns. In section 2.2. it was observed that a pronominal argument of $\mathrm{P}$ does not always take the shape of an R-pronoun. In addition to overal op (everywhere on $=$ on everything), there is a non-R variant op alles (on everything). This optionality applies to strong R-pronouns only. Furthermore, if a particular $P$, such as zonder, does not allow R-pronouns as arguments, it generally allows a non-R pronoun (*daar zonder (there without), zonder dat (without 
that)), with the exception of the weak pronoun: *er zonder, *zonder het. These two phenomena create a three-way distinction in the class of prepositional R-pronouns: R-pronouns that always have non-R variants (overal (everywhere), nergens (nowhere) and ergens (somewhere)); R-pronouns that have non-R variants if $P$ does not allow R-pronouns as arguments (daar (there), waar (where) and hier (here); R-pronouns that have no non-R variants (er). Such a classification of $\mathrm{R}$-pronouns Corresponds to the one proposed above.

A second factor that appears to be involved in the disambiguation of sentences with a locative and a prepositional R-pronoun involves a locality constraint. If there are two potential antecedents for a gap within PP, there is a tendency to consider the R-pronoun which is structurally closer to the antecedent the prepositional R-pronoun. A formulation of such a constraint would be similar to Koster's (1978a) Locality Principle. This strategy can be observed in (68),(74) and (75). The second $\mathrm{R}$-pronoun is separated from the gap by only one maximal projection, while at least two maximal projections separate the first R-pronoun and the gap. Again, this tendency can be overruled if no disambiguation is necessary for independent reasons, as in (71).

At present I do not know how these two strategies can be incorporated in the theory. I shall leave this problem for future research. What is relevant for our purposes is that this analysis allows us to maintain the idea that there is no R-position and no rule of R-movement. R-pronouns are subject to the rule of $\mathrm{S}$-internal adjunction, which is to be expected since they belong to the class of constituents that undergo the rule of 'light-XP-shift' most readily, i.e. pronominals. $[14 \mathrm{~J}$.

\subsection{Expletive er: a dummy pronoun?}

In this section I shall deal with the so-called expletive use of the pronoun er. It will be shown that there is evidence in favour of the presence of a fourth type of er. However, it will turn out that the occurrence of expletive er is not syntactically motivated but that it shows up for pragmatic reasons mainly. The analysis 
will lead us to the following two conclusions:

- expletive er has no thematic role; it is not an argument, because it does not occupy an argument position and is not coindexed with another constituent. Therefore, it should be analysed as $[\mathrm{pp}+\mathrm{R},-\mathrm{Q},-\mathrm{A}]$. It is interesting to observe that such a category is predicted to occur as a consequence of the R-pronoun characterization in (67). The fact that properties of expletive er warrant such a characterization is a confirmation of the theory presented in this chapter.

- although expletive er can be argued to be a dummy pronoun as a consequence of its non-thematic status, it does not fill an empty subject position. The distribution of expletive er confirms the theory in which there is no subject position as a general property of clauses. Acceptance of the Extended Projection Principle would lead us to adopt unnecessary, unmotivated and unattractive assumptions. In this respect the analysis of er is similar in spirit to the previous chapter on het.

As will be argued in section 3.6, the analysis of expletive er presented in this section provides a solution to the dat-t effect in Dutch, which has recently been a topic of considerable research and debate.

\subsubsection{The distribution of expletive er}

Before discussing the distribution of expletive er we have to determine whether the adoption of a fourth type of $\mathrm{R}$-pronoun is necessary. It is clear that er in (76) cannot be analysed as prepositional or quantitative, because there is no gap.

(76) Hij zei dat er niemand in Amsterdam op straat liep He said that there nobody in Amsterdam on street walked

A locative interpretation of er is improbable as well since the embedded sentence already contains two locative PPs, i.e. in Amsterdam and op straat. Furthermore, a locative reading of er is very improbable if er appears in existential sentences, as in (77). 
(77)a. Voor de grote knal was er niets Before the big bang was there nothing

b. Er bestaan verschillende theorieen over het ontstaan van de aarde

There exist several theories about the origin of the earth

On the basis of these observations the introduction of a fourth type of R-pronoun seems to be justified.

With respect to the distribution of expletive er it is often claimed that expletive er occurs only if the subject is indefinite and th, verb intransitive (cf.Bech 1952). [15]. It turns out that such a claim is incorrect for several reasons. Transitivity of th, verb appears to be irrelevant and the indefiniteness of the subject is clearly not sufficient. This can be illustrated with the two sentences in (78).

(78)a. dat er niemand iets gekocht heeft that there nobody anything bought has

b.??dat er niemand hel gekocht heeft that there nobody it bought has

(78a) is grammatical although the verb is transitive. If we drop the condition on the intransitivity of the verb, it is expected that (78b) is just as acceptable as (78a). The unacceptability of (78b) indicates that not only the definiteness of the subject but also the definiteness of the object is relevant for the occurrence of er. The contrast in (78) is problematical for most analyses of the definiteness effect, since these are exclusively based on the relation between er and the subject. Let us investigate the distribution in more detail. If the verb selects one argument only and this argument is indefinite er may appear. (16). This is shown in (79), which contains an intransitive verb, an ergative verb and a passive verb, respectively.

$$
\begin{aligned}
& \text { (79)a. dat er iemand/*Jan loopt } \\
& \text { that there someone/John walks }
\end{aligned}
$$


b. dat er iemand $/^{*}$ Jan valt

that there someone/John falls

c. dat er iemand/*Jan geslagen wordt that there someone/John beaten is

If the verb selects two arguments, the acceptability of er is dependent on the definiteness of both NFs, as appears from (80), which has a transitive verb.

(80) dat er niemand/*Jan een olifant/*hem gezien heeft that there nobody/John an elephant/Mary seen has

A Similar effect can be observed if the verb selects a prepositional argument, as in (81).

(81)a. dat er niemand op een cadeau rekende that there nobody on a present counted

b.??dat er niemand daar op rekende

that there nobody there on counted

from these observations we may conclude that the acceptability of the insertion of expletive er decreases if the sentence contains a definite argument. Such an account would be able to provide an explanation for the fact that expletive er appears in constructions without arguments as well. This is shown in the passive sentences in (82).

(82)a. dat er in het stadion wordt gevoetbald that there in the stadium is played-soccer

b. dat er wordt gezongen

that there is sung

After we have determined in which constructions expletive er may appear, we should investigate in which constructions expletive er must appear. Although some people (e.g.Den Besten 1981) have argued that the insertion of expletive er is obligatory, it appears to be the case that it is optional in most instances. first of all, expletive er can always be replaced by a locative PP. In all the 
grammatical examples discussed above er can be replaced by in Amsterdam without any effect on the grammaticality of these sentences. However, it is not always true that er can be left out of these sentences without affecting the acceptability. The sentences in (83) exemplify constructions in which er cannot be left out.

(83) a. dat ??(er) iemand loopt that there someone walks

b. dat ??(er) een jongen viel

that there a boy fell

c. dat ?? (er) wordt gezongen

that there is sung

The unacceptability of the sentences without er does not point to the obligatoriness of er because er can again be replaced by other expressions. For example the locative R-pronoun hier(here) may take the position of er. $[17 \mathrm{~J}$.

Er is also obligatory in examples of the type in (84).

(84)a. dat er een jongen werkt

that there a boy works

b. dat er boeken te koop zijn

that there books for sale are

If we leave out er in (84), the interpretation of these sentences changes quite drastically. In that case the subject is interpreted as generic, while the subjects are indefinite in (84). Again this change $1 \mathrm{n}$ interpretation cannot be made dependent on the presence of er. The sentences in (85) are interpreted in the same way as the sentences in (84).

(8S \}a. dat in dit bordeel een jongen werkt

that in this brothel a boy works

b. dat bij de slager boeken te koop zijn

that with the butcher books for sale are

It should be noted that these PPs do not have a complementary 
distribution with er. Besides the sentences in (84) and (85) we find variants with er and a PP in front of the subject, as in (86).

(86)a. dat er in dit bordeel een jongen werkt

b. dat er bij de slager boeken te koop zijn

From these observations it follows that in the unmarked case a constituent of the type [een $\mathrm{N}]$ or $[0 \mathrm{~N}]$ will be interpreted as generic if such an interpretation is available (cf.87b) and if it is not preceded by er or another PP.

A further observation which is relevant with respect to the distribution of expletive er is that expletive er always precedes the indefinite constituents within $S$, as in all the examples given above. This is illustrated by the ungrammaticality of the sentences in (87).

$$
\begin{aligned}
& \text { (87)a.*dat iemand er loopt } \\
& \text { that somebody there walks } \\
& \text { b.*dat boeken er te koop zijn } \\
& \text { that books there for sale are }
\end{aligned}
$$

The surface order can be changed by movement to a position outside $\mathrm{S}$, as in the main clause in (88).

(88) Boeken zijn [s er $\underline{t}$ niet te koop]

Books are there not for sale

The order of the constituents that appear before an indefinite subject is less strict. This implies that er does not necessarily occupy the first position in $S$, as is demonstrated in (89).

(89) ?dat morgen er op straat boeken zullen worden verkocht that tomorrow there on street books will be sold

Summarizing, we have seen that the following descriptive generalizations are relevant with respect to expletive er:

-expletive er appears if none of the arguments of the sentence in which er is contained is definite 
-within S expletive er appears before any indefinite argument -expletive er can be replaced by other PPs

-the appearance of expletive er or PP is virtually obligatory in sentences of the type in (83)

-the appearance of expletive er or pp is virtually obligatory in sentences of the type in (84) if a non-generic interpretation is intended

Below I shall indicate how a coherent explanation of these observations might be obtained. Before proceeding to do so, however, I shall demonstrate that no coherent syntactic explanation is conceivable within the framework adopted here.

\subsubsection{Syntactic analyses of the construction with expletive er}

Within the literature we find two distinct analyses to account for the occurrence of expletive er. The first, more traditional solution is that there is a rule of er-insertion that inserts er in a position in front of an indefinite subject (e.g.De Haan et al. 1974). The second approach is based on the assumptior. that indefinite subjects are moved to the right, i.e. to a position within VP, or are adjoined to $\mathrm{V}^{\prime}$. The empty subject position is then filled by the dummy pronoun er (e.g. Den Besten 1982, Hoekstra 1984, Bennis 1980a, Reuland 1983). I shall demonstrate that these two analyses are unsatisfactory.

First of all, the appearance of expletive er is exclusively dependent on the definiteness of the SUbject in these accounts. There is no possibility to account for the contrast in (90).

(90) $¥$. dat er niemand iets gezien heeft that there nobody something seen has b.??dat er niemand het gezien heeft that there nobody it seen has

As we have seen above, the definiteness restriction on the occurrence of expletive er applies to subjects and objects in a similar fashion. It would be unattractive to assume that the definiteness restriction on subjects is directly related to the 
insertion of er, while the definiteness restriction on objects is explained by some other, additional mechanism. It is difficult to imagine a solution of this problem within the approaches mentioned above.

The analysis in which er is inserted in front of the indefinite subject is problematical in view of the optionality of the insertion of er. In the previous section it was shown that er can always be replaced by other PPs. To account for this, a second rule of PP-insertion would be necessary as well. Such a PP-insertion rule should be subject to the same definiteness restrictions and should be able to apply in an iterative fashion. Furthermore, the rule of PP/er-insertion should be optional in most cases and virtually obligatory in sentences such as (91).

(91) dat ??(er/in de tuin) een jongen liep that there/in the garden a boy walked

Even if we take expletive er to be a pp and replace the rule of er-insertion by a rule of $P^{*}$-insertion, this would yield no perspective on an explanation of the obligatoriness of $\mathrm{PP}^{*}$-insertion in (91). Furthermore, if we take expletive er to be a $P P$, it remains unclear why this $P P$ occurs before the subject only.

Similar objections can be raised against an indefinite subject movement analysis. In most analyses of this type expletive er is considered to be an NP which occupies the subject position vacated by the moved indefinite subject. If this is correct, the optionality of the occurrence of er indicates that the empty subject position may remain empty as well. It then follows that expletive er is a dummy pronoun that fills a position that does not have to be filled. On this account it remains a mystery why pp or er are obligatorily present in (91) and why a nOn-generic interpretation requires er or pp in front of the subject in (92).

(92) dat er/in die fabriek gastarbeiders werken that there/in that factory foreign workers work

Furthermore, the assumption that $e r$ is an NP is unattractive given the fact that all other instances of R-pronouns can be analysed as 
PPs.

A further problem for the indefinite subject movement analysis has to do with the theoretical status of such a rule. A similar rule has been proposed in the literature to account for the inversion of the subject and the verb in languages like Italian and Spanish and for there-insertion contexts in English ((cf.Chomsky 1981, Belletti \& Rizzi 1981, Burzio 1981, etc.). The general line of reasoning is as follows: the subject is adjoined to VP, the trace in sUbject position is not c-commanded by its antecedent in $A^{\prime}$-position (i.e. it is not locally $A^{\prime}$-bound), therefore the trace must be covered by or coindexed with a dummy element. In pro-drop languages, there are no leXical dummy pronouns and the subject position is filled with an empty dummy pronoun. The occurrence of empty dummy pronouns in these languages is motivated by the fact that they allow pronouns to be dropped in general. In English, the subject position must be lexically filled since English is not a pro-drop language. Apparently, Dutch is like English in that it allows lexical dummy pronouns to appear and like Italian in that it allows empty dummy pronouns. In combination with the fact that Dutch allows dat-t configurations, this has led to several proposals in which Dutch has been argued to be a kind of weak pro-drop language (Taraldsen 1980, Pesetsky 1982a. Hoekstra 1983). This generalization faces several problems. For example, it is not clear in which way wh-traces in subject position and empty dummy pronouns constitute a natural class. Hoekstra(1g83) argues that the subject position may remain empty as a consequence of the fact that in Dutch the subject position is properly governed, whereas the occurrence of empty definite pronouns is dependent on properties of AGR. This seems to imply that the status of the empty dummy pronoun is similar to the status of a wh-trace. However, it has been argued in Rizzi(lg82) that in contrast to empty pronouns, including dummy pronouns, wh-extraction of a subject in Italian is possible from postverbal position only. Rizzi argues that the postverbal subject is properly governed, while the preverbal subject position is not. This implies that empty dummy pronouns need not be properly governed. If this is true, there is no correlation between wh-traces and empty dummy pronouns in the way proposed by Hoekstra. More seriously, it turns out that the occurrence of er (or pp) 
is not optional in a sentence such as (93).

(93) Wie denk je dat ??(er) $\underline{\mathrm{t}}$ komen

Who think you that there arrive

If the subject position is properly governed and empty dummy pronouns are allowed in Dutch, we expect the unacceptable variant of (93) to be acceptable. Either the subject is moved from the subject position directly or the subject is moved after indefinite subject movement, in which case an empty dummy pronoun is inserted in subject position. The obligatoriness of the occurrence of er (or PP) i.ndicates that the occurrence of empty dummy pronouns can not be made dependent on the ECP. I shall return to dat-t phenomena in section 3.6. From this it would follow that the occurrence of empty dummy pronouns in Dutch is an isolated phenomenon, which has to be stipulated in the grammar of Dutch.

A final problem related to the rule of downward adjunction is the fact that quite some specific machinery has to be introduced. After application of the rule, the relation between the trace and the moved NP should not be subject to binding. This can be achieved by stipulating that downward movement is not subject to the binding conditions (cf.Rizzi 1982,p.136) or by claiming that the relationship of a dummy pronoun in subject position and the moved subject is of a different nature, as indicated by a different kind of indexation, i.e. superscripting instead of subscripting (cf.Chomsky 1981,p.263) and that the binding theory applies to subscripting only. Although such an analysis might turn out to be necessary to account for this construction, it would be a desirable result if it could be maintained that instantiations of move alpha always show an upgrading effect as a consequence of general principles of the theory. I shall postpone a discussion of the relevant Italian and English constructions to ch.4.

With respect to Dutch, such an upgrading analysis is achieved if we assume that indefinite external arguments are not moved downward, but rather that er and other PPs may be adjoined to a position to the left of the subject. Such a rule is necessary anyway since constituents that are base-generated within the 
argument projection of $\mathrm{V}$ may show up to the left of an indefinite subject, as is shown in (94).

(94) dat daar niemand meer $[\underline{t}$ op] rekende that there nobody anymore on counted

It is clear that an adjunction analysis is able to derive all the grammatical sentences presented thus far. However, such an analysis is not able to explain that er and pp do not appear in front of a definite subject, that er or $\mathrm{pp}$ have to appear in front of the subject in (91) and (92), that expleti.ve er appears before the subject only and that a weak R-pronoun appears in this construction. I shall argue that this conglomerate of facts should be accounted for by semantic and pragmatic principles. The independently motivated rule of adjunction is sufficient with regard to the syntax. The fact that the syntax generates an enormous number of unacceptable sentences is not necessarily problematical since other modules of the theory restrict the class of well-formed sentences as well.

\subsubsection{Pragmatic motivation of er-insertion}

After the discussion of the distribution of expletive er in section 3.5.1 and the problems for a coherent syntactic account of the occurrence of expletive er in section 3.5.2, I shall now sketch the outlines of a theory in which the occurrence of expletive er will receive a pragmatic explanation. In section 3.5.3.1 I shall once more discuss the rule of adjunction or light_NP_shift which was introduced in ch.1. It has been pointed out that the application of this rule is pragmatically governed. No explicit proposals were then made to qualify this statement. Since we were concerned with the syntactic consequences of adjunction in the case of parasitic gaps and exceptional Case marking constructions, nothing was at stake. In this chapter it is necessary to look more closely at the pragmatic principles that determine the order of constituents. It turns out that the principles that govern adjunction are closely related to the principles which are involved in the construction 
with expletive er. This construction is discussed in section 3.5.3.2. It will be argued that a coherent explanation of the appearance of expletive er is possible if we take er to be a pragmatically motivated dummy pronoun. The central idea is that sentences must at least have one constituent in presupposition. If no constituent qualifies as presuppositional, expletive er must be inserted.

3.5.3.1 Pragmatic principles governing th, application of adjunction

In ch.1 the rule of adjunction was also referred to light-NP-shift. The latter term was selected to stress the correspondence with heavy-NP-shift(HNPS) in English. However, it is certainly not true that 'lightness' -interpreted in an intuitive way- is relevant with respect to adjunction in Dutch. Heavy NPs of the type which undergo HNPS in English can be subject to adjunction quite easily. An example is provided in (95).

(95) Ik ben mijn favoriete oom uit Cleveland gisteren in I am my favourite uncle from Cleveland yesterday in Amsterdam [zonder $\underline{e}$ te herkennen] t tegengekomen Amsterdam without to recognize met

Other criteria than heaviness seem to play a role. Adjunction of weak pronominals is obligatory whereas adjunction of non-specific indefinite NPs is almost impossible. This is shown in (96).

(96)a. dat ze me gisteren (??me) in Amsterdam (*me) gezien heeft that she me yesterday in Amsterdam seen has

b. dat hij (*een boek) gisteren (??een boek) in Amsterdam een boek gekocht heeft

that he yesterday in Amsterdam a book bought has

If we look more closely at the data, it turns out that there is a scale on which weak pronominals and [-spec] indefinite NPs are the extremes. This scale of availability for adjunction can be 
ordered as follows: weak pronominals - strong pronominals - names definite NPs - [+spec] indefinite NPs - [-spec] indefinite NPs. For strong pronominals and names there exists a strong tendency to move them to the left. Movement of definite NPs is optional and adjunction of indefinite NPs is marginally possible. How can we account for these observations? It is extremely improbable that this hierarchy can be motivated exclusively on semantic and/or syntactic grounds. It seems to be more promising to develop a pragmatic account. It is obvious that weak pronominals can only be used as presuppositional elements. Similarly, it seems clear that non-specific indefinite NPs belong to the part of the sentence that conveys new information, i.e. focus. If this is correct, the scale presented in (97) may represent the extent to which a particular expression is presuppositional.

A second important observation in this analysis is that the unmarked order of the middle-field in Dutch is Presupposition-focus. This assumption is made in Blom \& Daalder (1977) and Verhagen (1979). Verhagen Shows quite convincingly that the position of sentence adverbials can be determined to a large extent on the basis of pragmatic principles.

If these two observations, repeated in (97) and (98), are correct, we are able to explain the application of adjunction.

(97) Presuppositional Hierarchy

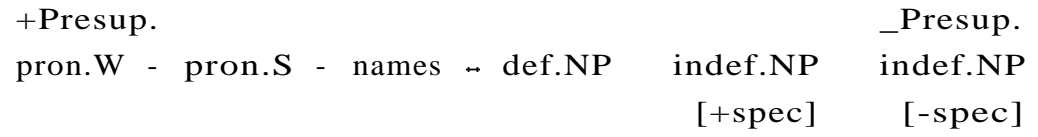

(981 Unmarked Pragmatic Order of Constituents: Presupposition - Focus

Within the limits imposed by the rule of adjunction, (97) and (98) determine the order of constituents in the middle field. 
3.5.3.2 Pragmatic principles and expletive er

Let us start with a discussion of the sentences in (99).

(99)a. dat een jongen werkt

that a boy works

b. dat er een jongen werkt

that there a boy works

Th, sentences in (99) pose two related questions. Why must th' NP in (99a) be interpreted as a generic NP and why can it not be interpreted as a non-specific indefinite NP? Why must th, NP in (99b) be interpreted a a non-specific indefinite NP and why can it not be interpreted in a generic way? Assuming that NPs of the form [een $\mathrm{N}$ ] are [ \pm generic], the question is how the insertion of er determines the value of that feature. In pragmatic terms the sentences in (99) differ to the extent that the NP in (99a) is presuppositional, i.e. it belongs to the class of definite NPs, whereas the NP in (99b) belongs to focus.

Similar observations can be made with respect to the sentences in (100).

$$
\begin{aligned}
& \text { (100)a.? dat een jongen werkte } \\
& \text { that a boy worked } \\
& \text { b. dat er een jongen werkte } \\
& \text { that there a boy worked }
\end{aligned}
$$

In (100a) the unacceptability is due to the fact that [een $\mathrm{N}$ ] must be interpreted as generic while a generic interpretation of the sentence is semantically implausible because of the past tense of the verb. In (100b) the $\mathrm{NP}$ is interpreted as indefinite. As indicated above, such a contrast does not appear in sentences of the type in (101).

(101)a. dat een jongen dat doet

that a boy that does

b.??dat er een jongen het doet

that there a boy j.t does 
In (101a) the sUbject can be interpreted as [ \pm generic]. The facts in (99)-(101) can be accounted for on the basis of the following condition.

(162) Empty Presupposition Condition (EPG) The configuration: [s (W) X (y) $\left.\mathrm{v}^{\emptyset} \quad(\mathrm{Z})\right]$ is pragmatically not well-formed unless $X \neq \emptyset$ and $\mathrm{X}$ is presuppositional

In (99a)\&(100a) the NP must appear in presupposition according to (102). An NP of the type [een N] is presuppositional if it is interpreted as [+generic]. [18]. If er is present. it is able to satisfy (102) since $e r$ is a weak pronominal which is [+presuppositional] according to the classification in (97). In this case the NP [een N] may be interpreted as non-presuppositional. In (101a) the object dat is a pronoun. Pronouns belong to the presupposition. The subject can thus be interpreted as non-presuppositional. It turns out that er in (99-100) and dat in (101) have a similar influence on the interpretation of the subject. A difference between dat in (101a) and er in $(99 b, 100 b)$ is that er forces the NP to be interpreted as non-presuppositional while the subject is [ \pm gen.] in (101a). In order to account for this difference I shall assume that er is a dummy pronoun that fills the presupposition only if there is no constituent with that pragmatic function present. The unacceptability of (101b) follows from this assumption.

Let us discuss some of the consequences of these tentative proposals. The contrast in (103) follows immediately.

\section{(103)a.??dat wordt gevoetbald that is played soccer \\ b. dat er wordt gevoetbald that there is played soccer}

In (103a) there is no constituent in presupposition which leads to a violation of the EPe. If the pragmatic dummy pronoun er is inserted. the EPC is no longer violated and the sentence is 
acceptable.

A second consequence is that we expect a difference in interpretation between (104a) and (104b).

(104)a. dat in het stadion wordt gevoetbald that in the stadium is played soccer

b. dat er in het stadion wordt gevoetbald that there in the stadium is played soccer

In (104a) the pp in het stadion must be in presupposition according to the EPC. In (104b) this pp might be in focus. Although the presuppositional hierarchy for PPs, in particular adjunct PPs, is more difficult to establish than for NPs, it appears to be the case that there exists a rather subtle difference between (104a) and (104b) which would seem to confirm the EPC.

More interesting are those cases in which a pp appears in postverbal position. As is well-known from the literature (cf. Guéron 1976,1980, Koster 1978a, Scherpenisse 1985) postverbal PPs are linked to focus, which implies that postverbal PPs are not able to satisfy the EPe. This turns out to be correct, as can be observed in (10S) and (106).

(105)a.??dat wordt gevoetbald in het stadion that is played soccer in the stadium

b. dat er wordt gevoetbald in het stadion that there is played soccer in the stadion

(106)a.??dat een jongen werkte in de fabriek that a boy worked in the factory

b. ?dat een jongen in de fabriek werkte that a boy in the factory worked

c. dat in de fabriek een jongen werkte that in the factory a boy worked

The unacceptability of (105a) and (106a) is similar to the unacceptability of (103a) and (100a), respectively. The appearance of a postverbal PP is irrelevant for the EPe since these PPs are linked to focus. Introduction of er makes these sentences acceptable. If the pp appears preverbally, it may be interpreted as 
presupposition, as in $(104 \mathrm{a})$ and $(106 \mathrm{~b}, \mathrm{c})$. The question mark in (106b) is due to the fact that presuppositional PPs are moved to the left by adjunction, in accordance with the unmarked pragmatic order of constituents (98).

Much more can be said about these pragmatic constraints. What is relevant for our purposes is that pragmatic constraints of this type are able to provide a coherent account for the distribution of expletive er. The distributional generalizations presented at the end of section 3.5.1 follow immediately.

- expletive er appears if all arguments are [-spec) indefinite NPs. This follows from the assumption that expletive er is a pragmatic dummy that fills an empty presupposition. If one of the arguments is presuppositional, expletive er is not inserted. [19].

- expletive er appears in first position as a consequence of the fact that it is a weak pronominal PP. In accordance with the pragmatic order of constituents, it precedes all indefinite NPs. [20].

- the fact that expletive er can be replaced by other PPs follows from the fact that other PPs may have a similar pragmatic function. - the fact that expletive er or PP is virtually obligatory if there is no constituent in presupposition follows from the EPe.

It has been argued above that expletive er is a kind of pragmatic dummy pronoun. Given its distribution a categorial status of PP is most likely. Such an analysis is supported by the fact that other R-pronouns are PPs as well. If the proposed analysis is correct, expletive er is not an argument. It has no thematic role either. It then follows that expletive er can be characterized as [pp+R,-A.-9). This characterization is predicted to appear on the basis of the general $\mathrm{R}$-pronoun characterization in (67). repeated below. The fact that $\mathrm{er}$ is the only $\mathrm{R}$-pronoun that can be used in this way follows from the fact that $e r$ is non-thematic in this function, just as the quantitative function of er. If R-pronouns are specified as $[+\theta]$, the full range of $R$-pronouns shows up, whereas $[-\theta]$ implies the exclusive appearance of er. Schematically this is represented in (107). 


$\begin{array}{llll}{[+\mathrm{Q},+\mathrm{A}]:} & \mathrm{R}-\text { pronouns } & \text { prepositional function } \\ {[+\mathrm{Q},-\mathrm{A}]:} & \mathrm{R}-\text { pronouns } & \text { locative function } \\ {[-\theta,+A]:} & \text { er } & \text { quantitative function } \\ {[-\theta,-A]:} & \text { er } & \text { pragmatic function }\end{array}$

Summarizing this discussion. I have argued that the occurrence and distribution of expletive er do not follow from syntactic principles. I have tried to demonstrate that the data warrant an analysis based on pragmatic principles. Although it is not my aim to provide a complete pragmatic account of these and related phenomena, several principles have been introduced as a first approximation of a pragmatic account. Several of these principles are independently motivated. The proposed pragmatic principles are: -the presupposition hierarchy (96)

-the unmarked pragmatic order of constituents (97)

-the empty presupposition condition (102)

-the linking-ta-focus of postverbal PPs

The adoption of these principles allows us to explain the occurrence and distribution of expletive er as a dummy PP which has the pragmatic function to fill the presupposition. It is evident that much more needs to be said on the status of these pragmatic principles. the status of a pragmatic component and the interaction of the syntactic and the pragmatic component. I will leave these issues for further research. In the next section I shall provide further evidence in favour of this approach in the form of a discussion of the interaction between expletive er and WH-movement.

\subsection{ER and wh-movement}

In the final section of this chapter I shall discuss the interaction between wh-movement and the occurrence of expletive er. There are several questions that have to be addressed here. such as the tendency to insert expletive er in simple questions. differences between questioning a subject and a non-subject, differences between questions and relative clauses and dat-t 
phenomena. I shall start with a discussion of the latter construction. It will be demonstrated that the theory developed thus far allows an explanation of the relevant data without recourse to additional stipulation.

\subsection{1 dat-t phenomena}

\subsubsection{Previous accounts}

Since Perlmutter observed in 1971 that Dutch was problematical with respect to long extraction of the subject, many proposals to deal with complementizer-trace phenomena in Dutch have been put forward. Before presenting an analysis here, I shall provide an overview of some of these proposals.

Perlmutter (1971) argued that in a range of languages there is a correlation between the obligatory presence of a lexical subject and the impossibility of 'long' wh-extraction from subject position. In languages like Italian and Spanish both the absence of a lexical subject and long subject extraction are allowed, whereas in French and English neither of these is possible. This is shown in (108).

(108)a. Ha trovato il libro (It.)

(He) has found the book

$a^{\prime}$. Chi credi che $t$ verra?

Who (you) believe that $\underline{t}$ will come

b. Hemos trabajado todo el día (Sp.)

(We) have worked all the day

$b^{\prime}$. Quién dijiste que $\mathrm{t}$ sali6 temprano?

Who (you) say that left early

c. *Avons travaille toute la journee (Fr.)

(We) have worked all the day

$\mathrm{c}^{\prime}$.*Qui a-t-il dit que $\mathrm{t}$ va venir ce soir?

Who has he said that will come this evening

d. *Have found the book

$\mathrm{d}^{\prime} . *$ Who do you think that $\mathrm{t}$ left? 
To account for this correlation, Perlmutter proposes the following constraint, which has the theoretical status of surface constraint and which was claimed to be part of the grammar of English and French, but not of Italian and Spanish.

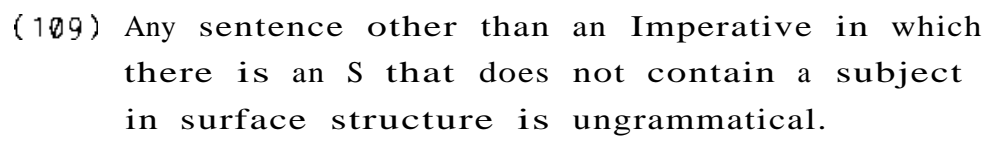

(Perlmutter 1971: 100)

As Perlmutter observed, Dutch constitutes an apparent counterexample to this generalization, since sentences without a lexical subject are not generally allowed, whereas long extraction of a subject is possible, as is illustrated in (110).

\author{
(110)a. *Heb het boek gevonden \\ Have the book found \\ b. Wie denk je dat $t$ het boek gevonden heeft? \\ Who think you that the book found has
}

Perlmutter argues that Dutch is a language of the Italian Spanish type in which the surface constraint in (109) is not obeyed. Since Perlmutter makes no claims about these languages. the ungrammaticality of (110a) should receive independent explanation.

Chomsky \& Lasnik(1977) implement Perlmutter's surface constraint in their framework of universal filters. The filter in (111a) and the related condition in (111b) replace (109).

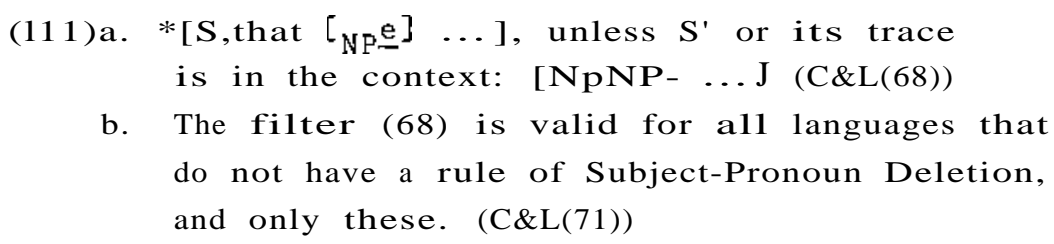

Chomsky \& Lasnik are aware of the problem of long extraction in Dutch, which leads to a violation of (111). They suggest that the acceptability of long extraction of the subject is restricted to 
certain dialects in which reasonable alternative analyses are available. Unfortunately, they do not indicate which dialects they mean and what the reasonable alternative might look like.

Maling \& Zaenen (1978) criticize Chomsky \& Lasnik on this particular issue. They argue against the universality of (111) and claim that there are two. non-regional or social dialects of Dutch, Dutch A and Dutch B. Dutch A allows long extraction of the subject and Dutch $B$ does not. In their view these variants differ in another respect as well. Dutch $B$ requires expletive er to appear if the subject is moved to the right by Indefinite NP Movement or if there is no subject, e.g. with impersonal passives, while the appearance of er is optional in Dutch A. They argue that the filter in (111a) might be maintained if (111b) is replaced by (112). [21J.

(112) Filter (68) is valid for all languages with obligatory dummy subjects, and only these $\left(M \& Z\left(2^{\prime}\right)\right)$

Within a framework based on On Binding (Chomsky.1980a) both Taraldsen(1980) and Pesetsky(1982) take Maling \& Zaenen's correlation between the oblifatoriness of the dummy pronoun er and the impossibility of long subject extraction to be the relevant generalization to provide an explanation of the Dutch problem. Taraldsen(1980) suggests that there is an er-position in front of S. In Dutch B, the er-position should be filled as a consequence of the filter *[ER e]. No such filter is present in Dutch A. Within Taraldsen's framework a wh-phrase in subject position cannot be moved to COMP in one step (this would constitute a violation of the Nominative Island Constraint), but has to be moved through the er-position. In Dutch B, this would lead to a violation of the er-filter, but not in Dutch A. Pesetsky (1982) suggests that Dutch $A$ is basically a null-subject language, such as Italian and Spanish. Dutch differs from these languages in that it does not allow null personal subjects. He claims that Dutch A lacks a rule of interpretation that relates the verbal morphology to the (empty) subject. The morphology of the Dutch finite verb is not rich enough to feed such a rule. Thus, only dummy subjects and traces in subject position are allowed, since the null-subject position in Dutch A is not subject to the NIC. Dutch B on the other hand does 
not allow traces in subject position nor empty dummies since in Dutch B empty subject NPs are subject to the NIC.[22].

The main problem with these analyses is that they are based on a correlation between dat- $t$ phenomena and dummy pronouns. As has been argued in Bennis\{1980.1983) no such correlation can be motivated. As far as I know, all speakers of Dutch allow sentences such as (113). in which no er is present.

(113) In Amsterdam wordt vaak gevochten

In Amsterdam is often fought

On the other hand, the acceptability of dat-t configurations seems to be dependent on the internal structure of the sentence from which the subject is extracted. Whereas (114a) is marginally acceptable, possibly subject to individual variation, (114b) is perfect for all speakers of Dutch.

(114)a.??Wie denk je dat $\underline{t}$ komt?

Who think you that comes

b. Wie denk Je dat $t$ dat boek gekocht heeft?

Who think you that that book bought has

(114a) can be improved by inserting expletive er in the subordinate clause, while the reverse effect is obtained by inserting expletive er in (114b).

Another problem with a Pesetsky-type solution to the Dutch problem resides in the fact that a null-subject language like Italian is subject to the COMP-: effect as well, as has been shown by Rizzi(1982). Kayne(1981) argued that the EC? is a principle that should apply at the level of Logical form. in order to explain the contrast in (11S).

(115)a. Je n'ai exigé qu'ils arretent per-sonne

I (neg) have required that they arrest nobody

b. *Je n'ai exigé que per-sonne soit arrêté

I (neg) have required that nobody is arrested

The position of ne $\left(\mathbf{n}^{\prime}\right)$ in (115) indicates that the negation ne .๑. 
personne has wide scope. If we assume that scope of quantifiers is determined by a movement rule analogous to wh-movement (cr.May 1977), the ungrammaticality of (115b) can be seen as a consequence of the COMP-t effect.

Given the possibility of null subjects in general in a language like Italian, it might be expected that a similar contrast cannot be observed in Italian. However, as Rizzi has shown, a comparable contrast is present in Italian as well.

(116)a. Non pretendo che tu arresti nessuno

Not (I) require that you arrest nobody

b. Non pretendo che nessuno ti arresti

Not (I) require that nobody you arrests

Only in (116a) can the sentence be interpreted as containing one negation with wide scope.[23J. The unavailability of the wide-scope interpretation of nesauno in $(116 \mathrm{~b})$ is exactly parallel to the unacceptability of (115b). If Kayne's explanation of (115) is correct, we have to assume that (116b) with wide-scope interpretation is unacceptable as a consequence of the ECP. This implies that obviously the COMP-t effect is observed in Italian as well. This analysis is motivated by the fact that a wide-scope interpretation is available in (117).

(117) Non pretendo che ti arresti nessuno

Not (I) require that you(DO) arrests nobody

If the subject appears in postverbal position, as in (117). a wide-scope interpretation is possible. These facts suggest that the COMP-t effect is observed in Italian and that apparent counterexamples, such as (118). involve extraction from postverbal position.

(118) Chi credi che verra $t$ ?

Who (you) believe that will come

It then fOllows that the COMP-t effect has no relation to the null-subject status of the language. It might be considered a 
general restriction on movement, which can be formulated as part of the ECP. If this is true, not only Pesetsky's analysis of the Dutch problem no longer holds, but it also indicates that a solution to the Dutch problem should be sought in the application of the ECP in Dutch.

A proposal to relate the dat-t configuration in Dutch to the application of the ECF was presented in Bennis\{1g80). In Pesetsky( 1982) and Chomsky(19800) it was argued that the COMP-t effect is related to the doubly-filled COMP filter. in order to explain the contrast in (119).

(119)a.*Who do you think that $\mathrm{t}$ will be there? b. Who do you think $t$ will be there?

The argument runs as follows. The ECP requires a trace to be properly governed. A subject trace can be properly governed if it is locally bound by a wh-phrase or trace in COMP. Given the fact that the COMP position can be filled by one constituent only, the trace in (119a) cannot be properly governed from the adjacent COMP. In (119b), there i8 no lexical complementizer and the COMP can be filled by an intermediate trace allowing the trace in subject position to be properly governed, as required by the ECP.

In Benni8(1980) it was proposed that there is no doubly-filled COMP filter in Dutch, given the possibility of sentences such as $(120)$.

(120) Ik weet niet [wie of dat] hij $\underline{t}$ gezien heeft

I know not Who whether that he seen has

It was argued there that the availability of a doubly-filled COMP allows a trace in subject position to be properly governed, even if a lexical complementizer immediately precedes the trace. This was formally achieved by allowing CaMP to be indexed by upward percolation if CaMP contains an indexed constituent. Since CaMP minimally c-"commands the trace in subject position, the trace is properly governed under coindexation and the ECP is satisfied. It was pointed out that Dutch $A$ and Dutch $B$ differ only with respect to the acceptability of dat-t configurations, while the occurrence 
of dummy pronouns is an unrelated issue. The difference between Dutch A and Dutch $B$ wa accounted for by assuming that the possibility of th, index-percolation to COMP was subject to variation. Percolation and subsequent proper government of a trace in subject position was assumed to be possible in Dutch A, but oot in Dutch B.

Hoekstra(lg83,1g84) and Koster(lg84) go one step further by assuming that there is no dat-t effect in Dutch at al1. [24]. They assume that long extraction of the subject is possible in all instances. Their analyses differ. On the assumption that INFL, which governs the subject position, is not a proper governor, extraction of the subject Should be licensed by the additional procedure of local coindexing. Hoekstra $(1 \mathrm{~g} 83, \lg 84)$ argues that Dutch INFL becomes a proper governor as a consequence of raising the finite verb into the position of INFL. By raising $V$, which is a proper governor, to INFL the subject position is governed by a lexical category, as required by the ECP, thereby allowing (long) extraction. In Hoekstra's view the possibility of subjectless sentences without dummy pronouns can be accounted for by the same mechanism. Empty positions including empty dummy pronouns Should be subject to the ECP. Since the subject position is properly governed, traces and empty dummy pronouns are expected to appear. The fact that empty personal pronouns are not allowed in Dutch follows from the fact that AGReement is not rich enough to identify the empty personal pronoun. His analysis resembles Pesetsky's solution to the Dutch problem. Hoekstra claims that in general subject positions may remain empty if they are governed by a proper governor or if they are coindexed with a sufficiently specified AGR. If this is correct, it is also predicted that wh-extraction from preverbal position in Italian is allowed, given that the subject is coindexed with AGR. This is in contradiction with Rizzi's(lg82 ) analysis of the wide-scope interpretation of nessuno, as was pointed out above (cf.(116)\}.

Koster(1g84) also argues that COMP-t effects are absent in Dutch. Following Aoun (1981), he assumes that wh-traces in subject position are subject to the NIC, implying that such traces should be bound within the minimal domain in which nominative Case is assigned. The difference between Dutch and English then resides in 
the fact that in English nominative Case is assigned by INFL within $S$, making $S$ the minimal domain in which the trace should be bound. In Dutch on the other hand, Case is assumed to be assigned by COMP, from which it follows that $S^{\prime}$ is the minimal domain of application of the NIC. From this difference in domain of application of the NIC it follows that in Dutch a trace in COMP can bind a trace in subject position to satisfy the NIC, while this is impossible in English. One of the problems this analysis faces is -again- long extraction in Italian. Since in Italian INFL is assumed to be S-internal, it follows that long extraction of the subject is impossible altogether, unless it is also assumed that coindexation between AGR and the subject is sufficient to satisfy the NIC. If we do so, we expect wh-extraction from preverbal position to yield correct results, which contradicts Rizzi(lg82).

While Koster and Hoekstra argue that all extractions from subject position are acceptable, Reuland(1g83) argues that there is a three-way distinction in acceptability. Some extractions are acceptable to all speakers of DutCh, such as (121a), some are acceptable to only a subclass of speakers, corresponding to the Dutch A speakers introduced above, such as (121b\&b'), and some extractions are ungrammatical for all speakers, as is shown by (121c) .

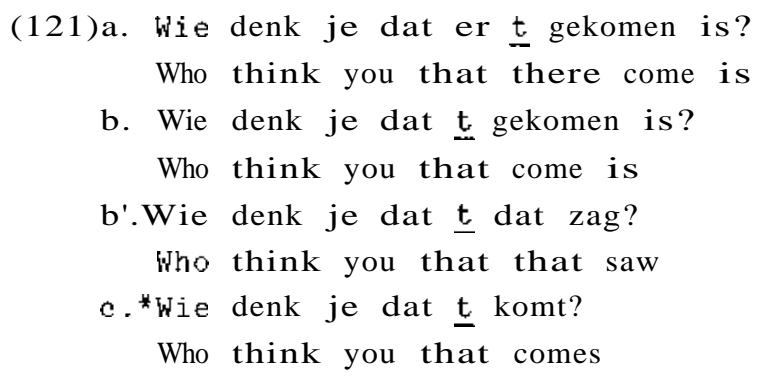

Reuland assumes that traces should be properly governed and that INEL is not a proper governor. The unquestioned acceptability of (121a) is accounted for on the assumption that the subject is moved from object position, which is properly governed by the verb. The subject is placed in object position as a consequence of er-insertion (cf.Den Besten 1981). The fact that in Dutch B 
(121b,b',c) are ungrammatical follows from an additional requirement in the grammar of Dutch B which imposes the condition that the structural subject must be either non-empty or governed by a coindexed non-empty element. If we call this principle $X$, it is claimed by Reuland that the sentences in (121) differ in such a way that (121a) is in accordance with both the ECP and X, $\left(121 b, b^{\prime}\right)$ are in accordance with the ECP but violate $X$, while (121c) violates both the ECP and X. A pertinent question, then, is how the ECP can be applied in such a way that $(121 \mathrm{c})$, but not $\left(121 \mathrm{~b}, \mathrm{~b}^{\prime}\right)$, violates it. Like Hoekstra, Reuland argues that the verb is moved to INFL. If verb and INFL merge, the resulting constituent is able to govern the trace in subject position properly. This explains the grammaticality of $\left(121 \mathrm{~b}, \mathrm{~b}^{\prime}\right)$ as far as the ECP is concerned. It does not explain the ungrammaticality of (121c). Reuland's claim is that the movement of the verb to INFL results either in a merged category in which the properties of the two constituent elements are preserved as properties of the resulting category or in a branching category as a result of adjunction of the verb to INFL, in which case the verbal properties are not properties of the whole category. It is clear that a merger of $\mathrm{V}$ and INFL is required for proper government of the trace in subject position. Reuland argues that such a merger leads to a violation of the theta-criterion in case of (121c), but not in $\left(121 \mathrm{~b}, \mathrm{~b}^{\prime}\right)$. In (121b) the auxiliary is moved to INFL. As epistemic auxiliaries do not assign theta-roles, the subject will be theta-marked only once, before the merger. In $\left(121 b^{\prime}\right)$, the verb has merged with INFL. The structure is well-formed since there are two NPs and two $\theta$-roles. However, in (121c) the subject will be theta-marked twice, once at D-structure and once after merger of $\mathrm{V}$ and INFL, since non_auxiliary verbs are able to assign a thematic role. In (121c), adjunction of the verb to INFL is required, which makes extraction of the subject impossible as it would violate the ECP. In addition to the fact that this analysis requires a number of weakly motivated assumptions, it leads to a number of observational problems. First of all, the three-way distinotion is hard to substantiate. There does seem to be a tendency according to which (121a) is more acceptable than (121b), while (121b) is more acceptable than $(121 \mathrm{c})$. However, the separation between what is grammatical and 
what is ungrammatical and between Dutch A and B is too black and white. (121b') is unquestionably acceptable to all speakers of Dutch, although Reuland predicts that this sentence is grammatical only for speakers of Dutch A. Furthermore, (121b) is less acceptable for all speakers of Dutch than the corresponding sentence in which expletive er is present. Although for all Speakers of Dutch (121c) seems to be relatively awkward, the verdict of ungrammaticality seems to be far too strong, especially in comparison with (121b). Finally, it is predicted that a sentence such as (122) should be ungrammatical, whereas it is perfectly aCCeptable and even better than (121b).

(122) Wie denk jij dat $\underline{t}$ in de tuin liep? Who think you that in the garden walked

Summarizing, I think that none of the proposals that I have discussed with respect to long extraction of the subject is fully satisfactory from a theoretical and descriptive point of view. Descriptively, we can distinguish between proposals that allow all long subject extractions to take place(Hoekstra,Koster), proposals that do not allow subject extraction in Dutch (Chomsky\&Lasnik) and proposals that distinguish betWeen two variants of Dutch, Dutch A and B (Maling\&Zaenen, Taraldsen, Pesetsky, Bennis, Reuland). Below, I shall argue that all long extractions from subject position are grammatical, but that not all of them lead to acceptable sentenCes. This unacceptability is to some extent subject to individual variation but is in no way consistent enough to justify a distinction between Dutch A and Dutch B. Theoretically, all proposals Create problems for the general theory of extraction. I shall demonstrate that an approach based on the Gap Condition and the pragmatic constraints formulated in section 3.5 provides a simple and consistent analysis of the Dutch problem. 


\subsubsection{Subject extraction and the Gap Condition}

In chapter 1 it has been argued that subject-object asymmetries can be accounted for quite elegantly by an approach based on Kayne's Connectedness Condition. The Gap Condition was introduced as a more restrictive version of Kayne's condition. Let uS now investigate whether the Gap Condition allows an explanation of the COMP-t phenomena and in particular of the possibility in Dutch to extract a wh-phrase from subject position.

A first assumption that has to made is that INFL is a governor that is in no way distinct from other governors. In most analyses INfL is considered to be a governor, but not a proper governor. This distinction is introduced in order to be able to account for the fact that long extraction of the subject is severely constrained, whereas no such restrictions are found with object extraction. Naturally, a theory in which no stipulated internal division in proper and non-proper governors is made is to be preferred. If INfL is a (proper) governor like other governors, such as $V$, the subject-object asymmetry with respect to extraction should receive a different explanation.

In fact, most of the COMP-t phenomena follow directly from the Gap Condition. In languages like English and French the subject precedes INfL. This is generally considered to be a reflection of the base rule $\mathrm{S} \rightarrow \mathrm{NP}$ INFL VP. In our approach one might say that INFL assigns Case to the left, which implies that external arguments should appear to the left of INFL to satisfy the Case requirement. On the other hand, the verb assigns Case to the right in these languages. It follows that canonical goverment is from left to right in French and English. It also follows that the subject position is governed by INFL, but not canonically. The Gap Condition requires extraction to take place from canonically governed positions. Consequently, extraction from subject position would violate the Gap Condition. Only by means of additional mechanisms. such as the que + qui-rule or deletion of the complementizer can subjents be extracted. The COMP-t effect Can thus be considered a direct consequence of the Gap Condition.

This explanation of the COMP-t eFfect in English and French resembles the explanation of the impossibility of 
preposition-stranding in Dutch, which was extensively discussed in chapter 1. In these two cases the direction of Case assignment differs from the direction of canonical government. In Dutch the direction of canonical government is from right to left. Prepositions assign case from left to right. Only in the case of postpositions does P-stranding appear to be possible. It follows that extraction of the subject in Dutch can be predicted to be possible. As indicated before, I shall assume that INFL in Dutch appears in a position following $S$. Arguments in favour of this claim can be found in Hoekstra (1984). INFL governs an NP within S, if it appears outside the argument projection of V. Given the fact that INFL governs from right to left, it canonically governs that NP. It thus follows that extraction of the subject is allowed as far as the Gap Condition is concerned. This situation illustrated in (123).

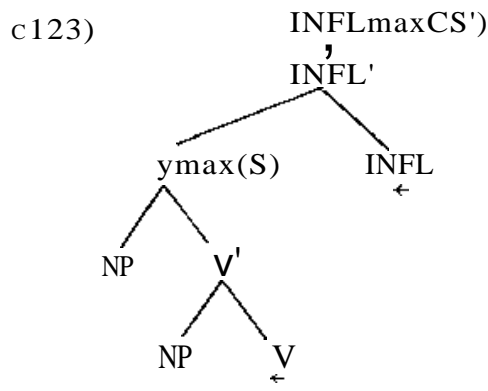

No merger between $\mathrm{V}$ and INFL CHoekstra, Reuland) or variation in domain for the application of the NIC (Koster) is necessary to arrive at an analysis in which long extraction of the subject in Dutch is allowed.

With respect to Italian, it follows that extraction of the subject is possible only from postverbal position. Italian is an YO language, just like French and English. It is therefore predicted that a nominative NP can be extracted only if it follows INFL. In preverbal position the NP precedes INFL and extraction would violate the Gap Condition. In postverbal position INFL governs the nominative NP canonically, in which case the Gap Condition is satisfied. Note that this analysis of Italian subject extraction differs considerably from the analyses presented in Rizzi(1982) and 
Chomsky(1981). They argue that extraction from postverbal position is possible since the postverbal NP is governed by $V$. This is necessary in their approach because INFL is not a proper governor. Only if the subject is governed by $\mathrm{V}$ is the ECP satisfied. Such an analysis requires a government definition in which the adjoined subject is part of the government domain of the verb. Such a definition is provided by Aoun \& Sportiche(1983\}, who claim that the upper boundary of government is the maximal projection of the governor. In chapters $1 \& 2$ it has been argued that government should be restricted to the argument projection of the governor, i.e. ' $X^{\prime}$. In our approach the postverbal subject is not governed by the verb. Instead, it is governed by INFL, similar to the way in which the nominative NP in Dutch is governed by INFL. In fact, the resulting structure appears to be the mirror image of (123). In postverbal position the subject is canonically governed by INFL and extraction is allowed by the Gap Condition (cf. ch.4.5.3 for a further elaboration of this analysis with respect to the occurrence of ne). The fact that the COMP-t effect seems to be present in Italian is therefore an interesting confirmation of the theory presented in chapter 1.

If the COMP-t effect is considered to be a consequence of the Gap Condition, it follows that we expect it to be absent in those languages in which the linear order of INFL and NPnom is similar to the order of $\mathrm{V}$ and $\mathrm{O}$. One of these languages is Dutch, as discussed above. Other languages in which the two orders are similar are German and Old English. Long subject extraction is permitted in Old English, as is illustrated in (124)(cf.Allen 1977,1980, Pesetsky 1982).

(124) Ac ic wolde witan hu je auhte be jam monnum 引e but I would know how thee seemed the man that wit $\mathrm{r}$ cwædon dxt unc suhte dxt $\mathrm{t}$ won we earlier said that us seemed that were wilddiorum gelicran jonne monnu wild-beast like-er than men

'But I would like to know how it seemed to you about the men that we said earlier that were more like wild beast than men' (B,XXVIII.5 p.122.13/ AlIen 1980,(3) 
According to Bayer (1984), COMP $-\underline{t}$ phenomena are not allowed in Standard German, contrary to what we might expect, However, it turns out that long extraction from object position is impossible as well, This is shown in (125).

\section{(125)a.*Wer glaubst du dass $t$ Emma liebt? \\ Who think yoo that Emma loves \\ b.*Wen glaubst du dass Emma $t$ liebt? \\ Whom think you that Emma loves}

No subject-object asymmetry with respect to long extraction shows up. Interestingly, Bayer(1984) shows that in the Bavarian dialect of German both long subject and long object extraction are allowed, as in (126).[25J.
(126)a. Wer moanst do dass $t$ d'Emma mog?
Who think you that Emma loves
b. Weam moanst do dass d'Emma $\underline{t} \operatorname{mog}$
Whom think yoo that Emma loves

The COMP-t effect does not show up in this dialect. Since German and Old English display basically the same order of constituents as Dutch, this is no surprise. I shall return to German and Old English in the next chapter.

A more complicated situation arises in Icelandic. As demonstrated by Maling \& Zaenen(1978), Icelandic allows COMP-t configurations, as in (127).

\footnotetext{
(127)a. Hver sagðir う̆ a $t$ væri kominn til Reykjavikur? who said you that was come to Reykjavik

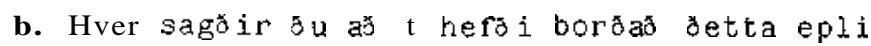
who said you that had eaten this apple
}

At first sight Icelandic seems to be a language with the order NP-INFL-[VpV-oJ, just like English, French, Norwegian etc. If this is correct, we expect that extraction of the subject violates the Gap Condition. However, Icelandic observes a verb-second constraint both in main and subordinate clauses. This is demonstrated in 
(128) .

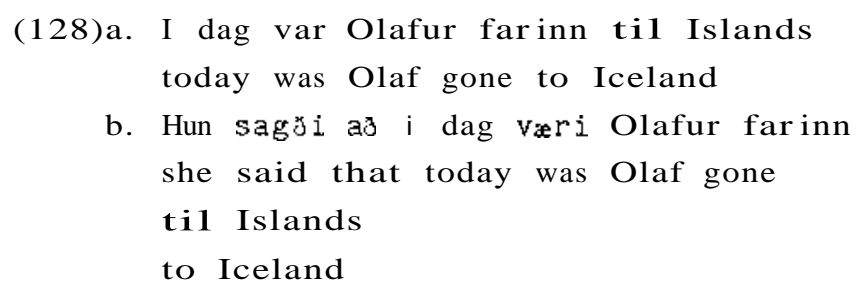

These facts indicate that the basic order in Icelandic might be something like XP-INFL-[sNP[V,V-OJJ. If this is true. the subject $\mathrm{NP}$ is canonically governed by INFL in its original position. Extraction of the subject NP would then proceed in accordance with the Gap Condition. [26J.

\subsubsection{Subject extraction and the EPC}

In the preceding section it has been argued that as far as syntax is concerned long extraction of the subject is allowed. We may then wonder what causes the low degree of acceptability of (129a), in particular when we compare this sentence to (129b).

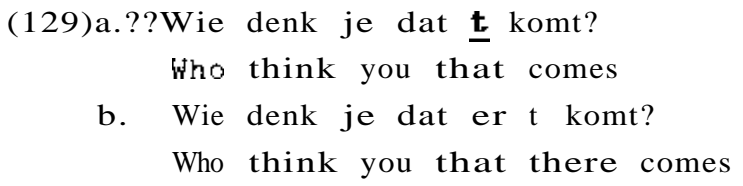

As it stands, this contrast follows directly from the Empty Presupposition Condition, introduced in section 5.3,(106). If at least one constituent is to belong to presupposition, the trace or rather the fronted wh-phrase should be interpreted in this way. This is in clear conflict with the nature of wh-constituents in questions. As they should be interpreted as part of focus, the EPC is violated in (129a). The introduction of expletive er in (129) as a minimal filler of the presupposition makes the sentence perfectly acceptable. 
The data relating to these subject extractions in the caSe of questions resemble the data on impersonal passives very closely. It is clear that the fronted wh-phrase cannot be interpreted as part of presupposition, while in impersonal passives there is no subject at all. In both cases something else is required to satisfy the EPC. I shall first demonstrate that the same acceptability judgements hold in this construction as in impersonal passives. It will then be shown that no such restrictions can be found if the extracted constituent can be interpreted as belonging to presupposition, which is the case in relative clauses.

If the sentence contains -in addition to the extracted sUbject- only a verb and a PP, the PP must appear preverbally. Consider the sentences in $(130)$.

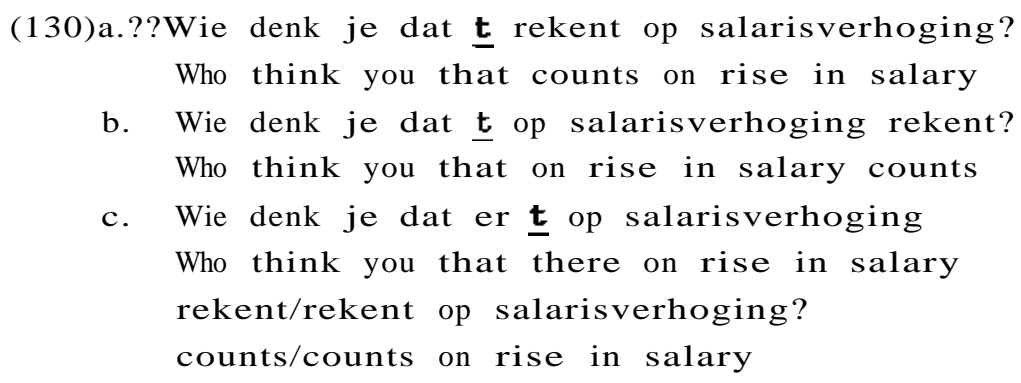

The contrast is brought about by the fact that the pp in (130a) must be interpreted as part of focus, as a consequence of its postverbal occurrence. In $(130 \mathrm{~b})$ the pp can be interpreted as part of presupposition.

If the verb is transitive, a reverse effect can be observed. The more clearly the object belongs to the presupposition, the less acceptable it is to insert expletive er. If the object belongs to focus quite clearly, there exists a strong tendency to insert er.

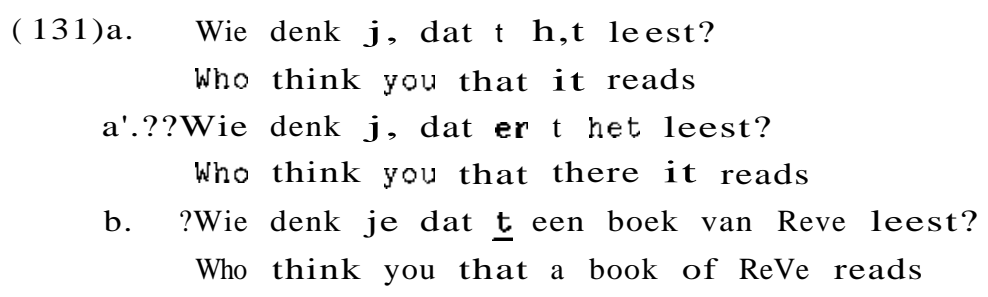


b'. Wie denk je dat er teen boek van Reve leest? Who think you that there a book of Reve reads

These facts follow from the EPe and from the analysis in which expletive er is considered to be a dummy pronoun that fills an empty presupposition. In (131a) the object is a pronoun. Pronouns belong to presupposition. It follows that the insertion of er leads to a contradiction, since insertion of er entails that the pronoun het is not part of presupposition. In (131b) the indefinite object belongs to focus in the unmarked case. The sentence with er filling the presupposition is unmarked.

A very striking argument against an analysis in which the occurrence of expletive er is related to the possibility of extraction is provided by the fact that there is a clear difference between different instantiations of wh-movement. If the subject is extracted in Topicalization, Relative Clause formation and elefting structures, expletive er does not show up. Examples of these constructions can be found in Brachin(1973) and Paardekooper(1971).

(132)a. Die man denk ik niet dat $t$ veel haast zal maken That man think I not that much haste will make 'That man I don't think will hurry much

b. vrienden die hij weet dat $\underline{t}$ met genoemde friends who he knows that with aforementioned firma zaken doen firm business do 'friends who he knows do business with the aforementioned firm'

c. Het is Piet die ze zeggen dat $t$ zou komen it is Pete who they say that would come

In those cases expletive er is not inserted, whatever the content of the sentence from which the subject is extracted. This is demonstrated in (133). [27J.

(133)a. de jongen die ik denk dat $t$ komt the boy who I think that comes 


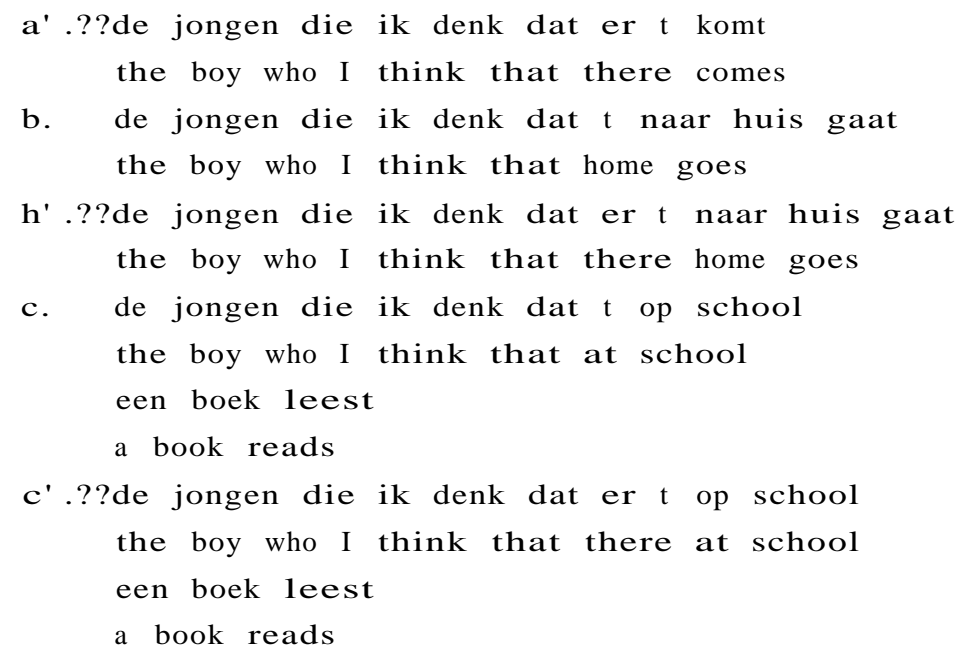

In the corresponding questions in (134) the appearance of expletive er is required (134a) or preferred $(134 \mathrm{~b}, \mathrm{c})$.

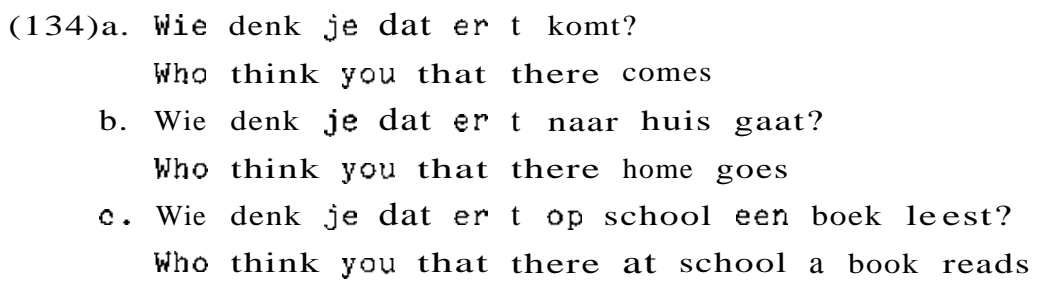

The facts in (132) and (133) follow immediately from our theory. The subject NP moved by wh-movement is a definite pronoun. Since definite pronouns belong to presupposition, er does not appear in its expletive use. In those theories in which extraction of the subject and the appearance of dummy pronouns are correlated, these facts are very problematical, since question formation and relativization are instantiations of the same rule schema. If this was to be given up, it would affect the move alpha approach very seriously.

It turns out that a separation of the syntactic conditions that allow extraction of the subject and the conditions that govern the appearance of expletive er is strongly suggested. The more so since the two relevant conditions, i.e. the Gap Condition and the 
EPC, can be supported independently of the COMP-t phenomena.

\subsubsection{Subject extraction in main clauses}

If the analysis presented in the last section is correct, we expect the occurrence of expletive er in case of short extraction of the subject under exactly the same conditions as with long extraction. This seems indeed to be the case, as is illustrated in (135).

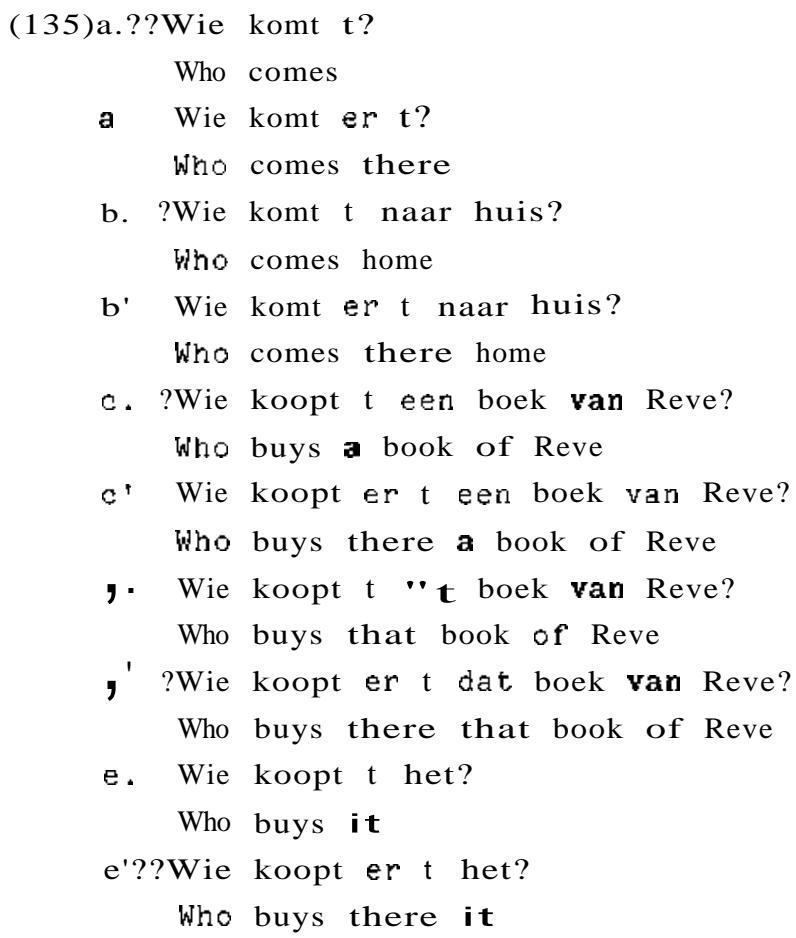

These observations indicate once more that the restrictions on the appearance of expletive er are completely unrelated to conditions on extraction. In a standard approach these simple extractions of the subject are unproblematical. The fact that the appearance of er in these simple questions matches the pattern of long extraction constitutes an argument in favour of the approach adopted here, in which the appearance of expletive er is pragmatically governed. [28],[29J. 


\subsection{Conclusion}

The main objective of this chapter has been to show that er is not a dummy pronoun that fills or binds the subject position for syntactic reasons. In doing so, we have had to discuss a number of rather complicated questions that are associated with the different functions of er. Although not all the problems with respect to er have been solved, it has been shown that on the basis of a fairly small number of independently motivated assumptions we can present a coherent explanation of a large number of problems.

The central hypothesis put forward in this chapter is that $\mathrm{R}$-pronouns can be characterized as elements that are specified as $[P P+R, \pm \theta, \pm A]$. The properties associated with the four different feature combinations correspond quite nicely to the four different types of er that are traditionally distinguished. This implies that we do not have to distinguish between four separate pronouns er, each with its own properties. The characterization predicts four different types to be possible, the properties of which follow from the different feature compositions.

A second important hypothesis is that the fact that apparently one occurrence of er may have more than one function can be considered to be a consequence of a phonologically motivated deletion rule. It has been argued that this rule applies at a level at which it does not affect the interpretation. This implies that at the level of interpretation several adjacent occurrences of er are possible.

Thirdly, it has been argued that no rule of R-movement nor base-generated $\mathrm{R}$-positions are required to account for the surface position of R-pronouns. The independently motivated rule of S-internal adjunction is sufficient.

As a consequence of the central objective of this chapter, a great deal of attention has been paid to the expletive function of er. Given its non-thematic, non-argument status it is a dummy pronoun with a pragmatic function. It fills an empty presupposition in order to prevent a violation of the Empty Presupposition Condition (EPC). From this analysis it follows that expletive er cannot be considered to fill empty subject positions. This analysis 
of expletive er has been shown to have several interesting consequences, in particular when compared to existing syntactic analyses of this type of er.

Finally, it has been demonstrated that a combination of the Gap Condition, introduced in chapter 1 , and the EPC is able to account for the long standing problem of the COMP-t effect in Dutch. 


\section{NOTES}

1. The asterisks and question marks in the examples in this chapter do not imply that the relevant examples are ungrammatical or less grammatical for syntactic reasons. They refer to unacceptable or less acceptable sentences. In semantic terms the unacceptability of the sentences in (3) is due to a tautology. In the sections 3.5 and 3.6 the asterisks and question marks often indicate that the relevant examples are unacceptable for pragmatic reasons.

2. Coppen(1985) argues that quantitative er is a determiner of $\mathrm{N}^{\prime \prime}$,which is moved from NP. He provides independent evidence in favour of his claim by assuming that the following two sentences are grammatical.

(j.) Boeken hebben we slechts een paar gelezen

(ii) Mooie boeken heb ik rnaar drie gezien

I have no doubt at all that these sentences are fully ungrammatical.

3. As indicated above, the first er, the quantitative er, cannot be replaced by other Ft-pronouns, since it lacks a paradigm, for reasons to be discussed below.

4. Schwa consonant deletion is a rather marked proces in agentive formation. Some verbs such as kliederen(to make a mess), in addition to the 'normal' agentive form kliederaar, which is formed by schwa-strengthening, allow a variant formed by schwa-consonant deletion, klieder. The same variation can be seen with the agentive formation of the verb babbelen(to chatter). Both babbelaar and babbel are possible variants with semantic specialization.

5. Den Besten ( $\lg 83)$ observes that there is a phenomenon similar to er-er contraction in Afrikaans. It involves contraction of two adjacent nie's.

6. Van Riemsdijk assumes that the ungrammaticality of (54b) follows from the stipulation that absolute met does not allow R-movement, i.e. does not select a [+R] position, on a par with prepositions such as zonder. It is clear that this assumption is unattractive given that met allows R-movement in other constructions, i.e. in the case of intrumental or comitative met. Moreover, it turns out that absolute met allows R-movement if met is followed by a single NP argument. Van Riemsdijk argues that met in (ia) is absolute. It then follows that according to his analysis (ib) should be just as ungrammatical as (55b), contrary to fact.

(i)a. [Met dit slechte weer] kun je beter thuis blijven

With this bad weather can you better home stay

b. Dit is het soort weer waarmee je beter thui.s kunt blijven

This is the type of weather where-with you better home can stay

for a discussion on this and related issues I refer to the articles mentioned above.

7. The claim that prepositional R-pronouns are PPs is a contradictio in terminis. It would be more correct to label them pro-PP. For the sake of convenience I will stick to the usual term R-pronoun. 
8. There are two exceptions to this claim. If the empty head is preceded by an adjective or immediately followed by a partitive pp quantitative er does not appear, as in (i);

(i)a. Ik heb een rode gekocht

I have a red bought

b. Ik heb twee van deze boeken gekocht

I have two of these books bought

c. Van deze boeken heb ik * (er) twee gekocht

Of these books have I there two bought

For a more detailed discussion of the distribution of quantitative er, I refer to $\operatorname{Blom}(19771$, Bennis $(1977,1979)$.

9. The ungrammaticality of (60b) with er holds for quantitative er. Er can of course be interpreted as a locative R-pronoun in this sentence.

10. As far as I know, all proposals concerning quantitative er explicitly or implicitly consider quantitative er to be homonymous with the weak form of the R-paradigm which we find with prepositional and locative er. Even Kirsner(19791, whose theoretical framework is based on the direct correspondence between form and content, acknowledges that quantitative er might be an accidental homonym. One of the arguments is that historically quantitative er developed from a different source, a genitive form of the third person singular, ira. In spite of this, I shall try to derive the properties of quantitative er from the assumption that quantitative er is an R-pronoun with basically the same properties as the other instances of R-pronouns.

11. Note that this analysis crucially differs from the analysis of quantitative ne presented by Belletti and Rizzi(19811. They argue that a quantified NP may contain PRO if the NP is not governed. If it is governed, ne should be moved from NP to clitic position. Their approach does not fit the approach adopted here for several reasons, such as their definition of government which is comparable to the one proposed in Aoun \& Sportiche(lg831. I shall present a detailed alternative to the Italian quantitative construction below (ch.4.5.31. I shall argue that PRO within a quantified NP must be bound if the NP is canonically governed.

12. Van Riemsdijk's Subjacency approach to the double-R-constraint is further supported by the following three arguments:

- if a locative and a prepositional er occur in one sentence only one er may appear and it must be interpreted as the object of the preposition. i.e.the locative reading is not available.

(i) ${ }^{*} \mathrm{Zij}_{\mathrm{j}}$ heeft $\mathrm{er}_{\mathrm{j}}$ er, vaak $\underline{t}_{j}\left[\mathrm{t}_{j}\right.$ over] gesproken She has there there often about talked

This fact indicates that only one R-pronoun can appear in the R-position. If one er is left out, the R-pronoun must be interpreted as the obligatory prepositional R-pronoun and cannot appear as an optional locative R_pronoun.

- in case of multiple wh-questions in which both wh-pronouns are R-pronouns, the R-pronoun in COMP must be the locative R-pronoun, again for reasons of Subjacency. 
(ii)a. Ik vraag mij af waar, zij waar. vaak t. [to over] gepraat heeft I wonder where she where oftenJabout talked about

b. *Ik vraag mij af waar zij waar $_{1}$ vaak $\underline{t}_{-1}$ [to over] gesproken heeft

- two prepositional R-pronouns in the same domain are excluded, no matter how they are associated with the two prepositional phrases

(iii)a. Dit is het boek waar ${ }_{i}$ ik gisteren $\left[\underline{t}_{i}\right.$ voor] naar de bibliotheek gegaan ben

This is the book where I yesterday for to the library gone have b. Dit is de bibliotheek waar. ik gisteren voor dat boek ${ }_{-}^{\text {[t. }} \mathbf{j}$ naar toe]
gegaan ben

This is the library where I yesterday for that book to gone have

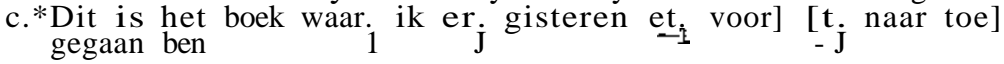

d. ${ }^{*}$ Dit is de bibliotheek waar. ik er. gisteren [to voor]
$\left[\mathbf{t}_{-\mathbf{j}}\right.$ naar toe] gegaan ben $\mathbf{j}$
-1

The facts in (iii) follow if it is assumed that there is only one R-position within S. In (iiic, d) the R-position is occupied by er. which implies that movement to COMP would have to proceed in one step, in violation of Subjacency.

The first and the third argument follow from our theory as well. The ungrammaticalityof (i) is due to the filter on two adjacent er's (section 2.6). The ungrammaticality of (iiic,d) follows from the Gap Condition, since it is impossible for the verb to govern two PPs canonically. The second argument will be discussed below.

13. Arguments against the double-R-constraint that are in several respects similar to the ones presented here can be found in Bennis(1980a,fnt. 11) and Van Bart \& Kager (1984). Stowell(1981,ch.7) develops a different theory of preposition stranding, based on the idea that stranding is possible only if the preposition is reanalysed as part of a complex verb. Stowell argues that R-pronouns are NPs that are inherently Case-marked. He proposes the following general principle: 'If a preposition subcategorizes for an NP object, then it must always assign Case to that NP, if the NP appears in a position of Case assignment. '(p.468). Given the fact that in Dutch prepositions assign CaSe to the right, it follows that R-pronouns have to precede prepositions. His account of the double-R-constraint is rather unsatisfactory, since it requires a verb position as the first constituent of the VP. As has been argued in ch.1.5.2 and more extensively by Hoekstra(1984) and Kuopman(19(4), sucll an ardalysis is completely unmotivated and so is his alternative account of the double-R-constraint in terms of a condition on complex verbs. One element in his account may be worth discussing in more detail. Stowell argues that a problem for Van Riemsdijk's R-position approach arises in cases such as (i).
(i) a. Waar ${ }_{i}$ probeert $\mathrm{zij}$ op blote voeten $\underline{t}_{\mathfrak{1}}$ in te klimmen Where tries she in bare feet ${ }^{-1}$ in to climb
b. Waar probeert zij er op blote voeten $t_{i}$ in te klimmen
Where tries she there on bare feet in to climb

The unacceptability of (ib) should be accounted for in the same way as the ungramrnaticality of $(67 \mathrm{c})$, i.e. as a regular case of the double-R-constraint. If the adposition in in (i) is a motional postposition, just as it seems to be in (ii), the R-position account does not provide an explanation for the non-wellformedness of (ib). 
(ii) Zij probeert de boom in te klimmen

She tries the tree into to climb

However, it appears to be the case that there is no reason to consider in in (i) to be a motional postposition, as in in (ii). If the R-pronoun in (i) belongs to a regular PP, Van Riemsdijk's double-R-constraint can be maintained in this respect. The example provided by Stowell is somewhat unfortunate. If we replace the postpositional pp in (ii) by a prepositional one, as in (iii), the sentence can still be interpreted as expressing a motional aspect. (iii) is ambiguous between a fiotional and a locative reading.

(iii) Zij probeert in de boom te klimmen She tries into the tree to climb

Consequently, the sentences in (i) may equally well correspond to (iii), in which case Stowell's argument loses it force. Moreover, it is possible to provide examples in which only a postpositional pp may express a motional aspect, whereas the corresponding prepositional pp can be interpreted as locative only. Examples are given in (iv).

(iv)a. Jan is de berg op gelopen John is the mountain up walked

b. * Jan is op de berg gelopen John is on the mountain walked

c. Jan heeft op de berg gelopen John has on the mountain walked

d. *Jan heeft de berg op gelopen John has the mountain on walked

The PP in (iva) can only be interpreted as motional, while the $\mathrm{pp}$ in (ivc) is locative. These sentences are interesting because the selection of the perfective auxiliary verb is dependent on the selection of a constituent expressing a motional aspect. For an extensive discussion of this matter, I refer to Hoekstra(1984,ch.3.2.5 \& 4.4). Whatever the reason for this difference, it follows from (iv) that the appearance of a motional postposition correlates with the appearance of the perfective auxiliary zijn. This provides us with a diagnostic test for the appearance of R-pronouns in relation to motional postpositions. From the relative clauses corresponding to (iv) it follows that only prepositional PPs allow R-pronouns, while the relatives with motional postpositions are formed in a way analogous to direct object relatives, suggesting that these apparent postpositional PPs are in fact NPs followed by a complex verb. This is illustrated in (v).

(v)a. De berg die Jan op gelopen is

The mountain which John on walked is

b.*De berg waar Jan op gelopen is

The mountain where John on walked is

c.*De berg die Jan op gelopen heeft

The mountain which John on walked has

d. De berg waar Jan op gelopen heeft

The mountain where John on walked has

These facts illustrate that it is indeed the case that motional postpositions do not allow R-pronoun complements. Consequently, the facts presented by Stowell do not constitute a problem for the double-R-constraint. 
14. Note that I have changed light-NP-shift into light-XP-shift here. The rule was labelled light-NP-shift or S-internal NP-adjunction in ch.1.5.2 because we were concerned with the movement of NP and because we considered this rule to be the Dutch counterpart of heavy-NP-shift in English. There is no reason to suppose that the rule of adjunction should be restricted to NP. To account for the relatively free word order in the Dutch 'Mittelfeld' rules of PP_adjunction and ADV-adjunction are required as well.

15. The construction with expletive er is essentially different from the English there-insertion construction. One of the main differences is that the occurrence of expletive er is not dependent on the choice of the verb. While in English the construction is restricted to sentences with the verb to be and a small class of similar 'existential' verbs, in Dutch this construction appears with all sorts of verbs.

16. I shall not be concerned here with precise definitions of definite/indefinite, which are without any doubt relevant to the construction under discussion. I shall merely assume that there exist semantic criteria that determine the definiteness of NPs.

17. To account for facts of the type in (83c) one might propose a filter that excludes configurations in which the complementizer immediately precedes the finite verb. Such a filter is proposed in Roelfszema (lg83). If the filter does not take into account intervening traces, it applies equally to that-t configurations in English and in Dutch. In fact, Roelfszema's argumentation is based on that-t configurations exclusively. However, it is clear that only a subset of the relevant data fall under such an analysis. Given that such a filter is completely ad hoc and does not include related phenomena, I shall not discuss this proposal in any detail.

18. In fact, the correct generalization is that [-spec] indefinite NPs cannot be interpreted as part of the presupposition. In a sentence such as (i), the indefinite $\mathrm{NP}$ is interpreted as [+specific].

(i) Jan zag dat een wielrenner viel John saw that a racing cyclist fell

A similar observation applies to sentences of the type in (ii).

(ii)a. De leraar wilde dat een jongen een meisje kuste

The teacher wanted that a boy a girl kissed

b. De leraar wilde dat er een jongen een meisje kuste

The teacher wanted that there a boy a girl kissed

In (iia) the first indefinite NP is interpreted as [+specific] indicating that a particular boy should kiss some girl. In (iib) the first NP is interpreted as [-specific], implying that some boy should kiss some girl.

We can test the differential status of these NPs by coreference tests of the type discussed in Reinhart (1g83). Definite pronouns may refer to [+spec] NPs but not to [-spec] NPs. This difference can be observed in (iii).

(iii)a. De leraar wilde dat een jongen een meisje kuste, maar hij weigerde

The teacher wanted that a boy a girl kissed but he refused

b.*De leraar wilde dat er een jongen een meisje kuste, maar hij weigerde

The teacher wanted that there a boy a girl kissed, but he refused 
The unacceptability of (iiib) indicates that the NP een jongen cannot be interpreted as $[+\mathrm{spec})$. A reverse effect is obtained in (iv).

(iv \}a.*De leraar wilde dat een jongen een meisje kuste, maar er bood zich The teacher wanted that a boy a girl kissed, but there volunteered niemand aan nobody

b. De leraar wilde dat er een jongen een meisje kuste, maar er The teacher wanted that there a boy a girl kissed, but there bood zich niemand aan volunteered nobody

The unacceptability of (iva) indicates that the NP een jongen cannot be interpreted as [-spec].

19. Kirsner (1979) argues that expletive er appears solely to shift the participant-in-focus to the background. Although Kirsner's central hypothesis concerning expletive er seems correct to me, I disagree with him in most other respects. For a discussion of Kirsner(19791, see Bennis(1982).

20. Under this approach the unacceptability of (i) is similar to the unacceptability of (iia).

(i) * dat een jongen er werkte that a boy there worked

(ii)a.*dat Jan gisteren ut zag that John yesterday it saw

b. dat Jan ut gisteren zag

21. Maling and zaenen eventually argue against (111a), since (112) does not follow from trace theory. The exact formulation of their account is irrelevant here. What is important is that they suppose that there is a correlation between dat-t phenomena and the obligatoriness of dummy pronouns.

22. A similar distinction between Dutch A and B is adopted in Safir(1985), who argues that Dutch A is a NOM-drop language, implying that, just as in German and Italian, nominative Case need not be phonetically realized, whereas in Dutch B nominative Case must be phonetically realized Where it is assigned.

23. (116b) is grammatical if the sentence is interpreted with a double negation, in which case nessuno has narrow scope.

24. Like Hoekstra and Koster, Koopman (1984) argues that long extraction of the subject is always possible in Dutch. Her theory differs from the other two proposals. She Claims that the subject position is properly governed by COMP. COMP governs the subject position under coindexation. The index on COMP is the result of upward percolation of the index of the moved wh-phrase. She observes correctly that main clauses and embedded clauses show parallel behaviour insofar as the possibility of extraction of subjects is concerned. This leads her to a theory in which subject extraction is always possible. № account is given for the unacceptability of those sentences Which led to the postulation of a dat- $t$ effect in Dutch.

25. Bayer(1984) accounts for the difference between Standard German and Bavarian by assuming that a version of the doubly-filled-COMP filter is part of the grammar of Standard German, but not of the grammar of Bavarian. Although I shall 
not discuss such a proposal in detail, I would like to suggest that the difference might be accounted for in a different manner. In ch.1, it was pointed out that we should not expect extraction from sentential complements to be possible in Dutch at all. The reason for this is that the postverbal sentential complement is not canonically governed by the governing verb. In order to allow movement to be possible, we argued that movement from an $\mathrm{A}^{\prime}$ _position (i.e.from COMP) might proceed without paying heed to canonical government and in violation of the Gap Condition. It might be the case that Standard German observes the Gap Condition more strictly than Dutch or Bavarian, in that it does not allow extraction from sentential complements as in (136).

26. This D-structure organization of Icelandic differs from what is generally taken to be the underlying structure of Icelandic (e.g.Thrainsson 1984, Platzack 1984), but see Thrainsson (1984,fnt.1).

27. (133a') is perfectly acceptable if er is interpreted as a locative expression. However, such an interpretation is not possible in (133b') since the sentence contains a motional $\mathrm{pp}$ that is difficult to combine with a locative expression.

28. A similar conclusion is reached in De Schutter(1974), Elffers(1977), Kirsner(1979) and Schermer-Vermeer(1985). However, their approach to the problem of the conditions on the appearance of (expletive) er differs considerably from the approach defended here.

29. An apparent problem for the theory presented here involves the contrast noted in Drewes et al.(1984\}:

$\{$ i $\}$ a. de manier waarop er wordt geantwoord the way where-in there is answered

b.??de vraag waarop er wordt geantwoord the question where-on there is answered

The contrast in (i) is rather peculiar, since it does not appear if er is left out or if there is no wh-movement, as in (ii).

(ii)a. dat (er) op die manier geantwoord wordt that there in that way answered is

b. dat (er) op die vraag geantwoord wordt that there on that question answered is

Drewes et al. provide a syntactic explanation for the contrast in (i) in terms of overlapping paths within the framework of Pesetsky (1982b). They argue that the following three factors are relevant:

wh-movement, to explain the absence of a contrast in (ii)

- insertion of er

- the status of the pp as a complement or an adjunct, which is the only syntactic difference between (ia) and (ib).

They argue that the combination of wh-movement from complement position and the insertion of er leads to a violation of Pesetsky's Path Containment Condition.

Although I think that the observations are basically correct and their analysis is an interesting attempt to apply Pesetsky's theory to a new domain of facts, their explanation is demonstrably wrong. If the analysis were correct, we would expect the same contrast to appear if the $\mathrm{pp}$ is questioned and not relativized. However, the contrast disappears completely if the PPs are questioned, as in (iii). 
(iii)a. Op welke manier wordt er $\mathrm{t}$ geantwoord?

In which way is there answered

b. Op welke vraag wordt er $\mathrm{t}$ geantwoord?

On which question is there answered

More striking, the absence of expletive er in questions produces unacceptable structures in these two cases.

(iv)a.??Op welke manier wordt $\mathrm{t}$ geantwoord

On which way is answered

b.??Op welke vraag wordt t geantwoord

On which question is answered

The difference between (iii) and (iv) follows directly from the EPe, since no constituent in (iv) can be interpreted as belonging to presupposition. The difference in acceptability between (iv) and (ii) follows from the difference between questions and relative clauses in the matter of the pragmatic status of the moved constituent. What remains as a problem is the contrast in (i). (ib) seems to suggest that the relativized PP should be interpreted as presupposition, thus making the appearance of er superfluous. This unacceptability is of the same order as the unacceptability of the sentence in (v).

(v) ??de jongens die er $\mathrm{t}$ komen the boys who there come

If er is not interpreted as a purely locative expression -an interpretation that is available for (ib) as well- the relative clause in (v) is unacceptable because the moved wh-phrase is a definite pronoun which belongs to presupposition. If in a sentence corresponding to (ib) there is no movement and the PP contains a pronominal object, the same unacceptability can be observed, as is demonstrated in (vi). This indicates again that wh-movement is irrelevant for the explanation of the unacceptability of (ib).

(vi) Hij hoopte dat (??er) daarop zou warden geantwoord $\mathrm{He}$ hoped that there there-on would be answered

We have thus reduced the problem to the acceptability of (ia). It is clear that the contrast in (i) should be related to the status of the extracted PP. It is interesting to observe that daarop in (vi) cannot be interpreted as a manner adverbial adjunct, corresponding to op die manier in (iia), nor can a sentence like (vii) be interpreted as questioning the way in which an answer is given, but only as questioning the prepositional object of the verb.

(vii) Waarop heeft hij geantwoord? Where-on has he answered

Only if there is a local antecedent for the R-pronoun can it be interpreted as being part of a manner adverbial. This is not a general property of adjunct PPs, since locative and directional PP-adjuncts do not show the same behaviour. I have no insights to offer to account for this phenomenon. It is possibly related to other differences between manner adverbials and other constituents (cf.Huang 1982, Lasnik \& Saito 1984, Aoun 1985, Koopman \& Sportiche 1985).

Although the answer to the problem with respect to (ia) has not been Solved in a satisfactory way, it should at least be clear that a syntactic solution for 
the contrast in (i), as proposed by Drewes et al., is inadequate as it cannot distinguish between wh-movement in questions and relative clauses. I shall leave the question as to how to account for the differences between manner adverbials and other constituents for further research. 


\section{Chapter 4}

\section{Some Related Topics}

\subsection{Introduction}

In this chapter I shall pursue some of the implications of the theory presented in the previous chapters. In the first few sections I shall basically be concerned with two theoretical issues. In the later sections I shall discuss the implications of the theory for several other languages. Although the two parts of this chapter are closely related, it is less homogeneneous than the preceding ones. It will also be rather sketchy, since it is impossible to discuss the distribution and properties of gaps and dummies in other languages in just as much detail as in Dutch. I shall provide some indications in which direction an explanation consistent with the theory developed above might be found.

In section 2 I shall discuss the rule of adjunction once more and argue that the theory of paths severely constrains the possibility of application of adjunction, whereas no such limitations apply to substitution.

Section 3 deals with the notion external argument. The question here is what the external argument is external to. There are basically two possible answers to this question. Either it is external to the maximal projection of the category assigning the external argument, or it is external to the argument projection of the $\theta$-assigning head. The first option is defended in recent work by Williams, whereas the second view is present in work by Stowell and Chomsky. I Shall defend the most restrictive option, i.e. that 
the external argument should not only be external to the argument projection but internal to the maximal projection of the category assigning the external $\theta-r o l e$ as well. Although such a view is relatively inconsequential for the analysis of Dutch, it has far-reaching consequences with respect to languages like English and Italian.

In what follows I shall discuss consequences and problems with respect to a number of languages. It will turn out that the theory is able to account for a number of problems in an interesting way. However, several problems cannot be satisfactorily accounted for. Given the rather tentative characteristic of this chapter, I shall leave these questions for further research.

\subsection{Adjunction and Connection}

In note 8 to chapter 1 it was observed that there is an asymmetry in Dutch in the case of parasitic gaps, depending on the position of the adjunct clause containing the parasitic gap If the adjunct clause appears preverbally, parasitic gaps are possible under the conditions imposed by the Gap Condition, whereas the parasitic gap appears to be impossible if the adjunct clause appears postverbally. This contrast is illustrated in (2). In (1) it is shown that no such contrast exists if no parasitic gap is present within the adjunct clause.

(1)a. Jan heeft deze boeken [zonder ze te bekijken] John has those books without them to inspect in de kast gezet

in the bookcase put

b. Jan heeft deze boeken in de kast gezet [zonder John has those books in the bookcase put without ze te bekijken them to inspect

(2)a. Jan heeft deze boeken [zonder e te bekijken] John has those books without to inspect in de kast gezet in the bookcase put 
b. *Jan heeft deze boeken in de kast gezet [zonder

John has those books in the bookcase put without

e te bekijken

to inspect

In chapter 1 it was argued that the difference in acceptability between (2a) and (2b) is a relative matter, in contrast to the sharp difference between parasitic gaps in finite and non-finite adjunct clauses. No explanation of the difference between (2a) and (2b) was provided. After reconsideration, I think that the difference between (2a) and (2b) is not relative at all. All informants consistently judge sentences of type (2b) to be unacceptable in comparison with sentences of type (2a). The theory proposed in the first chapter does not provide a straightforward explanation of this difference. AS far as the Gap Condition is concerned both structures seem to be similar. In each case the adjunct clause contains a parasitic gap the g-projection of which is properly connected with the g-projection of the real gap. This is demonstrated in (3).

(3) a .

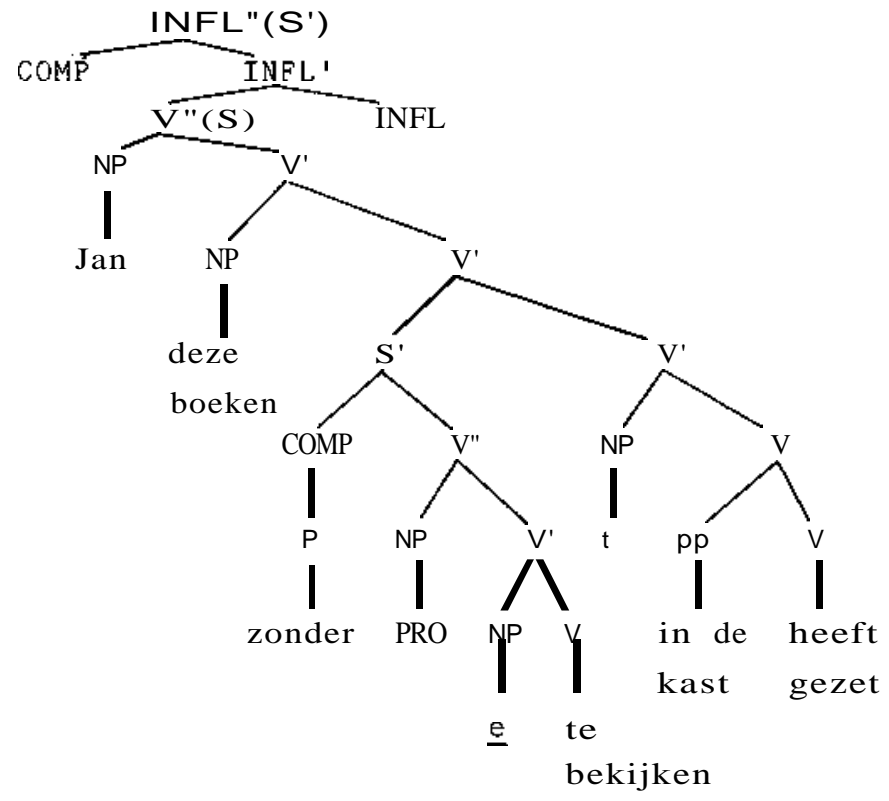


( 3) b.

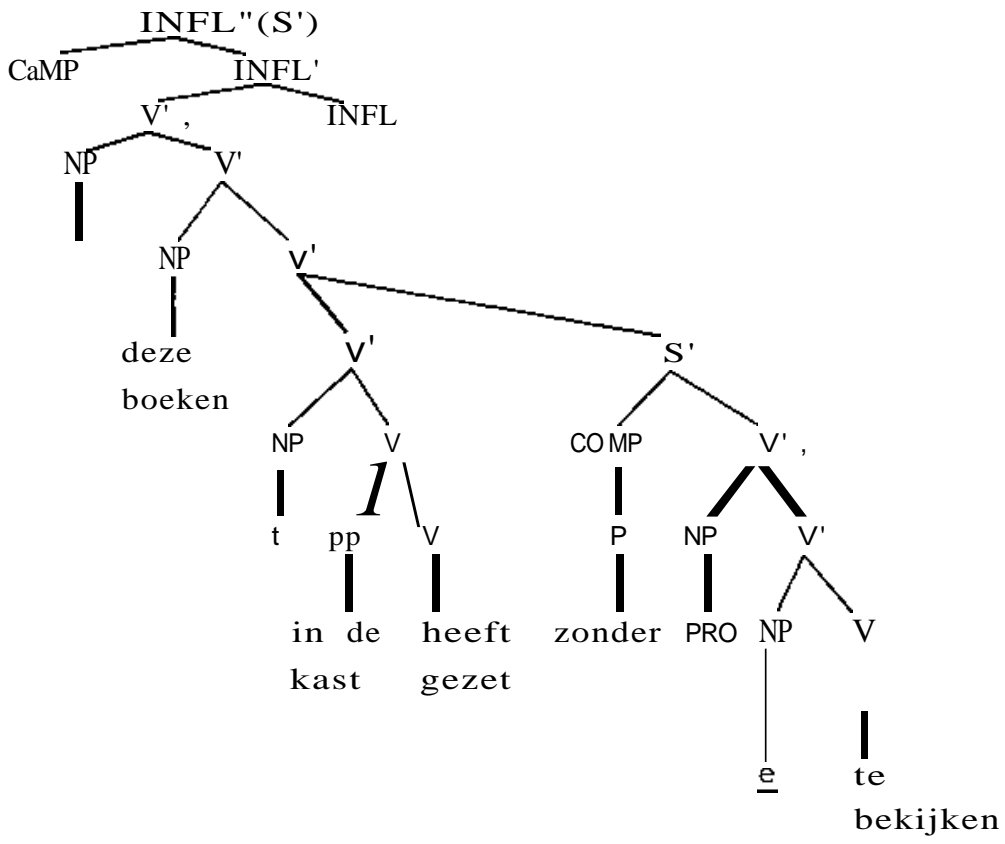

In each case, the path in the adjunct clauses is directly connected with the path in the main clause. The only difference between the two structures is the direction of this connection. As it stands, the Gap Condition does not distinguish between different directions of connection. Conceptually, the difference between (3a) and (3b) resembles the other left-right asymmetries discussed in chapter $\mathbf{1}$, which were argued to follow from the directional notion of canonical government. Suppose that we strengthen the Gap Condition , repeated here in (4a), in such a way that the direction of connection is taken into account. We may do so by introducing an additional condition such as (4b).

\section{(4)a. Gap Condition}

- A gap $Z$ in a tree $P$ is linked to its antecedent by a connected subtree of $\mathrm{P}$ which constitutes a g-projection

$-X P$ is a g-projection of the structural governor $W$ of $Z$ iff the head of XP c-governs $\mathrm{Z}$ or a g-projection of $\mathrm{W}$

$-\mathrm{X}$ c(anonically)-governs $\mathrm{Y}$ iff $\mathrm{X}$ precedes $\mathrm{Y}$ in a VO language and follows $\mathrm{Y}$ in an OV language 
(4)b. A g-projection $X$ is properly connected to a g-projection $\mathrm{Y}$ iff $\mathrm{X}$ and $\mathrm{Y}$ are in a canonical government configuration, i.e. $\mathrm{X}$ precedes $\mathrm{Y}$ in an DV language and follows $\mathrm{Y}$ in a VD language

SUCh an analysis would provide an explanation of the contrast in (2). The ungrammaticality of (2b) would follow from the fact that the g-projection in the adjunct clause is not properly connected to the g-projection in the matrix clause.

Unfortunately, a condition such as (4b) cannot be correct, since it would predict sentences such as $(S)$ to be ungrammatical.

(5) A person who close friends of $\underline{\text { e }}$ admire $t$

In (5) the parasitic gap is embedded in the subject NP. The g-projection containing the parasitic gap stops at the level of the subject NP. The subject NP is on a left branch. Thus. X precedes Y in a VO language, contrary to what is expected on the basis of (4b). Nevertheless, I shall argue below that (4b) provides the correct explanation for the contrast in (2). Before discussing the question as to how the violation of (4b) in (5) can be acccounted for, I shall first discuss another problem that was left unsolved in chapter 1. This problem shows some resemblance to the problem discussed above.

The rule of $\mathrm{S}$-internal adjunction has been discussed extensively in the preceding chapters. In chapter 1 , note 12, the question was raised why there is no adjunction to the right in Dutch and to the left in English. No answer to this question was given there. Let us try to relate this question to the problem raised above. The generalization seems to be that the landing site of the adjunction is on the same side of the governor as the extraction site itself. The position of the extraction site with respect to its governor is determined by the Gap Condition. Suppose that the landing site of adjunction is determined by an additional condition, such as (6). 
(6) an antecedent $\mathrm{X}$ can be linked to a g-projection $\mathrm{Y}$ iff $\mathrm{X}$ and $\mathrm{Y}$ are in a canonical government configuration, i.e. $\mathrm{X}$ precedes $\mathrm{Y}$ in an $\mathrm{OV}$ language and follows $\mathrm{Y}$ in a VO language

Condition (6) implies that the antecedent $X$ should precede a sister constituent belonging to the g-projection of the gap in an OV language and follow it in an VO language. Condition (6) correctly predicts that adjunction to the right in Dutch and to the left in English is impossible. It is evident that, if correct, (4t) and (6) should be combined into a more general condition. Within the theory of paths there is no explicit mention as to how the antecedent is related to the g-projection of the governor of the gap, apart from the fact that the g-projection should reach the level of the antecedent. Suppose that we claim that the antecedent should be connected with the g-projection in a way similar to the way in which a g-projection is connected with another g-projection. Such a view implies that the antecedent c-commands the gap as a consequence of the connectedness theory. An intervening node blocks connection. No explicit c-command requirement on movement is required. If we do so, (4b) and (6) can be combined quite easily, as in (7).

(7) If $X$ is an antecedent or a g-projection, $X$ may be connected to a $\mathrm{g}$-projection $\mathrm{Y}$ iff $\mathrm{X}$ and $\mathrm{Y}$ are in a canonical government configuration

Condition (7) is able to account for the contrast in (2) as well as for the unidirectionality of adjunction. Again, however, this condition cannot be correct. It would imply that in all cases the landing site of a movement rule should precede the g-projection in an av language and follow it in a VO language. It is clear that in a simple passive sentence in English for example, condition (7) is not obeyed. Either we have to drop condition (7) or we have to restrict its application in some preferably insightful way. If we restrict the application of (7) to adjuncts and adjunctions only, the correct results are derived. In that case we would have to replace (7) by (8). 
(8) For any non-designated position $X$ (i.e. a position that is not defined by + Case, $+Q$, +wh, or another feature), if $X$ contains an antecedent or a g-projection, $X$ may be connected to a $g$-projection $Y$ iff $X$ and $Y$ are in a canonical government configuration, i.e. $\mathrm{X}$ precedes $\mathrm{Y}$ in an OV languages and follows $\mathrm{Y}$ in a VO language.

As it stands, (8) discriminates between the parasitic-gap sentences in (2) and the one in (5). In (5) the parasitic gap appears in a subject NP, which might be considered a position defined by +Case (ef.next section), while in (2) the parasitic gap appears in an adjunct clause. In the same way (8) discriminates between the adjunction rule under discussion and passive in English, which might be considered movement to a +Case position. It follows from (8) that movement to a position in which the canonical government configuration is not observed must be movement to a designated position, i.e. substitution.

One of the consequences of this is that wh-movement to COMP must be substitution in VO-languages like English and French, whereas it can be adjunction in OV_languages such as Dutch and German. It is then predicted that a 'doubly-filled COMP' is possible in the latter case only. With respect to the languages mentioned above, this seems indeed to be the case, as is illustrated in (9)\&(10). [1J.

(9) Dutch: $1 \mathrm{k}$ vraag the af wat of dat hij $t$ zag

I wonder what whether that he saw

Bavarian: I woass ned wer dass $t$ des toa hod

I know not who that this done had

(10)English: 'I don't know who that John saw $t$

French: *Je me demande qui que tu as vu $t$

I wonder who that you have seen

In chapter 2 it has been argued that passive and raising in Dutch are instances of adjunction. The derived structure is in accordance with (8). We may now go one step further and claim that if a structure is in accordance with (8) it is formed by adjunction 
and if it is not, the rule involved must be substitution. The intuitive idea behind this claim is that if the top of the subtree containing antecedent and trace observes the canonical government requirement, just as all other levels of the relevant subtree, the structure is optimally in accordance with the unidirectional path-theorY. No additional provisions are required to determine the well-formedness of the relation between antecedent and trace. The antecedent is visible as a consequence of its 'canonical' position with respect to the path. If the antecedent is not connected with the path in accordance with the canonical-government requirement, it can be visible only if the antecedent position is independently motivated. This implies that the application of substitution is restricted and represents the marked case.

This situation resembles the situation found in the subject extraction cases discussed in ch.3. If long extraction proceeds in accordance with the relevant principles, as in Dutch, nothing else need be said. If, however, subject extraction violates the well-formedness constraint on the resulting subtree, it can only take place by means of additional provisos, as in English and french.

If this is correct, we can schematically represent adjunction and substitution in $\mathrm{OV}$ and $\mathrm{VO}$ languages in the following way.

(11) OV-languages

a.adjunction

b.substitution
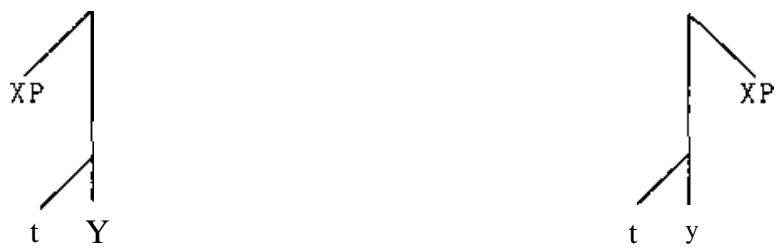
(12) VD-languages

a.adjunction

b.substitution
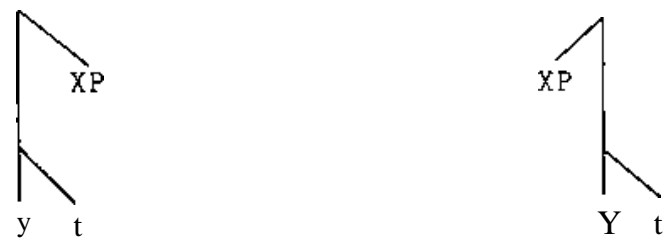

In the following sections it will be shown that such a typology of rules, based on a uniform application of the canonical government requirement on paths, has a number of interesting consequences.

\subsection{The external argument and the structure of Modern English}

In the preceding chapters it was argued that the external argument is a constituent that is assigned an external thematic role by a predicate. Whether or not a particular lexical category assigns an external argument is entirely dependent on the lexical specification of that category. rurthermore, it was argued that there is no base-generated NP position to which the external thematic role is assigned. In this section $I$ shall raise the question to which position the external argument is assigned. This implies that we have to determine what the external argument is external to and what the maximal upper limit of the projection is within which the external argument may be assigned. In the literature these questions have been discussed extensively with respect to Small Clauses. There are basically three different proposals for the structural representation of Small Clauses. SCs may be constituents or not. In the predication theory developed by Williams(1978) the subject-predicate relation is established by a rule of predication that causes the subject to be coindexed with its predicate. In this view subject and predicate do not constitute a single constituent, since the external argument is necessarily external to the maximal projection of the predicate. If subject and predicate are taken to form a single constituent, there are two different approaches. Either the external argument belongs to the 
projection of the predicate, the endocentric approach, or the subject is external to the projection of the predicate but is part of a constituent consisting of subject and predicate exclusively, the exocentric approach. The endocentric approach is developed in Stowell (1981,1983), whereas the exocentric approach can be found in Chomsky(1981).[1].

Schematically, the three different positions be represented as in (13).

$$
\text { (13)a. } \mathrm{NP}_{i} \ldots \mathrm{XP}_{i}
$$

Without going into much detail, I shall adopt Stowell's proposal that the external argument belongs to the projection of the predicate. This implies that Stowell's definition of SUBJECT (14) is taken over.

(14) The SUBJECT of a phrase XP is the argument of $X$ or $X^{\prime}$ which is directly dominated by $X^{\prime \prime}$

(Stowe11,1983,(21)

What is relevant to the discussion here is the structural position of the subject of $S$. Stowell argues that the subject of $S$ is covered by the definition in (14): "It (i.e.definition (14),H.B.) also accounts for the subject of $S$, provided that $S$ is incorporated into the $X$-bar system as an $X^{\prime \prime}$ projection of INFL. Then if $S: I^{\prime \prime}\left(: I N F L^{\prime)}\right.$, it must be that VP functions as a structural complement of INFL, so that there is a constituent $I^{\prime}$ (:INFL') corresponding to the traditional predicate phrase." (Stowe11,1983,p.2951. This assumption, i.e. that the subject of a sentence is the subject of a predicate phrase INFL', is 
problematical in several respects. The relevant configuration proposed by Stowell is depicted in (15).

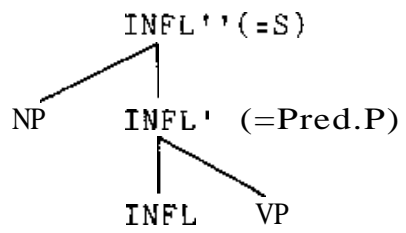

INfL. the head of $\mathrm{S}$, differs from the other lexical categories potentially taking a subject in that the presence or absence of a thematic external argument is not dependent on lexical properties of the head, but is entirely dependent on lexical properties of the complement of the head, i.e. VP. The lexical properties of INfL are completely immaterial in this respect. This implies that the endocentric approach is only apparent. It is saved by claiming that the external argument is an argument of INfL' rather than of vr. The theory of endocentric subjects is undermined since only in this case is the subject external to the maximal projection of the category that determines the assignment of its thematic role.

A further incompatibility in Stowell's theory of the subject of $S$ is the fact that the VP that is a complement of INfL does not have a subject. Stowell argues that Chomsky's claim that every $S$ must contain a subject can be made to follow from the requirement that every constituent that is interpreted as a clause must contain both a subject and a predicate. Given the endocentricity requirement it follows that there can be no constituents, i.e. maximal projections, that are predicates. It further follows that VP cannot be a predicate nor can it be a clause since it laCks a subject. The question thus arises as to the status of VP.

A related question involves the fact that VP may contain a subject with perception verb complements. If the VP contains a subject in (16), then why is it impossible in (17)? Or to put it differently, why can sing a song be a predicate in (16) but not in (17)?

(16) I heard [VP him [sing a song]

(17) He INFL [VP sing a song] 
We may stipulate that, just as with NPs, VPs need not contain a subject. The problem with this assumption is that VPs without a subject appear only if they are subcategorized by INFL. In that configuration they must appear without a subject, whereas VP in other configurations has to appear as a clause, i.e. as a subject and a predicate_

A third indication that Stowell's approach to the subject of $\mathrm{S}$ should be reconsidered can be derived from Dutch. As has been argued in the preceding chapters, the external argument in Dutch belongs to the $\mathrm{V}$-projection. [2]. The maximal projection of $\mathrm{V}$ contains both the argument projection of $V$ and the external argument. With respect to Dutch then, the endocentric approach can be maintained without problems. There is no problematic VP constituent and INFL is not part of the clause but rather an operator with the syntactic function to assign nominative Case if it is specified for [+Tense]. If this analysis is correct, we may wonder whether Universal Grammar allows variation in the determination of an external argument to such an extent that in Dutch the external argument is an argument of the $V$ projection only, Whereas in English the external argument is an argument of INFL and VP together. Such a variation seems highly unlikely. Given that INfL does not contribute to the selection of an external argument and that the status of the VP is problematic, it seems to be the case that the endocentric approach can be maintained only if English is like Dutch in this respect. This amounts to claiming that in English the maximal projection of $V$ contains the external argument as well. If such a claim cannot be motivated satisfactorily, we have to drop the attractive idea of a fully general endocentric conception of the subject-predicate relation, which reduces the number of base rules considerably.

In that case we may be forced to turn to a fully exocentric approach as defended by Williams, who claims that both in the case of Small Clauses and $S$ the subject is external to the constituent containing the predicate. This approach seems less attractive, for three reasons: it requires an additional rule of interpretation that relates subject and predicate; it is less restrictive with respect to the relative position of subject and predicate and it 
requires the base rules to provide an external argument position. Moreover, such an approach would force us to adopt the existence of a VP in Dutch, which is not independently motivated and runs into trouble with the adjunction analysis presented in the preceding chapters.

A third possibility is to adopt a mixed approach, as in Chomsky(1981). Some subject-predicate relations might be exocentric, such as the subject-predicate relation in $S$ in English, whereas others might be endocentric, as in Small Clauses. Although we may eventually have to turn to such an approach, it seems clear that this is the least attractive approach to this problem.

Let us thus try to motivate the endocentric approach described above. [3J. The only problem we have encountered thus far is the subject-predicate relation in $S$ in English. If the subject belongs to the $\mathrm{V}$ projection in English, there is no constituent VP and INFL is external to $\mathrm{V}^{\prime \prime}$, as in (18).

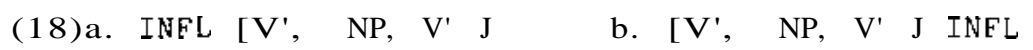

With respect to English there seems to be no motivation Whatsoever to assume that INFL should be clause final. Let us assume that (18a) is the correct underlying representation of English clauses. [4J. In order to derive a well-formed simple sentence the subject has to be moved to a position to the left of INFL. Why then is the subject obligatorily moved across INFL? Suppose the reason has to do with Case assignment, just as in other instances of obligatory movement of NP, for example in passives. How can this be achieved? Given the assumption that Case assignment is unidirectional, which is extensively motivated in Stowe11(19811, Hoekstra(1984) and in chapter 1 of this book, and that the direction of Case assignment in a particular language is not uniform, contrary to what is claimed in Stowell(1981) and Koopman(19841, we may propose that in English INFL assigns nominative Case to the left. In that case the external argument has to be moved to a position to the left of INFL in order to receive (nominative) Case. If it is correct that lack of Case is responsible for the movement of the external argument and consequently for its surface position, we may expect that there are cases in which the subject retains its original position if 
there are other mechanisms to assign Case. That is exactly what can be observed in the case of perception_verb complements, as in (19). $[5 \mathrm{~J}$.

(19) a. John saw [them leave]

b. I heard [him sing]

On this view, the complement of the perception verb is a bare 3, or rather the maximal $V$ projection including the external argument. The external argument can get Case since it is governed by the matrix verb in the correct direction, since $V$ assigns Case to the right. The relevant part of the structure of sentences of the type (19), is given in (20).

(20)

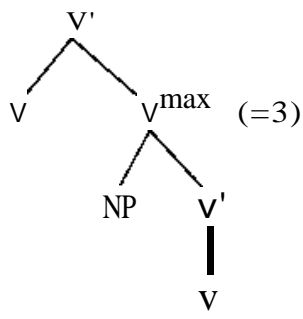

This structure is only minimally different from the one proposed by 3 towell. The difference resides in the fact that I shall assume that the external argument belongs to the $\mathrm{V}$ projection in underlying structure not only in this case but in all cases. This implies that the relevant part of the $\mathrm{S}$-structure representation of a simple sentence such as (21) is as given in (22).

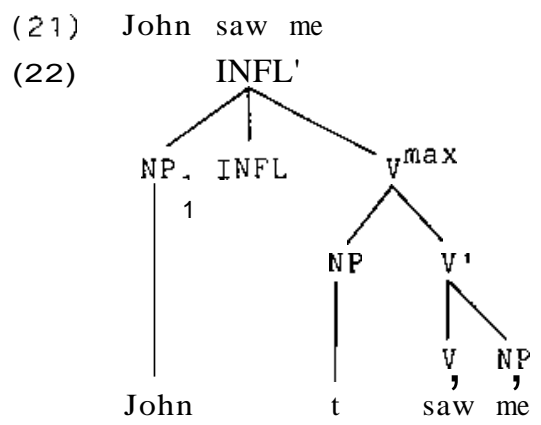


In order for (22) to be a well-formed structure the trace should be canonically governed, as required by the Gap Condition. The trace is not governed by $\mathrm{V}$, since government is restricted to the argument projection, i.e. $V^{\prime}$. However, the trace is governed by INfL, since we do not assume maximal projections to be barriers to government. Given the fact that English is a VG-language, INFL governs the trace canonically. Because the trace is not Case-marked, the trace in subject position is formally identical to a trace in passive constructions. Let us now turn to the landing site. If it is assumed that INFL assigns Case to its left, the NP in position NP 1 gets nominative Case. Given the direction of Case assignment the position preceding INFL is defined by nominative Case and thus constitutes a position which may serve as the landing site of a substitution rule. This analysis has the interesting consequence that it allows us to account for the fact that English sentences must contain an NP SUbject, whereas such a requirement seems to be lacking in Dutch. If there is an NP position in front of INFL, this position has to be filled during the derivation. If it is not, there is a non-canonically-governed empty NP position without a thematic role and without an antecedent. Such a position is clearly in violation of several principles of the theory, such as the Gap Condition. We may thus derive the requirement that in English $S$ must contain a subject from the fact that nominative Case defines an NP position in front of INFL, irrespective of the thematic structure of the sentence. Since QV-languages like Dutch and German do not enforce such a position for reasons of Case, it is expected that subjectless sentences of the type in (23) appear in Dutch and German, but not in English.

\section{(23)a. In de tuin wordt gedanst \\ b. Im Garten wurde getanzt \\ c.*1n the garden is danced}

Before proceeding to the next section in which I shall try to make this analysis plausible from a diachronic point of view, I shall once more discuss the phenomenon of exceptional Case-marking. 
In English there are tho different types of exceptional Case marking constructions. One involves the perception verb complements discussed above. Another ECM construction appears with infinitival complements of verbs like believe and expect, as in (24).

$$
\begin{aligned}
& \text { (24)a. I expect [him to win] } \\
& \text { b. I believe [him to be a fool] }
\end{aligned}
$$

One of the differences between (19) and (24) is the presence of to, which we may take to be a realization of INFL. [6]. In the same way temporal aspects may be expressed in constructions of the type in (24) but not in (19). Given the presence of INFL in the infinitival complements in (24), the maximal projection of the infinitival clause is INFL" and the subject is moved from its position within Vmax to the NP position in front of INFL. Apparently, both NP positions are available for exceptional Case-marking. As discussed in chapter 1, CaMP in English is the head of a CaMP projection. One of the reasons adduced there was that for in CaMP is able to govern the subject of an infinitival clause and assign Case to it, as in (25) .

(25) It was a pity [for [ John to lose]]

We thus have three ways to assign Case to a subject of an infinitival clause. These three ECM constructions can easily be accounted for if it is assumed that the structure of a full infinitival clause is as depicted in (26).

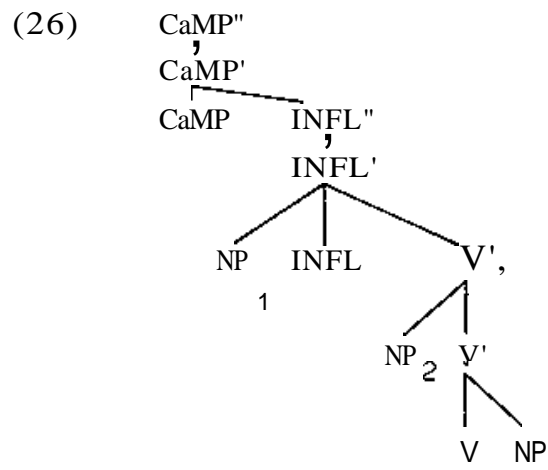


Assuming that an infinitival INFL is not a relevant governor, $\mathrm{NP}_{1}$ will be PRO, unless COMP contains a constituent that is able to govern $\mathrm{NP}_{1}$ and assign Case to it (for). Let us assume that lexical selection of the matrix verb determines whether a verb selects COMP" (the unmarked case), INFL" or V". If INFL" is selected (believe etc.), the matrix verb governs $\mathrm{NP}_{1}$ and assigns Case to it. If $\mathrm{V}^{\prime \prime}$ is selected (perception verbs) the matrix verb governs $\mathrm{NP}_{2}$ and assigns Case to it. It is interesting to observe that in Dutch there are no exceptional Case-marking constructions analagous to the English constructions with believe-type verbs. The reason for this is quite simple. In Dutch there is no NP position outside V" comparable to the NP, position in (26). Thus, the only case in which a matrix verb is able to assign Case to an embedded subject is when it selects a constituent of the type $\mathrm{V}^{\prime \prime}$, which is the case with perception-verb complements. [7).

A final remark in this section concerns the fact that if we accept (22) as the structure for English sentences, there is no longer a constituent VP. This implies that we can no longer formulate rules like VP-deletion and VP- fronting. However, if we call these rules $V^{\prime}$ '-deletion and $V^{\prime \prime}$-fronting, the same results might be obtained. In order to get Case the subject has to be moved from $\mathrm{V}^{\prime \prime}$ to NP, and the resulting constituent can either be fronted or deleted.

\subsection{The structure of Old English and its development into Modern English}

In this section I shall suggest that Old English is similar to Dutch in most relevant respects. It will then be proposed that many of the differences between Old English and Modern English may be derived from one change in the grammar of English. This change involves the position of INFL. If we take Vmax to be the maximal projection of $\mathrm{V}$ that contains all the arguments lexically selected by $\mathrm{V}$, including the external argument, INFL follows Vmax in Old English, just as in Dutch, whereas INFL precedes Vmax in Modern English. This difference would then be responsible for a vast number of differences between Old English and Modern English. such 
as the transition from $\mathrm{OV}$ to $\mathrm{VO}$, the obligatoriness of a lexical subject in Modern English, but not in Old English, the disappearance of the impersonal construction, the possibility of P-stranding in Modern English and the existence of that-t configurations in Old English.[8J.

If these rather tentative suggestions are in the correct direction, this section serves two additional purposes. First, it provides independent evidence that the analysis of Dutch given in the previous chapters is correct, since the same principles can be applied to OE. Second, it provides evidence in favour of the proposal made in the last section concerning the basic structure of Modern English.

\subsubsection{The structure of Old English}

\subsubsection{P-stranding}

Without much discussion I Shall assume that Old English is an aV-language. For discussion, see Canale(1978).[9J. If we assume this to be correct, it follows that canonical government is from right to left. Thus, we do not expect preposition stranding in OE, but only postposition strandi.ng, as in Dutch. This seems indeed to be the case. For instance, only a few examples of prepositional passives can be found from before the fifteenth century (Visser 1963, Van der Gaaf 1930, Lightfoot 1979). As demonstrated by Wende (1915), there are three different cases of P-stranding in OE.

\section{A. preposition stranding by R-pronouns}

In OE, pronouns like oxp(there) and her(here) may function as arguments of P. In those cases they precede P, as in (27).

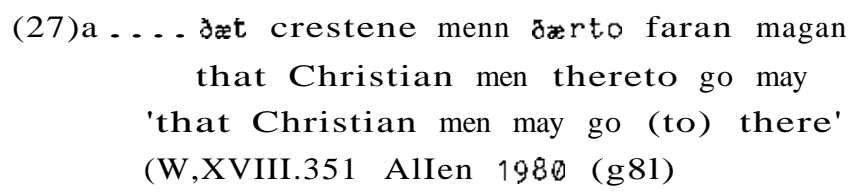




\section{Some Related Topics}

b.... swa swa aæt godspel her baftan chæs

as the gospel hereafter relates

(AHT,I,524,21/ Van Kemenade 1984b (4))

These R-pronouns can be stranded, as is shown in (28).

(28)a .... det hie jar mehten betst fri binnan habban

that they there might best security within have

'that they might have the best security in there'

(Q,p.116.61 AlIen 1980 (102))

b... gif gar gebedo after fylgea

if there prayers after follow

'if prayers follow after that'

$(C P, 399,331$ Vat 1978 (35))

Given the QV-structure of $\mathrm{QE}$ and the Gap Condition, the possibility of stranding in (28) is exactly as expected. The fact that stranding is impossible with full NP complements of prepositions follows in the same way.

B. preposition stranding by personal pronouns

QE allows personal pronouns to appear optionally in front of $\mathrm{P}$, as is demonstrated in (29). [10].

$$
\begin{aligned}
& \text { (29)a. He hire mid gehmde } \\
& \text { he her with slept } \\
& \text { 'He slept with her' } \\
& \text { (CP,415,17/ Vat } 1978 \text { (28)) }
\end{aligned}
$$

b. and hi ne dorsten him fore gebiddan

and they not dared him for pray

'and they dared not pray for him'

(AHP,XIX,2261 Van Kemenade 1984b (1))

As expected, these personal pronouns can be moved from PP. leaving the preposition stranded. This is demonstrated in (30). 
(30)a. Jat him man symle jat tacn beforan bar that him someone often the ensign before carried 'that the ensign was often carried before him' (Bede,146,21 Vat 1978 (31)

b. Da wendon hi me heora bæc to

Then turned they me their back to

'Then they turned their backs to me' $\{$ B,II,8,12/ Van Kemenade 1984b (2))

Given that only R-pronouns and personal pronouns may appear in front of $\mathrm{P}$ as arguments, the observation that these two categories can be moved out of $\mathrm{pp}$ is an interesting confirmation of the idea that the direction of government is relevant with respect to extraction, as is implied by the Gap Condition.

C. preposition stranding in relative clauses

A more complicated situation emerges in case of relative clauses. There are several strategies in $O E$ to form a relative clause. A relative clause in $\mathrm{OE}$ is introduced either by a relative complementizer (므 or sometimes a combination of a relative pronoun and a relative complementizer (se je). A preposition cannot be stranded by moving a relative pronoun of the se paradigm. In our terms the reason for this seems to be obvious given the fact that relative pronouns, just like demonstrative pronouns, do not appear in front of P. In those cases pied piping is obligatory. Examples are given in (31).

(31)a. and het getimbrian medomlic hus, on atet rænig and ordered to build small house in which no wer næfde ingang man not-had entrance 'and ordered a small house built, in which no man had admittance'

(Mart.,p.106.5/ AlIen 1980 (23»

b. Wa gam men zurh done $\underline{\text { e }}$ by mannes sunu belæwed woe the man through whom that is man's son betrayed 'Woe the man through whom the son of man is betrayed' (St.Mat.,1561/ AlIen 1980 (28)) 
In (31a) and (31b) the whole $p p$ is relativized. In (31b) the relativized $\mathrm{pp}$ is followed by the complementizer ge.

As expected, if the relativized pronoun is an $R$-pronoun, the $P$ can be stranded. This is shown in (32).

(32) to urum edele, jar we to gescapene waron to our land where we for created were 'to our land, for which we were created' (AE,I, 162,191 Vat 1978 (23))

Somewhat surprisingly, it i.s very difficult to find examples of Pied Piping in this construction. Maling (1978) claims that stranding is obligatory in $r$-relatives. Vat(1978) argues that it should be possible to find instances of pied piping, although Vat was unable to find any. AlIen (1980) provides only three examples of pied piping, from which she concludes "that it was an idiosyncracy of $\mathrm{pp}$ split that it was obligatory, or nearly so, with relative $y_{r}$." (Allen 1980,fnt.43). One of the relevant examples is given in (33).

...he wæs on Simones huse dæs lie roweres, ðærin

he was in Simon's house the leper's wherein geat dot wif oa deorwyr an smerene5se on his heafod poured the woman the precious ointment on his head 'He was in the house of Simon the leper. wherein the woman poured the precious ointment on his head' (BH,p.73.21 AlIen 1980 (fnt.43 (i)))

Let us suppose that both Vat and AlIen are correct in that pied piping in axr-relatives is possible in principle, but that it is severely restri.cted for some idiosyncratic reason. If this is correct, the pattern of relativization from pp discussed thus far is completely similar to relativization in Dutch. Relative pronouns require pied piping, unless they are $\mathrm{R}$-pronouns.

$\mathrm{OE}$ and Dutch differ with respect to the third strategy of relativization. the case in which the relative clause is introduced by a lexical complementizer only. This pattern appears in Dutch 
only in the case of infinitival relatives (cf.note 11 ). In studies of $\mathrm{OE}$ this is called the de-pattern. In this construction the object of a preposition can be relativized, just as other NPs. If the relativized constituent is the object of $\mathrm{P}, \mathrm{P}$ must be stranded. An example is provided in (34) (cf.(32).

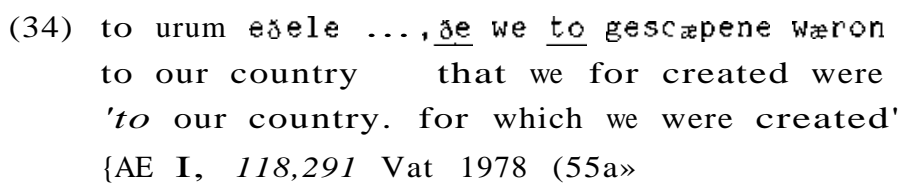

This construction has been subject to much discussion (cf. Vat 1978, AlIen 1980 and Van Kemenade 1984b). The relevant question is whether this construction is the result of movement (R-movement) followed by deletion in COMP (Vat), unbounded deletion (AlIen) or a resumptive pronoun strategy involving neither movement nor deletion (Van Kemenade).

There are several arguments in favour of a movement approach. If there is movement we expect the Complex-NP-Constraint and the WH-island constraint to be obeyed. This is indeed the case. Both AlIen and Van Kemenade argue that Subjacency should be considered a condition on coindexation (as proposed by Bresnan \& Grimshaw (1978», in order to account for the fact that ge-relatives obey Subjacency. A second indication that movement is involved follows from the fact that was Alien observes- "the surface position of the stranded preposition was nearly always directly before the verb of the relative clause (or else before ne 'not' or to, which were inseparable from the verb"(Allen(1980),p.267). This observation, which as far as I know is left unexplained in all analyses of $P$-stranding in OE, is of course reminiscent of the condition on P-stranding in Dutch, discussed in chapter 1. As argued there, this generalization follows from the Gap Condition, since the pp containing the gap should be canonically governed (by V). It is not immediately clear that the Gap Condition should apply to unbounded deletions or to the base-generated empty categories PRO and pro. It does apply to gaps resulting from movement and to parasitic gaps, i.e. gaps requiring an antecedent in a non-thematic position. Since the gap in the pp in (34) is not parasitic, a movement analysis is 
suggested by the adjacency of the stranded $P$ to the verb. Given these arguments I shall adopt the movement analysis proposed in Vat(1978). [1 $11 \mathrm{~J}$.

What is relevant to our discussion is the fact that the pattern of $P$ _stranding in $O E$ observes the left-right asymmetry expected of an OV-language.

\subsubsection{That-t configurations}

Because the external argument generally precedes the internal argument(s) in subordinate clauses, we may conclude that $O E$ is a SOV language. In principle, INFL may appear before or after the Vmax. There are several indications, however, that, just as in Dutch, INFL should follow Vmax. First, the finite verb appears clause-finally in subordinate clauses, whereas it appears in second position in main clauses (cf.Canale 1978, Van Kemenade 1984a). Examples are given in (35).

(35)a. On twam zingum hefde God aæs mannes sawle gegodod with two things had God man's soul endowed (AHT,I,1.183/ Van Kemenade 1984a (1e))

b. det ie oas boe of Ledenum gereorde to Engilsere that I this book from Latin language to English spræce awende tongue translate \{AHT,I,pref.6/ Van Kemenade 1984a (4a))

Just as in Dutch and German, this phenomenon can be explained by assuming the basic position of the finite verb to be clause final. The finite verb position in main clauses is then derived by a rule of Verb Second (cf.Koster 1975, Den Besten 1983).

Another indication that INFL follows $V \max$ in $\mathrm{OE}$ is the fact that in OE long extraction of the subject is permitted, without yielding a COMP-t effect, as was shown in ch.3,(124), repeated here. 
(36) Ac ic wolde witan hu de zuhte be jom monnum se but I would know how thee seemed the man that wit $r$ cwdon at unc ouhte axt $\underline{t}$ wron we earlier said that us seemed that were wilddiorum gelicran ‡onne monnu wild-beast like-er than men

'But I would like to know how it seemed to you about the men that we said earlier that were more like wild beast than men' (B,XXVIII.5 p.122.131 AlIen 198m,(3»)

For discussion see AlIen (1977, 1980), Pesetsky (1982a).

If INEL follows $V \max$ in OE, INFL governs the subject canonically, i.e. from right to left, from which it fOllows that the subject can be extracted.

\subsubsection{Impersonal constructions}

OE exhibits a variety of constructions without a lexical NF subject. This so-called impersonal construction has been the subject of much research. Important descriptive studies on this construction are Van der Gaaf (1904), Wahlen (1925), Elmer (1981). Different analyses for the impersonal construction in $\mathrm{OE}$ and its development into personal constructions in Modern English haVe been proposed by Jespersen (1927), Lightfoot\{1979,1981). Tripp(1978) and fischer \& Van der Leek\{1g83). I shall not discuss the merits of these different proposals here. I shall instead put forward a different analysis, which is in several respects similar to the account of Eischer \& Van der Leek. Before discussing the relevant data, I would like to propose to refer to this construction as the 'nominative-less construction', instead of impersonal or slJbjectless construction. I prefer this term because the label 'impersonal construction' is generally taken to refer to constructions in which the verb selects an NP argument which has no nominative Case. I shall include constructions in which there is no NP at all. Given the discussion of the notion subject above, the term 'subjectless construction' seems really rather inappropriate. 
The relevant generalization seems to be that constructions are involved in which there is no nominative NP. If it is assumed that agreement of NP and verb is defined on nominative Case (cf.ch.2), the lack of agreement is simply a consequence of the lack of a nominative NP.

Just as in Dutch, nominative-less constructions appear in passives of intransitive verbs or verbs taking a sentential or pp complement.

(37)a. Hu maeg jonne jar bean fram him gebeden

How can then there be by him prayed

$(C P, 336,51$ Wahlen 1925 , p.12)

b. be jom was eac gecueden aurh Iohannis aone godspellere about that was also spoken by John the evangelist $(\mathrm{CP}, 445.18)$

c. $\mathrm{Nu}$ is gesene дæt

Now is seen that

(C\&S 2281 Visser 1963, IV,p.2109)

A second nominative-less construction involves cases in which the verb does not select an external argument and there is no internal argument NP, as in (38).

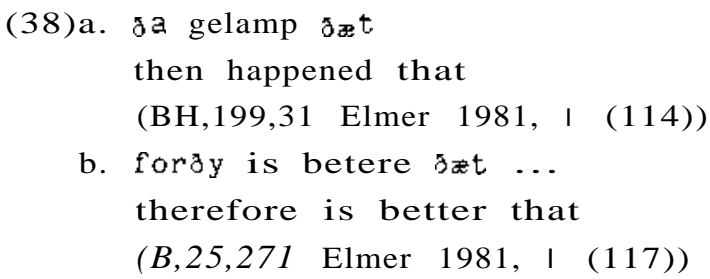

The third type is the construction in which the verb does not select an external argument and there is one inherently Case-marked NP and a sentential complement. These NPs take objective Case, generally Dative, sometimes Accusative (sceamian, lystan and langian). The lack of an external argument can be lexically determined or is the consequence of passive. Examples are given in (39) and (40). 
(39)a. Me ذineð nu dæt

Me seems now that

(B,27.15/ Elmer 1981, I (4»)

b. ¿a of unte him ठ̊xt

then rued him that

$(0,116,141$ Elmer 1981, I (48))

(40) Nas nanum men forgipen $\partial x t$

Not-was no one(D) forgiven that

(AHT,48,3/ Visser 1963, IV, p.2109)

In these three constructions $O E$ is like Dutch. as can be demonstrated with the following corresponding examples.

$$
\begin{aligned}
& \text { (41)a. In de tuin wordt gedanst } \\
& \text { In the garden is danced } \\
& \text { b. Daarover werd niet gesproken } \\
& \text { Thereabout was not spoken } \\
& \text { c. In de tuin werd verteld dat } \\
& \text { In the garden was told that } \\
& \text { d. Toen bleek dat ... } \\
& \text { Then appeared that } \\
& \text { e. Beter is dat ... } \\
& \text { Better is that .. } \\
& \text { f. Mij bleek dat ... } \\
& \text { Me appeared that } \\
& \text { g. Hem irriteert dat } \\
& \text { Him irritates that ... } \\
& \text { h. Hem werd verteld dat... } \\
& \text { Him was told that ... }
\end{aligned}
$$

As in Dutch, if the verb takes a propositional complement, it may sometimes be expressed by an NP (hit (it)). If hit is present in these constructions it is an argument. It receives nominative Case if no objective Case is available. Examples are given in (42).

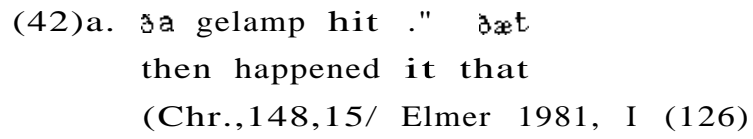


b. hit ne gerist nanum ricum cynincge ðæt

it not becometh any rich king that

(Lives,382,2601 Elmer 1981, I (81»)

A further similarity to Dutch is that with some of the verbs allowing these nominative-less constructions the objective NP may sometimes become nominative, triggering agreement with the verb. Dutch examples are given in (43) and $\mathrm{OE}$ in (44).

(43) a. Ons werd verzocht weg te gaan

Us was requested to leave

b. Wij werden verzocht weg te gaan

We were requested to leave

(44) a. us sceamao to secgenne

us shames to say

'we feel ashamed to say'

(AHT, I, 370,100/ Elmer 1981, I (24)

b. gif we oonne scomiao ozt $\ldots$

if we are ashamed that

$(C P, 63,51$ Elmer 1981, । (49»)

The situation becomes more complicated in those nominative_less constructions in which two NPs are involved. The class of verbs allowing a nominative-less construction with a sentential complement shows up in three different constructions if these verbs have two internal NP-arguments. Only one of these three is a nominative-less construction.

1. A subclass of the class of bitransitive verbs allowing the NPobj-V-S' construction without external argument allows a nominative-less construction of the type NPobj-NPgen-V as well. Examples are given in (45).

(45)a. se scamode swelces gedwolan you\{DAT) were-ashamed such an error\{GEN) $(8,19,30 /$ Elmer 1981, 11 (3)) 
b. hine das langode

$\operatorname{him}(\mathrm{DAT})$ this(GEN) longed

'He longed for this'

$(B H, 227,11$ Elmer 1981, I (7))

Given that one of the NPs receives genitive Case, which is not the Case assigned to direct objects in transitive structures, we may assume that the assignment of genitive Case is lexically determined. Accepting the Burzio generalization, we do not expect the verb to assign structural Case if it does not select an external argument. If it is assumed that the Burzio generalization only involves structural Case assignment, the Case assigned by the verb to its object must be lexical. A further indication that genitive Case is not structurally determined can be derived from sentences such as $(45 \mathrm{c}, \mathrm{d})$.

(45)c. Jat him wurde oftogen orymmes and wada and pegnugna that him (DAT) was taken away glory and clothes and money and $d$ zs anwalda and the power(GEN) $(8,25,31 /$ Visser 1963, IV, p.2136)

d. hi hire unrihtlice benumen ware he(NOM) her(GEN) unrightly deprived-of was 'She was taken away from him' (Bede,460.331 Visser 1963, IV,p.2136)

These constructions involve passives of verbs taking an external argument, an indirect object and a genitive direct object. In these passives the genitive object remains in the genitive, while the indirect object may retain its dative Case resulting in a nominative-less construction (45c) or may become nominative, as in (45d). If genitive Case had been structurally assigned, we would have expected the direct object to lose its Case under passivization, which would result in constructions in which the direct object is moved in order to receive nominative Case.

The nominative-less construction in $(45 \mathrm{a}, \mathrm{b})$ thus involves verbs with two internal arguments only, both of which are Case-marked non-structurally. Since there is no subject position 
and since there is no requirement that every $S$ should contain a subject, these structures are well-formed. The structure is depicted in (46), where NP1 has objective Case and NP2 genitive Case.

(46)

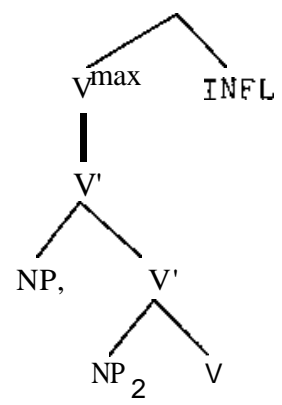

There are two other double NF constructions associated with the set of verbs that allows nominative-less constructions of the type NP-V-S'. Both involve constructions with a nominative NP. Either NP1 or NP2 receives nominative Case, while the Case of the other NP is preserved.

2. Let us start with the construction in which NP2 has nominative Case. Examples are given in (47).

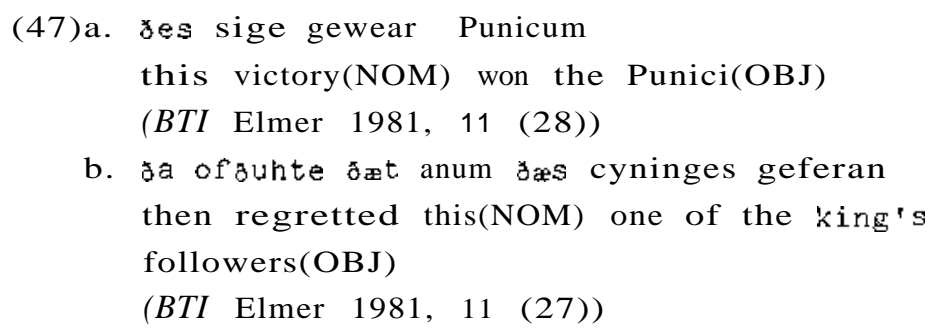

We may explain the occurrence of this construction by assuming that in these cases the verb is not able to assign lexical genitive Case. If this is so, the NP has to be moved to a position in which it may receive Case. Since nominative Case is available, NP2 can be moved from the argument projection to a position in which it is governed and Case_marked by INEL, as in (47c). 
(47)c.

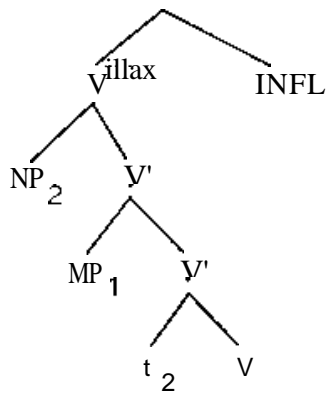

Such an analysis is exactly parallel to the analysis of ergative verbs with an indirect object in Dutch, discussed in chapter 2, Recall that these Dutch constructions were recognizable because they allowed Inversion, If the analysis of this QE construction is correct, we expect Inversion to occur, This is indeed the case, as is demonstrated by the following examples.

(48)a, hu him se sige gelicade

How him(OBJ) this victory(NOM) pleased

$(0,156,251$ Elmer 1981, I I (34))

b. gif aam gifran ungemetlicu spræc ne eglde

if the greedy(OBJ) the loquacity(NOM) not grieved

$(C P, 309,21$ Elmer 1981, 11 (33))

The appearance of Inversion in DE is natural in this construction given the fact that neither of the two NPs is an external argument and the availability of adjunction, [12J.

Our analysis of this construction is based on the assumption that NP2 cannot receive Case as a consequence of lexical properties of a subclass of the verbs allowing nominative-less constructions of the type NP-V-S'. If this is correct we expect a division within this class of verbs between verbs that assign genitive Case and verbs that do not, In general it seems to be true that verbs that are able to assign genitive Case do not appear in this construction. For example, both lician (to please) and lystan(to cause pleasure) appear in the construction him lician/lystan at .,., but only lystan is able to assign genitive case. It then follows that if it takes two NP-arguments, lystan requires the pattern depicted in (46), i.e. NPobj-NPgen-V, while it cannot be 
found in the pattern NPnom-NPobj-V, shown in (47c). Lician, however, requires the latter pattern and cannot be found in the former one. There are only two exceptions to the general observation that particular verbs enter in only one of these constructions as a consequence of their Case-assigning capacity. The verbs hreowan(to rue) and of zyncan(to rue) allow both patterns. So both him ŏ Obviously, the verb assigns Case optionally to NP2. Interestingly, the two available constructions do not seem to correspond with two different semantic readings, as is demonstrated by $\operatorname{Elmer}(1981)$. Although the possibility of assigning genitive Case might be correlated with a semantic property, such as the degree of transitivity (Fischer \& Van der Leek 1983), these exceptional cases demonstrate quite clearly that the explanation of the occurrence of these two constructions should be based on syntactic properties.

3. The third construction involves cases in which NP1 is nominative and NP2 genitive. Examples are given in (49).

(49)a. да se maessepreost $ə \approx$ mannes ofhreow then the priest(NOM) that $\operatorname{man}\{$ GEN) grieved (Lives,II,142,262/ Elmer 1981, 11 (40)

b. nu behofad ure freo-dom afre godes fultumes now needeth our freedom(NOM) ever God's assistance(GEN) (Lives,I,382,266/ Elmer 198111 (44)

I would like to argue that this construction is derived from the nominative-less construction by assigning nominative Case to the Objective NP, which has been moved into the government domain of INFL. Nominative Case overrules Objective/Dative Case as a marked phenomenon. The structure is as given in (50).

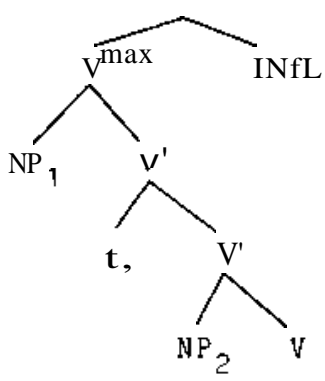


If this is correct we expect a) that the class of verbs appearing in this construction is a proper subset of the class of verbs that appear in the corresponding nominative-less construction (c[.(46)) and $b)$ that the class of verbs appearing in this construction is a proper subset of the class of verbs appearing in the construction NPnom-V-S' discussed above (see (44b)). Both claims seem to be correct. Each verb appearing in this construction appears in the nominative-less construction as well. Similarly, with the exception of one verb (hreowan), each verb appearing in this construction also shows up in the construction of the type in (44). Given the relative exceptionality of both these constructions, I would like to consider the fact that hreowan is not attested in the construction of the type in (44) an accidental gap. Interestingly, neither this construction nor the nominative-less construction shows Inversion. The order is NPobj/nom-NPgen-V. As in Dutch, Inversion appears only if the two NPs involved are both internal arguments. A final remark concerning this construction is that the difference between the nominative-less construction and this construction cannot be semantically motivated. We may thus consider this construction to be a syntactic variant of the nominative-less construction (46). These two constructions differ only with respect to the Case assigned to NP1.

We may now draw the following tentative conclusions:

a nominative $\mathrm{NP}$ is not required in $\mathrm{OE}$ sentencesj

if there is no nominative NP, none of the NPs present can be analysed as the subject;

- the class of verbs that only select two internal arguments can be divided into verbs assigning genitive Case and verbs that do not;

- if such a verb assigns genitive Case, the construction has no subject;

- if the verb does not assign genitive Case, the Case-less NP has to be moved by adjunction in order to receive (nominative)Casej

- NP-Inversion applies only if the verb does not assign Genitive,

i.e. if one $\mathrm{NP}$ has to be moved for reasons of Case. Only then are both NP orders syntactically motivated;

- Objective Case (in most instances Dative) can exceptionally be 
overruled by Nominative Case if there is no other NP requiring Nominative;

With the exception of the lexically determined option of assigning Genitive Case to an internal argument, $\mathrm{OE}$ is similar to Dutch in all relevant respects. In the next section I shall try to explain why and how the nominative-less construction disappeared from the language.

4.4.2 Development into Modern English: the INFL parameter

In this paragraph I shall provide a tentative explanation of the differences between $\mathrm{OE}$ and ME. Suppose $\mathrm{OE}$ was indeed basically similar to Dutch, having a base structure such as (51).

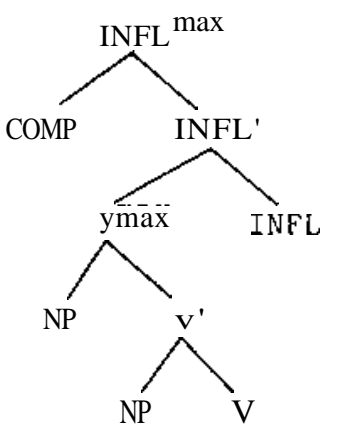

$Y$ and INFL assign structural Case to the left, while $P$ assigns Case to the right. Since $Y$ assigns Case to the left, canonical government is from right to left. The external argument can receive nominative Case within Vmax, since INFL (canonically) governs it. P-stranding of full NPs is impossible since they appear in a non-canonically governed position for reasons of Case. The external argument can be extracted since it is canonically governed by INFL. Clauses without nominative NP occur if the verb does not select an external argument and the internal NP-arguments, if present, may receive Case in their D-structure position.

Now suppose that in the development of the language a change takes place in the position of INFL relative to Vrnax, in such a way that INFL precedes Vmax rather than follows it. The reason for this 
change might be the generalization of the main clause pattern, which was derived by Verb Second. A further change, which can be considered an immediate consequence of the change in position of INfL, is the change from OV to VO. This follows if we assume that $V$ and INFL should be adjacent. The reason why we adopt adjacency of INfL and $\mathrm{V}$ is that we may consider the rule moving the verb (or more precisely one of the verbal elements) to INFL a local rule. One argument in favour of the locality of this movement rule is that the application of the rule is blocked if a lexical subject intervenes, as is the case in Subject-AUX-Inversion constructions (cf.note 5). Furthermore, it is clear that the rule moving one of the verbal elements to INFL or INFL to the V-position cannot be considered a major movement rule. The relevant $\mathrm{V}$ is not a constituent but rather the head of a constituent. Moreover, the relevant $\mathrm{V}$ might even be part of the $\mathrm{V}$-node. If INFL is moved to $\mathrm{V}$ (cf.rule R (Chomsky 1981)), the rule would move INfL downwards, leaving an ungoverned trace without a c-commanding antecedent. If the rule relating INFL and $V$ is a local rule, the change in position of INFL in the development of English requires a change in position of $\mathrm{V}$ as well. [13J.

One way to achieve this effect is to assume that the direction of structural Case assignment of $\mathrm{V}$ is reversed. Such a step would imply that the direction of canonical government changes from right-left to left-right. The change in P-stranding possibilities would be an immediate consequence of this shift. The direction of Case assignment of $P$ remains the same. However, the object of a preposition can now be stranded in accordance with canonical government, whereas postposition stranding with R-pronouns and personal pronouns violated the Gap Condition. This is exactly what can be observed.

A consequence of the change in position of INfL and the change in the direction of Case assignment of $\mathrm{V}$ is that the subject within Vmax is canonically governed by INfL. However, if it is assumed that the direction of Case assignment of INfL is not changed, the subject cannot receive Case from INFL directly. In order to receive Case the external argument has to be moved to a position to the left of INFL. This movement cannot be adjunction, according to the typology of movement rules discussed in section 2 of this chapter. 
An NP position defined by the presence of nominative Case has to be created in order to move the external argument as an instance of substitution. If such a nominative position is created, the structure will be as in (52).

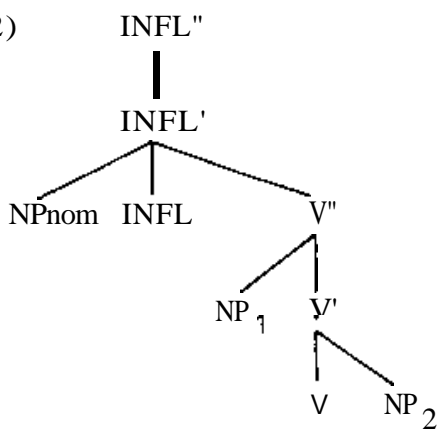

Given this structure NPl has to be moved to NPnom in order to receive Case. The movement from NP1 to NPnom is licit since position NP1 is canonically governed by INFL. No extraction can take place from the NPnom position since this position is not canonically governed. We thus expect the introduction of the that-t effect as a consequence.

Let us now turn to the demise of the nominative-less construction. There are two effects that play a decisive role in this development. The first effect concerns the loss of the possibility of assigning the lexically determined genitive Case to an internal argument of a verb that does not select an external argument. This loss may simply follow from the fact that Case assignment is directional. As English changed from av to va, we may assume that lexical Case, which was assigned from right to left, is lost. It then follows that verbs can assign Case structurally only. The second important effect involves the introduction of the position NPnom. This position cannot remain empty during the derivation.

These two factors determine what is going to happen to the verbs Which are involved here. Given the Burzio generalization it is predicted that verbs that do not select an external argument do not assign structural Case. If genitive Case is lost, these verbs are not able to assign Case at all. 
Let us first discuss the development of the construction with a sentential complement and an inherently Case-marked NP. This construction violates the requirement that a nominative NP should be present as a consequence of NPnom. There are two ways to solve this problem. Either the dative NP becomes nominative or the propositional argument is introduced by an NP related to an adjunct $S^{\prime}$. The NP (it) is moved to position NPnom. These two constructions were already present in OE, as demonstrated above. Although the nominative-less construction was preserved for a long time in exceptional cases like me seems that ..., it is virtually extinct in the 16th century. Verbs like like, happen and long developed by moving the indirect object into the NPnom position. Verbs like seem, grieve and become have taken the other direction.

With respect to the double-NP construction, there seems to be only one solution at first sight. The inherently Case-marked NP keeps its Case and the other NP is moved to NPnom in order to receive Case. For a subclass of the relevant verbs, i.e. the verbS that were unable to assign genitive, this was already the only possibility in OE. This subclass included verbs like 1ioian. This construction is strongly archaic in sentences of the type it likes me not and is found with verbs like happen and become.

There are, however, two other strategies to solve the Case problem. The first is to introduce a preposition to assign Case to the object NP and to move the indirect object to NPnom. This strategy is found with the verb long.

The final strategy is that the verb assigns structural Case to the object. Given the Burzio generalization this implies that there should be an external argument. This can be achieved by making the indirect object an external argument. This process of transitivization, which is of course accompanied by a change in meaning, can be observed with verbs like like and rue. [14].

Although most OE nominative-less verbs have developed into one pattern or have disappeared from the language, it is interesting to observe that in Middle English most of these verbs still allow several strategies to escape from the Case problem. Although the remaining verbs are preserved in Modern English in a number of different ways. they have in common that their development can be argued to be the result of the change in position of INFL with 
respect to Vmax.

The fact that a variety of changes in the development of English can be accounted for by one change in the grammar provides evidence for the correctness of the hypothesis that in English the external argument is base-generated within Vmax, as proposed in section 3. The diachronic analysis proposed here is crucially dependent on this endocentric approach. [15J.

4.5 Some remarks on the structure of the Romance languages

We have derived the assumption from theory that the external argument of $\mathrm{S}$ should be generated as a constituent external to $\mathrm{V}^{\prime}$ but internal to Vmax. This implies that we have to reconsider the underlying structure of all apparent NF-INFL-VP languages. Aside from English, obvious candidates are Romance languages like Italian, Spanish and French. I would like to claim that these languages are basically languages of the type [INFL[[Vo]S]. The major argument in favour of this assumption is the fact that all three languages allow the external argument to appear sentence-finally in the so-called (stylistic) Inversion construction. Examples are provided in (52).

(52)a. Fr.: A qui donnera ce cadeau ton frère?

to whom will give that present your brother

b. Sp.: Trajo una carta para mi el criado

Brought a letter for me the servant

c. It.: Scrive una lettera Giovanni

Writes a letter Giovanni

On the assumption that the external argument is base-generated in postverbal position, it follows that a preverbal subject in these languages is moved from postverbal position. 
4.5.1 The postverbal subject in Spanish

For Spanish such an analysis is adopted in Contreras(1983) and Groos \& Bok-Bennema (1985). They argue that INFJ is preceded by a pragmatically motivated XP position, which is optionally filled by a constitituent which is not necessarily the external argument. The optional preverbal XP position is motivated by the fact that in normal clauses only one consituent may precede the verb and that in questions the wh-word is moved into XP-position, which prevents any other movement to that position. This analysis is able to account for the well-known word order problem in questions (cf.Torrego 1984) without having to postulate a verb-preposing rule.

If this is correct, INFL is followed by Vmax, which has to include the external argument. Contreras and Groos \& Bok-Bennema argue that the basic ordering of $\operatorname{Vmax}$ is ([VO]S]. Although the surface order of constituents following the verb is rather free, they argue that Spanish is a configurational language and that the surface order of a sentence such as (53) is derived by adjunction.

(53) Trajo el criado una carta para mí brought the servant a letter for me

One of the arguments of Bok-Bennema \& Groos in favour of a configurational $S$ in Spanish involves a certain type of parasitic gap. The contrast in (54) can be explained if we assume that the object dos trajes is moved in ( 5 tb) by adjunction to the right.

$$
\begin{aligned}
& \text { (54)a. *Ayer compré dos trajes [sin probarme e] } \\
& \text { Yesterday I-bought two suits without trying-on } \\
& \text { b. Ayer compré } t \text { [sin probarme e] dos trajes }
\end{aligned}
$$

Given that the preverbal position in Spanish is clearly not a subject position and that Spanish is a conrigurational language, it follows that in Spanish INFL assigns nominative Case to the right to the external argument in its D-structure position. [16J.

In this regard Spanish might be different from Italian and French. Let us concentrate on French first. 


\subsubsection{Stylistic Inversion in french}

In french the occurrence of a postverbal subject is severely limited. There are basically three constructions in which the SUbject appears in final position. These conslructions are wh-questions, subjunctive clauses and presentative clauses. [17J. Examples of these three constructions are presented in (55).

$$
\begin{aligned}
& \text { (55)a. Quand partira ce garcon? } \\
& \text { When will-leave that boy } \\
& \text { b. Je veux que parte Paul } \\
& \text { I want that leave Paul } \\
& \text { c. } 11 \text { est arrivé trois filles } \\
& \text { It is arrived three girls }
\end{aligned}
$$

The presentative construction exemplified in (55c) differs in several respects from the other two constructions. This construction requires the postverbal NP to be indefinite, it applies only to intransitive structures while neither the finite verb nor the participle agrees in person, number and gender with the postverbal NP, cf. (56).

$$
\begin{aligned}
& \text { (56)a. } \text { Il est arrivé ce garcon } \\
& \text { It is arrived this boy } \\
& \text { b.*Il mangera cette tarte trois filles } \\
& \text { It will-eat this pie three girls } \\
& \text { c. }{ }^{\text {II }} \text { sont arrivées trois filles } \\
& \text { it are arrived three girls }
\end{aligned}
$$

As Burzio(1981) observes. constructions of the type in (55c) appear only with subjects that are D-structure objects. It shows up with ergative verbs, as in (SSc), which generally take the perfective auxiliary etre(to be) and not avoir(to have), with passives, as in (57a), and in constructions with "se-moyen", as shown in (57b). 
(57)a. 11 a été mangé plusieur tartes

It has been eaten several pies

b. 11 se construit beaucoup d'immeubles dans cette ville It "se't builds many buildings in this town

In these three constructions there is no D-structure external argument as a consequence of lexical properties (ergative verbs), passivization or the introduction of se. [18J.

Given the generalization that verbs in constructions without external argument are not able to assign Case, there is a Case problem in these constructions. This problem can be solved by moving the object into a position in which it may receive nominative Case. In French, just as in English, this position in front of INFL is defined by the presence of nominative Case. If we do so, the following results are obtained.

(58)a. Trois filles sont arrivees

b. Plusieurs tartes ant ete mangees

c. Beaucoup d'immeubles se construisent dans cette ville

The question is how the Case problem is to be solved in the "i1-construction". I would like to propose that the Case problem is solved by transitivization. 11 is an argument NP requiring Case. Suppose it differs from other NPs in that it does not require a 9-role. In this sense 11 in this construction is a kind of dummy pronoun. If $\mathrm{il}$ is inserted as the external argument in D-structure, the structure is syntactically transitive. The D-structure object remains in its D-structure position in which it may receive objective Case. The external, non-thematic argument il is moved into preverbal position in order to receive nominative Case. Most of the restrictions on the occurrence of the "i1-construction" follow immediately. The fact that this construction appears only in case of intransitive structures without a lexically determined external argument is a consequence of the properties of il. The fact that there is no agreement between D-structure object and verb or participle follows from the fact that agreement is defined as a relation between verb and nominative NP. In this construction the verb agrees with i1 only. [19J. 
It is interesting to note that il not only appears in the three constructions mentioned above, but also in impersonal passives, as in (59) (cf.Zribi-Hertz 1982).

(59)a. 11 a été dormi ici recemment

It has been slept here recently

b. 11 a été discute de cette question hier

It has been discussed about this question yesterday

This construction, which of course appears only in case of non-ergative intransitive verbs (*il a été arrive ici recemment), demonstrates that il should be considered a non-thematic nominative $\mathrm{NP}$ in these impersonal constructions. [20].

An additional argument in favour of the analysis in which the postverbal NP in (55c) and (57) occupies the object position in $\mathrm{S}$-structure concerns the fact that if the indefinite NP contains an empty head, the clitic en is required, just as with regular objects. (21).

(60) $11 *(e n)$ est arrivé trois

It nen $^{\mathrm{n}}$ is arrived three

If it is accepted that the nil-construction ${ }^{n}$ is not construction with a postverbal subject, only two constructions

1eft. Both (55a) and (55b) differ considerably from the "il-construction". The postverbal NP agrees with the verb and participle, as in (61a), there is no definiteness constraint, as shown in (61b), and the verb can be transitive, as in (61c).

(61)a. Je veux que viennent 35 personnes

I want that come 35 people

b. A que $11 \mathrm{e}$ heure sont arrivees ces filles?

At what time are arrived these girls

c. Que voulait manger $t$ ce jeune homme?

What wanted eat that young man

These constructions seem to involve clear instances of postverbal subjects. They differ from all other constructions in that the 
preverbal NP-position is not filled. I would like to claim that in these cases there is no preverbal nominative NP position. The external argument can receive Case directly from INFL without moving to a preverbal position. This can be expressed by (62).

(62) INFL assigns nominative Case to the left, unless it appears in the domain of WH or [+Subjunctive]

(62) expresses that if INFL is in the domain of WH or subjunctive Case can be assigned in both directions. One immediate advantage of this analysis is that it follows that (63) is ungrammatical.

(63) *Qu' il voulait manger ce jeune homme? What it will-eat that young man

In other analyses involving rightward movement of the subject and a dummy status of il, we expect it to be possible for the dummy pronoun to occupy the position vacated by the downward movement of the subject. If INFL assigns Case to the right as a consequence of (62) there is no NP position to the left of INFL, since such a position is motivated only in case nominative Case is assigned to the left. If INFL assigns Case to the left, (63) is ungrammatical since there are two NPs and only one Case.

Another interesting argument in favour of such an analysis can be derived from an observation made by Kayne \& Pollock(1978). They point out that subjectless impersonal sentences appear in Inversion environments only. Impersonal passives without 11 can be found both in subjunctive complements, as in (64a), and in wh-clauses, as in (64b).

(64)a. J'exige que soit mis fin à ce conflit

I require that be put end to this conflict

b.?Quand sera mis fin au conflit?

When will-be put end to the conflict

These il-less impersonals are completely ungrammatical if the complement is not subjunctive or if there is no wh-movement within the relevant clause. 
(651a.*Elle dit que sera mis fin à ce conflit

She says that will-be put end to this conflict

b.*Qui t'a dit que sera mis fin à ce conflit?

Who you has told that will-be put end to this conflict

The sentences in (65) require a preverbal il, whereas the occurrence of i1 is optional in sentences of the type in (64). The correlation between the possibility of postverbal subjects and the occurrence of subjectless sentences constitutes an argument in favour of the underlying postverbal position of the external argument. In the exceptional case that INFL is able to assign Case to the right, no NP position has to be created. External arguments receive Case in their D-structure position and Case-less internal arguments by adjunction to a position within the government domain of INFL. If there is no external argument nor an internal NP_argument requiring Case, the sentence may be subjectless without violating any principle. The situation is exactly the mirror image of Dutch. If INFL assigns Case to the left, which is the normal case, nominative Case defines a position, which has to be filled during the derivation, thereby preventing subjectless sentences of the type in (65).

4.5.3 The structure of Italian and the syntax of ne

The relevant question is whether Italian is like French or like Spanish. If it is like Spanish, the external argument is assigned Case in its postverbal position, from which it can optionally be moved to a preverbal position. If Italian is like French, nominative Case is assigned to the preverbal NP position and the postverbal NP has to be moved into that position or coindexed with an empty category in preverbal position in order to receive Case. Neither of these two options is very attractive. It is not clear at all that Italian has a preverbal XP position with a topic function, as in Spanish. It rather seems to be the case that there is a preverbal NP position. If this is correct we have to assume that INFL assigns Case to the left in order to define such a position. 
On the other hand, if it is assumed that there exists such a preverbal NP position, it turns out that we have to assume that there is a empty dummy pronoun that can be inserted in that position in order to transmit Case to a postverbal lexical subject. A third possibility is that nominative Case can be assigned in both directions. If it is assigned to the left. it defines an NP position. If it is assigned to the right, it assigns Case directly to a postverbal NP. [22J.

Let us see whether there are any arguments in favour of one of these approaches. The occurrence of ne in relation to quantified NPs with an empty head might provide some indication as to which option should be preferred. As shown by Belletti \& Rizzi(1g81), there is an asymmetry between NP-movement and wh-movement in the ne-construction. This asymmetry is demonstrated in (66).

(66) a. Quanti *(ne) ha letti Gianni? How-many "ne" has read Gianni

b. Tre (*ne) sono stati letti da Gianni Three "ne" have been read by Gianni

If the object is moved by wh-movement ne is obligatorily present, whereas ne must be absent if the object is moved by NP-movement. In chapter 1, it was argued that the position relevant to binding relations is the position in the chain to which Case is assigned. If we assume that the moved object is assigned Case in object position in (66a) but not in (66b), the contrast between (66a) and (66b) can be explained. In (66a), but not in (66b), the clitic ne c-commands the quantified NP at the relevant level. A related asymmetry involves postverbal subjects, as demonstrated in (67).
a. *(ne) sono passate tre
"ne" are elapsed three
b. *(*ne) hanno parlato tre
"ne" have spoken three

As has been argued by Burzio(1981), the class of verbs requiring ne in this construction is the class of ergative verbs, which take the aspectual auxiliary essere. If we want to base the 
account of these asymmetries on c-command of the quantified NP by ne at the level relevant for binding relations, we have to assume that the postverbal NP in (67a) occupies the object position on that level, as is assumed by Burzio(1g81) and Belletti \& Rizzi(1g81). This implies that nominative Case is assigned in object position, where these ergative subjects are base-generated. An alternative analysis in which the ergative subject is adjoined to $\mathrm{V}^{\prime}$ in order to receive Case from INFL directly -assuming that INFL assigns Case to the right- is impossible, since we would not expect the contrast in (67) to show up. Since INFL is not able to govern an NP within the argument projection of $\mathrm{V}$ structurally, we are forced to adopt an analysis in which the postverbal nominative NP receives Case by coindexing. Let us thus suppose that there exists an empty dummy pronoun in Italian, which is able to transmit Case to a coindexed N. Such an analysis is similar to the analyses in Burzio(lg81) and Rizzi(lg82) in most respects. It then follows that in Italian nominative Case is assigned by INFL to the left. In order to realize nominative Case and to fill the preverbal NP position, there are two strategies. Either a postverbal NP which does not receive Case in its D-structure position is moved to the preverbal position or the empty dummy is inserted in the preverbal position, assigning Case to a postverbal NP by coindexation. [23J.

In chapter 2 it has been argued that it is rather unattractive to adopt the existence of empty dummy pronouns. Given the limited adoption of dummy pronouns in general and the pro-drop status of Italian, the unattractiveness of the adoption of an empty dummy pronoun in Italian is someWhat mitigated. However, there is an alternative analysis in which an internal argument that is not Case-marked by the verb may receive nominative Case in its D-structure position. This involves the process of Chain_government proposed in Den Besten(19821. Although I have argued against Chain-government as a necessary mechanism to account for Inversion constructions in Dutch in chapter 2, it may provide us with a solution to the problem discussed in this section, without raving to adopt the existence of an empty dummy pronoun. In such an approach the D-structure object receives nominative Case either from INFL directly, in which case it has to be moved to preverbal position, or from $\mathrm{V}$ by chain-government. 
The contrast between NP-movement and wh-movement illustrated in (68) follows in both analyses.

$$
\begin{array}{r}
\text { (68) 8. Tre (*ne) sono passate } \\
\text { Three "ne' are elapsed } \\
\text { b. Quanti *(ne) sono passate } \\
\text { How many "ne" are elapsed }
\end{array}
$$

The obligatory absence of ne in (68a) indicates that nominative Case is assigned in preverbal position. Since according to the TR-condition (ch.1) the position in which an NP is Case-marked is relevant for establishing binding relations, ne does not c-command the quantified NP at the relevant level. In both theories the preverbal NP must receive Case in its surface position. In the 'dummy-pronoun approach' nominative Case can be assigned to a postverbal NP by coindexation. If a dummy pronoun is present, the postverbal NP cannot be moved to preverbal position, since this position is occupied by dummy-pro. In a 'chain-government approach' a preverbal NP position is present only if the INFL assigns Case to that position. If the postverbal $\mathrm{NP}$ is assigned Case by chain government no preverbal NP position is present. The obligatory presence of ne in (68b) follows as well. In both analyses the preverbal NP position is not canonically governed by INFL. It then follows that wh-movement can take place from postverbal position only.

Both theories differ with respect to the postverbal occurrence of external arguments. In the dummy approach it has to be assumed that the postverbal external argument receives Case under coindexing with an empty dummy in preverbal position. This analysis has the advantage that we can assume that INFL assigns Case unidirectionally. The chain-government approach implies that we should allow INFL to assign Case to both sides. I shall leave the choice between these different approaches for further research.

With respect to the syntax of ne, we are now able to formulate the following principle. 
(69) In the context [NP Q PRO] PRO must be bound if the NP is canonically governed

If the quantified NP receives Case in object position, the clitic ne is able to bind PRO, in accordance with (69). If the quantified $\mathrm{NP}$ is an external argument in postverbal position, PRO should be bound since the postverbal NP is canonically governed by INFL. Since ne cannot c-command anything outside the argument projection of $V$, ne cannot bind PRO. This accounts for the data in (67b). In preverbal position the quantified NP is not canonically governed, which implies that PRO can be free, as in (66b).

Finally, adverbial quantified NPs are not allowed in postverbal position, as is shown in (70).

(70) Gianni * (*ne) è rimasto tre a Milano Gianni "ne" is remained three in Milano

Just as postverbal external arguments, these quantified NPs are canonically governed by INFL and outside the c-command domain of ne. Consequently, both options are excluded. However, if these adverbials are in a left-dislocated position, they are not canonically governed. It follows that unbound PRO should be allowed. This is shown in (71).

(71) (Di questi settimane) Due è rimasto a Milano

Of these weeks two he is remained in Milano

A similar analysis of the quantitative construction based on (69) is possible for both French and Dutch. In French, objects and impersonal 'subjects' require the presence of en.

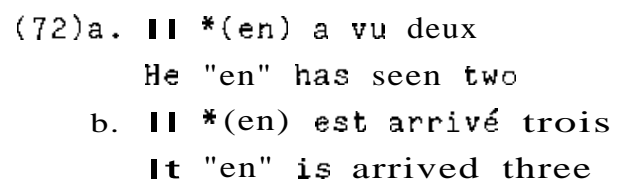

In preverbal position en is not possible because lack c-command. Only unbound PRO is possible. 
(73la. Trois (*enl sont arrivés

Three "ne" are arrived

b. Le jour oì aucune n'(*en) est venue

The day when no-one is come

In Inversion structures the two options are not allowed (cf.Kayne 1979) .

(74) Le jour ou $n^{\prime *}(*$ en) est venue aucune

The day when NEG "en" is come no-one

In this construction, there is a minimal contrast between French and Italian. This contrast is demonstrated in (75).

$$
\begin{aligned}
& \text { (75) a. *Le jour où en sont venus deux } \\
& \text { b. Ne sono venuti due }
\end{aligned}
$$

The ergative subject in postverbal position in Italian can be bound by ne, as in (75b), but an ergative subject in French cannot be bound by en (cf.Pollock 1984). This contrast follows from the assumptions about Case assignment made above. In Italian an ergative subject may remain in object position, receiving Case by coindexation or chain-government. In French an ergative subject has to be moved from the argument projection of $\mathrm{V}$ in order to receive Case structurally. This can be done either by moving it into preverbal position or by adjunction to $\mathrm{V}^{\prime}$. In either case the position in Which Case is assigned to the ergative subject is outside the c-command domain of en. The occurrence of unbound PRO in (74) is impossible since the NP is canonically governed by INFL.

As in Italian there is a contrast between NP-movement and wh-movement in French, as demonstrated in (76).

(76)a. Deux (*en) ont été achete $\mathrm{t}$ Two "en" have been bought

b. Combien *(enl a-t-il acheté $\mathrm{t}$ How many "en" has he bought 
In Dutch the situation is apparently quite different from Italian and French. It appears to be the case that unbound PRO is never allowed. Some of the relevant cases are given in (77). [24].

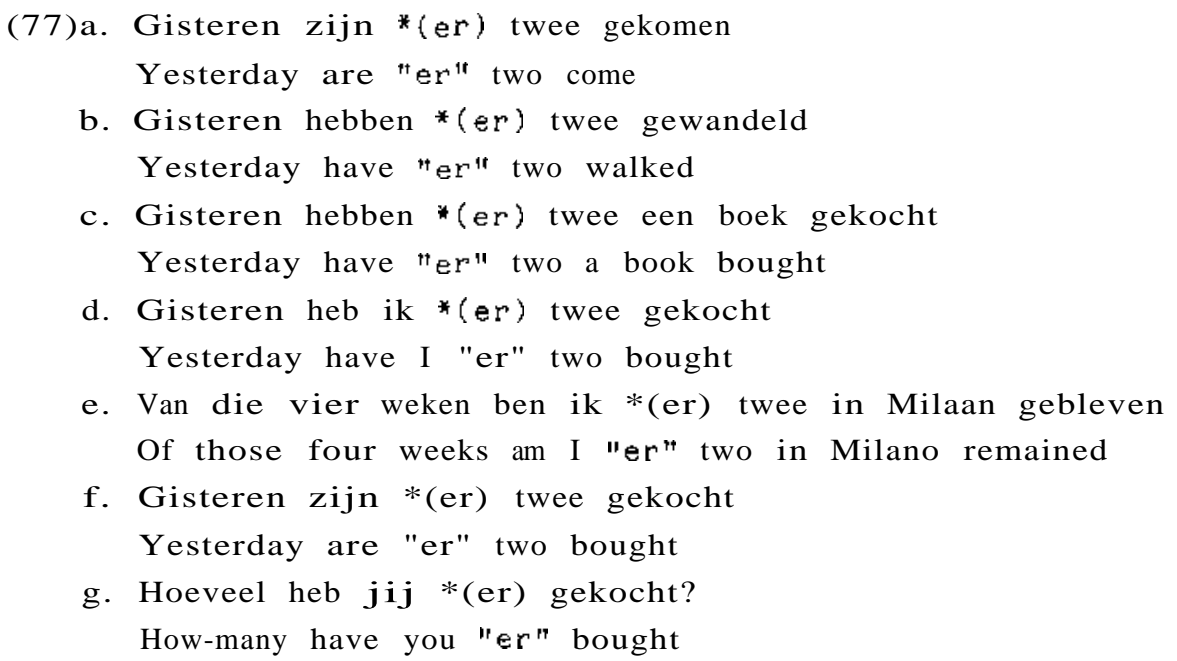

In all the constructions given above er is obligatorily present. In (77a) the quantified NP is an ergative subject; in (77b) it is a non-ergative subject of an intransitive verb; in $(77 \mathrm{c})$ it is a subject of a transitive verb and in (77d) an object. In (77e) er binds an adjunct NP. (77f) is an instance of NP-movement and $(77 \mathrm{~g})$ of wh-movement. However, given the structure of Dutch and the properties of er, this is exactly what we expect. The quantified NP is canonically governed in all cases, which excludes the appearance of unbound PRO. From the fact that er is not a clitic on $V$ but rather a weak adverbial that is moved to the left by adjunction, it follows that er can c-command any NP within S. [25J.

What I have tried to show in this Section is that it is indeed possible to consider French, Spanish and Italian to have the underlying structure INFL [[VO]SJ, although apparently they have the underlying structure NP INFL VP. Of course, many potentially relevant issues have been left out of consideration, such as the distribution of $\mathrm{si}$ in Italian, the Aux-to-COMP rule, the difference between ce and il in French etc. A full discussion of all relevant issues in these languages would take us too far afield. 
4.6 The pronoun es in German

In this section I shall discuss the question as to whether there are dummy pronouns in German. I shall mainly concentrate on those aspects in which German differs from Dutch.

In most respects, the distribution of German es is similar to that of het in Dutch. [26J. It shows up as a neuter pronoun in (78a), as the external argument with weather-verbs in (78b) and as a resumptive pronoun, i.e. a pronoun in argument position related to a c-commanding $S^{\prime}$ in $A^{\prime}$-position. This resumptive pronoun may remain in object position if Case can be assigned, as in (780). If not, it has to be moved to a position in which it may receive nominative Case, as shown by (78d).

(78)a. Das Kind war krank. Es blieb deshalb zu hause The child was ill. It remained therefore home.

b. Es regnet It rains

c. Viele bedauern es, dass er nicht auch in Bonn die Many regret it that he not also in Bonn the erste Geige spielt first violin plays

d. Mir ist es angenehm, dass er nur Einfluss im Süden hat $\mathrm{Me}$ is it nice that he only influence in the south has

In all these cases the distribution of es can be explained in the same way as the distribution of Dutch het, discussed in ch.2. As predicted, e may be absent in constructions of the type illustrated in $(78 \mathrm{c}, \mathrm{d})$, as demonstrated in (79).

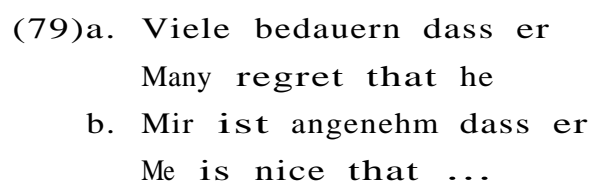

However, there is one class of constructions in which es appears, which differs quite substantially from Dutch. This concerns 
sentences of the type illustrated in (80).

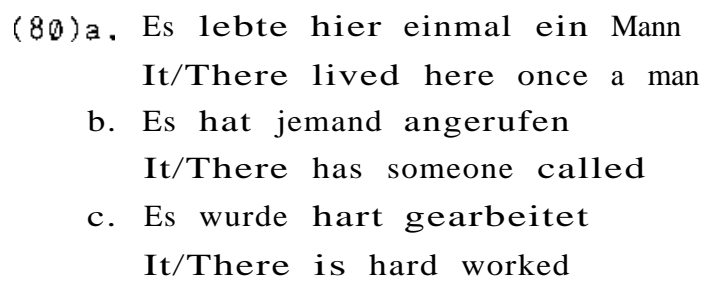

In the case of impersonal passives, as in $(80 \mathrm{c})$, or sentences with an indefinite external argument, as in $(8 \emptyset a, b)$ : es may appear sentence-initially. As discussed in ch.2\&3, the corresponding sentences in Dutch may take the pragmatically motivated dummy er, both in first position and within $S$. The construction exemplified in (86) does not only differ from Dutch, but also from the other constructions in which es shows up. One important difference between (80) and (78) is that ea in (80) is allowed as the first constituent in main clauses (in COMP) only, whereas es in (78) may appear within $S$ as well. This difference is illustrated in (81).

(81)a. Mir ist (es) angenehm dass

$\mathrm{Me}$ is it nice that ...

b.... dass (es) mir angenehm ist dass

that it me nice is that ...

c. Hier lebte (*es) einmal ein Mann

Here lived it once a man

d.... dass (*es) hart gearbeitet wurde

that it hard worked was

With respect to the construction in $(80)$ there are two related but logically independent questions:

-why does es appear in sentences of type $(80)$ ?

-why is es not allowed in $(81 \mathrm{c}, \mathrm{d})$ ?

Suppose we take the optimal point of view that ea is basically similar in all the constructions in which it occurs. This implies that in all cases es is a referential expression bearing a thematic role and requiring Case. If we do so, we are able to explain the occurrence of es in (78) in a way analogous to the explanation of 
the occurrence of Dutch het. At the same time we are able to account for the fact that es does not appear in $(81 \mathrm{c}, \mathrm{d})$. In both (81e) and (81d) there is no Q-role available for es. [27]. It then follows that the analysis which was developed for Dutch het is able to account for the complete distribution of German ea, with the exception of the occurrence of ea in first position in (80).

Within the literature there are two analyses available to account for the occurrence of es in (8ø). In Haiman(1974), Breckenridge(1975), McCray(1981) and Safir(1984) it is assumed that ea is inserted in first position in CaMP, as a dummy pronoun that is necessary to satisfy the V2 requirement in main clauses. A problem with these accounts is that they consider es in (78b-c) to be a dummy pronoun as well. Since es in constructions of the type in (7Sb-c) does not necessarily appear in first position, it has to be assumed that dummy es can be inserted in several positions. We then need a kind of filter to exclude the appearance of es within $S$ in specific configurations.

An alternative approach is presented in Den Besten (1983). He claims that es is generated as a (dummy) pronoun in subject position. From this position it can be moved to initial position by the general rule of Constituent Preposing. Furthermore, there is a rule of ES-deletion, which may delete es if it immediately follows COMP. One problem with this analysis is the fact that the rule of es-deletion must be either obligátory, optional or impossible, depending on the construction in which ea appears, as is demonstrated below.

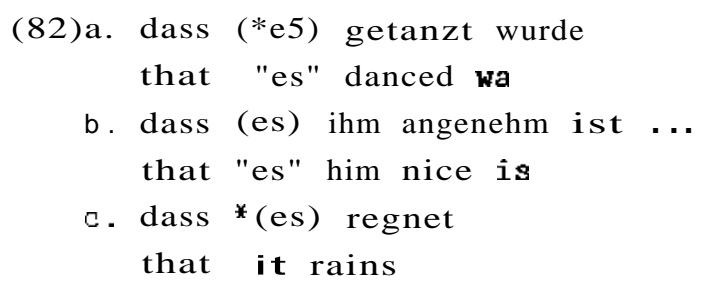

In order to account for the distribution of es, I shall assume that ea is always an NP requiring a thematic role. A further assumption is that thematic role assigned to the Topic position, i.e. the first position in main clauses. This thematic 
role is an adjunct role if a constituent that already possesses a thematic role is moved to the first position (cf.Zubizarreta 1982). If nothing is moved into the first position, es can be inserted in Topic position, receiving this thematic role. From this analysis the ungrammaticality of es in (82a) follows, since there is no available thematic role to assign to es. Although such an analysis is able to account for the appearance of es, it predicts the acceptability of sentences of the type in (83).

(83) *Er wurde getanzt

He was danced

In this sentence er may receive the thematic role 'topic', just as es. The main difference between $(80)$ and (83) is that the NP in topic position is referential in (83) but not in (80). In chapter 1 , it was proposed that the referentiality of NPs is related to Case. No Case is assigned to Topic position. Suppose that es differs from all other NPs in that it does not require Case, which corresponds with the observation that es mayor may not be used referentially. If this is correct, it follows that es in (80) is grammatical as a non-referential thematic NP, whereas (83) is ungrammatical since the NP generated in Topic position is not assigned Case. One might object that in (83) nominative Case is available for the NP in initial position. However, if that NP is assigned nominative Case, it must have been moved from a position within $\mathrm{S}$, to which Case is assigned structurally. Such a derivation is impossible since no such position is provided by the base rules. Since passive verbs do not assign an external thematic role, no NP can be generated as external argument. Base generation of the NP in (83) within $\mathrm{S}$ is excluded for thematic reasons while generation in Topic position is impossible for reasons of Case/reference. The occurrence and distribution of es can thus be accounted for with the following two statements. [28J.

(84) a. es is an NP, characterized by $[+\mathrm{G}, \pm C]$

b. the Topic position is assigned an (adjunct)

thematic role 
Although we have provided an account of the occurrence and the distribution of es, we may still wonder why German differs from Dutch with respect to the construction exemplified in (80). Put differently, why is there no pronoun similar to Dutch er in German? To some extent, German appears to have a pronominal element that is similar to Dutch er. This is the adverbial pronoun da. Da appears as a pure locative pronominal, as in (85a), and as an argument of $\mathrm{P}$, as in (85b).

(85)a. Tch habe dich da gesehen

$\mathrm{T}$ have you there seen

b. Tch habe nicht damit gerechnet

I have not there on counted

As the R-pronouns in Dutch, da precedes P, whereas NPs follow P. We may thus try to develop an analysis along the lines of the analysis given in ch.3 for er. The relevant German pronouns differ from Dutch in that none of them Can be used in a way similar to the Dutch expletive and quantitative use of er. This suggests that the class of adverbial pronouns in German cannot be specified as non-thematic, Which is the common property of quantitative and expletive er. As indicated in chapter 3, the ultimate selection of a particular item as non-thematic is purely a language specific property. Tt is thus in no way surprising to find a German paradigm of adverbial pronouns which is similar to the Dutch paradigm with the exception that they are not selected as non-thematic constituents. An advantage of the theory developed in chapter 3 is that it allows us to express the difference between Dutch and German with respect to the occurrence and distribution of adverbial pronouns by one parameter. [29J.

\section{$4.7 \mathrm{Tt}$ as a referential expression}

On the basis of what has been argued so far it should be possible to provide a consistent analysis of English it. In this section I shall maintain that it is similar to Dutch het in all relevant respects. Distributional differences follow from independent 
differences between Dutch and English.

We find it in all the English Counterparts to the constructions discussed in chapter 2. It can be the subject of weather-verbs, it may be a regular non-human pronoun, it (optionally) appears as an object with verbs taking a propositional complement, it appears as the subject of raising verbs taking finite complements, etc. Examples are provided in (86).

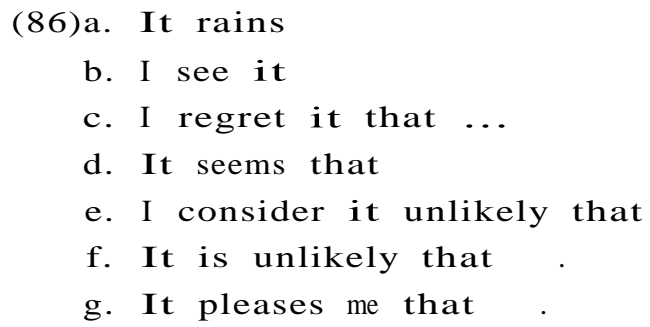

In general, the analysis defended in chapter 2 for Dutch het carries over to English it.

However, there are two important differences between Dutch and English. The appearance of it is optional only if it is the direct object of the verb, i.e. in sentences of the type in (86c). In chapter 2 we saw that the occurrence of het is optional in other constructions as well. A second di.fference between Dutch and English involves the fact that in English wh-extraction from $S^{\prime}$ is possible even if it is present. We have seen that the availability of extraction in Dutch is generally confined to constructions without het. Potentially, these two differences are serious problems for the theory defended here. If the possibility of extraction from $S^{\prime}$ forces us to assume that $S^{\prime}$ in sentences of the type in $(86 \mathrm{~d}, \mathrm{f}, \mathrm{g})$ is a direct argument of the verb, we have to assume that it is generated as a non-thematic SUbject, i.e. a dummy pronoun filling the subject position. One argument in favour of such an analysis could be the obligatory presence of it in these constructions.

Let us start with a discussion of wh-extraction from $\mathrm{S}^{\prime}$. The relevant question is whether the extraction in (87) is extraction from an argument $5^{\prime}$ or an adjunct $5^{\prime}$. 
(87) Who is it essential [that John will visit t]?

In our analysis it is a referential expression with a thematic role and Case. At the level of D-structure it is the subject of a small clause. It is moved to subject position in order to receive Case. from this analysis it follows that the embedded $S^{\prime}$ must be an adjunct clause. In a dummy pronoun approach, it might be a dummy pronoun which has been inserted in subject position and the embedded S' can be an argument directly. In order to show the correctness of our hypothesis concerning it, I shall have to prove that the extraction in (87) involves extraction from an adjunct $S^{\prime}$.

It is interesting to observe that extraction from adjunct clauses in English is possible to a certain extent. Chomsky (1985) argues that adjuncts are not islands to extraction. A relevant example is given in (88).

(88) ?he is the person who they left [before meeting t]

I will not be concerned here with the exact analysis of these extractions. What is important for our analysis is that extraction from adjuncts seems to be possible in English, but not in Dutch, as is demonstrated by the corresponding Dutch sentence in (89).

\footnotetext{
$(89)^{*} h i j$ is de man die zij weggingen alvorens $t$ te ontmoeten he is the man who they left before to meet
}

As Chomsky observes, there is a contrast between extraction of arguments and adjuncts from adjunct clauses. This contrast is illustrated in (90).

(90)a.?Who did you leave [before meeting t]? b. How did you leave [before fixing the car t]?

Obviously, extraction of an adjunct from an adjunct clause impossible. This asymmetry does not show up in extraction from argument clauses, as is illustrated in (91).

(91)a. Who do you think [that John saw $\underline{t}$ ]? 
b. How do you think [that John will fix the car tJ?

If these observations are correct, it provides us with a criterion to determine whether an $S^{\prime}$ is an adjunct or not. If the $S^{\prime}$ that co-occurs with it is an argument, we expect adjunct extraction from $S^{\prime}$ to be possible, while we expect it to be impossible if the $S^{\prime}$ is an adjunct clause. It appears to be the case that a contrast of the type in $(90)$ shows up in it $\bullet . . S^{\prime}$ constructions. Chomsky (1985) discusses the following contrast:

$\{92\}$ a. Who is it time [(for John) to visit $\underline{t}]$ ?

b. How is it time [(for John) to fix the car $t]$ ?

A similar contrast seems to appear in the sentences in (93) and (94). [30J.

(93) a. Who is it clear [that John will visit $\underline{t}$ ]?

b.??How is it clear [that John will fix the car $t$ ]

(94)a. Who does it please you [that John will visit $\underline{t}$ ]

b.??How does it please you [that John will fix the car $\underline{t}$ ]

If these observations are correct, they demonstrate that extraction from $S^{\prime}$ in (92)-(94) involves extraction from an adjunct clause. It then follows that in these sentences it must be an argument receiving a thematic role directly. Thus it turns out that an apparent problem for our hypothesis concerning it can be turned into an argument in favour of this hypothesis.

The second apparent problem for the referential status of it is the obligatoriness of it in subject position. In chapter 2 it was shown that in Dutch the occurrence of het is optional in subject and object position. This is illustrated once more in (95).

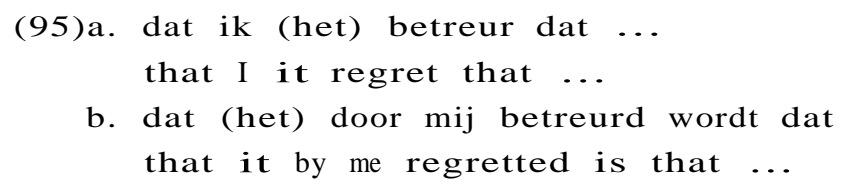

In the corresponding sentences in English in (96) it is optional in 
object position but obligatory in subject position.

(96)a. that I regret (it) that ...

b. that $*$ (it) was regretted by me that $\ldots$

We have to explain why it must be present in (96b). In view of what has been said in section 3 of this chapter, the obligatoriness of it follows directly from the assumption that nominative Case defines a (NP) position to the left of INFL. This position must be filled at S-structure. Such an analysis is confirmed by the fact that subjectless sentences of the type in (96b) are abundantly present in Old English, as demonstrated in section 4.

One potential argument against such an analysis is the fact that there are cases in which it cannot appear as an object of a particular verb while it has to appear in the passive counterpart (cf.Williams 1981). This is shown in (97).

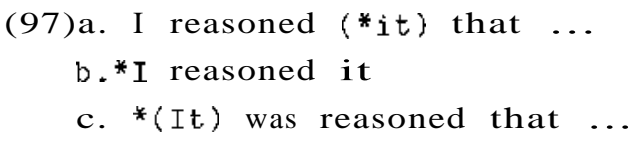

There is a difference between the ungrammaticality of (97a,b) where it is present and the ungrammaticality caused the absence of it in (97c). The ungrammaticality of (97a) with it is solely dependent on properties of the particular verb, while the ungrammaticality of (97c) without it is a structural property of English. To account for these facts, I shall assume that the selection of it or $S^{\prime}$ as the internal argument of $\mathrm{V}$ is structul'ally free. The actual selection of it or $S^{\prime}$ is dependent on lexically determined factors such as factivity (cf.Kiparsky \& Kiparsky 1970). If the verb is passivized, the choice between $S^{\prime}$ or it is determined by syntactic principles. If $S^{\prime}$ is selected, the sentence will become ungrammatical because the NPnom position will remain unfilled. It has to be selected for syntactic reasons. 


\subsection{Concluding remarks}

In this chapter we have provided fairly tentative analyses of a variety of issues. The common denominator in these superficially unrelated topics is their relation to central issues in the preceding chapters. In the first few sections of this chapter we were concerned with a further elaboration of two central theoretical topics: the concept of connectedness and the theory of endocentric subjects.

With respect to connectedness it has been argued that a further extension of this concept can be achieved if we assume that the upper level of a subtree is subject to conditions on connection as well. It was demonstrated that the c-command condition can be seen as an instance of the connection requirements and that differences between adjunction and substitution can be made to follow from configurational properties with respect to the direction of connection of the antecedent.

In section 3 it was argued that the general concept of small clauses should be extended in such a way that the subject of $S$ is base_generated as an external argument within the V-projection. This generalization of the endocentric subject theory has important consequences for the analysis of languages with an apparent NP-INFL-VP order. It was Shown that the requirement that English sentences have a subject should not follow from a universal principle, as proposed in Chomsky(1982), but rather from the fact that in English nominative Case defines a position external to the $\mathrm{V}$-projection. This position must be filled during the derivation by moving a non-Case-marked NP.

Empirical evidence supporting these theoretical claims has been provided in the following sections. A discussion of Old English has made it clear that a variety of differences between Old English and Modern English can be explained by the theory developed here. The occurrence of various types of subjectless sentences in Old English has been particularly relevant in this connection. It would be completely ad hoc to assume that there exists a variety of empty dummy pronouns in Old English. This assumption would be necessary to maintain the Extended Projection Principle as a principle belonging to UG. In our theory the occurrence of 
subjectless sentences in $\mathrm{OE}$ is not surprising at all. As in Dutch, INFL is able to assign Case to an external argument or a non-Case-marked internal argument directly under government. If no such NP is present, no principle is violated. The difference between Old English and Modern English lies mainly in the position of INFL with respect to Vmax.

A discussion of several Romance languages has been included to demonstrate that these languages can be argued to have an underlying postverbal subject. The 'normal' preverbal position of the subject is either a position defined by nominative Case (French, Italian) or a topic position (Spanish).

In the final two sections, it has been shown that German es and English it are not dummy pronouns but rather referential expressions which are in most respects similar to Dutch het. 
NOTES

1. Chomsky(1981) argues that subcategorized SCs are endocentric. whereas adjunct SCs are exocentric. One reason for this distinction is that adjunct SCs may have PRO subjects. Given the fact that Chomsky adopts the Aoun-Sportiche definition of government the subject of an endocentric SC would be governed by the head of the SC. This implies that Pro can only appear whenever the subject is not part of the maximal projection of the predicate, since PRO would be governed otherwise.

2. One argument in favour of a VP constituent in av languages is presented in Haegeman \&Van Riemsdijk (1984). They argue that there is a VP_external NP position in West-Flemish and Zurituutsch in order to account for the fact that apparently the subject cannot undergo Verb Projection Raising (VPR). As far as I can see, however, their argument is not conclusive. The fact that a subject of a complement to a caussative or perception verb cannot be moved via VPR to a position to the right of the perception verb can be made to follow from the fact that the perception verb assigns Case to the left. Such an account would be similar to the account presented in Hoekstra(1984) of the impossibility of postverbal perception-verb complements in Dutch.

3. In general, this approach severely delimi.ts the possible underlying structures of languages. Although in the endocentric approach no language is supposed to have a VP as a separate constituent, the notions of argument projection and endocentric subject-predicate relation imply that there are eight possible configurations for finite clauses, abbreviated in (i).

(i) $[$ INFL, $[$ Subj, [V,OJJJ

A further investigation of the consequences of (i) will be left for future research.

4. A similar underlying structure is proposed in Rigter \& Beukema(1985) and Rigter(1985).

5. Another construction for which it might be claimed that the external argument receives Case in its D_structure position involves the subject-Aux_inversion construction ( $\mathrm{SAl}$ ), illustrated in (i).

(i) When did you see him

Given the fact that we have claimed that in 'normal' cases subject-AUX-inversion takes place to the extent that the subject is moved to a Dosition to the left of INFL, (i) might be the result of the absence of movement of the subject. If this is true, INFL must be able to assign Case to the right. It might be the case that INFL is able to assign Case to the right in main clause questions only. Such an account would be comparable to the account of Stylistic Inversion in French, discussed in section 5.3. This assumption, together with the assumptions that INFLIAUX may not. remain empty and that movement of $\mathrm{V}$ to INFL is blocked by the presence of an intervening lexical SUbject, allows us to account for the SAl-construction and the phenomenon of do_support.

6. The assumption that teCto) in Dutch is also part of INFL is rather problematical. One major problem is that in raising complements te is 
obligatorily present. In the account given here this is unexpected, since raising should be allowed in Dutch only if the complement is Vmax. The problem regarding the presence or absence of te in Dutch is quite complicated. In postverbal position an infinitival complement always requires the presence of te. However, in preverbal position a variety of factors are relevant for the presence of te. I Shall leave these problems out of consideration here.

7. There is a further difference between Dutch and English that is relevant here. In Dutch, COMP is a speeifier of the INFL projection (ef.chapter 1). This implies that a lexical complementizer, such as the prepositional complementizer om, is not able to assign Case to an embedded subject. Thus, of the three possible ECM constructions in English only one is present in Dutch.

8. The results presented in section 4 on Old English and the development into Modern English are rather tentative and incomplete. More detailed research in this direction is required, in particular with respect to the diachronic development.

The abbreviations under the $\mathrm{QE}$ examples refer to $\mathrm{OE}$ texts. $A$ list of these texts is provided below.

9. This assumption is adopted in most recent analyses of DE, see e.g. Lightfoot (1979,1981), Fischer \& Van der Leek (1983), Van Kemenade (1984a).

10. The fact that pronouns may appear in front of $\mathrm{P}$ is somewhat problematical within the framework defended here, since Case is assumed to be assigned directionally. Given the fact that full NPs must and personal pronouns may appear after the preposition, we have to assume that in $\mathrm{OE}$ prepositions assign Case to the right. If we assumed that personal pronouns may be moved to the left of $\mathrm{P}$, we would have a violation of the Gap Condition, since the trace would not be canonically governed. Such a movement approach is assumed in most analyses, such as Allen(1980), Vat(1978) and Van Kemenade(1984b\}. If personal pronouns were base-generated in front of $\mathrm{P}$, no Case could be assigned to them directly. We must therefore assume that personal pronouns preceding Pare clitic-like elements that are base-generated in front of $\mathrm{P}$ and receive Case inherently or by coindexation with the empty NP(pro that follows P. Aclitic analysis of these personal pronouns is proposed in Van Kemenade(1984b).

11. There are several arguments against an analysis in which an R-pronoun or a personal pronoun is moved from $\mathrm{pp}$ to COMP. Relative pronouns are similar to demonstrative pronouns in that they cannot occur in front of $\mathrm{P}$. The assumption that in se-relatives personal pronouns are moved into COMP and subsequently deleted would be completely ad hoc. A movement analysis would then have to assume that the relative R-pronoun $\mathrm{z}_{\mathrm{ar}}$ is moved from $\mathrm{pp}$ to COMP and subsequently deleted. Such an analysis would be in line with the theory of extraction proposed in chapter 1 . One problem with this analysis is the fact that there are no dær-relatives with animate heads, while there are many instances of oe-relatives with animate heads. If this is a general phenomenon, it implies that deletion in COMP would be obligatory if the antecedent is animate, while it is optional with inanimate antecedents.

A potential solution to this problem is to assume that there is a resumptive pronoun strategy for oe-relativization in $\mathrm{OE}$, as proposed by Van Kemenade (1984b). In that case the pp contains a base-generated empty resumptive pronoun, locally A'-bound by an (empty) operator in COMP. It seems reasonable to assume that the Gap Condition applies to resumptive pronouns in the same way in which it applies to traces, since the two categories require a local antecedent in a non-thematic position. Thus, the adjacency between $\mathrm{F}$ and $\mathrm{V}$ in this 
construction can be made to follow from the Gap Condition. The SUbjacency effect follows from the fact that the resumptive pronoun should be locally A'-bound. Movement of the operator proceeds in accordance with conditions on movement. If such an analysis of oe-relativization is correct, the resumptive pronoun must be generated in front of $\mathrm{P}$, in order to satisfy the Gap Condition. Given that in $\mathrm{OE}$ personal pronouns may optionally precede $\mathrm{P}$ and that resumptive pronouns generally belong to the class of personal pronouns, the empty resumptive pronoun can be generated in front of P. It is clear that this analysis may proceed within the general framework outlined in chapter 1. However, a major problem with this theory is that we have to adopt the existence of an empty resumptive pronoun and an empty operator in COMP. Both claims are not independently motivated.

It seems better to stick to an R-movement analysis. The obligatory deletion of the R-pronoun in COMP if the antecedent is [+animateJ is reminiscent of the normative pattern in Dutch. As observed in chapter 3, R-pronouns cannot be [+humanJ according to normative grammar. According to this view (ia) is ungrammatical, and should be replaced by (ib).

(i)a. de jongen waar ik mee gewerkt heb

the boy where I with worked have

b. de jongen met wie ik gewerkt heb the boy with whom I worked have

In infinitival relatives the relative pronoun is obligatorily deleted and pied piping is impossible. Neverthess, F-stranding is possible from a normative point of view, even if the antedent is [+humanJ. This is shown in (ii).

(ii) een leuk meisje om mee te werken a nice girl for with to work

There can be no doubt that (ii) is derived by means of wh-movement of an R-pronoun, followed by obligatory deletion. All the conditions and restrictions on R-movement can be found in these infinitival relatives. For instance, R-pronouns are not allowed with certain prepositions. such as zonder(without). If the preposition met in (ii) is replaced by zonder, the sentence will become ungrammatical.

Apparently, the lexical presence of an R-pronoun blocks a [+humanJ interpretation in normative grammar, while this interpretation is available if the R-pronoun is deleted. It turns out then that the situation in 'normative Dutch' is exactly parallel to the situation found in Old English. Given the fact that in 'normative Dutch' there is no restriction on [+human] R-pronouns (cf. (ii)) but only on lexical [+humanJ R-pronouns, as in (ia), the non-occurrence of lexical R_relatives with [+humanJ antecedents in Old English might be an instance of the same phenomenon.

12. The order NFobj.... NPnom can be derived by other rules as well. Particularly in root clauses, Topicalization of the NFobj to the position in front of the finite verb may cause this effect. However, the sentences in (48) do not show the verb-second effect of root clauses. The two NPs precede the verb. A sentence like (i) cannot be argued to be the result of Inversion, but seems derived by Topicalization.

(i) Hem behof $€ 3$ Cristes helpe Them(OBJ) needs Christ's help(NOM) (Chr. ,262. 18/ Elmer 1981, II (35)) 
13. This step in particular has to be motivated more extensively. For instance, the locality requirement on the movement of V to INFL applies only if INFL and V are separated by a lexical NP, as in the case of Subject-AUX-Inversion constructions, or not. In the framework adopted here, we have to assume that the trace of a moved subject and adverbials are irrelevant. If this analysis turns out to be incorrect. we have to assume that the two important changes in the development of English, i.e. the position of INFL with respect to Vmax and the position of $\mathrm{V}$ with respect to its objects, are unrelated.

14. Note that it follows from the Burzio generalization that 'transitivization' and 'personalisation' are necessarily combined in these constructions.

15. Although the development from Middle Dutch into Modern Dutch does not involve such drastic changes as the development of English, one change deserves to be mentioned in this chapter. The Case system which was present in Middle Dutch is almost completely lost in Modern DutCh. One of the consequences is that Middle Dutch Shows a wider range of nominative-less constructions than Modern Dutch. The range of nominative-less constructions in Middle DutCh is discussed in Van den Berg (1985). As in Old English, several verbs were able to assign a lexically determined genitive Case to an internal argument. If such a verb does not select an external argument, a nominative-less construction of the type (i) is possible.

(i) mi wondert des me(OBJ) wonders that(GEN)

The general pattern of these Middle Dutch constructions is exactly similar to the Old English pattern discussed in 4.1.3. Given this similarity I shall not discuss this construction and its development here.

An interesting and problematic construction discussed by Van den Berg involves nominative-less sentences with an accusative argument. Examples are provided in (ii).

(ii)a. daer is den brief there is the letter(OBJ)

b. te Wyc stont bi di,e brugge enen torre in wyo was-standing at the bridge a tower(OBJ)

c. groten strijt was daer gevochten big battle(OBJ) was there fought

This construction seems to be rather common in Middle Dutch with verbs like zijn (to be) and staen (to stand). Van den Berg argues that this construction shows up only with non-agentive 'subjects', which are base-generated in object position. He claims that these verbs optionally assign structural objective Case. The problem with this analysis is the fact that these verbs do not assign an external argument. Given the Burzio generalization, we do not expect these verbs to assign structural Case. In order to maintain the generalization we might assume that verbs like zijn and staen optionally assign lexical accusative Case. In particular, the passive sentence in (iic) seems to point in this direction. The appearance of an accusative NP, thematically the direct object of the passivized verb, is in direct violation of the theory of passivization. In order to maintain this theory we have to appeal to an ad-hoc meChanism. The fact that the verb zijn is able to assign lexical accusative Case in (iia) as well as in (iic) is to some extent an argument in favour of such an ad-hoc mechanism of Case assignment. 
16. An argument against the postverbal base position of the external argument is given in Jaeggli (1982, ch.4). He argues that the intonation pattern of (i) indicates that (ia) is the base-generated structure.

(i)a. Juan compr6 una casa ayer

Juan bought a house yesterday

b. Compr6 una casa ayer Juan

He claims that (ia) "has the typical intonation pattern of a sentence in what might be called canonical word order"(Jaeggli (1982),p.141). However, it is not clear to me in what way the intonation pattern of a sentence can provide information concerning the underlying structure of a sentence. As long as there are no theories on the relation between intonation patterns and basic sentence structure that settle the issue, I consider this argument to be non-valid.

17. I shall not discuss the phenomenon of subject clitics. These may also appear after a finite verb. The phenomenon of inverSion of verb and clitic \{subject-clitic inversion (SCI)) has properties that are quite different from the 'stylistic inversion' construction (SI) under discussion, as has been demonstrated in Kayne (1972). Some of these differences are: SeI, but not SI, is applicable in root Clauses only; SeI, but not SI, appears in yes-no questions; SeI, but not SI, moves the subject immediately to the right of the leftmost verb. Further discussion of SCI can be found in Emonds (1976), Den Besten (1983) and Jaeggli (1982), etc.

18. I shall assume that se absorbs objective Case, with the absorption of the external $\theta$-role as a consequence, cf.note 19.

19. At first sight, the ungrammaticality of (i) seems to be problematical.

(i) *11 se mange bien dans ce restaurant

It "se" eats well in this restaurant

The derivation of (i) should proceed as follows: se absorbs the external thematic role and il is inserted as the non-thematic external argument in order to fill up the nominative NP-position. However, as indicated in note 18, I shall assume that se absorbs objective Case, in a way similar to zich in Dutch. The absorption of the external argument is merely a natural consequence, in accordance with the Burzio generalization. Consequently, se cannot be inserted with verbs that do not take an internal NP-argument. Similarly, se cannot be inserted with verbs that do not assign objective Case to their D-structure internal argument as a consequence of lexical properties (ergative verbs), as shown in (ii), or passivization, as shown in (iii). In these three cases no Case can be absorbed.

(ii) *11 s'a été invite

It "se" has been invited

(iii) *11 s'est arrivé

It "se" is arrived

Burzio (1981) claims that the non-occurrence of (i)-\{iii) derives from the fact that il must bind a nominative NP. Although such an analysis is possible for the construction under discussion, it does not extend to other constructions in which il is used as a non-thematic argument, as, for instance in passives of intransitive verbs. 
20. In this respect french differs from Dutch. As pointed out in ch.3, impersonal passives in Dutch are allowed without the insertion of a dummy pronoun. This possibility is not available for french, since French requires the preverbal NP position to be filled. However, as will be demonstrated below, there are constructions in which there is no such preverbal NP-position. In those cases the introduction of the dummy pronoun il is indeed optional.

21. A similar analysis may be available for the "il y a-construction". The postverbal NP does not agree with the verb and there is a definiteness effect, as is shown in (i).

(i) $11 \mathrm{Y}$ a deux $/^{*}$ ces livres sur la table

It there has two/these books on the table

If it is assumed that the phrase [deux livres sur la table] is a Small Clause with an NP subject, deux livres should receive Case from the matrix verb. If it receives Case from avoir, the verb must be a normal transitive verb. Again, 11 serves as an external argument to satisfy this requirement syntactically. It is interesting to observe that different verbs are chosen in (i) and the corresponding (ii).

(ii) Ces livres sont/*ont sur la table

These books are on the table

22. This option is in fact comparable to french, with the extension that Case assignment to the right is not restricted to specific environments.

23. It follows from this analysis that we have to consider Inversion and null-subjects to be separate properties. There seems to be no way to predict the non-existence of a) languages with obligatory lexical subjects that have a lexical dummy pronoun with the same function as the empty dummy in Italian, b) languages that allow null-subjects but do not have such a dummy pronoun.

English might be an instance of a language of type a), although the phenomenon of postverbal subjects is greatly restricted by lexical factors. With respect to a language of type b), Rizzi(1982, ch.4, fnt.20) notes that Brazilian Portuguese might be an instance of a language allowing null-subjects but no free application of Inversion. He refers to an unpublished paper by chao(1980).

24. $(77 \mathrm{~g})$ is not ungrammatical without er, but in that interpretation hoeveel is an NP rather than a OP followed by an empty noun. A similar contrast appears in (i).

(i)a. Ik heb veel gekocht

I have much bought

I have bought much,

b. Ik heb er veel gekocht

I have "er" many bought

tI have bought many,

25. The sentences without er seem to improve somewhat if the quantified NP is topicalized, as in (i).

(i) (Wat betreft deze boeken) Twee heb ik ??(er) gekocht (Concerning these books) Two have I "er" bought 
Particularly in listing the construction without er appears to improve, as in (ii).

(ii) (wat betreft deze jongens) Twee lopen ?(er) in de tuin, (concerning these boys) Two walk "er" in the garden drie zijn ?(er) weggegaan en vier zitten ?(er) binnen three are "er" away gone and four sit "er" inside

I have no genuine explanation for this decrease in ungrammaticality. There are two factors which might be involved. First, contrary to all S-internal positions, the first position in main clauses is not canonically governed. It might be the case that somehow the derived position is taken to be the position at which binding relations are established. Secondly, it is a well-known phenomenon that empty categories are possible in first position in main clauses that are not possible within S. Substandard sentences typical of spoken language show this quite clearly. Examples are provided in (iii).

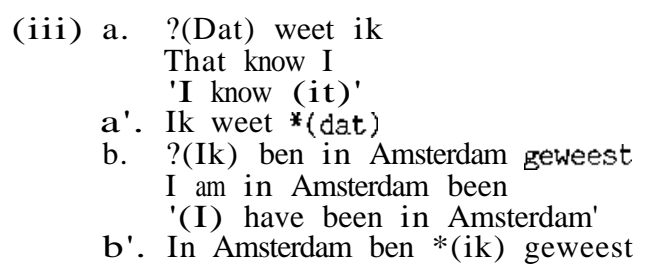

It might be the case that by way of exception empty categories in first position can be contextually bound. for (i) and (ii) this would mean that er is not necessarily present to bind PRO, since PRO in that position might be bound otherwise.

26. The distribution of es is extensively described in Putz(197S). Most of the examples given in this section are taken from Putz. A discussion of the similarities and differences between Dutch er and het and German es, within a framework similar to the one proposed here, is presented in Van Leeuwen(1g8S). Other articles relevant to this issue are Den Besten(1983) and Safir(1g84).

27. Note that we cannot relate the ungrammaticality of $(81 \mathrm{c}, \mathrm{d})$ to the requirement that NPs ,including es, should receive Case. Such an explanation would correctly exclude es in (81c), but not in (81d), since nominative Case is available in (81d).

28. This analysis predicts that non-referential es may always appear as the first constituent in main clauses. Obviously, this is incorrect, since this is generally not allowed in case of definite external arguments. I shall assume that the actual appearance of es is determined by pragmatic/semantic principles, in a way similar to the appearance of dummy er in Dutch. Relevant factors appear to be the thematic function of es, which might be described as presentative, and the semantic/pragmatic properties of the constituents within S.

29. There is one further relevant difference between Dutch and German. With the exception of some northern dialects (cf.Van Riemsdijk 1978a) it is impossible to strand prepositions. The Gap Condition predicts stranding of prepositions to be possible in German if the argument of $\mathrm{P}$ precedes $\mathrm{P}$ and if $\mathrm{PP}$ is (canonically) governed by $P$. It turns out, however, that in those circumstances stranding is impossible, as is illustrated in (i). 
(i) Da habe ich nicht [t mit $\mathrm{J}$ gerechnet There have I not on-counted

Logically, there are two conceivable structural reasons for the ungramrnaticality of (i). Either $\mathrm{P}$ is not able to govern the trace correctly or $\mathrm{V}$ does not govern pp correctly. Given that, even PP-internally, adjunction turns out to be impossible, as demonstrated in (ii), it follows that the first option has to be selected.

(ii) a. Ich habe [genau davor] gestanden

I have exactly there for stood

b. *Ich habe [da genau $t$ vor] gestanden

Obviously, German differs from Dutch to the extent that $P$ is a structural governor in Dutch but not in German. This difference is similar to the difference between English and french concerning P-stranding (cf.Kayne 1984). It thus follows that P-stranding is possible only if a) $\mathrm{P}$ is a structural governor (this holds for English and Dutch, but not for French and German) and b) P governs its argument canonically (to the left in Dutch and to the right in English). These conditions on P-stranding are part of the Gap Condition, as formulated in ch.l.

30. The possibility of extraction from adjunct clauses is clearly related to extraction from adjunct PPs. As discussed in Van Riemsdijk (1978a) and Hornstein \&Weinberg (1981) extraction from adjunct PPs is possible, as in (i).

(i) Who did John'S mother travel with

From the acceptability of (i) it follows that we have to assume that the adjunct $\mathrm{pp}$ is governed by V. If not, (i) would constitute a violation of the Gap Condition. If the government domain of $\mathrm{V}$ in English can be extended upwards to include adjunct PPs, it is expected that the same analysis applies to adjunct clauses. It has been observed by Hornstein \& Weinberg that not all adjunct PPs can be stranded. In particular temporal adjunct PPs appear to be islands, as is illustrated in (ii).

(ii)*Which meal did John speak to Bill after?

It is assumed that the difference between (i) and (ii) is caused by a difference in the level of adjunction. It is likely that the difference in acceptability between (90a) and (93a) is caused by the same factor.

List of OE Texts:

Aelfric's Lives of Saints (LiVeS), ed. W.Skeat, EETS 76,82,94 \& 114 University Press, Oxford, 1881-1900

The Homilies of the Anglow Saxon Church (ART) ed. B.Thorpe, 2 vols.,

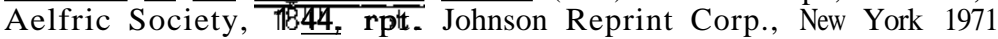

Homilies of Aelfric: a Supplementary Collection (AHP), ed. J.Pope, EETS 259 \& $\overline{260}$, University Press, OXford, 1967-1968 
King Alfred's Old English Version of Boethius (8), ed. W.Sedgefield, 1899 rpt. Wissenschaftliche Buchgesel Ischaft, Darrnstadt, 1968.

King Alfred's Orosius (0), ed.H.Sweet, EETS 79, N.Trubner, London, 1883.

King Alfred's West-Saxon Version of Gregory's Pastoral Care (CP),

---ed.H.Sweet, EETS 45 \&50, N.Trubner, London, $1871+1872$.

Old English Version of Bede's Ecclesiastical History of the English People

--- (Bede), ed. T.MiITer, EETS 95 \&96, N.Trubner, London 1890-1891.

The Blickling Homilies of the Tenth Century (BH), ed. R.Morris

-- EETS 58,63 \& 73, N.Trubner, Oxford 1880.

An Old English Martyrology (Mart.), ed. J.Herzfield, EETS 116

-- Kegan Paul, Trench, Trubner, and Co., London 1900.

Two of the Saxon Chronicles (Chr.), ed. C.Plurnmer, Clarendon Press, Oxford 1924.

The Homilies of Wulfstan(W), ed. D.Bethurum, Clarendon Press, Oxford 1957.

'Gospel of St.Matthew', in: The West-Saxon Gospels (St.Mat.)

ed. M.Grunberg, Scheltena \& Holkema, Amsterdam 1967.

Bosworth-Toller, An Anglo-Saxon Dictionary (ST), Oxford. 



\section{References}

AlIen, C.L.

1977 Topics in diachronic English syntax, diss. U.Mass, Amherst.

1980 "Movement and deletion in Old English", Linguistic Inquiry 11, 251-323.

Aoun, J.

1981 The formal nature of anaphoric relations, diss.MlT.

1985 "A typology of wh-interrogatives", paper read at the GLOW conference, Brussels, April 1985.

Aoun, J. and D.Sportiche

1983 "On the formal theory of government", The Linguistic Review 2,211-236.

Bach, E. and G.Horn

1976 "Remarks on 'Conditions on transformations"', Linquistic Inquiry 7, $265-300$.

Bart, P.van \& R.Kager

1984 "Er is hier - een alternatief voar een diagnose", in G.J.de Haan, M.Trommelen \& W.Zonneveld (eds) Van periferie naar kern, Foris Publications, Dordrecht, 1_11.

Barwise, J. \& R.Cooper

1980 "Generalized quantifiers and natural language",

Linguistics and Philosophy 4, 159-219.

Bayer, J

1984 "COMP in Bavarian syntax", The Linguistic Review 3, 209-274.

Bech, G.

1952 Ueber das niederländische Adverbialpronomen er, Travaux du cercle linguistique de Copenhague 8 .

Belletti, A.

1980 "'Morphological' passive and Pro-drop. A note on the impersonal construction in Italian", unpub1.ms. MIT.

Belletti, A. and L.Rizzi

1981 "The syr.tax of ne: some theoretical implications", The Linguistic Review 1, 117-154.

Bennis, $\mathrm{H}$.

1977 "Het kwantitatieve er in komparatief konstrukties", Spektator 6, 384-387.

1979 "Appositie en de interne struktuur van NP", Spektator 8, 209-228.

1980a "Er_deletion in a modular grammar", in S.Daalder \&M.Cerritsen (eds) Linguistics in the Netherlands 1980, North-Holland, Amsterdam, 58-68.

$1980 \mathrm{~b} \quad$ "Coindexing 2nd complementizer-trace phenomena", paper read at the GLOW conference, Nijrnegen, April 1980.

1982 "Boekbespreking van: R.S.Kirsner 'The problem of presentative sentences in modern Dutch"', CLOT 5, 1-13. 


\section{References}

1983 "De PRO-drop parameter en subjectloze zinnen in het Nederlands", Spektator 12, 409-427.

1985 "Het-Raising", in H.Bennis ... F.Beukema (eds) Linguistics in the Netherlands 1985, Foris Publications, Dordrecht, 11-20.

Bennis. H. \&L.Haegeman

1984 "On the status of agreement and relative clauses in West-Flemish", in W.de Geest ... Y.Putseys (eds) Sentential complementation, Foris Publications, Dordrecht, 33-55.

Bennis, H... T.Hoekstra

1984a "The distribution and interpretation of gaps", ms. Univ. of Leiden.

1984b "Gaps and parasitic gaps", The Linguistic Review 4, 29-87.

1985 "A parametrized Gap Condition", paper read at the GLOW conference, Brussels, April 1985.

Bennis, H.... A.Hulk

1979 "A comparative study of the quantitative construction", paper read at the conference Levels of Syntactic Representation, Paris, Dec. 1979.

Berg, E.van den

1985 "Onpersoonlijke konstrukties, subjekten en nominatieve NP's in het Middelnederlands", De nieuwe taalgids 78, 201-213.

Besten, H.den

1981 "Government, syntaktische Struktur und Kasus", in M.Kohrt ... J.Lenerz (eds) Sprache: Formen und Strukturen, Niemeyer Verlag, TUbingen, 97-107.

1982 "Some remarks on the ergative hypothesis", Groninger Arbeiten zur Germanistischen Linguistik 21, 61-82.

1983 "On the interaction of root transformations and lexical deletive rules" in W.Abraham (ed.J, On the formal syntax of the Westgermania, John Benjamins, Amsterdam, 47-131.

Beukema, F.... T.Hoekstra

1983 "Met met PRO of met zonder PRO", De nieuwe taalgids 76, 532-548.

Blom, A.

1977 "Het kwantitative er". Spektator 6, 387-395.

Blom, A. \& S.Daalder

1977 Syntaktische theorie en taalbeschrijving, Muiderberg.

Booij, G.E.

1977 Dutch morphology: a study of word formation in generative granmar, Foris Publications, Dordrecht.

Brachin, $\mathrm{P}$.

1973/74 "Een in dubbel opzicht 'vreemde' constructie", De nieuwe taalgids $66,59-60 ; 67,177-202$.

Breckenridge, $\mathbf{J}$.

1975 "The post-cyclicity of es-insertion in German", in R.Grossman, J.San \& T.Vance (eds) Papers from the eleventh regional meeting of the Chicago Linguistic Society, Chicago, 81-91. 
Bresnan, J. \&J.Grimshaw

1978 "The syntax of free relatives in English", Linguistic Inquiry 9 331-391.

8urzia, L.

1981 Intransitive verbs and Italian auxiliaries, diss.MIT.

Canale, M.

1978 Word order change in Old English: base reanalysis in generative gramar, diss. McGill University.

Chomsky, N.

1965 Aspects of the theory of syntax, MIT Press, Cambridge, Mass.

1970 "Remarks on nominalization", in R.A.Jacobs \& P.Rosenbaum Zeds) Readings in English transformational grammar, Ginn \& Comp., New York.

1977 "On WH-movement", in P.Culicover, T.Wasow and A.Akrnajian (eds) Formal syntax, Academic Press, New York, 71-132.

1979 "Markedness and core grammar", in A.Belletti et al. (eds) Theory of markedness in generative grammar, Scuola Normale Superiore, Pisa.

1980 "On binding", Linguistic Inquiry 11, 1-46.

1981 Lectures on government and binding, Foris Publications, Dordrecht.

1982 Some concepts and consequences of the theory of government and binding, MIT Press, Cambridge, Mass.

1985 "Barriers", ms. MIT.

Chomsky, N, \& H.Lasnik

1977 "Filters and control", Linguistic Inquiry 8, 425-504.

Contreras, $\mathrm{H}$.

1983 "Small Clauses in Spanish", to appear in A.Hurtado (ed.)

Spanish syntax and linguistic theory, Foris Publications, Dordrecht.

Coppen, P.A.

1985 "De aard van het quantitatieve er", De nieuwe taalgids 78, 149-163.

Coppen, P.A., L.Huiskens, M.Klein and P.Wever

1983 "Over de complementstructuur van perceptiewerkwoorden",

De nieuwe taalgids 76, 1-10.

Drewes, H.J., E.Jacobs, F.v.d.Maagdenburg, J.Veld \& M.de Walff

1984 "Crossing R-graphs", in G.J.de Haan, M.Trommelen \&W.Zonneveld (eds)

Van periferie naar kern, Foris Publications, Dordrecht, 29-39.

Elffers, E.

1977 "Er-verkenningen", Spektator 6, 417-422.

Elmer, W.

1981 Diachronic grammar: the history of Old and Middle English subjectless constructions, Max Niemeyer Verlag, TUbingen.

Emonds, J.

1970 Root and structure-preserving transformations, diss. MIT.

1976 A transforwational approach to English syntax, Academic Press: New York. 


\section{References}

Engdahl, E.

1983 "Parasitic gaps", Linguistics and Philosophy 6, 5-34.

Everaert, $M$.

1982 "A syntactic passive in Dutch", Utrecht Working Papers

in Linguistics 11, 37-73.

Evers, $A$.

1975 The transformational cycle in Dutch and German,

distributed by Indiana University Linguistics Club.

Felix, S.

1983 "Parasitic gaps in German",

Groninger Arbeiten zur Germanistischen Linguistik 22, 1_46.

Fischer, O. \& F.van der Leek

1983 "The demise of the Old English impersonal construction",

Journal of Linguistics 19, 337-368.

Gaaf, W.van der

1904 The transition frow the impersonal to the personal construction in

Middle English, Carl Winter, Heidelberg.

1930 "The passive of a verb accompanied by a preposition",

English Studies 12, 1-24.

Ceijn-Brouwers, M.van

1982 Parasitic gaps een NederIands fenomeen?,

MA thesis, University of Amsterdam.

Craos, A.

1983 "Sentential complements and theta-marking", paper read at CILS, Barcelona.

Groos，A. \& R.Bok-Bennema

1985 "The structure of the sentence in Spanish", ms.

Guéron, $\mathrm{J}$.

1976 "Interpretation of pp complements: a semantic filter for pp extraposition", in H.C.van Riemsdijk (ed.) Green ideas blown up Publikaties van het instituut voor Algemene Taalwetenschap UvA, 13.

1980 "On the syntax and semantics of PP extraposition", Linguistic Inquiry 11, 637-678.

Haaften, T.van

1983 "Over gaten in zitmen", Spektator 12, 428-451.

Haan, C.de

1979 Conditions on rules, Foris Publications, Dordrecht.

Haan, C.de, C.A.T.Koefoed \& A.L.Tombe

1974 Basiskursus algemene taalwetenschap, Van Corcum, Assen.

Haegeman, L. and H.van Riemsdijk

1984 Verb projection raising, scope and the typology of verb movement rules, Tilburg Papers in Language and Literature 64. 


\section{References}

Haider, $\mathrm{H}$.

1984

"Topic, focus and verb-second in German", Groninger Arbeiten zur Germanistischen Linguistik 25, 72-120.

Haiman, J.

1974 Targets and syntactic change, Mouton, The Hague.

Hoek, Th.van den

1970 "Opmerkingen over zinscomplementatie", Studia Neerlandica 7, 189-215.

Hoekstra, T.

1983 "The distribution of sentential complements", in H.Bennis \&W.U.S.van Lessen Kloeke(eds) Linguisties in the Netherlands 1983, Foris Publications, Dordrecht, p.93-103.

1984 Transitivity: gramatical relations in government and binding theory, Foris Publications, Dordrecht.

Hornstein, N. and A.Weinberg

1981 "Case theory and preposition stranding",

Linguistic Inquiry 12, 55-94.

Huang, J.

1982 Logical relations in Chinese and the theory of grammar, diss. MIT.

Huybregts, M.A.C.

1983 "Cross_serial dependencies and the form of syntactic structure", paper read at the Brussels Conference on Sentential Complementation, June 1983.

Huybregts, M.A.C. \&H.van Riemsdijk

1985 Parasitic gaps and ATE, Tilburg Papers in Language and Literature 76.

Hulk, A.

1982 Het clitisch pronomen en, diss. RUD.

Jackendoff, R.

1977 X'-syntax, MIT Press, Cambridge, Mass.

Jaeggli, o.

1982 Topics in Romance syntax, Foris Publications, Dordrecht.

Jespersen, 0 .

1927 A modern English gramar on historical principles, AlIen \& Unwin, Londor.

Kayne, R.

1972 "Subject inversion in French interrogatives", in J .Casagrande \&

B.Saciuk (eds) Generative studies in Romance Languages, Newbury House, Rowley, Mass., 70-126.

1975 French syntax: the transformationaI cycle, MIT-Press, Cambridge, Mass.

1979 "Rightward NP movement in French and English", Linguistic Inquiry 10 710-719.

1981 "Two notes on the NIC". in A.Belletti. 1...Brandi \& 1...Rizzi (eds) A theory of markedness in generative grammar Proceedings of the 1979 Gl..OW conference, Scuola Normale Superiore, Pisa.

1984 Connectedness and binary branching, Foris Publications, Dordrecht. 


\section{References}

Kayne, R. \& J.Y.Pollock

1978 "Stylistic inversion, successive cyclicity and move NP in French", Linguistic Inquiry 9, 595-621.

Kemenade, A.van

1984a "Verb second and clitics in Old English", in H.Bennis \& W.U.S.van Lessen Kloeke (eds) Linguistics in the Netherlands 1984, Foris Publications, Dordrecht, $101+109$.

1984b "Preposition stranding in Old English", in G.de Haan, M.Trommelen \& W.Zonneveld (eds) Van periferie naar kern, Foris Publications, Dordrecht, 129-139.

Kerstens, J.

1978 "Over WH-verplaatsing en Cl-verplaatsing in het Nederlands", Spektator 8, 340-359.

Kiparsky, P.\& C.Kiparsky

1970 "Fact", in Steinberg \& Jacobovits (eds) Semantics, Cambridge University Press, Cambridge.

Kirsner, R.S.

1979 The problem of presentative sentences in modern Dutch, North_Holland.

Klein. M.

1983 "Over de zgn. absolute met-constructie". De nieuwe taalgids 76, 151_164.

Koopman, $\mathrm{H}$

1984 The syntax of verbs: from verb movement rules in Kru languages to Universal Grammar, Foris Publications, Dordrecht.

Koopman, H. and D.Sportiche

1981 "Variables and the bijection principle",

1985 "Q-theory and extraction", paper read at the GLOW conference, Brussels, April 1985.

Koster, J.

1975 "Dutch as an SOV language", Linguistic Analysis 1, 111-136.

1978a Locality principles in syntax, Foris Publications, Dordrecht.

1978b "Why subject sentences don't exist", in S.J.Keyser (ed.) Recent transformational studies in European languages, MIT-Press, 53-65.

1983 "Subjectsporen in het Nederlands", Spektator 13, 156-166.

1984 Global harmony, Tilburg Papers in Language and Literature 61.

Lasnik, H. \& M.Saito

1984 "On the nature of proper government", Linguistic Inquiry 15, 235-289.

Leeuwen, A.van

1985 "Es, er en het: een taalvergelijkende studie naar de statiss en distributie van zogenaamde dummy_pronomina,i, MA thesis, Leiden.

Lenerz, J.

1977 Zur abfo1ge nominaler Satzglieder im Deutschen,

TBL Verlag Gunter Narr, Tübingen. 
Lightfoot, D.W.

1979 Principles of diachronic syntax, Cambridge University Press, Cambridge.

1981 "The history of Noun Phrase movement", in C.L.Baker \& J.McCarthy (eds)

The logical problem of language acquisition, MlT-Press, 86-119.

Lubbe, H.f.A.van der

1985 "De structuur van de zgn. absolute met-constructie",

De nieuwe taalgids 78, 6-17.

Maling, J.

1978 "An asymmetry with respect to WH_islands",

Linguistic Inquiry 9, 75-89.

Maling, J. \& A.Zaenen

1978 "The non-universality of a surface filter",

Linguistic Inquiry 9, 475-497.

Manzini, M.-R.

1983 "On control and control theory", Linguistic Inquiry 14, 421-446.

May, R.

1977 The grammar of quantification, diss. MIT.

McCray, A .

1981 "Clause initial elements in German", in R.Hendrick, C.Masek \& M.Miller (eds) Papers from the seventeenth regional meeting of the Chicago Linguistic Socjety, Chicago, 205-220.

Paardekooper, P.C.

1971 Beknopte ABN-syntaxis, Malmberg, Den 803ch.

Perlmutter, D.

1971 Deep and surface structure constraints in syntax,

1978 Holt, Rinehart and Winston, New York. annual meeting of the Berkeley Linguistic Society 4, 157-189.

Pesetsky, D.

1982a "Complementizer-trace phenomena and the Nominative Island Condition", in The Linguistic Review 1, 297-344.

1982b Paths and categories, diss. MIT.

Platzack, C.

1984 "The position of the finite verb in Icelandic", in W.de Geest \& Y.Putseys (eds) Sentential complementation, Foris Publications, Dordrecht, 195-205.

Pollock, J.Y.

1984 "Sur la syntaxe de en et le paramètre du sujet nU1", ms. Paris.

Putz, H.

1975 Ueber die Syntax der Pronominalform es im modernen Deutsch,

Verlag Gunter Narr, TGbingen. 
Reinhart, T.

1983 "Coreference and bound anaphora", Linguistics and Philosophy 6, 47-88.

Reuland, E.

1983 "Movement versus merger: relations between inflection and verb", NELS XIII.

Riemsdijk, H.van

1978a A case study in syntactic markedness, Foris Publications, Dordrecht.

$1978 \mathrm{~b}$ "On the diagnosis of WH-movement", in S.J.Keyser (ed) Recent transformational studies in European Languages, MIT-Press, 189-206.

Riemsdijk, H.van and E.Williams

1981 "NP-structure", The Linguistic Review 1, 171-219.

Rigter, B.

1985 "TO and PRO", in H.Bennis \& F.Beukema (eds) Linguistics in the Netherlands 1985, Foris Publications, Dordrecht, 157-166.

Rigter，B. \& F.Beukema

1985 A government and binding approach to English sentence structure, Van Walraven, Apeldoorn.

Rizzi, L.

1982 Issues in Italian syntax, Foris Publications, Dordrecht.

1983 "On chain formation", paper read at the GLOW conference,

York, April 1983.

Roelfszema, J.

1983 "Over that-trace-verschijnselen", TABU 13, 37-47.

Ross, J.R.

1967 Constraints on variables in syntax, diss. MIT.

1973 "The same side filter", in C.Corum, T.Smith-Stark and A.Weiser (eds)

Papers from the ninth regional meeting of the Chicago Linguistic

Society, Univ.of Chicago.

Safir, K.

1984 "Missing subjects in German", to appear in J.Toman (ed.) Linguistic

1985 theory and the grammar of German, Foris Publications, Dordrecht. Brussels, April 1985.

Sag, I.

1982 "Coordination, extraction, and Generalized Phrase Structure Grammar", Linguistic Inquiry 13, 329-336.

Schermer-Vermeer, E.C.

1985 "De onthullende status van er in de generatieve grammatica", Spektator $15,65-84$.

Scherpenisse, W.

1985 "The final field in German: extraposition and frozen positions", Groninger Arbeiten zur Genmanistischen Linguistik 26, 80-99. 


\section{References}

Schutter, C.de

1974 De Nederlandse zin. Poging tot beschrijving van zijn struktuur, Brugge.

Smith, N.S.H.

1976 "-AAR", Leuvense bijdragen 65, 485-496.

Smits, R. \&J.Vat

1985 "Met jouw tanden in mijn bek, een onderzoek naar met-constructies". Spektator 14, 445-470.

Stowell, T.

1981 Origins of phrase structure, diss. MIT.

1983 "Subjects across categories", in The Linguistic Review 2, 285-312.

Taraldsen, $\mathrm{T}$.

1980 On the Nominative Island Condition, vacuous application and the that-t filter, Indiana University Linguisties Club.

Thrainsson, $\mathrm{H}$.

1984 "Different types of infinitival complements in Icelandic", in W.de Geest \& Y.Putseys (eds) Sentential complementation, Foris Publications, Dordrecht, 247-257.

Torrego, E.

1984 "On inversion in Spanish and some of its effects", Linguistic Inquiry 15, 1.

Tripp, H.P.

1978 "The psychology of impersonal constructions", Glossa 12, 177-189.

Vat, $\mathbf{J}$.

1978 "On footnote 2: evidence for the pronominal status of $ə \approx \mathrm{r}$ in Old English relatives", Linguistic Inquiry 9, 695-716.

Verhagen, A.

1979 "fokusbepalingen en grarnmatikale theorie", Spektator 8, 372 4402.

Visser, f.Th.

1963 A historical syntax of the English language, Brill, Leiden.

Wahlen, $\mathrm{N}$.

1925 The Old English impersonalia, part I, Goteborg.

Wende, $\mathrm{F}$.

1915 Ueber die nachgestellten Praepositionen im Angelsachsischen, Mayer \& Muller, Berlin.

Williams, E.

1978 "Predication", Linguistic Inquiry 11, 203-237.

1981 "Argument structure and morphology", The Linguistic Review 1, 81-114.

1984 "Grammatical relations", Linguistic Inquiry 15, 639-673. 


\section{References}

Zribi-Hertz, A.

1982 "La morphologie verbale passive en Francais: essai d'explication", in J.Gueron \& T.Sowley (eds) Grammaire transformationnellej theorie et methodologies, Paris.

Zubizarreta, M.L.

1982 On the relationship of the lexicon to syntax, diss. MIT.

Zwarts, F.

1981 "Negatief polaire uitdrukkingen I", GLOT 4, 35-132. 
Andriessen, L. and Schönberger, E. The Apollonian Clockwork, 2005 (ISBN 905356856 5) Appel, R. and Muysken, P. Language Contact and Bilingualism, 2005 (ISBN 905356857 3) Bal, M. Reading Rembrandt, 2005 (ISBN 905356858 1)

Bennis, H. Gaps and Dummies, 2005 (ISBN 905356859 x)

Blom, H. De muiterij op De Zeven Provinciën, 2005 (ISBN 905356844 1)

Dehue, T. De regels van het vak, 2005 (ISBN 905356845 x)

Engbersen, G. Publieke bijstandsgeheimen, 2005 (ISBN 905356852 2)

Engbersen, G.; Schuyt, K.; Timmer, J. and Waarden, F. van Cultures of Unemployment, 2005 (ISBN 9053568468 )

Goedegebuure, J. De schrift herschreven, 2005 (ISBN 9053568476 )

Goedegebuure, J. De veelvervige rok, 2005 (ISBN 905356848 4)

Hugenholtz, B. Auteursrecht op informatie, 2005 (ISBN 905356849 2)

Idema, H. and Haft, L. Chinese letterkunde, 2005 (ISBN 905356842 5)

Janssens, J. De middeleeuwen zijn anders, 2005 (ISBN 9053568506 )

Kohnstamm, D. Ik ben ik, 2005 (ISBN 905356853 o)

Komter, A. Omstreden gelijkheid, 2005 (ISBN 9053568549 )

Meijer, M. In tekst gevat, 2005 (ISBN 905356855 7)

Oostindie, G. Ethnicity in the Caribbean, 2005 (ISBN 905356851 4)

Pinkster, H. On Latin Adverbs, 2005 (ISBN 905356843 3)

Tilburg, M. van and Vingerhoets, A. Psychological Aspects of Geographical Moves, 2005 (ISBN 9053568603 ) 